Pontifícia Universidade $C_{\text {atólica }}$

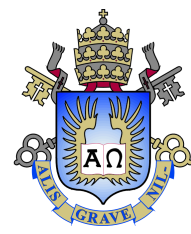

William Fernando Lopez Candela

Escoamento de Bolhas de Gás em Materiais

Viscoplásticos e Tixotrópicos

Tese de Doutorado

Tese apresentada como requisito parcial para obtenção do grau de Doutor pelo Programa de Pós-graduação em Engenharia Mecânica da PUC-Rio.

Orientador: Prof. Mônica Feijó Naccache 

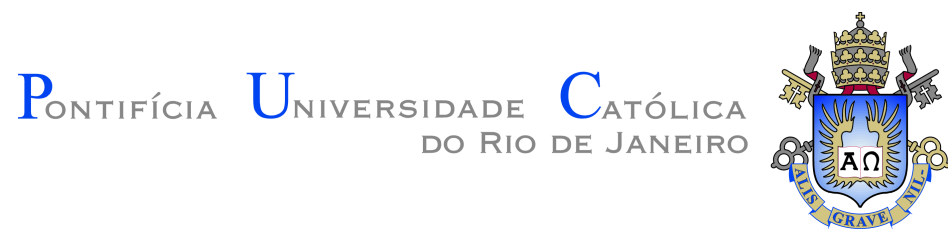

William Fernando Lopez Candela

\section{Escoamento de Bolhas de Gás em Materiais Viscoplásticos e Tixotrópicos}

Tese apresentada como requisito parcial para obtenção do grau de Doutor pelo Programa de Pós-graduação em Engenharia Mecânica da PUC-Rio. Aprovada pela Comissão Examinadora abaixo assinada.

Prof. Mônica Feijó Naccache

Orientador

Departamento de Engenharia Mecânica - PUC-Rio

Prof. Paulo Roberto de Souza Mendes

Departamento de Engenharia Mecânica - PUC-Rio

Prof. Roney Leon Thompson

Departamento de Engenharia Mecânica - UFRJ

Prof. Rafael Menezes de Oliveira

Departamento de Engenharia Mecânica - PUC-Rio

\section{Dr. André Leibsohn Martins}

CENPES - Petrobras

Dr. Cristiane Richard de Miranda

CENPES - Petrobras

Prof. Márcio da Silveira Carvalho

Coordenador Setorial do Centro Técnico Científico - PUC-Rio 
Todos os direitos reservados. É proibida a reprodução total ou parcial do trabalho sem autorização da universidade, do autor e do orientador.

\section{William Fernando Lopez Candela}

Graduou-se em Engenharia Mecânica na Universidad Industrial de Santander UIS na Colômbia em 2009. Em 2013 obteve o título de mestre em Engenharia Mecânica na Pontifícia Universidade Católica do Rio de Janeiro PUC-Rio na área de Petróleo e Energia onde trabalhou com interfaces imiscíveis e dinâmica de fluidos.

Ficha Catalográfica

Lopez Candela, William Fernando

Escoamento de Bolhas de Gás em Materiais Viscoplásticos e Tixotrópicos / William Fernando Lopez Candela; orientador: Mônica Feijó Naccache. - Rio de janeiro: PUC-Rio, Departamento de Engenharia Mecânica, 2018.

v., 135 f: il. color. ; $30 \mathrm{~cm}$

Tese (doutorado) - Pontifícia Universidade Católica do Rio de Janeiro, Departamento de Engenharia Mecânica.

Inclui bibliografia

1. Engenharia Mecânica - Teses. 2. Dinâmica de fluidos Teses. 3. Bolhas de gás - Teses. 4. Bolhas de Gás;. 5. Fluidos Viscoplasticos;. 6. Fluidos Tixotropicos;. I. Feijó Naccache, Mônica. II. Pontifícia Universidade Católica do Rio de Janeiro. Departamento de Engenharia Mecânica. III. Título. 
A minha inquieta, barulhenta e bagunceira Fernanda.

"And we are still alive Try to hold on And we have survived Try to hold on And no one should deny

We tried to hold onto the pulse of the feedback current Into the flow of encrypted movement Slapback kills the ancient remnants That try to hold on

Try to hold on To this heart alive Try to hold on To this love aloud Try to hold on And we are still alive Try to hold on And we have survived Try to hold on" 


\section{Agradecimentos}

À minha orientadora Mônica F. Naccache por me ensinar profissionalismo, disciplina e qualidade na minha labor como pesquisador e especialmente pelo trato humano oferecido aos estudantes.

A todos os professores do departamento de Engenharia Mecânica e especialmente ao professor Paulo de Souza Mendes pela qualidade dos cursos ministrados e o alto nível exigido.

Aos meus amigos, amigos em todo o sentido da palavra, que me acompanharam nos caminhos mais escuros e ante a fadiga não duvidaram em me ajudar; Eliana Marin, Julie Salcedo, Pablo Barreiro, David Efraín, Pedro Tobar, Dario Prada, Giovanny Meneses, Lorena Rodrigues, Leonardo Pereira, Julian Ortiz, Daniel Rojas, Fabian Caballero, Roberta Kamei, Nicolas Vargas e Behbood Abedi, Elias Conceição.

A você Jaione Tirapu não tenho palavras para agradecer tanto. Neste mundo indiferente você demostrou empatia infinita e amor ao próximo para cuidar de outro ser humano, nunca terei como expressar minha gratidão.

Peter Bryant, você me ensinou humildade e paciência no trato às pessoas. Um dos profissionais mais competentes que tive a fortuna de conhecer e como orientador você se tornou referência para mim.

Aos colegas de Greo (Grupo de Reologia/PUC-Rio) por dividir seu conhecimento e experiência nestes anos.

Aos colegas de IBM; Mathias Steiner, Rodrigo Neumann, Ronaldo Giro, Michael Engel e Takashi Imamichi que testaram meus conhecimentos e me levaram ao limite.

O presente trabalho foi realizado com apoio da Coordenação de aperfeiçoamento de Pessoal de Nível Superior - Brasil (CAPES) - Código de Financiamento 0001.

A Petrobras, FAPERJ, CNPq, IBM-Brasil, IBM-USA, e PUC-Rio por acreditar em mim e conceder o apoio financeiro sem o qual este trabalho e outros não poderiam ter sido realizados.

Aos meus pais e meu irmão pela infinita compreensão e paciência, sei que na minha interminável busca por respostas acabo me perdendo, mas vocês sempre acreditaram e apoiaram sem questionar.

A minha família que no momento certo sempre entrou para me apoiar. Não importa a situação, eu estou tranquilo pois sei que vocês estão cuidando de mim. 


\section{Resumo}

Lopez Candela, William Fernando; Feijó Naccache, Mônica. Escoamento de Bolhas de Gás em Materiais Viscoplásticos e Tixotrópicos. Rio de Janeiro, 2018. 135p. Tese de Doutorado - Departamento de Engenharia Mecânica, Pontifícia Universidade Católica do Rio de Janeiro.

O escoamento de gás em fluidos complexos é um fenômeno presente em industrias como alimentos \& bebidas, farmacêutica, química e petróleo \& gás. Nesta pesquisa foi abordado o fenômeno de invasão de gás em pastas de cimento durante o processo de cimentação de poços de petróleo. Este problema é governado por diferentes parâmetros como tamanho, geometria e velocidade das bolhas, reologia do fluido, histórico de cisalhamento do material, pressão e vazão de injeção. Neste trabalho estuda-se experimentalmente a dinâmica de uma bolha de ar não esférica em regime de Stokes ou laminar, escoando em materiais que simulam pastas de cimento com diferentes níveis de viscosidade. As pastas de cimento e suas propriedades viscoplásticas e tixotrópicas são reproduzidas usando suspensões de Carbopol® e Laponita®, respectivamente. Apresenta-se também um modelo matemático simplificado para a dinâmica do fenômeno de migração de gás, com aplicação na indústria do petróleo. No estudo com Carbopol, investigase o efeito da tensão limite de escoamento e a relação entre forças viscosas e inerciais, e sua influência na dinâmica e na geometria da bolha de gás. A análise com Laponita visa simular o processo de invasão e migração de gás durante o processo de cura do cimento. O efeito da tixotropia no formato e na dinâmica de migração das bolhas é analisado. Estes resultados simulam também a complexa dinâmica da migração de gás em fluidos com reologia dependente do tempo, como as pastas de cimento ao longo de seu processo de cura. Observou-se a formação de bolhas de gás com geometria plana, que permitem o escoamento com baixa resistência e formam caminhos preferenciais, que podem se tornar canais de escoamento de gás a alta vazão.

\section{Palavras-chave}

Bolhas de Gás; Fluidos Viscoplásticos; Fluidos Tixotrópicos; 


\section{Abstract}

Lopez Candela, William Fernando; Feijó Naccache, Mônica (Advisor). Flow of gas bubbles in viscoplastic and thixotropic fluids. Rio de Janeiro, 2018. 135p. Tese de doutorado - Departamento de Engenharia Mecânica, Pontifícia Universidade Católica do Rio de Janeiro.

The gas flow in complex fluids is a phenomenon present in industries such as foods \& beverage, pharmaceuticals, chemistry and oil \& gas. In this research the phenomenon of gas invasion in cement pastes during the cementation process of wells of petroleum was analyzed. This problem is governed by different parameters such as bubble size, geometry and velocity, fluid rheology, material shear history, injection pressure and flow rate. In this work, we perform an experimental study of the dynamics of a non-spherical air bubble under a Stokes or laminar regime, flowing in materials that simulate cement pastes with different levels of viscosity. Cement pastes and their viscoplastic and thixotropic properties are reproduced using suspensions of Carbopol and Laponite, respectively. A simplified mathematical model for the dynamics of the phenomenon of gas migration, with application in the petroleum industry, is also presented. In the Carbopol study, the effect of the yield stress and the relationship between viscous and inertial forces and their influence on the dynamics and geometry of the gas bubble is investigated. The analysis with Laponite aims to simulate the process of invasion and gas migration during the cement cure process. The effect of thixotropy on the shape and dynamics of bubble migration is analyzed. These results also simulate the complex dynamics of gas migration in fluids with time dependent rheology, such as cement pastes during their curing process. The formation of gas bubbles with flat geometry has been observed, allowing the gas to flow with lower resistance and to form preferred paths that can become channels with high gas flow rates.

\section{Keywords}

Gas Bubbles; Viscoplastic Fluids; Thixotropic Fluids; 


\section{Sumário}

1 Introdução $\quad 18$

1.1 Motivação 19

1.2 Objetivos 21

1.3 Organização do Trabalho 22

2 Revisão bibliográfica $\quad 23$

2.1 Cimentação de poços de petróleo e reologia de pastas de cimento 23

2.2 Formação de bolhas de gás 25

2.3 Dinâmica de partículas solidas e gasosas em baixos Re - Regime de Stokes 26

2.4 Dinâmica de partículas solidas e gasosas em altos Re - Regime Laminar 27

2.5 Dinâmica de partículas gasosas em fluidos altamente gelificados 32

3 Materiais e Métodos $\quad 34$

3.1 Loop para visualização 34

3.1.1 Metodologia de acondicionamento da suspensão para testes experimentais 37

3.1.2 Metodologia de injeção de bolhas de gás 39

3.1.3 Metodologia de captura e pós-processamento de imagens 41

3.2 Preparo dos fluidos Não-Newtonianos 44

3.2.1 Metodologia de Preparação de Suspensões 46

3.2.1.1 Preparação do Carbopol 47

3.2.1.2 Preparação da Laponita 48

3.2.2 Caracterização Reológica $\quad 50$

3.2.3 Reologia do Carbopol 52

$\begin{array}{lll}\text { 3.2.4 Reologia da Laponita } & 55\end{array}$

3.2.5 Metodologia de Solução do Modelo Matemático 61

4 Resultados Experimentais $\quad 62$

4.1 Resultados Experimentais da Bancada 62

4.1.1 Pre-acondicionamento dos materiais e da bancada experimental 63

4.1.2 Dinâmica de bolhas de gás escoando em Carbopol 66

4.1.3 Dinamica de bolhas de gás escoando em Laponita 76

4.1.4 Migração de bolhas de gás em suspensões de Laponita altamente gelificada 84

$\begin{array}{lll}5 & \text { Modelamento Matemático } & 91\end{array}$

$\begin{array}{lll}6 & \text { Conclusões } & 97\end{array}$

$\begin{array}{lll}6.1 & \text { Trabalhos futuros } & 98\end{array}$

$\begin{array}{lll}7 & \text { Referências bibliográficas } & 99\end{array}$

$\begin{array}{lll}\text { A Preparação suspensões aquosas } & 107\end{array}$

A.1 Preparação Carbopol 980 - Carbomero 108 
$\begin{array}{lll}\text { A.2 Preparação da Laponita } & 110\end{array}$

B Rotinas em Matlab 112

B.1 Rotina de Post-Processamento de Imagens 112

B.2 Rotina de Solução do Modelo Matemático e calculo dos parâmetros de ajuste 


\section{Lista de figuras}

Figura 1.1 Linhas de corrente na vizinhança de uma bolha de gás escoando num fluido Newtoniano (77).

Figura 1.2 Parâmetros que contribuem à migração de gás durante a cimentação de poços de petróleo (58) (78). (a) Densidade errada da pasta; (b) problemas na remoção do reboco ou filter cake;(c) Gelação prematura da pasta; (d) excessiva perda de liquido da pasta; (e) Alta permeabilidade da pasta; (f) Alta contração durante a cura; (g) Falha da coluna de cimento baixo esforço e;(h) pobre aderência interfacial entre a coluna e a formação.

Figura 1.3 Caminhos preferenciais formados por bolhas de gás durante a cimentação de um poço de petróleo; (a) Vista frontal e (b) Vista transversal de poço.

Figura 3.1 Bancada experimental construída para injeção de bolhas de ar num tanque com fluido em repouso. (a) Imagem geral da bancada; (b) Sistema de iluminação do tanque com painéis LED e esfriamento das paredes com ventilador; (c) Bomba de seringa e linha externa de ar pressurizado.

Figura 3.2 Diagrama simplificado da Bancada experimental. (a) Diagrama geral da bancada; (b) Dimensões do tanque da bancada e bolha de ar.

Figura 3.3 Injetores projetados para injetar gás na Bancada expe-rimenta (2) (23) (22) ; (a) Injetor horizontal de corte diagonal;(b) injetor horizontal de corte cônico e (c) injetor vertical de corte cônico.

Figura 3.4 Efeitos negativos na migração de gás em suspensões heterogêneas. (a) Trajetória e velocidade irregular nas bolhas;(b) Estagnação do gás; e (c) Formação de caminhos preferenciais para múltiplas bolhas.

Figura 3.5 Ferramenta usada para desestruturar e homogeneizar a suspensão de Laponita. (a) Vista frontal; e (b) Vista superior. 38 Figura 3.6 Invasão de ar na suspensão de Laponita. (a) Invasão de ar durante o processo de homogeneização; e (b) Invasão de ar na Laponita após um processo errado de homogeneização.

Figura 3.7 Comportamento instável do gás no interior de Laponita não homogeneizada completamente. (a) Bolha de gás após um curto processo de homogeneização; (b) Bolha de gás após um processo de homogeneização maior, mas ainda precisando mais tempo de cisalhamento.

Figura 3.8 Metodologia de captura de imagens para pósprocessamento. (a) Teste experimental de injeção manual sendo executado; (b) Câmera Canon 7D. 
Figura 3.9 Vídeos necessários para pós-processar os testes experimentais de injeção de bolhas de gás usando Matlab. (a) Vídeo de injeção de bolha de gás; (b) Imagem de referência para extrair o fundo; e (c) Esfera de diâmetro conhecido para calibração da escala.

Figura 3.10 Vídeos pós-processados após uso da rotina em Matlab. (a) esfera de calibração pós-processada; e (b) Imagens de bolhas pósprocessadas.

Figura 3.11 Curvas de resultados da dinâmica de múltiplas bolhas de ar em regime transiente migrando na bancada experimental. (a) Diâmetro efetivo da bolha em função do deslocamento vertical; (b) Volume da bolha em função do deslocamento vertical; (c) Razão de aspecto da bolha em função do deslocamento vertical; e (d) Velocidade da bolha em função do deslocamento vertical.

Figura 3.12 Microestrutura encontrada em diversas suspensões com-plexas em repouso e as alterações sofridas apos ser perturbadas (48).

Figura 3.13 Misturadores e hélices usadas na preparação das suspen-sões; (a) Misturador Fisatom 722 com base planetária e raspador nas paredes do tanque: (b) Misturador IKA Eurostar; (c) Hélice tipo borboleta; (d) Hélice tipo centrifuga dentada; e (e) Hélice Tipo âncora.

Figura 3.14 Equipamentos adicionais: (a) Tensiômetro Lauda TE1CA; e (b) Forno Nova Etica 400/7D.

Figura 3.15 Configuração Misturador-Base planetáriaRaspador usada na preparação das suspensões: (a) Carbopol 980; e (b) Laponita.

Figura 3.16 Estrutura cristalina e heterogênea da suspensão de Carbopol: (a) Microscopia confocal (43); e (b) Diagramas de Voronoi de microscopia com partículas traçadoras MPT (Multipleparticle tracking), áreas viscosas em branco e áreas elásticas em negro (44).

Figura 3.17 Estrutura tixotrópica da Laponita: (a) Amostra de Laponita gelificada; e (b) Diagrama de estado de Laponita $(\mathrm{PH}=10)$ em função da concentração de polímero (eixo horizontal) e a concentração de $\mathrm{NaCl}$ que determina os esforços iônicos do fluido I(M) (eixo vertical) (76).

Figura 3.18 Gelificação da Laponita presente, imediatamente após o fim da preparação.

Figura 3.19 Reômetros rotacionais da marca TA Instruments usados neste trabalho. (a) ARG2; (b) Discovery HR-3; e (c) Ares G2.

Figura 3.20 Geometria de placas paralelas ranhuradas (crosshatch) usadas nos reômetros para taxas de cisalhamento de até $100 \mathrm{~s}-1$.

Figura 3.21 Geometria Couette ranhurada usada nos reômetros para testes com maiores taxas de cisalhamento.

Figura 3.22 Teste Flow curve em Carbopol 980 de concentração $0.09 \%$ ww $0.10 \%$ ww $0.12 \%$ ww, $0.15 \%$ ww e $0.20 \%$ ww. 
Figura 3.23 Teste strain sweep em Carbopol 980 de concentração $0.09 \%$ ww, $0.10 \%$ ww, $0.12 \%$ ww, $0.15 \%$ ww e $0.20 \%$ ww. Frequência angular $6.28 \mathrm{rad} / \mathrm{s}$.

Figura 3.24 Teste frequency sweep em Carbopol 980 de concentração $0.09 \%$ ww, $0.10 \%$ ww, $0.12 \%$ ww, $0.15 \%$ ww e $0.20 \%$ ww. $0.01 \%$ strain

Figura 3.25 Histerese apresentada na Flowcurve de fluidos tixotrópicos e reopéticos (48).

Figura 3.26 Teste Time Sweep para diferentes taxas de cisalhamento em laponita $2 \%$ ww. Tempo de repouso da amostra 30s. Faixa de Taxa de cisalhamento 0.01-100 $\mathrm{s}^{-1}$.

Figura 3.27 Teste Time Sweep para diferentes taxas de cisalhamento em Laponita $3 \%$ ww. Tempo de repouso da amostra 15min. Faixa de Taxa de cisalhamento 0.01-100 (1/s).

Figura 3.28 Perfil de cisalhamento em materiais com reologia homogênea e perfil em materiais que sofrem Shear banding com reologia heterogênea.

Figura 3.29 Teste Flowcurve da Laponita com concentrações de $2 \%$ ww e $3 \%$ ww

Figura 3.30 Teste Strain Sweep em Laponita $2 \%$ ww e $3 \%$ ww. Frequência $6.283(\mathrm{rad} / \mathrm{s})$

Figura 3.31 Teste Frequency Sweep em Laponita 2\% ww e 3\% ww. $\%$ Strain $1 \%$

Figura 4.1 Bolha de ar escoando por caminho preferencial for-mado por pré-cisalhamento do fluido localizado numa trajetória diagonal-retilínea. Foi usada uma barra sólida de $1 \mathrm{~cm}$ de diâmetro para formar o caminho preferencial.

Figura 4.2 Velocidade V e Diâmetro efetivo D em função do Tempo t de injeção de bolhas de ar em Carbopol 980 de concentração 0.10 \%ww. O processo de homogeneização só foi usado prévio à injeção da primeira bolha.

Figura 4.3 Velocidade V e Relação de aspecto Altura/Largura H/W em função do Tempo t de injeção de bolhas de ar em Carbopol 980 de concentração $0.10 \%$ ww. O processo de homogeneização só foi usado prévio à injeção da primeira bolha.

Figura 4.4 Geometria de bolhas de ar em Carbopol 0.10\% ww em função do Número de Reynolds Re.

Figura 4.5 Geometria de bolhas de ar em Carbopol 0.20\% ww em função do Número de Reynolds Re

Figura 4.6 Número de Reynolds Re e Número de Bingham Bi em função do Diâmetro efetivo D da bolha de ar em Carbopol 980 de concentração $0.09 \%$ ww, $0.10 \%$ ww, $0.12 \%$ ww, $0.15 \%$ ww e $0.20 \%$ ww.

Figura 4.7 Número de Reynolds Re e Número de Deborah De em função do Diâmetro efetivo D da bolha de ar em Carbopol 980 de concentração $0.09 \%$ ww, $0.10 \%$ ww, $0.12 \%$ ww, $0.15 \%$ ww e $0.20 \%$ ww. 
Figura 4.8 Velocidade V em função do Diâmetro efetivo D da bolha de ar em Carbopol 980 de concentração 0.09\% ww, $0.10 \%$ ww, $0.12 \%$ ww, $0.15 \%$ ww e $0.20 \%$ ww.

Figura 4.9 Numero de Reynolds Re e Numero de Deborah De em função do Número de Bingham Bi da bolha de ar em Carbopol 980 de concentração $0.09 \%$ ww, $0.10 \%$ ww, $0.12 \%$ ww, $0.15 \%$ ww e $0.20 \%$ ww.

Figura 4.10 Razão de aspecto Altura/Largura H/W em função da razão d Diâmetro efetivo/Largura $\mathrm{D} / \mathrm{W}$ da bolha de ar em Carbopol 980 de concentração $0.09 \%$ ww, $0.10 \%$ ww, $0.12 \%$ ww, $0.15 \%$ ww e $0.20 \%$ ww.

Figura 4.11 Razão de aspecto Altura/Largura H/W em função da relação Numero de Reynolds/Numero de Deborah Re/De da bolha de ar em Carbopol 980 de concentração 0.09\% ww, $0.10 \%$ ww, $0.12 \%$ ww, $0.15 \%$ ww e $0.20 \%$ ww.

Figura 4.12 Relação de aspecto Altura/Largura H/W em função do Número de Bingham Bi da bolha de ar em Carbopol 980 de concentração $0.09 \%$ ww, $0.10 \%$ ww, $0.12 \%$ ww, $0.15 \%$ ww e $0.20 \%$ ww.

Figura 4.13 Coeficiente de arrasto Cd em função da relação Número de Reynolds Re da bolha de ar em Carbopol 980 de concentração $0.09 \%$ ww, $0.10 \%$ ww, $0.12 \%$ ww, $0.15 \%$ ww e $0.20 \%$ ww.

Figura 4.14 Coeficiente de arrasto Cd em função da relação Número de Reynolds / Numero de Deborah Re/De da bolha de ar em Carbopol 980 de concentração $0.09 \%$ ww, $0.10 \%$ ww, $0.12 \%$ ww, $0.15 \%$ ww e $0.20 \%$ ww.

Figura 4.15 Coeficiente de arrasto Cd em função do Número de Bingham Bi da bolha de ar em Carbopol 980 de concentração 0.09\% ww, $0.10 \%$ ww, $0.12 \%$ ww, $0.15 \%$ ww e $0.20 \%$ ww.

Figura 4.16 Geometria de bolhas de ar em Laponita $2 \%$ ww em função do número de Reynolds Re. Tempo de repouso da suspensão igual a $30 \mathrm{~s}$.

Figura 4.17 Geometria de bolhas de ar em Laponita 3\% ww em função do número de Reynolds Re. Tempo de repouso da suspensão igual a 3 min.

Figura 4.18 Número de Reynolds Re e número de Bingham Bi em função do diâmetro efetivo D em Laponita $2 \%$ ww e $3 \%$ ww. Tempos de repouso iguais a $30 \mathrm{~s}, 3 \mathrm{~min}$ e $15 \mathrm{~min}$.

Figura 4.19 Número de Reynolds Re e número de Deborah De em função do diâmetro efetivo D em Laponita $2 \%$ ww e $3 \%$ ww. Tempos de repouso iguais a $30 \mathrm{~s}, 3 \mathrm{~min}$ e $15 \mathrm{~min}$.

Figura 4.20 Velocidade $\mathrm{V}$ em função do diâmetro efetivo $\mathrm{D}$ em Laponita $2 \% \mathrm{ww}$ e $3 \% \mathrm{ww}$. Tempos de repouso iguais a $30 \mathrm{~s}, 3 \mathrm{~min}$ e 15 min.

Figura 4.21 Razão de aspecto altura/largura $\mathrm{H} / \mathrm{W}$ em função do diâmetro efetivo/largura D/W em Laponita $2 \%$ ww e $3 \%$ ww.

Tempos de repouso iguais a $30 \mathrm{~s}, 3 \mathrm{~min}$ e $15 \mathrm{~min}$. 
Figura 4.22 Razão de aspecto altura/largura H/W em função do número de Reynolds/número de Deborah Re/De em Laponita $2 \% \mathrm{ww}$ e $3 \% \mathrm{ww}$. Tempos de repouso iguais a $30 \mathrm{~s}, 3$ min e 15 min.

Figura 4.23 Coeficiente de arrasto $C_{d}$ em função do número de Reynolds Re em Laponita $2 \%$ ww e $3 \%$ ww. Tempos de repouso iguais a $30 \mathrm{~s}, 3 \mathrm{~min}$ e $15 \mathrm{~min}$.

Figura 4.24 Coeficiente de arrasto $C_{d}$ em função do número de Reynolds/Numero de Deborah Re/De em Laponita $2 \%$ ww e $3 \%$ ww. Tempos de repouso iguais a $30 \mathrm{~s}, 3 \mathrm{~min}$ e $15 \mathrm{~min}$.

Figura 4.25 Aparência de bolhas de gás escoando em Carbopol $0.2 \%$ ww com tempo de repouso de duas (2) semanas para aumentar a gelificação.

Figura 4.26 Aparência de bolhas de gás escoando em Laponita $2.5 \% \mathrm{ww}$ com diferentes tempos de repouso após homogeneização da suspensão. (a) $t=30 \mathrm{~s}$; (b) $\mathrm{t}=1 \mathrm{hr}$; (c) $\mathrm{t}=3 \mathrm{hr}$; (d) $\mathrm{t}=14 \mathrm{hr}$; (e) $\mathrm{t}=17 \mathrm{hr}$; (f) 20hr; (g) t=94hr; e (h) t=192hr.

Figura 4.27 Aparência de bolhas de gás escoando em Laponita 3\%ww com diferentes tempos de gelificação após homogeneização da suspensão. (a) $t=1 \mathrm{~min}$; (b) $\mathrm{t}=1 \mathrm{hr}$; (c) $\mathrm{t}=2 \mathrm{hr} ; \quad$ (d) $\mathrm{t}=3 \mathrm{hr} ;$ (e) $\mathrm{t}=6 \mathrm{hr} ;$ (f) $\mathrm{t}=13 \mathrm{hr}$; e (g) $\mathrm{t}=17 \mathrm{hr}$. L=Vista lateral; $\mathrm{F}=$ Vista frontal.

Figura 4.28 Mecanismo de formação de canais de escoamento de gás para fontes pressurizadas em Laponita $3 \%$ ww. (a) $\mathrm{t}=0 \mathrm{~s} ;$ (b) $\mathrm{t}=15 \mathrm{~s} ; \quad$ (c) $\mathrm{t}=3 \mathrm{~min} ; \quad$ (d) $\mathrm{t}=6 \mathrm{~min} ; \quad$ (e) $\mathrm{t}=10 \mathrm{~min} ; \quad$ (f) $\mathrm{t}=13 \mathrm{~min} ; \mathrm{e} \quad(\mathrm{g}) \mathrm{t}=15 \mathrm{~min}$. $\mathrm{L}=$ Vista lateral; $\mathrm{F}=$ Vista frontal. Figura 4.29 Mecanismo de formação de canais de escoamento de gás para fontes pressurizadas em Laponita $3 \%$ ww. (a) Primeiro ca-minho preferencial formado; (b) Segundo caminho preferencial formado; e (c) Canais formado após vazão continua de fonte pressurizada.

Figura 5.1 Balanço de forças de uma bolha de gás escoando num fluido. Considera-se a Força de empuxo $F_{b}$ e Força de arrasto $F_{D}$ Figura 5.2 Regiões de fluido afetado ao redor da bolha escoando. Figura 5.3 Modelo matemático ajustado (Eq. 5-7) em Carbopol $0.09 \%$ ww, $0.10 \%$ ww, $0.12 \%$ ww, $0.15 \%$ ww e $0.20 \%$ ww.

Figura 5.4 Ajuste do parâmetro $C_{1}$ do modelo matemático proposto (Eq. 5-7) em Carbopol 0.09\% ww, 0.10\% ww, 0.12\% ww, 0.15\%ww e $0.20 \%$ ww.

Figura 5.5 Ajuste do parâmetro $C_{2}$ do modelo matemático proposto (Eq. 5-7) em Carbopol 0.09\% ww, 0.10\% ww, 0.12\% ww, 0.15\%ww e $0.20 \%$ ww

Figura 5.6 Ajuste do parâmetro $C_{3}$ do modelo matemático proposto (Eq. 5-7) em Carbopol 0.09\% ww, 0.10\% ww, 0.12\% ww, 0.15\%ww e $0.20 \%$ ww

Figura A.1 Materiais, reagentes e equipamento de segurança necessários na preparação das suspensões aquosas usadas nesta pesquisa. 


\section{Lista de tabelas}

Tabela 3.1 Reologia de suspensões de Carbopol 980. $\mathrm{T}=23.4^{\circ} \mathrm{C} \quad 55$

Tabela 3.2 Reologia de suspensões de Laponita com concentração $2 \%$ ww e $3 \%$ ww.

61

Tabela 5.1 Parâmetros de ajuste do modelo matemático em Carbopol 980 .

Tabela A.1 Quantidade de polímero de Laponita necessária para um tanque de 4L de suspensão em função da concentração em peso (\% ww) (76)

Tabela A.2 Quantidade de $\mathrm{NaCl}$ e $\mathrm{NaOH}$ para um tanque de $4 \mathrm{~L}$ de Laponita em função das concentrações desejadas (76) 


\section{Lista de Abreviaturas}

$A_{f}=$ Área a montante ou da seção transversal frontal da bolha de gás $\left[\mathrm{m}^{2}\right]$.

$A_{\text {num }}=$ Área transversal da esfera de calibração no vídeo $\left[p x^{2}\right]$.

$\mathrm{Bi}=$ Numero de Bingham [-].

$C_{1}=$ Fator de ajuste ou correção [-].

$C_{2}=$ Fator de ajuste ou correção [-].

$C_{3}=$ Fator de ajuste ou correção [-].

$C_{d}=$ Coeficiente de arrasto [-].

$\mathrm{D}=$ Diâmetro efetivo da bolha de gás $[\mathrm{m}]$.

$D_{c}=$ Diâmetro efetivo crítico da bolha de gás [m].

De $=$ Numero de Deborah [-]

$D_{\text {num }}=$ Diâmetro da esfera de calibração no vídeo [px]

$D_{\text {real }}=$ Diâmetro medido da esfera de calibração $[\mathrm{m}]$.

$\mathrm{D} / \mathrm{W}=$ Relação de aspecto da bolha de gás Diâmetro efetivo/Largura [-].

$\mathrm{F}=$ Vista frontal da bancada experimental.

$F_{d}=$ Forca de arrasto $[\mathrm{N}]$.

$F_{b}=$ Forca de empuxo $[\mathrm{N}]$.

$\mathrm{g}=$ Gravidade da terra $9.81\left[\mathrm{~m} / \mathrm{s}^{2}\right]$.

$\mathrm{G}^{\prime}=$ Modulo elástico ou de armazenamento [Pa].

$\mathrm{G} "=$ Modulo viscoso ou de perda $[\mathrm{Pa}]$.

$\mathrm{GAP}=$ Distancia intermediaria entre as placas paralelas do reômetro rotacional $[\mu m]$.

$\mathrm{H}=$ Altura da bolha de gás [m].

$\mathrm{H} / \mathrm{W}=$ Relação de aspecto da bolha de gás Altura/Largura [-].

$\mathrm{j}=$ Vetor unitário na direção vertical [-]

$\mathrm{K}=$ Índice de consistência [Pa].

$k=$ Curvatura interfacial $[\mathrm{m}]$

$\mathrm{L}=$ Vista lateral da bancada experimental.

$\mathrm{n}=$ Índice Power-Law [-].

$n=$ Vetor unitário normal à interface [-].

$R=$ Raio efetivo da bolha de gás [m].

Re $=$ Numero de Reynolds [-].

$\mathrm{S}=$ Largura do tanque da bancada experimental $[\mathrm{m}]$. 
$S c=$ Escala do vídeo usado nos testes de injeção de gás $[\mathrm{m} / \mathrm{px}]$.

$\mathrm{t}=$ tempo $[\mathrm{s}][\mathrm{min}]$.

$t_{c}=$ Tempo característico do Número de Deborah De $[\mathrm{s}]$.

$\mathrm{u}=$ Campo de velocidades $[\mathrm{m} / \mathrm{s}]$.

$\mathrm{V}=$ Velocidade absoluta da partícula gasosa $[\mathrm{m} / \mathrm{s}]$.

$V_{c}=$ Velocidade característica da partícula $[\mathrm{m} / \mathrm{s}]$.

$V_{L}=$ Velocidade da fase continua ou fluido em contato com a superfície da partícula $[\mathrm{m} / \mathrm{s}]$.

$V_{c a m}=$ Velocidade de gravação da câmera usada [frames $\left./ \mathrm{s}\right]$.

$\mathrm{W}=$ Largura da bolha de gás $[\mathrm{m}]$.

$w=$ Frequência $[\mathrm{Hz}]$.

$\mathrm{X}=$ Posição da bolha de gás no eixo Horizontal $[\mathrm{m}]$.

$X_{c}=$ Fator de correção no modelo matemático proposto [-].

$\mathrm{Y}=$ Posição da bolha de gás no eixo vertical [m].

$\lambda=$ Tempo de relaxamento $[\mathrm{s}]$.

$\rho=$ Densidade da fase discreta ou bolhas de gás $\left[\mathrm{kg} / \mathrm{m}^{3}\right]$.

$\rho_{c}=$ Densidade da fase continua ou material usado no tanque $\left[\mathrm{kg} / \mathrm{m}^{3}\right]$.

$\sigma=$ Tensão superficial $[\mathrm{N} / \mathrm{m}]$.

$\delta=$ Função Delta de Dirac [-].

$\eta=$ Viscosidade [Pa.s].

$\eta=$ Viscosidade característica [Pa.s].

$\tau=$ Tensão de cisalhamento $[\mathrm{Pa}]$.

$\tau_{0}=$ Tensão limite $[\mathrm{Pa}]$.

$\forall=$ Volume da bolha de gás $\left[\mathrm{m}^{3}\right]$.

$\dot{\gamma}=$ Taxa de cisalhamento $\left[s^{-1}\right]$.

$\dot{\gamma}_{c}=$ Taxa de cisalhamento característica $\left[s^{-1}\right]$.

$\dot{\gamma}_{0}=$ Taxa de cisalhamento até onde a tensão se considera constante na Flowcurve da Laponita $\left[s^{-1}\right]$.

$\Delta X=$ Deslocamento horizontal do centroide da bolha na bancada $[\mathrm{m}]$.

$\Delta Y=$ Deslocamento vertical do centroide da bolha na bancada [m].

$\Delta P=$ Deslocamento absoluto do centroide da bolha na bancada $[\mathrm{m}]$.

$\%$ strain $=$ Porcentagem de deformação elástica em função do GAP do reômetro [\%]. 


\section{Introdução}

Escoamentos de bolhas de gás em materiais viscoplásticos e tixotrópicos se observam em diversos processos industriais e naturais. Em alguns casos as condições reológicas e operacionais são bem comportadas, facilitando o estudo do fenômeno. Porém, estas situações são escassas e tanto as condições reológicas como as operacionais são bem mais complexas que o desejado tornando um desafio a compreensão e controle dos fenômenos físicos relacionados. Reatores químicos, tanques de mistura e fermentação, processos de cimentação em formações rochosas, absorção de gases para beneficiamento de processos industriais são só alguns casos onde as características do fenômeno se afastam do ideal ou são difíceis de identificar e separar.
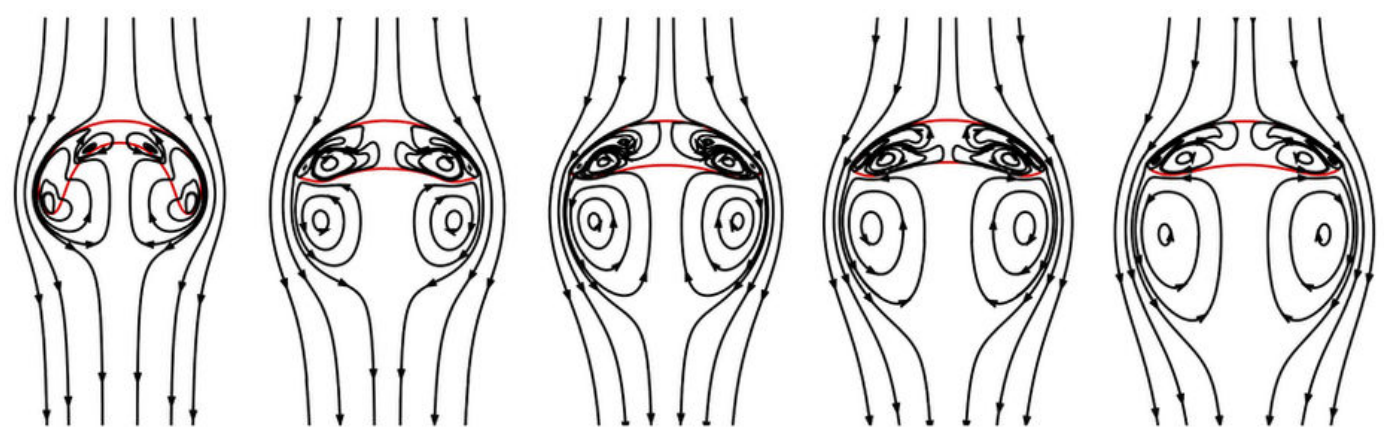

Figura 1.1: Linhas de corrente na vizinhança de uma bolha de gás escoando num fluido Newtoniano (77).

O estudo de escoamentos de bolhas de gás em fluidos complexos requer a análise de diversos fenômenos que atuam de forma concomitante. Já antes da formação da bolha, parâmetros como a geometria e direção do injetor, além da vazão de injeção, têm um papel importante no tamanho e forma da bolha de gás. O efeito da tensão superficial $\sigma$ e molhabilidade da interface gásliquido-solido no bico do injetor também já constituem uma área interessante e complexa de estudo.

Quando o escoamento se inicia, parâmetros como o número de Reynolds e as características reológicas do fluido são importantes. Quando o número de Reynolds de uma bolha migrando aumenta, a inércia associada ao deslocamento do fluido na vizinhança se torna predominante e as forças viscosas 
se tornam desprezíveis, causando importantes efeitos na dinâmica e geometria da bolha. A Fig. 1.1 mostra as linhas de corrente em região próxima a uma bolha de gás escoando num fluido Newtoniano, onde observa-se a variação do formato da bolha e do escoamento em torno da mesma, em função do número de Reynolds. Outras propriedades como elasticidade e em menor medida a tensão superficial da interface $\tau$ podem também ter influência no escoamento da bolha.

Fluidos viscoplásticos oferecem desafios adicionais por causa da tensão limite do material $\tau_{0}$. A tensão limite de escoamento é a propriedade do material que caracteriza a necessidade de uma tensão mínima que deve ser imposta ao material para que ele se deforme. Assim, para que uma bolha de gás escoe num fluido com tensão limite é necessário um volume mínimo da bolha, de tal forma que as forças de empuxo sejam suficientes para vencer as forças cisalhantes. Já os materiais tixotrópicos possuem uma reologia que é função da taxa de cisalhamento e do histórico de cisalhamento. Este comportamento permite simular a análise do processo de cura de uma pasta de cimento, e assim investigar a influência da variação da reologia com o tempo na dinâmica e geometria das bolhas de gás. Outra característica estudada nas suspensões usadas no presente trabalho é a alta heterogeneidade do material em função do processo de preparação e do histórico de cisalhamento, já que as pastas de cimento usadas no campo podem apresentar heterogeneidades. A não homogeneidade pode formar caminhos preferencias para o escoamento das bolhas de gás.

Os resultados da literatura e do presente trabalho mostram que estes diversos fatores citados acima afetam a geometria e a dinâmica da bolha. Porém, todos estes fatores agem de forma simultânea, e é muito difícil isolar seus efeitos numa análise experimental. Altos Re causam regiões de alta pressão no topo da bolha tornando a bolha mais larga, fluidos mais viscosos tornam a bolha mais fina, a elasticidade forma bolhas com caldas longas que afetam a recirculação de fluido na vizinhança, só para apresentar alguns exemplos e demonstrar a complexidade do fenômeno, e o muito que tem que ser estudado para se avançar na compreensão e controle do fenômeno.

\section{1}

\section{Motivação}

A cimentação de poços de petróleo é um estágio importante na produção de hidrocarbonetos, ela evita o desabamento da formação rochosa do poço, isola regiões indesejadas como aquíferos ou depósitos de gás, e permite o controle da produção mediante a separação das diversas áreas pressurizadas. 

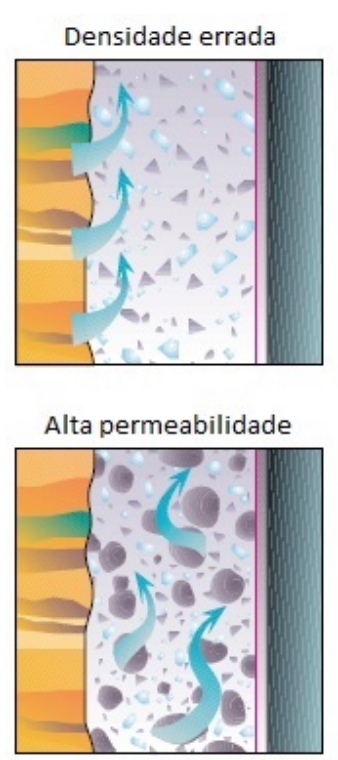

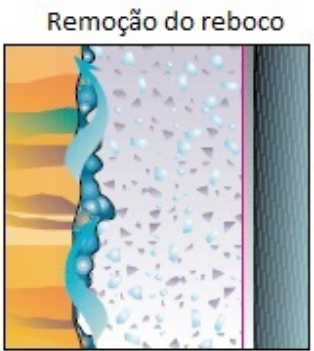

Alta contração

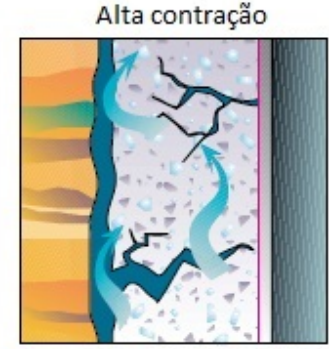

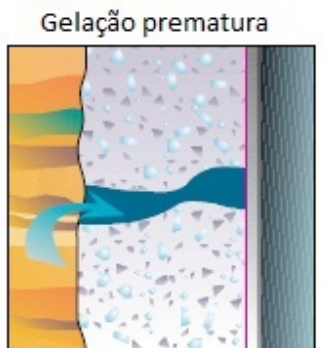

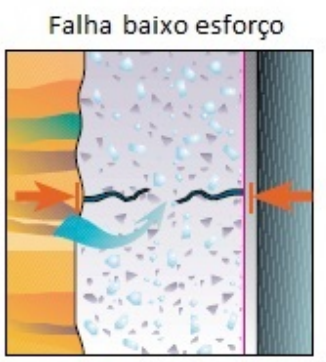

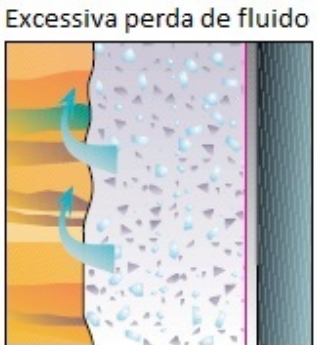

Pobre aderência interfacial

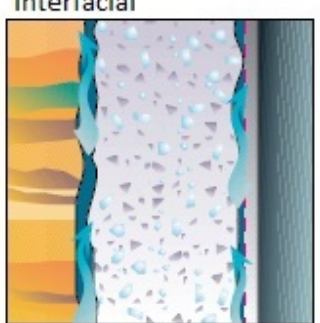

Figura 1.2: Parâmetros que contribuem à migração de gás durante a cimentação de poços de petróleo (58) (78). (a) Densidade errada da pasta; (b) problemas na remoção do reboco ou filter cake; (c) Gelação prematura da pasta; (d) excessiva perda de liquido da pasta; (e) Alta permeabilidade da pasta; (f) Alta contração durante a cura; (g) Falha da coluna de cimento baixo esforço e; (h) pobre aderência interfacial entre a coluna e a formação.

O processo de cimentação é afetado por diversas condições que podem deteriorar ou inclusive inabilitar totalmente o poço, o gás pode invadir a coluna de cimento devido a uma queda ou gradiente de pressão na coluna que favorece o fenômeno. A Fig. 1.2 expõe alguns dos parâmetros que podem contribuir à migração de gás, entre as principais causas esta (a) uma densidade errada da pasta que pode causar um desbalance hidrostático, (b) problemas na remoção do reboco na interface entre a coluna de cimento e a formação que favorece um caminho para o gás migrar, (c) gelação prematura que pode causar uma perda de pressão hidrostática, (d) perda de liquido disponibiliza espaço na coluna para o gas migrar, (e) alta permeabilidade causa uma perda de isolação das regiões pressurizadas e oferece pouca resistência à migração, (f) alta contração permite espaço para migração e aumenta os esforços internos que causa microanéis na coluna, (g) esforços na coluna causa microanéis e (h) pobre aderência pode causar falhas na interface entre a coluna, o casing e a formação rochosa.

Este trabalho estuda um fenômeno especifico, a invasão de gás durante o processo de cimentação e cura da coluna de cimento. Bolhas de gás pressurizadas com origem na formação rochosa conseguem invadir a pasta de cimento e se deslocar na coluna durante o processo de cura (Fig. 1.3). Se este fenômeno não for controlado pode causar sérias dificuldades na operação de produção de 


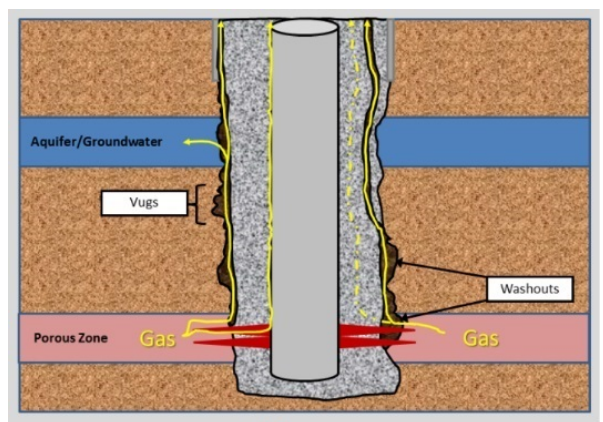

(a)

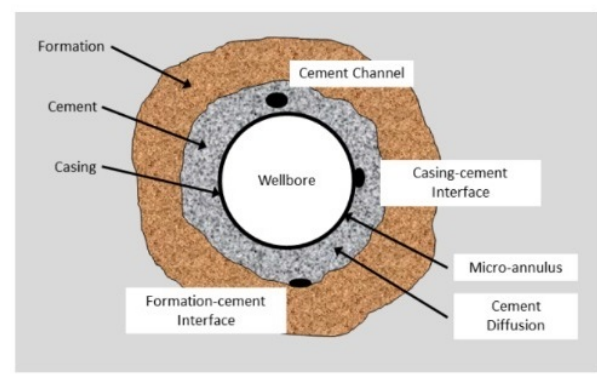

(b)

Figura 1.3: Caminhos preferenciais formados por bolhas de gás durante a cimentação de um poço de petróleo; (a) Vista frontal e (b) Vista transversal de poço.

óleo e gás ou até causar perda completa do poço. Os canais de gás formados na coluna de cimento podem comunicar diferentes zonas pressurizadas, facilitar a invasão de aquíferos e uma grande quantidade de problemas de produção. A invasão de gás é um sério risco à segurança dos funcionários, e existem diversas situações documentadas onde infelizmente ocorreram perdas de vidas, e a operação de cimentação foi comprometida pelo fenômeno de migração de gás em poços.

Durante o processo de cimentação de um poço, independente do cuidado tomado durante a perfuração do poço, a preparação da pasta ou a cimentação, poderão acontecer instabilidades que permitirão migração de gás com consequências negativas para o poço. A complexidade do processo de cimentação pode ser observada na Fig. ??.a onde parâmetros como pressão e vazão de injeção oscilam de forma incerta. Por esta razão é tão difícil evitar a migração de gás e se faz necessário estudar melhor o fenômeno de migração para mitigar seus efeitos negativos e os riscos associados.

\section{2}

\section{Objetivos}

O presente trabalho visa contribuir para a melhor compreensão dos mecanismos físicos associados ao escoamento de bolhas de gás em materiais viscoplásticos e tixotrópicos. Com esta finalidade, os objetivos são definidos a seguir.

- Estudo de preparação, acondicionamento e caracterização de suspensões aquosas com propriedades reológicas similares às pastas de cimento

- Trabalho experimental de injeção de bolhas de ar em suspensões poliméricas viscoplásticas para o estudo de migração de gás em suspensões 
heterogêneas como as pastas de cimento.

- Trabalho experimental de injeção de bolhas de ar em suspensões tixotrópicas altamente gelificadas para melhor compreensão dos mecanismos de migração de gás em pastas de cimento num processo avançado de cura.

- Modelo matemático simplificado para simular o comportamento de bolhas de gás não esféricas escoando em regime de Stokes e laminar em fluidos viscoplásticos e tixotrópicos, a fim de melhorar o controle do fenômeno de migração de gás em pastas de cimento.

\section{3 \\ Organização do Trabalho}

Este trabalho é dividido em cinco (6) capítulos: Introdução, Revisão Bibliográfica, Materiais e Métodos, Resultados experimentais, Modelamento Matemático e Conclusões. Na parte final deste trabalho são adicionadas as Referências Bibliográficas e os Apêndices.

O Capitulo 1 inclui a motivação do trabalho e os objetivos da pesquisa, assim como uma breve descrição do tema a estudar.

O Capitulo 2 de revisão bibliográfica está dividido em sete (7) seções onde é feita a revisão do estado da arte em áreas como cimentação de poços de petróleo, reologia de pastas de cimento, formação de bolhas de gás, escoamento de partículas sólidas e gasosas em fluidos Newtonianos e não-Newtonianos, e modelamento matemático.

O Capitulo 3 apresenta os materiais e métodos empregados na pesquisa. Descreve-se a bancada experimental assim como reômetros e misturadores utilizados, entre outros equipamentos. Metodologias para preparação das suspensões aquosas, realização de testes experimentais, caracterização de fluidos e pós-processamento de imagens também são descritos neste capítulo.

O capitulo 4 expõe os resultados dos testes experimentais e da caracterização reológica em suspensões aquosas com baixo e alto nível de gelificação.

O capitulo 5 apresenta o trabalho de modelamento matemático para escoamento de bolhas em suspensões aquosas de baixo nível de gelificação.

O último Capitulo 6 apresenta as conclusões e propostas para trabalhos futuros.

Para fechar este documento se incluem as Referências Bibliográficas e os Apêndices. Os procedimentos de preparação das suspensões aquosas estão no Apêndice A e as rotinas em Matlab usadas para post-processar as imagens e para solucionar o modelo matemático proposto são apresentadas no Apêndice B. 


\section{2}

\section{Revisão bibliográfica}

Neste trabalho foram consultadas referências diversas sobre partículas solidas e gasosas em fluidos Newtonianos e Não-Newtonianos, também trabalhos sobre formação de bolhas de gás, simulações CFD, interfaces não-miscíveis, cimentação, entre outros. Na área de migração de partículas em reologias diversas é possível encontrar uma grande quantidade de artigos relacionados, esta é uma área de grande interesse na indústria e com um longo histórico de pesquisas e avanços, por esta razão será feita uma breve resenha dos trabalhos mais interessantes, mas sendo conscientes que existem vários autores ausentes neste estudo.

Neste trabalho foram usados alguns livros como base de consulta. No estudo reológico, caracterização de fluidos e dinâmica de suspensões aquosas foram utilizados os livros de Bird et al. (50), Barnes (49) e Schramm (84). Como base para o estudo de escoamento de partículas em fluidos diversos foram considerados os livros de Chhabra (48) e Chhabra \& Richardson (51), estes trabalhos oferecem um ponto de vista geral sobre temas como tixotropia, elasticidade, viscoplasticidade, regimes de escoamento, modelos matemáticos, caracterização de fluidos, migração de gás, entre outros. Adicionalmente foram usadas algumas revisões extensas sobre escoamento de partículas solidas e gasosas em diversos materiais complexos como Kulkarni \& Joshi (2) que apresenta uma das melhores revisões sobre formação de bolhas em diversos fluidos, além de oferecer detalhes sobre os métodos experimentais de observação e a modelagem matemática relacionada. Outras revisões com informações sobre coeficientes de arrasto $C_{D}$ em diversas condições encontramos em Karimipour \& Pugsley (52), Kelbaliyev (13) e Magnaudet et al. (71). Para o estudo do processo industrial de cimentação de poços de petróleo, métodos preditivos de migração de gás e técnicas de controle do fenômeno foram usados os livros de Rosa (81), Rocha (82) e Thomas (83).

\section{1}

\section{Cimentação de poços de petróleo e reologia de pastas de cimento}

A invasão e migração de gás durante a cimentação de poços de petróleo é um fenômeno que agrupa diversas causas químicas e mecânicas que levam 
a uma queda de pressão na coluna de cimento até valores inferiores à pressão da formação rochosa, facilitando a invasão de gás e sua posterior migração. O trabalho de Bonett (58) explica em detalhe os diferentes mecanismos que podem causar invasão de gás numa coluna de cimento: perda de liquido, gelificação prematura, alta permeabilidade, densidade incorreta da pasta, problemas na preparação ou na injeção da pasta, remoção não adequada do fluido de perfuração ou do separador, entre outras causas. Este trabalho mostra a complexidade no controle do processo de cimentação e a não existência de uma formula única para solucionar o problema de migração.

Parcevaux (78) além de apresentar os mecanismos de invasão e migração, faz uma boa revisão de métodos de controle da migração e os métodos de laboratório disponíveis para tentar predizer este fenômeno. Métodos físicos como sistemas de contrapressão anular, cimentos compressivos, expansivos ou impermeáveis, surfactantes, uso de Latex, sistemas de controle de perda de água entre outros foram estudados para entender melhor o fenômeno. Trabalhos similares ao de Prohaska (64) nos permitiram conhecer o efeito do processo de cura na reologia da pasta de cimento, mostrando a alteração das propriedades em função do tempo. O trabalho também mostra os métodos preditivos de migração de gás em pastas de cimento, e a modelagem matemática usada na indústria para estudar este fenômeno.

O cimento é uma suspensão complexa com propriedades elásticas, viscoplásticas e tixotrópicas que devem ser reproduzidas em laboratório para conseguir fazer testes experimentais em condições controladas. Para isto, foi necessário revisar a literatura sobre as características reológicas do cimento e achar os materiais que podem ser substitutos adequados em laboratório. Nehdi (47) apresenta um trabalho de caracterização de pastas de cimento com diferentes concentrações e aditivos, analisa o tipo de reômetro, a influência da geometria usada, a folga usada, entre outros parâmetros. O autor também define estatisticamente o modelo matemático reológico adequado para o cimento. Banfill (57) faz uma revisão de diversos autores e as tentativas de caracterizar o cimento em laboratório, define as principais propriedades do material e apresenta um estudo matemático e estatístico com diversos modelos que se ajustam ao material. Outros autores similares como Feys et al. (45) e Gucuyener (46) desenvolveram alguns modelos modificados mais precisos mas também mais complexos e difíceis de solucionar.

Para reproduzir as propriedades viscoplásticas, elásticas e tixotrópicas das pastas de cimento foram usados dois tipos de suspensões aquosas, a saber, uma suspensão de Carbopol 980 e uma de Laponita. Os dois materiais são viscoplásticos e elásticos, mas só a Laponita é altamente tixotrópica. O 
Carbopol geralmente não é considerado tixotrópico mas existe sim esta propriedade no material mas em baixa intensidade como confirma Dinkgreve (87) , são necessários grandes períodos de tempo para observar alterações na reologia, dependendo a aplicação ou experimento pode ser necessário considerar esta propriedade. Com estas características, estas suspensões podem ser utilizadas para substituir o cimento pelas suspensões nos testes experimentais, possibilitando testes mais controlados e a visualização com câmeras de vídeo para o estudo da dinâmica de migração e análise do formato das bolhas de gás em fluidos com reologia similar à pasta de cimento.

\section{2}

\section{Formação de bolhas de gás}

O processo de formação da bolhas foi investigado para o projeto de construção e operação da bancada experimental (Fig. 3.1). Foram estudados parâmetros como o angulo de injeção, a geometria do bico do injetor, a técnica de injeção do gás, além de propriedades como a molhabilidade da interface no bico do injetor e o diâmetro crítico da bolha $D_{c}$ (tamanho mínimo para a bolha escoar) em fluidos viscoplásticos.

Kulkarni (2) trabalhou com formação de bolhas de gás em diversos tipos de fluidos onde foi estudada a influência de diversos parâmetros na dinâmica da formação como a relação entre a vazão de injeção e o volume da bolha formada $\forall$, a influência da tensão superficial $\sigma$, o diâmetro crítico da bolha $D_{c}$, o efeito da molhabilidade no instante em que a bolha se separa do injetor, a influência da viscosidade $\eta$ e densidade da fase continua $\rho_{c}$ e discreta $\rho$, diâmetro interno do injetor, entre outros. A direção de injeção do gás e a geometria do bico injetor também são analisados, este trabalho foi muito importante para entender os desafios relacionados à fabricação de algo aparentemente simples como o injetor da bancada experimental. Ramakrishnan (23) fez um trabalho matemático para determinar a influência da vazão de injeção no tamanho da bolha $\mathrm{D}$, e apresenta um modelo matemático validado experimentalmente. Ele também analisa a influência da tensão superficial $\sigma \mathrm{em}$ bolhas muito pequenas com vazões de injeção baixas onde esta propriedade é importante. Quanto menor o tamanho da bolha, maior a influência da tensão superficial na geometria da bolha. Outros trabalhos similares consultados foram Satyanarayan (32) e Gaddis (8), onde se utilizam fluidos e condições operacionais diversas, e que também oferecem diferentes propostas para o modelamento do fenômeno de formação e separação da bolha.

O trabalho de Teresaka (22) estuda o diâmetro critico de separação $D_{c}$ da bolha em suspensões de Carbopol, e estuda o tamanho da bolha injetada 
em função de diversos parâmetros como a tensão limite do fluido $\tau_{0}$, vazão de injeção, o diâmetro interno do injetor, a tensão superficial $\sigma$, entre outros. Este trabalho foi muito útil para compreender a formação de bolhas em fluidos similares ao cimento.

\section{3}

\section{Dinâmica de partículas solidas e gasosas em baixos Re - Regime de Stokes}

A pesquisa sobre o escoamento de partículas no regime de Stokes ( $R e \ll$ 1) tem sido amplamente estudada devido ao fato de que o fenômeno é bem comportado e fácil de prever. Ele pode ser modelado pela equação de Stokes (Eq. 2-1) onde a partícula gasosa tem geometria esférica, a camada viscosa na interface não sofre desprendimento da superfície, e não existe turbulência ou vórtices que afetem a dinâmica do escoamento da bolha. Existe um grande acervo de referências sobre o tema, por isso serão apresentadas só algumas das referências encontradas. O escoamento de partículas solidas e gasosas em regime de Stokes não é o caso de estudo deste trabalho, mas foi usado em trabalhos anteriores (Lopez e Naccache (75)) para entender o fenômeno em condições ideais onde os fenômenos envolvidos podem ser isolados.

Um dos primeiros trabalhos encontrados foi o de Bond (73) (74) no ano 1927 sobre bolhas de gás e partículas solidas escoando em fluidos viscosos. Eles estudam as primeiras expressões para escoamento de partículas esféricas (solidas, liquidas e gasosas) usando a Lei de Stokes $(R e \ll 1)$, onde se consideram a força de empuxo $F_{b}$, as forças viscosas e a tensão superficial $\sigma$ na modelagem. A Eq. 2-1 aplica para partículas esféricas em regime de Stokes citada no trabalho de Bond (73) (74).

$$
C_{D}=\frac{24}{R e}
$$

Onde Re é o Número de Reynolds Re e $C_{d}$ é o Coeficiente de arrasto.

Haberman (61) apresenta a Eq. 2-2 para considerar fatores que podem causar desvios na Eq. 2-1 em partículas fluidas, a característica principal é a condição de deslizamento na superfície da partícula que ocorre em bolhas de gás, gotas de liquido não miscível ou até fluidos contaminados onde a velocidade na superfície da partícula é diferente de zero $(V \neq 0)$. Tudo isto reduz o valor da forca de arrasto $C_{D}$ na partícula chegando na Eq. 2-2 (61).

$$
C_{D}=\frac{16}{R e}
$$

A Eq. 2-3 aparece nos trabalhos de Clift (80) e Reynolds (41) para partículas fluidas em diversas condições experimentais que causam um desvio maior na Eq. 2-1. Neste caso, o fator principal do desvio é a recirculação interna de fluido que causa a condição de deslizamento na superfície e os desvios 
causados por perda de massa da bolha de gás ou gota liquida imiscível, também considera a inércia da partícula caso seja muito grande. O parâmetro $X_{c}$ representa um fator de correção para considerar todos os desvios já indicados.

$$
C_{D}=\frac{24 X_{c}}{R e}
$$

Onde $X_{c}$ é o fator de correção para desvios do comportamento ideal em Regime Stokes.

Astarita e Apuzzo (12) trabalharam com partículas gasosas e sólidas em suspensões poliméricas viscoplásticas como Carbopol (Carbomero), CMC (Carboxy Methyl Cellulose), CSB (Clear Synthetic Bentonite) e HEC (Hydroxy ethyl cellulose), entre outros fluidos. Estes autores realizaram alterações na equação característica de viscosidade $\mu$ e ajustaram diversos valores de $X_{c}$ na Eq. 2-3. Estas modificações permitiram o uso do modelo de Stokes em fluidos generalizados tipo Bingham, Power-Law ou Herschel-Bulkley. Os autores também desenvolveram expressões para o cálculo do diâmetro crítico da partícula $D_{c}$ (tamanho mínimo para a bolha escoar com tensão limite $\tau_{0}$ no fluido) em fluidos viscoplásticos como os indicados previamente.

Fraggedakis (9) fez um estudo numérico com partículas esféricas solidas escoando em regime de Stokes $(R e \ll 1)$ numa suspensão viscoplástica e elástica como a suspensão de Carbopol. O autor analisa a falta de simetria a montante e jusante da partícula e a reologia. Ele estuda a elasticidade e a tixotropia do Carbopol como causadora deste fenômeno. O autor analisa o processo de destruição e construção da microestrutura viscoplástica do Carbopol, assim como a tensão extensional por conta da alta elasticidade do fluido. Também é discutida a importância de considerar elasticidade em fluidos tradicionalmente tratados como viscoplásticos como no caso do Carbopol. A elasticidade altera a geometria da bolha e a sua dinâmica de forma importante. Fluidos com alguma propriedade elástica permitem um leve deslocamento do fluido da vizinhança, mas sem quebrar a microestrutura viscoplástica. Considerar este fenômeno pode afetar significativamente os resultados.

\section{4}

\section{Dinâmica de partículas solidas e gasosas em altos Re - Regime Laminar}

A dinâmica de partículas escoando em regime laminar muda de forma importante, quando o Re aumenta $(R e \geq 1)$ a hidrodinâmica do fluido deslocado não pode ser desprezada, a inércia se torna dominante e as forças viscosas se tornam desprezíveis, alterando significativamente os modelos matemáticos usados na predição do fenômeno. Autores como Moore (79) no ano 1965 começaram a trabalhar com esta nova dinâmica e basicamente adicionam um 
novo termo à Eq. 2-3 para considerar a hidrodinâmica da fase continua e seu crescimento em função do Re $(f(R e))$ como mostra a Eq. 2-4. Os autores que trabalham com escoamento de partículas sólidas estudam o efeito da reologia da fase contínua na velocidade terminal da partícula. Como a geometria e o volume das partículas solidas não muda, a força de empuxo $F_{b}$ também não, e por esta razão as partículas solidas atingem uma velocidade máxima constante ao longo do deslocamento. Autores como Valentik (54) estudaram a influência da reologia de fluidos tipo Bingham na velocidade terminal. Neste trabalho foram usadas suspensões aquosas china clay com propriedades viscoplásticas e foram analisados os efeitos da reologia.

$$
C_{D}=\frac{24 X_{c}}{R e}(1+f(R e))
$$

O segundo termo da Eq. 2-4 considera a inércia do fluido deslocado pela partícula, este termo pode crescer exponencialmente, polinomicamente ou segundo outras curvas de tendência segundo o autor consultado, o importante é que este termo cresce em função do Re. Existe uma grande quantidade de artigos para inúmeras condições reológicas e operacionais de partículas escoando em reologias complexas, temperaturas variadas, vazões de injeção, pressões de injeção, tipos de partículas, entre outros. O trabalho de Tabuteau et al. (27) e Dolejs et al. (33) mostra o efeito da tensão limite $\tau_{0}$ de diversos fluidos viscoplásticos no escoamento de partículas solidas. O autor altera o diâmetro D das partículas solidas e a densidade para estudar diferentes regimes de escoamento e o efeito das forças viscosas e inerciais. Hariharaputhiran (35) fez um trabalho diferente, utilizando múltiplas esferas solidas de diferentes materiais como aço, cerâmica, bronze e vidro de diferentes diâmetros e densidades escoando em Carbopol-941. O fluido foi modelado pela equação de Herschel-Bulkley. No trabalho se analisa o efeito de cada parâmetro na velocidade terminal, e como a mesma varia em função do intervalo de tempo entre esferas. O autor observa uma relação direta entre o período de injeção das esferas e a velocidade limite destas, e conclui que existe um processo leve de gelificação e destruição da estrutura do Carbopol, em função da distância entre as esferas. Acharya (42) apresenta uma revisão da literatura para partículas solidas esféricas escoando em fluidos como CMC (Carboxymethyl cellulose), HEC (Hydroxy ethyl cellulose), PEO (Polyethylene oxide), PAA (Polyacrylamide), glicerol, entre outros fluidos inelásticos e elásticos. O autor apresenta resultados experimentais e modelos matemáticos que permitem observar o desvio do modelo de Stokes (Eq. 2-1) numa ampla faixa de Re, e conclui que ocorre uma queda importante no arrasto da partícula para altos Re em fluidos elásticos. Ansley (36), Dedegil (37), Reynolds (41) e Atapattu (56) reforçam os resultados de veloci- 
dade terminal de partículas em fluidos viscoplásticos como ketchup, Carbopol 940, Carbopol 941 e suspensões de agua-bentonita, onde se altera o diâmetro e densidade das partículas solidas.

Raymond (16) faz um trabalho experimental e numérico de injeção de bolhas de gás em fluidos viscosos, permitindo analisar o desvio na Eq. 2-3 em regime laminar e analisar a geometria das bolhas nestas condições. O trabalho de Joseph (39) e Derksen (38) oferecem resultados experimentais em novas condições reológicas e experimentais e foi usado na validação da Eq. 2-3. Bozzano (4) analisou a influência da tensão superficial $\sigma$ na geometria e dinâmica da bolha de gás em fluidos Newtonianos. O trabalho mostra a relação entre forças viscosas, inerciais e superficiais, e valida com resultados experimentais de diversos autores. Finalmente, apresenta-se um modelo matemático que funciona adequadamente numa ampla faixa de Re. Neste trabalho o diâmetro D da partícula é bem maior do que o valor critico onde a tensão superficial $\sigma$ ainda é importante, e por isso o autor concluiu que a mesma podia ser desprezada.

Atapattu et al. (25), Beaulne \& Mitsoulis (24), Tripathi (19), Dubash (7), Dimakopoulos (5) e Blackery \& Mitsoulis (26) mostram resultados com partículas gasosas em suspensões poliméricas viscoplásticas e elásticas. Usando modelos reológicos generalizados tipo Herschel-Bulkley, Bingham, Power-Law e versões analogas à Eq. 2-3 é possível avaliar a hidrodinâmica da fase continua e a influência da reologia na dinâmica das partículas. Estes autores estudaram numericamente duas regiões de fluido na vizinhança da particula (yielded/unyielded regions): uma fina camada fluidizada ou desestruturada em contato com a superfície da partícula, e uma outra região mais afastada que sofre deformação elástica mas sem desestruturação ou fluidização. Este comportamento é função do Re, da tensão limite $\tau_{0}$ e da elasticidade do fluido. Saha et. al (31) trabalharam com gás em fluidos viscoplásticos e viscoelásticos como CMC (Carboxymethyl cellulose), Carbopol e ET497, e mostram a influência da elasticidade no cálculo do diâmetro crítico $D_{c}$ da bolha de gás. Sikorski (17) oferece um dos trabalhos mais importantes para validação dos resultados desta pesquisa. O autor fez um estudo experimental de injeção de bolhas de gás em fluidos viscoplásticos e elásticos como Carbopol, em concentrações de até 1,8\%. A suspensão foi considerada tipo Herschel-Bulkley e o autor estuda principalmente a influência da plasticidade no tamanho crítico da bolha $D_{c}$ de gás além da influência da elasticidade (G' e G") na formação da calda da bolha.

Outras propostas de modelamento matemático para abordar o problema do deslocamento de bolhas foram analisadas. Ohl et al. (30) apresenta a Eq. 2-5 onde considera que a inércia do fluido deslocado é proporcional ao volume 
$\forall$ e à velocidade na superfície da partícula. Os autores incluem uma massa virtual ou Added Mass para adicionar artificialmente uma inércia ao modelo. A dificuldade está em obter as informações necessárias para o modelo, como volume deslocado e velocidade da partícula, para calcular a aceleração do fluido na vizinhança da bolha. Abbas (1) avalia outras expressões para o cálculo da massa virtual em diferentes regimes de escoamento, inclusive com várias partículas ao mesmo tempo para analisar o efeito população. Brennen (85) fez um ótimo trabalho sobre massa virtual numa extensa lista de geometrias, aplicações industriais e regimes de escoamento. No trabalho calcula-se os coeficientes de ajuste do modelo em função das características geométricas, regime de escoamento e reologia usada. Também estuda-se os efeitos de compressibilidade, efeitos viscosos e efeito de parede. Outros trabalhos similares foram consultados como Abbas (86) com a modelagem matemática detalhada, Zhang (21) que considera a aceleração da bolha como produto do aumento do diâmetro efetivo D da bolha ao cair a pressão hidrostática.

$$
\frac{2}{3} \pi \rho \frac{d}{d t}\left[R^{3}\left(V-V_{L}\right)\right]=\frac{4}{3} \pi R^{3} \rho g-\frac{1}{2} \pi R^{2} \rho C_{D}\left|V-V_{L}\right|+\frac{4}{3} \pi R^{3} \rho \frac{d V_{L}}{d t}
$$

Onde $\rho$ é a densidade da fase continua, $\mathrm{R}$ é o diâmetro efetivo da partícula, V é a velocidade da partícula, $V_{L}$ é a velocidade relativa de escoamento da fase continua e $C_{D}$ é o coeficiente de arrasto da partícula

Premlata et al. (40) fez um estudo numérico para observar a evolução da geometria e da dinâmica de uma bolha de gás em fluidos tipo Power-Law ou shear thinning/thickenning. Neste trabalho é analisada a recirculação do fluido e as linhas de corrente na vizinhança da bolha, e a influência na reologia do material fluidizado (yielded region) na interface. Hua (28) apresenta um trabalho numérico e experimental aplicado em fluidos viscosos. O autor valida os resultados de Raymond (16) e estuda os campos de velocidade e pressão no fluido circundante à bolha, observando o efeito da pressão da fase continua na geometria da bolha, e mostrando como a inércia do fluido deslocado na parte superior da bolha causa um aumento da pressão e força a geometria da bolha a ficar mais larga em altos Re. Os trabalhos numéricos analisados nesta pesquisa estão baseados na solução das equações de conservação de massa e quantidade de movimento. Diferentes modelos reológicos do fluido são utilizados, bem como as condições iniciais, condições de contorno e termos adicionais para avaliar novas hipóteses, mas em essência todos os modelos têm a mesma base.

Putz (15) e Tsamopoulos (53) fizeram trabalhos numéricos relacionados a escoamento de bolhas de gás num fluido viscoplástico e elástico, onde foi analisado o efeito do escoamento da partícula na vizinhança. Foram analisados 
o campo de velocidades e pressões, as regiões fluidizadas (yielded regions) e as regiões deformadas elasticamente (unyielded regions). Em fluidos elásticos mas pouco viscoplásticos a região fluidizada (yielded region) corresponde a quase toda a região afetada pela partícula; mas conforme a plasticidade aumenta, a região fluidizada (yielded region) diminui até se tornar uma camada muito fina ao redor da partícula. O resto da região afetada pela partícula corresponde a uma região deformada elasticamente (unyielded region) sem desestruturação. Os autores mostram a importância da relação entre tensão limite $\tau_{0}$ e elasticidade (através do módulo de armazenamento, $G^{\prime}$ ), mas também chamam a atenção sobre as diferenças existentes nos resultados numéricos de diferentes autores em função do modelamento usado, e das condições iniciais e de fronteira assumidas. Lind (59) fez um trabalho numérico com resultados que concordam com Sikorski (17), onde a elasticidade é responsável pelo formação da calda na bolha. Além disso mostra a esteira negativa no fluido da vizinhança, que afeta a parte inferior da bolha e gera vórtices que favorecem a formação da calda. O autor também afirma que a descontinuidade na subida de bolhas pode ocorrer em fluidos altamente elásticos, algo que não foi observado neste trabalho. Funfschillin (11) apresenta um trabalho em fluidos Newtonianos elásticos que permite observar melhor a formação da esteira negativa (negative wake), a vorticidade causada pela elasticidade, e a sua influência na dinâmica e geometria da bolha.

No presente trabalho foram injetadas bolhas individuais para evitar a coalescência ou o efeito de população que afetam a reologia do fluido circundante, e em consequência a dinâmica das bolhas injetadas. Autores como Vélez-Cordero (20), Chen (63), Islam (18), Funfschillin (10), Frank (67) e Smolianski (3) estudaram as consequências do efeito de população na viscosidade da fase continua. Usando métodos numéricos mostram a interação entre múltiplas partículas em termos de gradientes de pressão, linhas de corrente, viscosidade, campos de velocidade, etc. Os autores também analisam os efeitos viscosos, geometria da bolha, dissolução da bolha e o efeito da tensão superficial $\sigma$ na coalescência. A coalescência tornaria ainda mais complexo o estudo, por isso trabalhamos para evitar este fenômeno nos experimentos.

Um outro fenômeno analisado no presente trabalho é a trajetória oscilante de bolhas de gás em diversos de fluidos. Autores como Maldonado (69), Mikaelian (68), Hassan (62) e Liu (70) (72) apresentam bolhas escoando em fluido viscosos e viscoplásticos de baixa concentração. Eles concluem que fluidos com baixas propriedades viscosas e viscoplásticas facilitam a formação de vórtices ao redor da bolha, que alteram a geometria da mesma e desequilibram a distribuição de forças sobre a partícula, causando oscilação 
na trajetória. Fluidos viscoplásticos poliméricos de alta concentração como os usados neste trabalho apresentam trajetória retilínea e vertical, mas só após um processo de homogeneização que será apresentado mais na frente.

\section{5}

\section{Dinâmica de partículas gasosas em fluidos altamente gelificados}

Existe um grande acervo de pesquisas sobre bolhas de gás escoando nas mais diversas condições reológicas e operacionais, mas ainda assim existem problemas para encontrar métodos preditivos e técnicas de controle efetivos na migração de gás em pastas de cimento. O cimento é uma suspensão viscoplástica, elástica, heterogênea e que cura em função do tempo, tornando ainda mais complexo o estudo. Mougin (14) fez um trabalho experimental e numérico em fluidos viscoplásticos de alta concentração usando Carbopol. Os resultados mostram a influência do histórico de cisalhamento na dinâmica da bolha. O principal aporte do autor é que ele estudou a formação de caminhos preferênciais, e a geometria atípica das bolhas neste tipo de fluidos altamente gelificados. Nas seções anteriores (Sec. 2.3 e Sec. 2.4) as partículas sempre tiveram simetria axial ao se deslocar, mas em fluidos altamente gelificados a geometria é assimétrica com a tendência a formar bolhas planas. Esta tendência aumenta em função da concentração de polímero que incrementa a tensão limite $\tau_{0}$ do fluido causando uma queda importante na inércia e no arrasto da partícula.

Sadeghy (65) apresenta um estudo numérico com materiais viscosos e tixotrópicos. Para modelar esta reologia o autor apresenta uma expressão em função do nível de gelificação e um parâmetro em função do tempo de repouso. Dessa forma, ele simula a influência do histórico de cisalhamento na dinâmica da bolha de gás. Adicionalmente ele analisa a geometria da bolha e os efeitos do cisalhamento na reologia da vizinhança da partícula.

Soto (66) fez experimentos com HASE (hydrophobically alkali-soluble emulsions) de alta concentração, onde mostra os efeitos da reologia na geometria da bolha. O autor conclui que a elasticidade do fluido é a responsável pelas alterações na geometria e especificamente pela formação de uma extensa calda nas bolhas. O autor também observa uma geometria plana na ponta da calda e relaciona o fenômeno à natureza viscoelástica do fluido.

Tabuteau (34) fez um dos trabalhos mais importantes para esta pesquisa. Nele, foram realizados testes experimentais com partículas sólidas escoando em suspensões viscoplásticas e tixotrópicas como Carbopol e Laponita. Foi desprezada a inércia do fluido deslocado (Regime Stokes). Este trabalho foi importante porque a parte experimental é similar ao apresentado aqui, onde 
o material foi homogeneizado para atingir uma reologia inicial uniforme em todos os experimentos e onde foram analisados fenômenos como a estruturação da Laponita e a viscoplasticidade e elasticidade do Carbopol. Neste trabalho foi analisada a diminuição da velocidade terminal das esferas solidas em função do tempo de gelificação da Laponita, mostrando os efeitos deste fenômeno na dinâmica e no cálculo do tamanho crítico das partículas. O autor também afirma a ocorrência da existência de uma camada fluidizada ou desestruturada muito fina ao redor da partícula em Laponita altamente gelificada, concordando com resultados prévios onde a camada é mais fina com o aumento da tensão limite $\tau_{0}$. As regiões mais afastadas ao redor da partícula se deformam elasticamente sem causar quebra da estrutura do fluido. O autor também apresenta a caracterização da Laponita no reômetro em baixas taxas de cisalhamento $\dot{\gamma}$, onde se suspeita da presença do fenômeno de shear banding, algo que também foi observado neste trabalho. O autor também trabalha com Carbopol em outra pesquisa (27) com resultados similares.

Para o cálculo do coeficiente de arrasto em partículas solidas não esféricas em fluidos viscoplásticos foi consultado o trabalho de Mitsoulis (29). O autor utiliza inicialmente o modelo reológico Herschel-Bulkley mas para evitar a descontinuidade para baixas taxas de cisalhamento $\dot{\gamma}$ utiliza o modelo de Papanastasiou. Neste trabalho se mostram as regiões fluidizadas ou desestruturadas e também as deformadas elasticamente (yielded/unyielded regions), com bolhas de geometrias diversas. Apresenta-se um modelo de força de arrasto em função do diâmetro efetivo, válido para uma ampla faixa de aplicação em termos geométricos. Este trabalho é uma boa referência para as situações com bolhas de gás em fluidos gelificados onde a geometria da bolha se afasta da esférica. 


\section{3}

\section{Materiais e Métodos}

\section{1}

\section{Loop para visualização}

A Fig. 3.1.a mostra a bancada experimental desenvolvida para analisar o deslocamento vertical de bolhas de gás em fluidos com tensão limite de escoamento. Uma coluna vertical de fluido é mantida em repouso, quando se injeta gás (ar) em condições controladas de vazão ou pressão. A migração do gás é observada através de câmeras que gravam o fenômeno para pósprocessamento e análise. Na parte inferior é posicionado um injetor conectado a uma bomba de seringa, ou a uma linha externa de gás pressurizado. Painéis Led são usados nas paredes da bancada para melhorar o contraste da interface gásliquido das bolhas nas imagens. Também foi instalado um sistema de circulação de ar com ventilador para esfriar as paredes aquecidas de acrílico, devido ao calor emitido pelos painéis.

A Fig. 3.2 mostra o diagrama do tanque de acrílico ou polimetilmetacrilato (PMMA) com base quadrada, altura de $60 \mathrm{~cm}$ e paredes laterais de $19.5 \mathrm{~cm}$ de largura e $1 \mathrm{~cm}$ de espessura. O tanque é bem maior que o tamanho das bolhas injetadas, que atingem até $4 \mathrm{~cm}$ na sua dimensão maior, para evitar o efeito de parede no deslocamento das bolhas. Por outro lado, o volume do tanque é limitado pelas características ópticas da Laponita, um dos fluidos utilizados no trabalho. A Laponita nas concentrações utilizadas é uma suspensão com aspecto leitoso, que torna difícil a visualização do escoamento das bolhas em seu interior. O injetor de gás é um tubo de aço inox de $3.175 \mathrm{~mm}$ de diâmetro interno com o bico localizado a uma altura de $13 \mathrm{~cm}$ desde o fundo da bancada, o bico do injetor é cônico e orientado verticalmente como explica a Fig. 3.3. Para injetar o gás existem dois métodos: uma bomba de seringa que permite controlar a vazão e o volume de gás injetado, e uma linha pressurizada de ar que permite injeção continua de gás a pressão controlada. A bomba possui seringas de $1 \mathrm{~mL}, 5 \mathrm{~mL}, 10 \mathrm{~mL}$ e $50 \mathrm{~mL}$. A vazão de injeção é determinada pelo diâmetro da seringa e pela velocidade de avanço do êmbolo da bomba. Painéis Led de 20x20 cm são usados nas paredes da bancada para melhorar a qualidade de observação da bolha nas vistas frontal e lateral. Estes painéis são instalados 


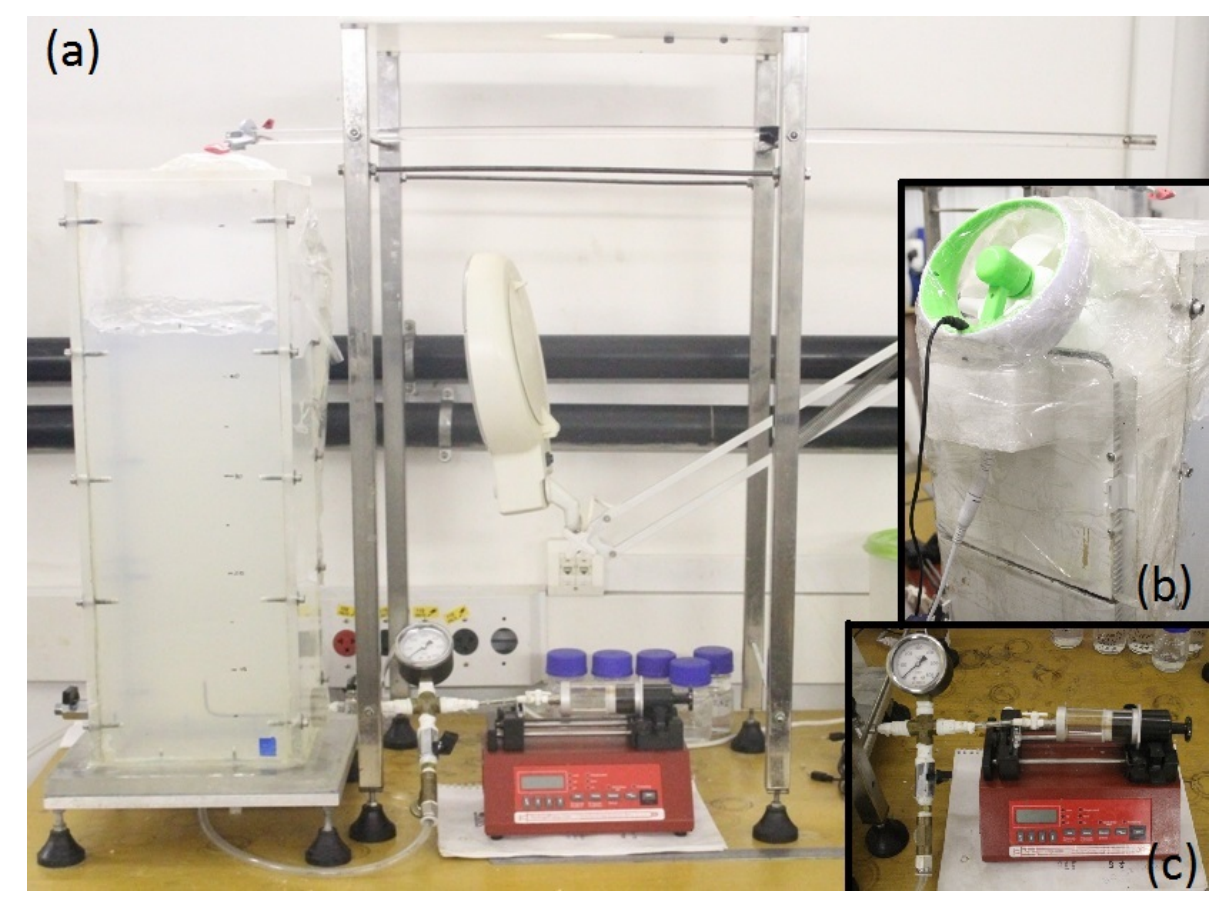

Figura 3.1: Bancada experimental construída para injeção de bolhas de ar num tanque com fluido em repouso. (a) Imagem geral da bancada; (b) Sistema de iluminação do tanque com painéis LED e esfriamento das paredes com ventilador; (c) Bomba de seringa e linha externa de ar pressurizado.

a 3cm de distância das paredes de acrílico para reduzir seu aquecimento e em consequência o aquecimento do fluido, e permitem uma imagem com luz mais homogênea nas câmeras. São quatro (4) painéis instalados, e as paredes foram forradas em papel branco para homogeneizar a iluminação. Um pequeno ventilador é instalado na parte superior da bancada para favorecer a circulação de ar entre os painéis Led a as paredes de acrílico. Este equipamento está localizado sobre um bloco de espuma que amortece as pequenas vibrações que poderiam afetar os experimentos. A câmera de vídeo usada é modelo Canon 7D da Fig. 3.8.b com resolução de até 18 MP (1920x1088 px) e 29 frames/s e é localizada a uma altura de entre $15 \mathrm{~cm}$ e $18 \mathrm{~cm}$ abaixo do nível do fluido.

O injetor localizado na parte inferior da bancada foi desenvolvido para solucionar algumas dificuldades observadas durante a injeção da bolha. Quando a direção de injeção é horizontal como mostra a Fig. 3.3.a e Fig. 3.3.b, o canal de gás que comunica a bolha com o injetor é estreitado, e causa uma separação prematura da bolha. Como a suspensão é viscoplástica, a bolha não consegue se deslocar porque a força de empuxo é incapaz de superar a tensão limite do fluido. Outra dificuldade é a geometria do usado no bico do injetor, o corte cônico usado na Fig. 3.3.b favorece a aparição do fenômeno de molhabilidade na interface gás-liquido-solido da bolha no bico injetor, que 


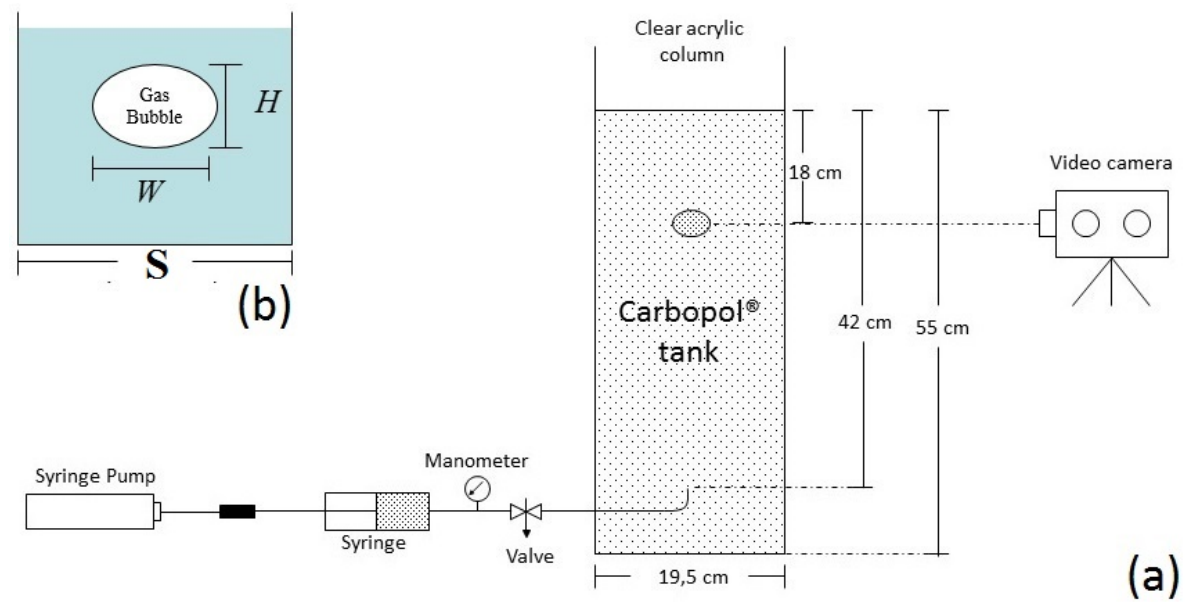

Figura 3.2: Diagrama simplificado da Bancada experimental. (a) Diagrama geral da bancada; (b) Dimensões do tanque da bancada e bolha de ar.

evita que a bolha se separe e comece a migrar. A molhabilidade gruda a bolha ao injetor e não permite que ela se desloque, sendo necessário um volume maior ao Volume critico $V_{c}$ (mínimo volume para a força de empuxo superar a tensão limite do fluido) para ela se deslocar. Por esta razão foi projetado e usinado um injetor com bico cônico e injeção na direção vertical. Esta configuração evita o estreitamento do canal de alimentação de ar, e reduz a molhabilidade que segura a bolha no bico injetor como mostra a Fig. 3.3.c. Nesta figura, podemos observar um canal de gás não estreitado, e que a bolha não se gruda ao injetor, permitindo calcular corretamente o diâmetro critico $D_{c}$ da bolha, i.e., o diâmetro mínimo onde a forca de empuxo da bolha supera o arrasto da bolha causado pela reologia do material ou a dinâmica do regime de escoamento, quando isto ocorre a partícula começa a escoar.

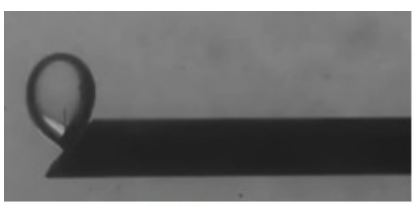

(a)

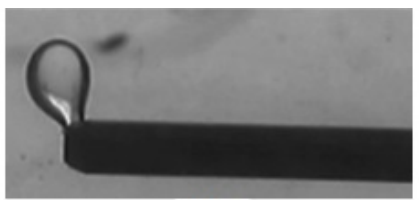

(b)

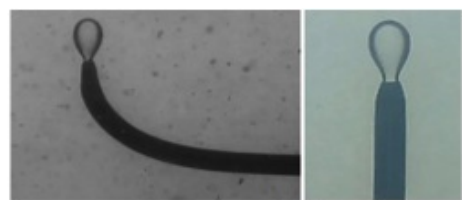

(c)

Figura 3.3: Injetores projetados para injetar gás na Bancada experimenta (2) (23) (22) ; (a) Injetor horizontal de corte diagonal; (b) injetor horizontal de corte cônico e (c) injetor vertical de corte cônico. 


\subsection{1}

\section{Metodologia de acondicionamento da suspensão para testes experimen- tais}

Antes de injetar qualquer bolha no tanque da bancada é necessário solucionar dois problemas: homogeneizar a concentração de partículas na suspensão e ao mesmo tempo evitar a entrada de ar durante o procedimento. Na Fig. 3.4 se observa o ocorrido com o gás injetado numa suspensão não homogeneizada: a trajetória e a velocidade da bolha são imprevisíveis como mostra a Fig. 3.4.a. Também pode acontecer a estagnação do gás no interior do fluido como mostra a Fig. 3.4.b, e a formação de grandes depósitos de gás. Outro efeito da não homogeneização é a formação de caminhos preferenciais como mostra a Fig. 3.4.c, afetando o tamanho, trajetória e velocidade das bolhas injetadas e impedindo a repetibilidade dos experimentos. Para evitar estes efeitos negativos foi desenvolvido um procedimento para eliminar caminhos preferenciais, homogeneizar a solução na base aquosa e retirar bolhas de gás estagnadas na suspensão. Este procedimento é aplicado antes de injetar cada uma das bolhas de gás para a visualização.

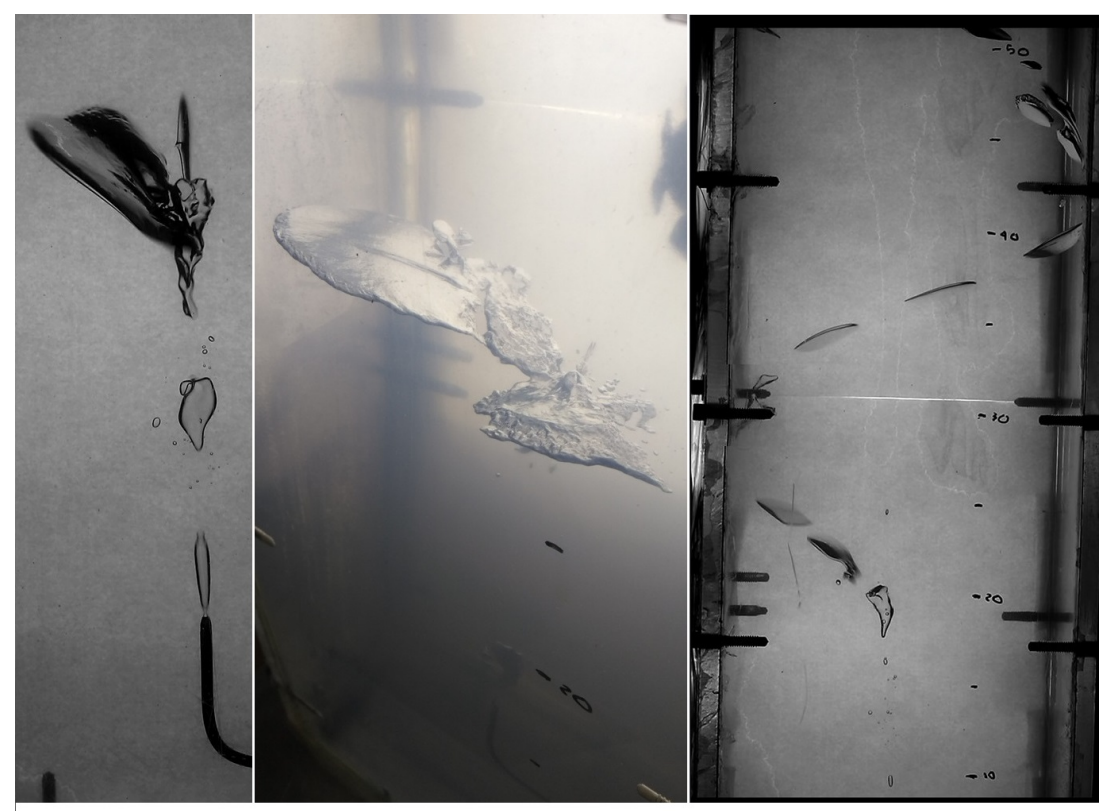

(a)

(b)

(c)

Figura 3.4: Efeitos negativos na migração de gás em suspensões heterogêneas. (a) Trajetória e velocidade irregular nas bolhas; (b) Estagnação do gás; e (c) Formação de caminhos preferenciais para múltiplas bolhas.

A Fig. 3.5 mostra o método de homogeneização da suspensão utilizando uma ferramenta metálica como a da Fig. 3.13.d, para fluidizar a suspensão da bancada através de movimentos verticais em todo o volume do tanque, desta forma eliminando caminhos preferenciais e conseguindo uma concentração 
uniforme de partículas no volume. Existem alguns cuidados a serem tomados. Perto da superfície é difícil cisalhar o fluido com a mesma intensidade que no meio ou no fundo do tanque para não introduzir ar no fluido, conforme mostra a Fig. 3.5.b. Por conta disto a reologia da suspensão muda levemente perto da superfície e afeta a velocidade das bolhas como mostra a Fig. 3.11.c. Esta é a razão de fazer testes experimentais a no mínimo $15 \mathrm{~cm}$ da superfície, onde a reologia é uniforme e portanto as medidas são realizadas numa região estável de velocidade, diâmetro e geometria da bolha como mostra a Fig. 3.11.

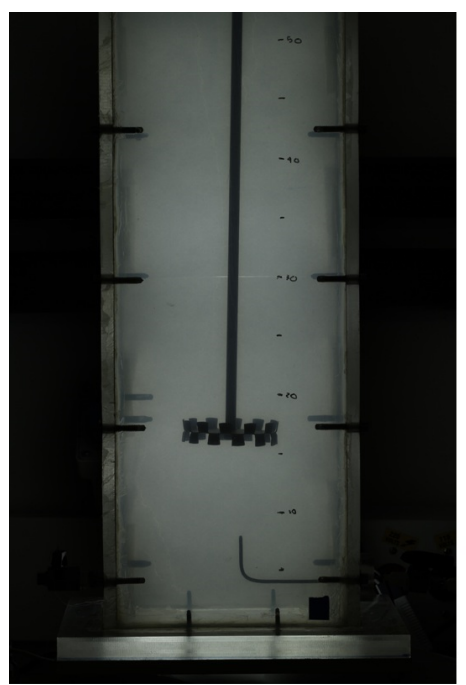

(a)

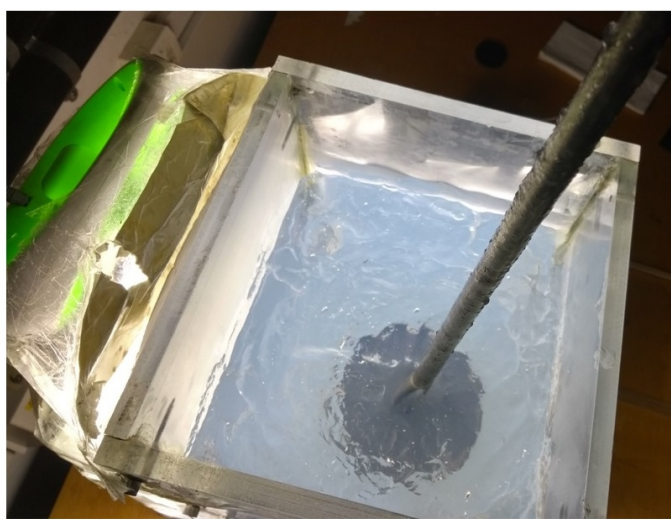

(b)

Figura 3.5: Ferramenta usada para desestruturar e homogeneizar a suspensão de Laponita. (a) Vista frontal; e (b) Vista superior.

Introduzir gás na suspensão se torna especialmente complicado na Laponita por conta do fenômeno de gelificação. Como mostra a Fig. 3.6.a a superfície do material se cristaliza e forma crateras que geram bolhas de ar muito difíceis de retirar posteriormente. A entrada de ar durante a preparação da Laponita ou durante o preenchimento do tanque ou homogeneização pode causar a perda total do material como mostra a Fig. 3.6.b, que mostra uma grande quantidade de bolhas na Laponita após ser homogeneizada de forma errada, permitindo a entrada de ar: o ar não se desloca e se divide em múltiplas bolhas menores após cada tentativa de eliminação, tornando impossível a retirada das bolhas.

O tempo de homogeneização depende da concentração de partículas da suspensão. Na Fig. 3.7 é possível observar dois processos de homogeneização com diferentes tempo de duração. A Fig. 3.7.a apresenta um tempo curto de cisalhamento o que causa bolhas com geometria, trajetória e velocidade irregular, chegando a se estagnar em algumas ocasiões. A Fig. 3.7.b mostra a bolha ao aumentar o tempo de cisalhamento. A velocidade se torna mais 


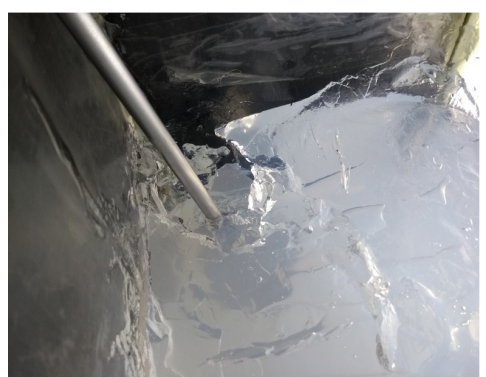

(a)

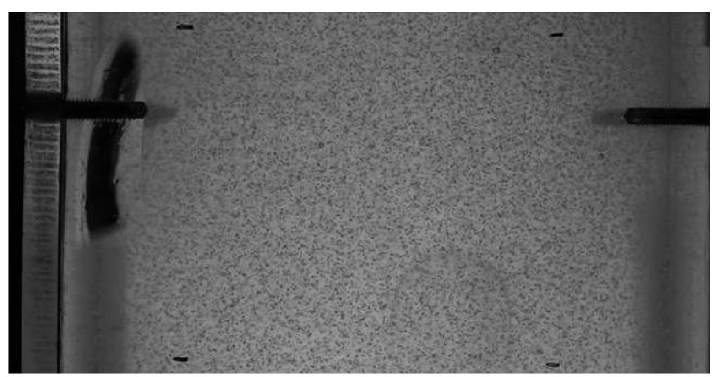

(b)

Figura 3.6: Invasão de ar na suspensão de Laponita. (a) Invasão de ar durante o processo de homogeneização; e (b) Invasão de ar na Laponita após um processo errado de homogeneização.

uniforme, melhora a trajetória retilínea vertical e a geometria é mais simétrica na direção axial. Um tempo adequado de homogeneização fornece resultados estáveis e mais repetitivos. Os tempos oscilam entre 3 min para o Carbopol de baixa concentração até mais de 15 min para a Laponita de alta concentração. Este tempo deve ser determinado experimentalmente até conseguir a qualidade nos resultados desejada, lembrando que o processo se aplica antes de injetar cada uma das bolhas de gás.

\subsection{2}

\section{Metodologia de injeção de bolhas de gás}

Quando a suspensão está homogeneizada e sem bolhas estagnadas, é possível injetar as bolhas de ar em condições estáveis. A Fig. 3.8.a mostra o arranjo de câmera, bancada experimental e sistema de injeção de bolhas. Na bancada se utilizam painéis LED para melhorar o contraste da interfase gás-liquido das bolhas, e a câmera de vídeo se localiza a uma distância de aproximadamente $1 \mathrm{~m}$ da bancada e através do controle remoto é acionada para fazer os vídeos. Para injetar a bolha de ar são usados três métodos em função da necessidade. Considerando que o tamanho da bolha é função da vazão de gás injetado, a bomba de seringa se utiliza para injetar bolhas menores porque a velocidade do êmbolo é baixa. Para maiores vazões de injeção é necessário um êmbolo de maior velocidade e como não temos uma bomba de seringa com essas características, por esta razão para bolhas maiores se faz injeção manual na seringa. A Fig. 3.8.a mostra uma injeção manual onde é possível atingir uma vazão maior, e em consequência bolhas de maior volume. O último método é através de uma linha de ar pressurizada para injetar gás por um tempo indeterminado com vazão constante, este método se utiliza para analisar a formação e crescimento de canais no material viscoplástico.

Nesta pesquisa foi controlada a vazão e não a pressão de injeção, mas se 


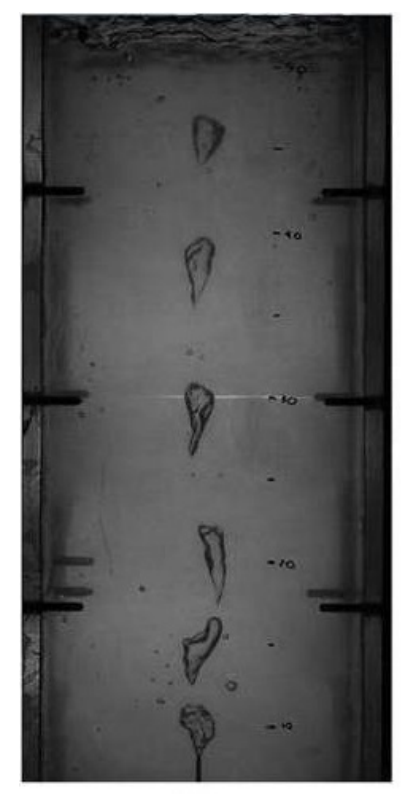

(a)

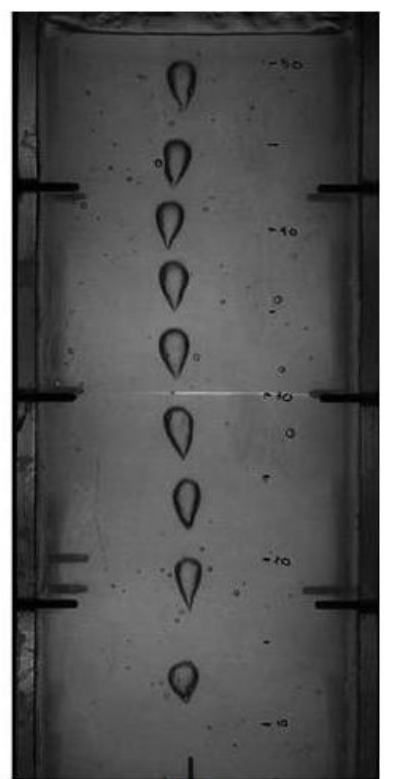

(b)

Figura 3.7: Comportamento instável do gás no interior de Laponita não homogeneizada completamente. (a) Bolha de gás após um curto processo de homogeneização; (b) Bolha de gás após um processo de homogeneização maior, mas ainda precisando mais tempo de cisalhamento.

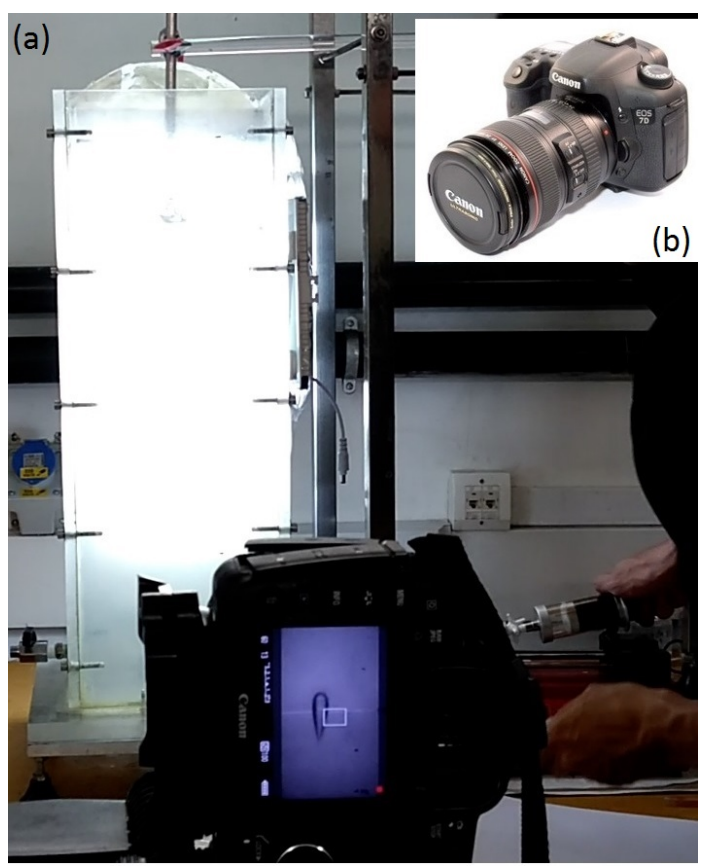

Figura 3.8: Metodologia de captura de imagens para pós-processamento. (a) Teste experimental de injeção manual sendo executado; (b) Câmera Canon 7D. 
observou que a pressão pode variar entre 45 mBar até mais de $200 \mathrm{mBar}$ em função da reologia do fluido e da vazão de injeção. Maiores vazões precisam de pressões maiores, e reologias altamente viscoplásticas ou tixotrópicas também precisam pressões maiores.

\subsection{3}

\section{Metodologia de captura e pós-processamento de imagens}

Após obter as imagens da injeção de bolhas de gás na bancada experimental é necessário pós-processar os vídeos. Para isto foi escrito um código em Matlab® (Apêndice B.1) para obter essencialmente quatro parâmetros: velocidade da bolha $\mathrm{V}$, altura da bolha $\mathrm{H}$, largura da bolha $\mathrm{W}$ e diâmetro efetivo da bolha D que representa o diâmetro de uma bolha esférica do mesmo volume da bolha experimental. A partir destes valores, outros parâmetros são calculados, como por exemplo o número de Reynolds Re, o número de Deborah De, o coeficiente de arrasto $C_{D}$, entre outros. A definição destes parâmetros é mostrada mais na frente.

Para conseguir estas informações são necessários três (3) vídeos com características diferentes, mas com a câmera na mesma posição para não perder a referência espacial nem a escala:

- O primeiro vídeo da bancada apresentado na Fig. 3.9.a com a bolha escoando.

- O segundo vídeo da bancada apresentado na Fig. 3.9.b é sem bolhas escoando nem qualquer outro objeto, só a bancada. Este vídeo permite subtrair o fundo do vídeo da bolha escoando (Fig. 3.9.a) para identificar a partícula e capturar as informações.

- O último vídeo da bancada apresentado na Fig. 3.9.c é com uma esfera solida de diâmetro conhecido no centro do tanque e à mesma altura da câmera. Esta esfera é usada para calcular a escala do vídeo.

Finalmente se usam as informações da câmera como a resolução da imagem em pixeis e a velocidade de captura de vídeo em frames/s para calcular as distâncias e velocidades reais no experimento.

Para capturar o fundo da imagem e a escala de calibração são feitos vídeos e não fotografias para manter a mesma resolução e configurações da câmera, mas para estas tarefas o código em Matlab só usa um frame, o resto é descartado. Maiores detalhes do procedimento de pós-processamento são apresentados no Apêndice B.1.

O resultado do pós-processamento dos vídeos é mostrado na Fig. 3.10. A primeira imagem na Fig. 3.10.a mostra a esfera de diâmetro conhecido 


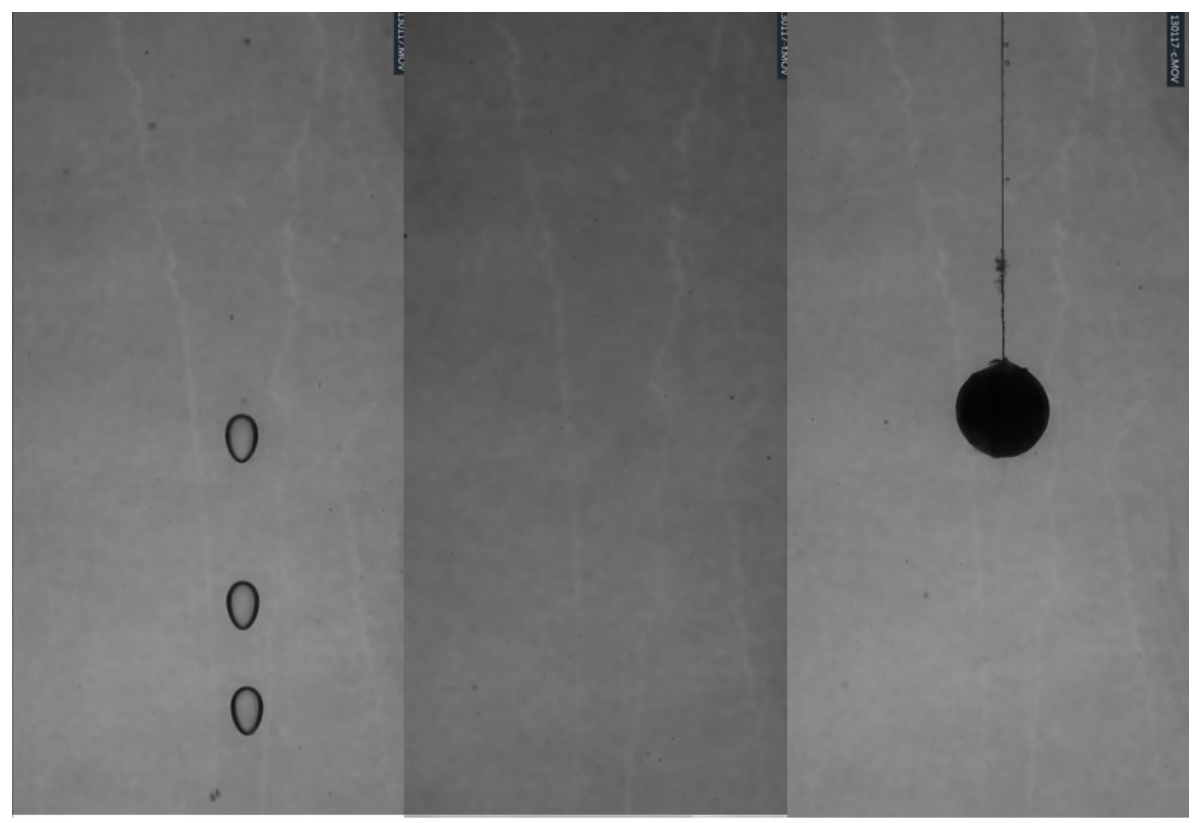

(a)

(b)

(c)

Figura 3.9: Vídeos necessários para pós-processar os testes experimentais de injeção de bolhas de gás usando Matlab. (a) Vídeo de injeção de bolha de gás; (b) Imagem de referência para extrair o fundo; e (c) Esfera de diâmetro conhecido para calibração da escala.

binarizada e com o fundo subtraído, a escala é calculada com a área transversal da esfera de diâmetro conhecido e o número de pixeis no círculo da imagem binarizada da Fig. 3.10.a. Usar a área transversal da imagem binarizada é muito mais preciso do que medir diretamente o diâmetro, com este método se amortecem as incertezas e erros de medição.

A Fig. 3.10.b mostra as bolhas de gás pós-processadas. Esta imagem permite calcular a área transversal da bolha e calcular o diâmetro efetivo da bolha D, além de calcular o centroide, largura da bolha $\mathrm{W}$ e altura da bolha H. Para medir a velocidade $\mathrm{V}$ da bolha utiliza-se a posição do centroide da partícula em cada frame junto com as informações de velocidade de captura da câmera em frames/s.

Para o cálculo do diâmetro efetivo D da bolha se usam as seguintes expressões matemáticas. A Eq. 3-1 permite calcular o diâmetro da esfera de calibração do vídeo em pixeis e a Eq. 3-2 permite calcular a escala $S_{c}$ do vídeo em $\mathrm{m} /$ pixeis.

$$
A_{\text {num }}=\pi\left(\frac{D_{\text {num }}}{2}\right)^{2}
$$

Onde $A_{\text {num }}$ corresponde à área da esfera de calibração no vídeo em pixeis ${ }^{2}$ fornecido pelo código em Matlab (Ap. B.1) e $D_{\text {num }}$ é o diâmetro da esfera de 


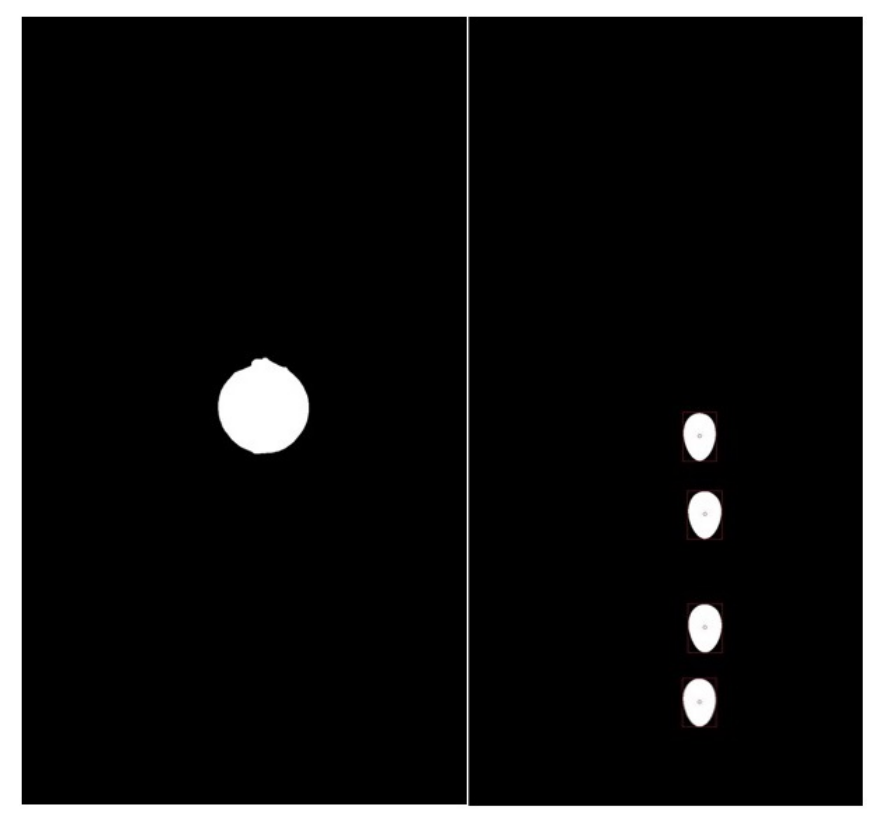

(a)

(b)

Figura 3.10: Vídeos pós-processados após uso da rotina em Matlab. (a) esfera de calibração pós-processada; e (b) Imagens de bolhas pós-processadas.

calibração em pixeis.

$$
S c=\frac{D_{\text {real }}}{D_{\text {num }}}
$$

onde $S_{c}$ é a escala do vídeo em $\mathrm{m} /$ pixeis e $D_{\text {real }}$ é o diâmetro medido da esfera de calibração em m. Para o cálculo do deslocamento da bolha se utiliza a Eq. 3-3.

$$
\Delta P=\sqrt{\Delta X^{2}+\Delta Y^{2}}
$$

onde $\Delta P$ é o deslocamento do centróide da bolha em termos absolutos, $\Delta X$ é o deslocamento no eixo horizontal do centróide da bolha e $\Delta Y$ é o deslocamento do centróide da bolha no eixo vertical em pixeis. Para o cálculo da velocidade V da partícula se utiliza a Eq. 3-4.

$$
V=\Delta P . V_{\text {cam }}
$$

onde $V_{\text {cam }}$ é a velocidade de captura da câmera em frames/s.

Os resultados em regime transiente da bolha de gás são apresentados na Fig. 3.11. As curvas mostram o diâmetro efetivo da bolha D na Fig. 3.11.a, a razão de aspecto da bolha $\mathrm{H} / \mathrm{W}$ na Fig. 3.11.b e a velocidade da bolha $\mathrm{V}$ na Fig. 3.11.c em função do deslocamento da bolha $\Delta P$. Os resultados de diâmetro efetivo $\mathrm{D}$ e razão de aspecto $\mathrm{H} / \mathrm{W}$ são estáveis em todo o deslocamento da bolha, mas a curva de velocidade $\mathrm{V}$ mostra instabilidade 
no final. Este fenômeno se explica pela dificuldade de cisalhar o fluido perto da superfície com a mesma intensidade que o resto do volume, isto ocorre pelo cuidado necessário para evitar a entrada de ar no fluido durante o processo de homogeneização. Por conta deste fenômeno as medições feitas na bolha de gás são feitas numa profundidade maior do que $15 \mathrm{~cm}$, assim se evita esta instabilidade nos resultados.

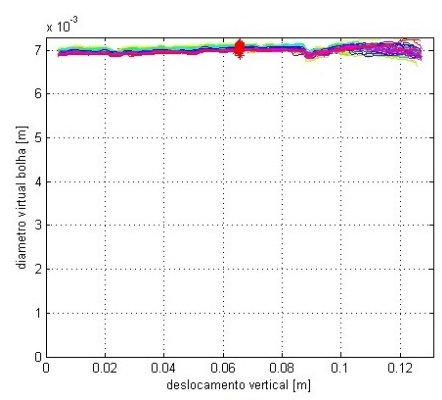

(a)

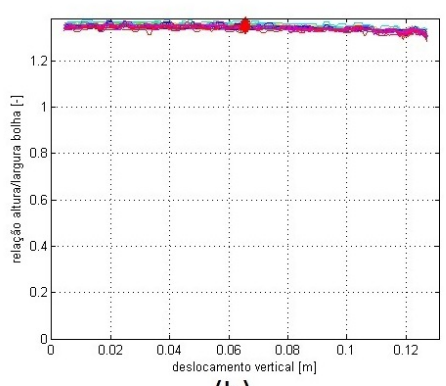

(b)

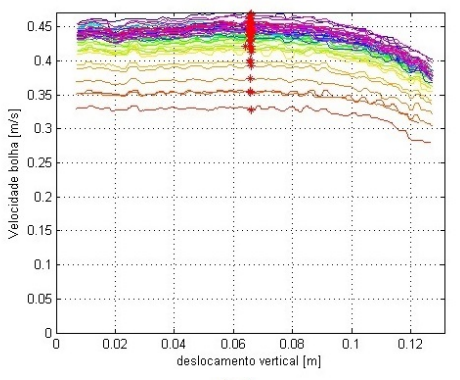

(c)

Figura 3.11: Curvas de resultados da dinâmica de múltiplas bolhas de ar em regime transiente migrando na bancada experimental. (a) Diâmetro efetivo da bolha em função do deslocamento vertical; (b) Volume da bolha em função do deslocamento vertical; (c) Razão de aspecto da bolha em função do deslocamento vertical; e (d) Velocidade da bolha em função do deslocamento vertical.

\section{2}

\section{Preparo dos fluidos Não-Newtonianos}

A origem dos fluidos Não-Newtonianos esta maiormente relacionada aos chamados fluidos estruturados, nestes materiais existe uma ligação direta entre o comportamento do fluido, a tensão aplicada $\tau$ e o estado da estrutura do material. Os fluidos Newtonianos possuem uma microestrutura que em aplicações industriais pode ser desprezada e permite assumir a hipótese de propriedades isotrópicas. Por outro lado, suspensões poliméricas, materiais coloidais, espumas, materiais micelares e materiais fundidos possuem estruturas microscópicas que podem ser perturbadas em função da tensão de cisalhamento $\tau$ aplicada. A Fig. 3.12 mostra esquematicamente vários tipos de microestruturas encontradas em materiais complexos em repouso e os efeitos na microestrutura após ser perturbados. Estes materiais se caracterizam por distribuições de partículas irregulares em formato e tamanho como ocorre em emulsões e espumas. Moléculas ramificadas e/ou entrelaçadas como em materiais poliméricos. Clusters ou grumos como no caso de suspensões. Em níveis baixos de cisalhamento o esforço necessário para deformar o material pode estar relacionado à tensão limite $\tau_{0}$, conforme a taxa de cisalhamento aumento a estrutura se orienta 
ou deforma para se alinhar com a direção do fluxo. Este comportamento da microestrutura define a reologia complexa dos materiais usados nesta pesquisa.

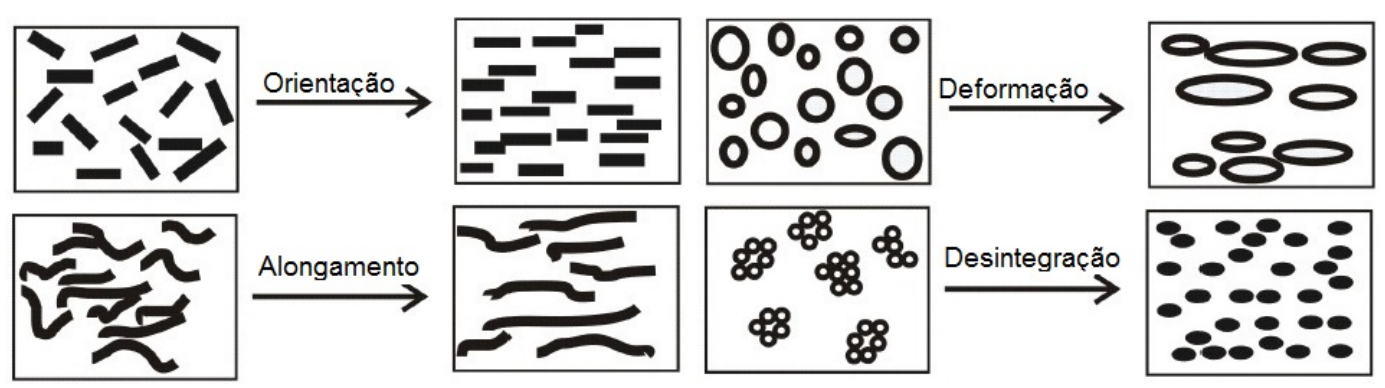

Figura 3.12: Microestrutura encontrada em diversas suspensões complexas em repouso e as alterações sofridas apos ser perturbadas (48).

Para a preparação das suspensões foram utilizadas duas marcas de misturadores, o modelo FISATOM 722 da Fig. 3.13.a e o modelo IKA Eurostar da Fig. 3.13.b onde o principal requerimento era atingir uma rotação mínima de 1600RPM. Adicional ao misturador foi usada uma base planetária, um tanque de $15 \mathrm{~L}$ de capacidade e um raspador nas paredes do tanque. Quando se preparam grandes volumes de um material viscoplástico é difícil manter a concentração de polímero homogênea no tanque. As concentrações da suspensão podem variar nas paredes laterais ou no fundo, e consequentemente o fluido irá ficar heterogêneo. As hélices são fundamentais no processo de preparação, cada uma tem funções bem definidas, e em suspensões aquosas a importância é maior. Se utiliza uma hélice borboleta como da Fig. 3.13.c para conseguir uma alta recirculação do fluido e dissolver completamente os grumos formados pelo polímero. Estas suspensões são especialmente heterogêneas porque o polímero forma grumos que não entram em solução com a base aquosa, especialmente no caso do Carbopol. Infelizmente, ainda com todo o cuidado na preparação, a suspensão sempre forma grumos em maior ou menor quantidade. A hélice centrifuga dentada da Fig. 3.13.d é especial para a dissolução desses grumos mais complicados e também é muito boa para desfazer bolhas de ar que se formam no interior da suspensão. Alguns autores usam hélices tipo âncora como da Fig. 3.13.e na preparação, mas se observou que com uma montagem misturadorbase planetária-raspador se consegue uma boa recirculação do fluido e se faz desnecessário o uso desta hélice âncora, porque os grumos são dissolvidos de forma adequada e rapidamente. A hélice âncora atrasa o processo de dissolução dos grumos (que neste caso pode levar até 5 dias), e existe a suspeita de que geram torques muito elevados no misturador, causando fadiga prematura no equipamento. 


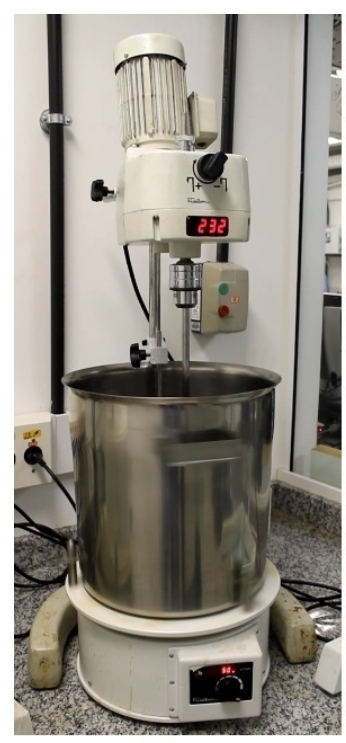

(a)

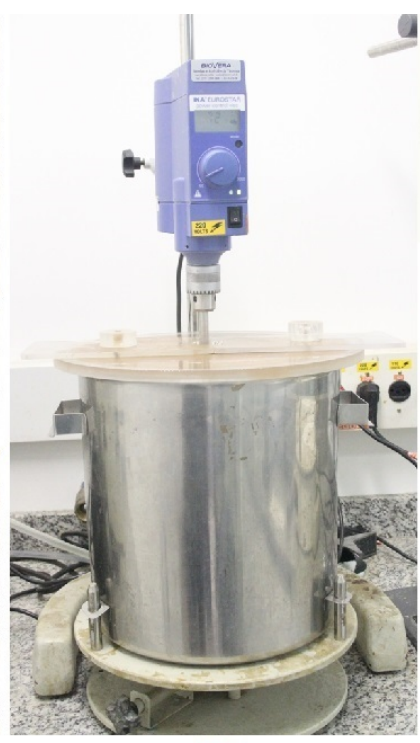

(b)
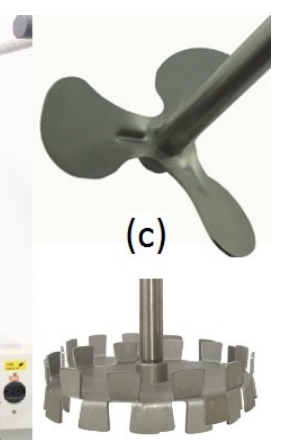

(d)

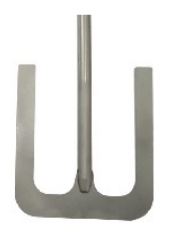

(e)

Figura 3.13: Misturadores e hélices usadas na preparação das suspensões; (a) Misturador Fisatom 722 com base planetária e raspador nas paredes do tanque: (b) Misturador IKA Eurostar; (c) Hélice tipo borboleta; (d) Hélice tipo centrifuga dentada; e (e) Hélice Tipo âncora.

Alguns equipamentos usados ocasionalmente foram o tensiômetro Lauda TE1CA da Fig. 3.14.a e o forno Etica 400/7D da Fig. 3.14.b. O forno foi usado para eliminar a umidade do polímero antes de ser adicionado na base aquosa, o que reduz a formação de grumos e facilita a dispersão no tanque. Uma bomba de seringa New Era NE-1000 como da Fig. 3.1.c também foi usada.

\subsection{1}

\section{Metodologia de Preparação de Suspensões}

Nesta pesquisa foi necessária a utilização de dois tipos de suspensões com características reológicas e processos de preparação diferentes. O Carbopol é uma suspensão viscoplástica que possui a tendência a formar grumos, e a Laponita uma suspensão viscoplástica e tixotrópica que deve ser preparada a uma alta velocidade de rotação. No processo foram usados os misturadores já informados na Fig. 3.13 num arranjo de misturador-base planetária-raspador como mostra a Fig. 3.15. Existem na literatura diferentes processos de preparação para as suspensões, que foram modificados para as necessidades da pesquisa e para o uso dos equipamentos disponíveis no laboratório. 


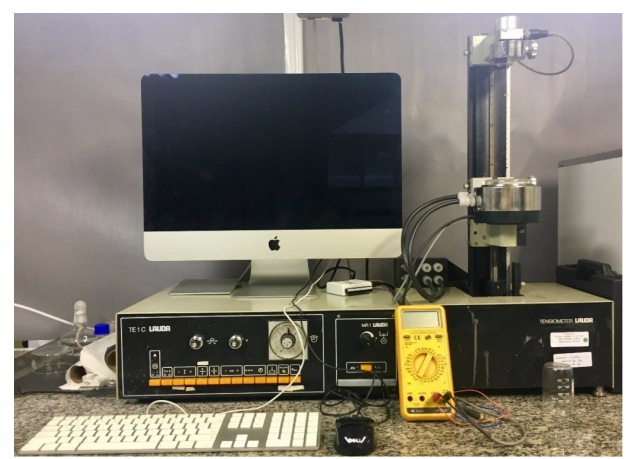

(a)

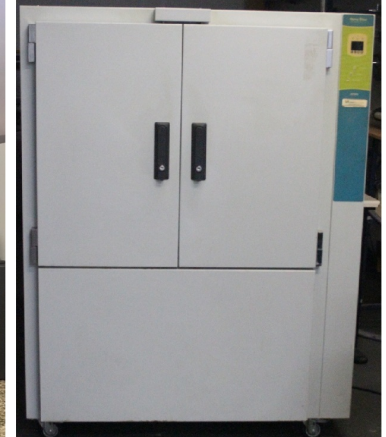

(b)

Figura 3.14: Equipamentos adicionais: (a) Tensiômetro Lauda TE1CA; e (b) Forno Nova Etica 400/7D.

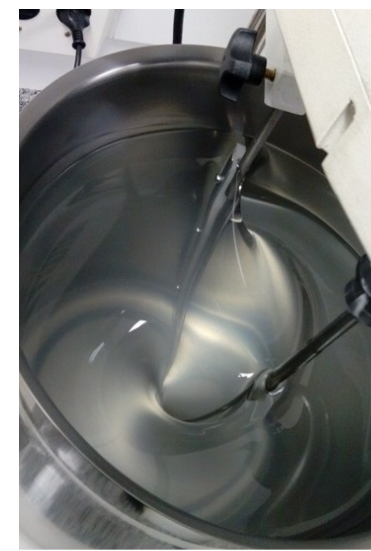

(a)

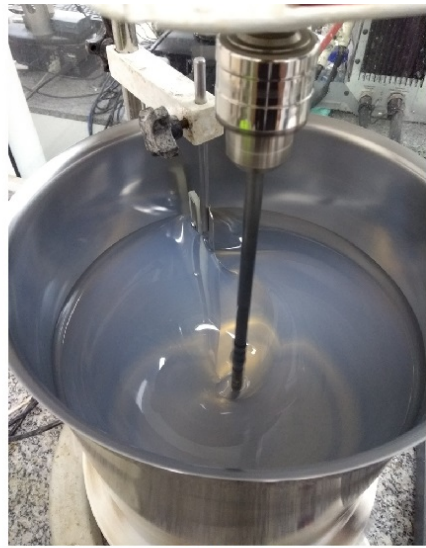

(b)

Figura 3.15: Configuração Misturador-Base planetária-Raspador usada na preparação das suspensões: (a) Carbopol 980; e (b) Laponita.

\subsubsection{1}

\section{Preparação do Carbopol}

A suspensão polimérica de Carbopol é composta por uma base aquosa e cristais de polímero que não entram em solução, formando um material heterogêneo como mostra a Fig. 3.16 e com comportamento mecânico viscoplástico. Devido a isto, o fluido tende a formar grumos e regiões com propriedades reológicas heterogêneas. Por isso se faz necessário um processo de homogeneização prévio aos testes na bancada experimental.

Devido à tendência da suspensão a formar grumos, no procedimento original de preparação era necessário misturar o fluido no tanque com $4 \mathrm{~L}$ de suspensão por cinco dias de forma ininterrupta com uma hélice tipo âncora, até dissolver totalmente os grumos de Carbopol. Para a obtenção dos resultados, são necessários quase $25 \mathrm{~L}$ de suspensão para encher o tanque da bancada e por esta razão seria inviável usar o método original, pois teríamos que usar 

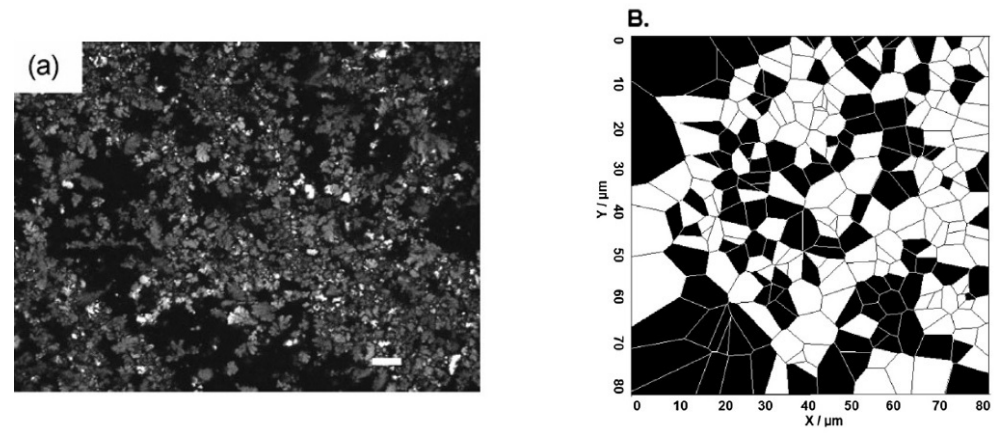

Figura 3.16: Estrutura cristalina e heterogênea da suspensão de Carbopol: (a) Microscopia confocal (43); e (b) Diagramas de Voronoi de microscopia com partículas traçadoras MPT (Multiple-particle tracking), áreas viscosas em branco e áreas elásticas em negro (44).

todos os misturadores do laboratório de forma simultânea ou esperar semanas até preparar o volume necessário. Adicionalmente, existem suspeitas de fadiga prematura nos misturadores causada pelo tempo necessário em preparar este material no laboratório.

Foi desenvolvido outro método baseado em aumentar a recirculação do fluido no tanque, para acelerar a dissolução dos grumos e preparar num curto tempo volumes maiores, evitando possível fadiga o misturador. Além do misturador, foi adicionada uma base planetária e um raspador nas paredes como mostra a Fig. 3.13. Além disso, foi eliminada a hélice tipo âncora, que mistura um volume grande de suspensão, mas não cria a recirculação necessária no tanque. Foram usadas hélices tipo borboleta para criar recirculação, e finalmente uma hélice centrifuga dentada para eliminar os grumos mais difíceis de dissolver no fluido. O polímero é adicionado muito lentamente, chegando a demorar mais de meia hora para concluir este processo, para evitar ao máximo a formação dos grumos. O tempo de preparação é de três (3) hrs e a qualidade do fluido é adequada para os testes experimentais.

No apêndice A.1 é apresentado o processo detalhado de preparação, neste capitulo se comentam apenas as principais características do processo.

\subsubsection{2}

\section{Preparação da Laponita}

A Laponita é uma suspensão de argila que tem características viscoplásticas e tixotrópicas. Ela não forma grumos como o Carbopol, mas precisa ser preparada usando-se procedimentos de mistura com alta taxa de cisalhamento. A vantagem é que não é necessário o uso de uma hélice centrifuga dentada para desfazer grumos, e o polímero pode ser adicionado rapidamente no tanque do 
misturador. A dificuldade com esta suspensão é o comportamento tixotrópico, que faz com que o fluido gelifique rapidamente, como mostra a Fig. 3.17.a. Além disso o material captura as bolhas de ar no interior do fluido, e por isto é muito importante evitar a entrada de ar na suspensão durante a preparação, porque pode causar perda total do fluido devido às incontáveis bolhas que se formam.

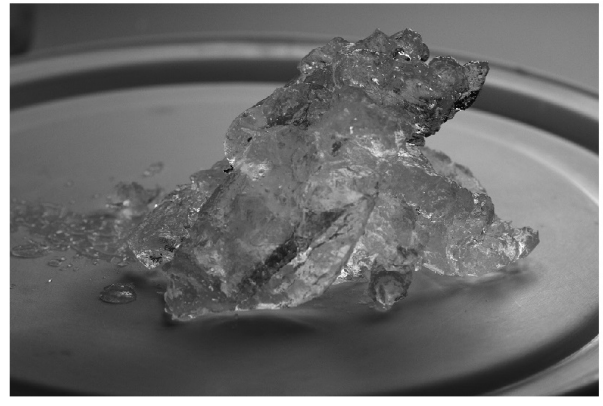

(a)

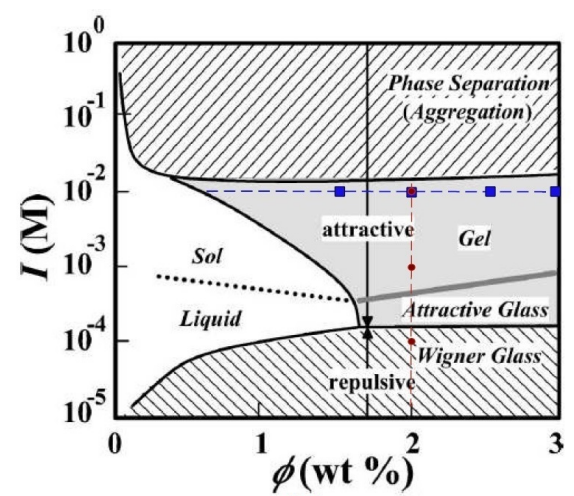

(b)

Figura 3.17: Estrutura tixotrópica da Laponita: (a) Amostra de Laponita gelificada; e (b) Diagrama de estado de Laponita $(\mathrm{PH}=10)$ em função da concentração de polímero (eixo horizontal) e a concentração de $\mathrm{NaCl}$ que determina os esforços iônicos do fluido $I(M)$ (eixo vertical) (76).

A Laponita é um fluido complexo com diferentes propriedades em função da concentração de partículas, concentração de $\mathrm{NaCl}$ e $\mathrm{NaOH}$ (PH). A Fig. 3.17.b mostra as fases da Laponita em função da concentração (eixo horizontal), e a concentração de $\mathrm{NaCl}$ (eixo vertical) que afeta as forças iônicas $I(M)$ de uma suspensão com $\mathrm{pH}=10$. A imagem mostra um pouco a complexidade desta suspensão e o potencial para ser usando em diversas aplicações industriais.

Nesta pesquisa o fluido ira se manter no estado de gel com pH=10 ( Fig. 3.17.b), onde as propriedades viscoplásticas e tixotrópicas são adequadas para os experimentos. Dependendo das concentrações dos reagentes e de partículas, a suspensão pode se cristalizar impedindo a injeção de gás, ou se comportar como uma solução com clusters com tempo de vida finita, que diferem de uma solução homogênea e não possuem as propriedades reológicas desejadas (76).

Esta suspensão pode ser preparada em uma hora, com velocidades de rotação de 1600 RPM e não tem problemas com formação de grumos. Durante todo o processo de preparação e adição no tanque da bancada experimental é necessário cuidado com a entrada de ar no fluido porque ele começa a gelificar assim que pára de ser misturado conforme mostra a Fig. 3.18. O processo de preparação é descrito em detalhe no Apêndice A.2. 


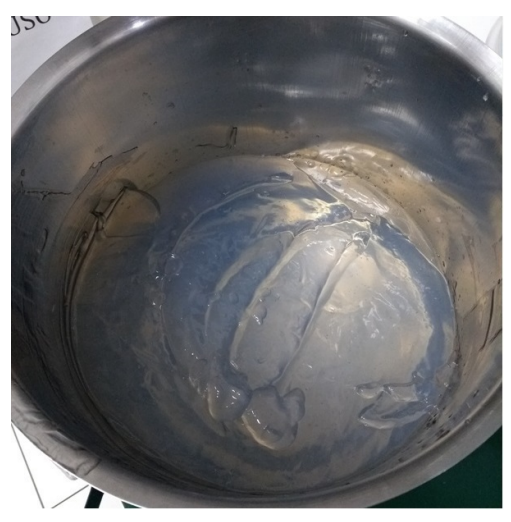

Figura 3.18: Gelificação da Laponita presente, imediatamente após o fim da preparação.

\subsection{2}

\section{Caracterização Reológica}

Nesta pesquisa foram utilizadas suspensões de Carbopol e Laponita, que têm comportamento não Newtoniano. Para a avaliação das propriedades reológicas dos fluidos utilizados e para a determinação do seu comportamento mecânico foi realizada a caracterização reológicas dos fluidos. Testes em regime permanente foram realizados para a obtenção da curva de escoamento (Flow curve). Além disso, foram realizados testes oscilatórios de varredura de deformação (strain sweep) e de frequência (frequency sweep) a fim de quantificar as propriedades viscoplasticas, elásticas e tixotrópicas dos materiais. Também foram feitos testes com taxa de cisalhamento constante para observar o estado transiente da reologia em fluidos tixotrópicos. Foram medidos parâmetros como viscosidade $\mu$, tensão de cisalhamento $\tau$, módulo de perda G" e modulo de armazenamento G'. A temperatura dos testes foi de $23,4^{\circ} \mathrm{C}$ que representa a temperatura média dos experimentos na bancada.

Para fazer a caracterização reológica dos fluidos usados nesta pesquisa foram usados três reômetros rotacionais da marca TA instruments: modelo ARG2, Discovery HR-3 e Ares G2 , mostrados na Fig. 3.19. Os modelos ARG2 e DHR-3 foram usados para controle de tensão de cisalhamento ou para taxas de cisalhamento maiores a $1 * 10^{-2} s^{-1}$, enquanto o modelo Ares G2 foi usado quando foram necessárias taxas de cisalhamento inferiores a $1 * 10^{-2} s^{-1}$ e um bom controle da velocidade. Como dito anteriormente, nos reômetros foram usadas geometrias de placas paralelas ranhuradas e Couette com taxas de cisalhamento a partir de $1 * 10^{-2} s^{-1}$ até $3600 s^{-1}$.

Foi usada a geometria de placas paralelas ranhuradas da Fig. 3.20 para taxa de cisalhamento menor do que $100 \mathrm{~s}^{-1}$, isto porque em taxas maiores o fluido pode vazar da geometria devido à forca centrifuga causada pela alta 


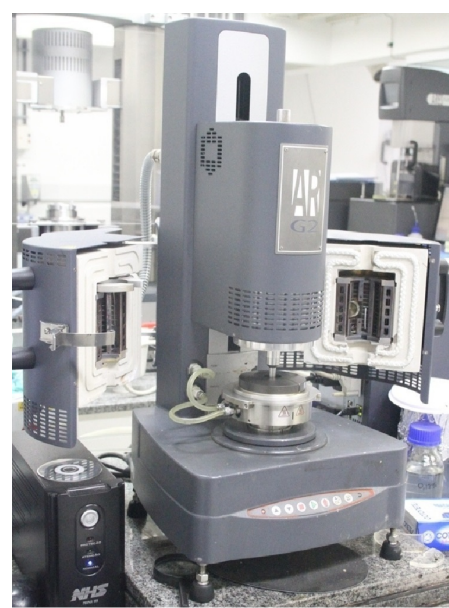

(a)

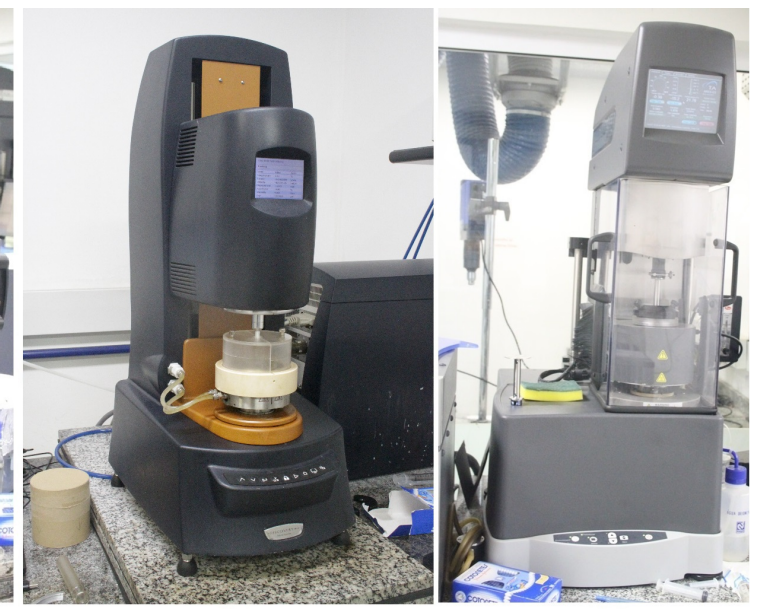

(b)

(c)

Figura 3.19: Reômetros rotacionais da marca TA Instruments usados neste trabalho. (a) ARG2; (b) Discovery HR-3; e (c) Ares G2.

velocidade de rotação. As placas são ranhuradas para evitar o deslizamento da amostra, pois os fluidos base água deslizam facilmente em superfícies lisas. A folga entre as placas usada nos testes foi de $1 \mathrm{~mm}$. Para evitar a evaporação da amostra foi usada uma proteção metálica sobre as placas ranhuradas para evitar contato da amostra com o ar externo, e foi adicionado um pequeno deposito de água para saturar o ar no interior da proteção metálica, dessa forma foi possível realizar testes de várias horas sem apresentar evaporação.

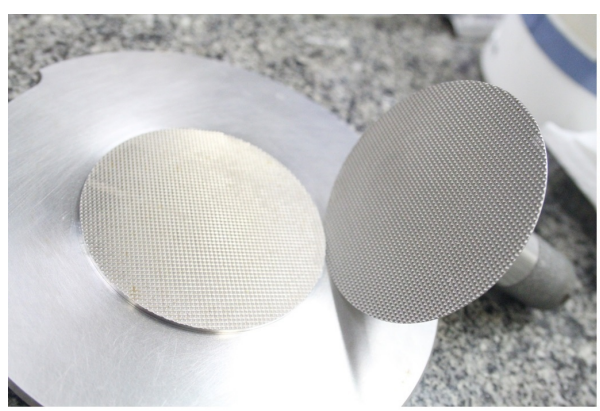

(a)

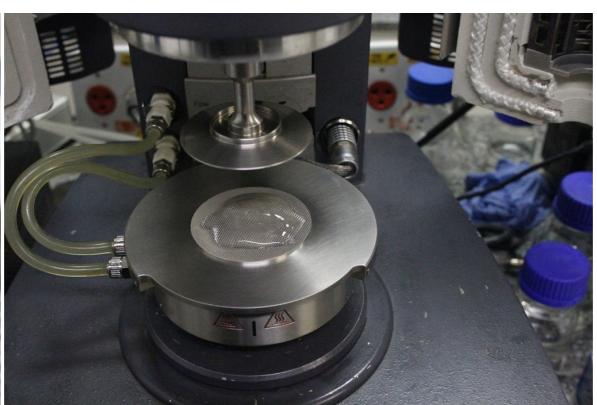

(b)

Figura 3.20: Geometria de placas paralelas ranhuradas (crosshatch) usadas nos reômetros para taxas de cisalhamento de até $100 \mathrm{~s}^{-1}$.

A geometria Couette ranhurada da Fig. 3.21 foi usada para testes com altas taxas de cisalhamento como no caso da flowcurve da Laponita (Fig. 3.29), que foi realizada para taxas de cisalhamento até $3600 \mathrm{~s}^{-1}$. Esta geometria evita o vazamento de fluido por conta das altas velocidades de rotação, e a superfície ranhurada evita o deslizamento nas paredes. Esta geometria precisa de maior volume de liquido para o teste, e por esta razão se faz desnecessário algum 
deposito de água para saturar o ambiente da amostra.

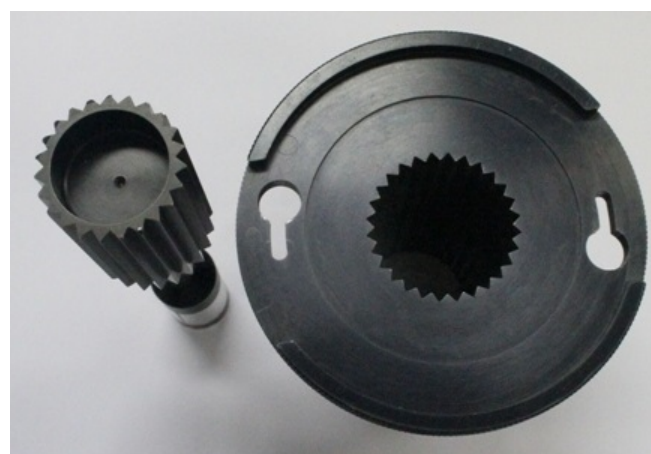

(a)

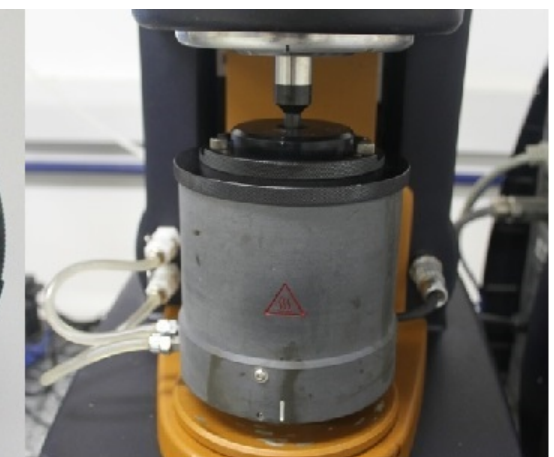

(b)

Figura 3.21: Geometria Couette ranhurada usada nos reômetros para testes com maiores taxas de cisalhamento.

A temperatura usada na caracterização foi de $23,4{ }^{\circ} \mathrm{C}$. É importante ressaltar que a temperatura do fluido no tanque da bancada experimental foi controlado com o sistema de ar condicionado da sala, e não com algum banho térmico de recirculação do fluido. O fluido deve estar em repouso durante a injeção do gás, especialmente na Laponita onde o material precisa atingir o nível desejado de gelificação após um tempo de repouso. Um banho térmico para controlar a temperatura teria afetado os resultados dos testes experimentais e a reologia dos fluidos. A temperatura do fluido oscilou entre os $21^{\circ} \mathrm{C}$ e $25^{\circ} \mathrm{C}$ porque a temperatura da sala mudou em função da hora do dia e a estação do ano, embora a sala tenha sistema de ar condicionado é impossível evitar oscilações na temperatura. Para determinar uma temperatura adequada para caracterização e modelagem matemática foi calculada a media aritmética da temperatura do material no tanque durante os testes experimentais conforme a equacao $3-5$, o valor médio calculado é de $23.4{ }^{\circ} \mathrm{C}$.

$$
T=\frac{\sum T_{i}}{i_{\max }}
$$

A reologia não muda significativamente nesta faixa de temperatura (21$25^{\circ} \mathrm{C}$ ) conforme Bhatia (88) confirma. Isto pode ser conferido nos resultados experimentais da Seção 4 onde se observa uma clara tendência nas curvas de resultados sem oscilações nem resultados atípicos.

\subsection{3}

\section{Reologia do Carbopol}

A suspensão de Carbopol foi caracterizada em reômetro rotacional com geometria de placas paralelas ranhuradas, temperatura meia de $23.4^{\circ} \mathrm{C}$ e um tempo de amostragem para cada medição de 10s. A primeira suspensão utili- 
zada foi de Carbopol-980 em cinco (5) concentrações diferentes de polímero: $0.09 \%$ ww, $0.10 \%$ ww, $0.12 \%$ ww, $0.15 \%$ ww e $0.20 \%$ ww. As curvas de escoamento obtidas são apresentadas na Fig. 3.22. Como esperado, neste tipo de material observa-se uma tensão limite de escoamento, e um comportamento pseudoplástico a tensões mais elevadas, que se ajusta ao modelo reológico Herschel-Bulkley da Eq. 3-6.

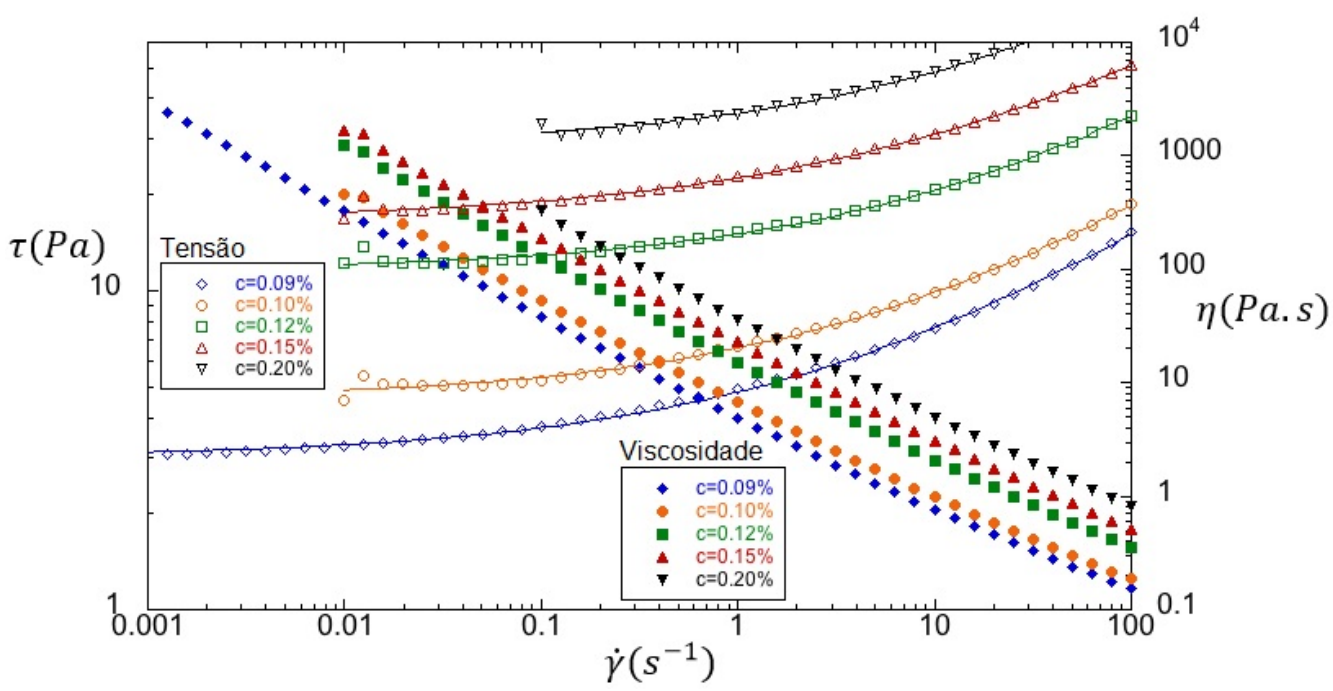

Figura 3.22: Teste Flow curve em Carbopol 980 de concentração 0.09\% ww, $0.10 \%$ ww, $0.12 \%$ ww, $0.15 \%$ ww e $0.20 \%$ ww.

Observa-se também um comportamento crescente na tensão de cisalhamento $\tau$ e da tensão limite $\tau_{0}$ com o aumento da concentração de polímero (\% ww) e da taxa de cisalhamento $\dot{\gamma}$. A viscosidade $\mu$ (Eq. 3-7) como esperado decresce com o aumento da taxa de cisalhamento $\dot{\gamma}$.

$$
\left\{\begin{array}{cl}
\eta=\frac{\tau_{y}}{\dot{\gamma}}+K \dot{\gamma}^{n-1} & \text { if } \tau \geq \tau_{0} \\
\dot{\gamma}=0 & \text { caso contrario } \\
\tau=\eta \dot{\gamma}
\end{array}\right.
$$

Os valores dos parâmetros do modelo Herschel-Bulkley como tensão limite $\tau_{0}$, índice de consistência $\mathrm{K}$ e índice Power-Law $\mathrm{n}$ da Eq. 3-6 são mostrados na Tabela 3.1. Para determinar os parâmetros elásticos do material foram usados dois tipos de testes oscilatórios, o primeiro teste é um strain sweep onde se determina a região viscoelástica linear do material. Esta região se caracteriza por valores constantes de G' e G" devido a recuperação elástica do material em função da deformação do material (\%strain). Valores maiores de deformação indicam escoamento e quebra da microestrutura do material, com a perda de recuperação elástica da suspensão. Na Fig. 3.23 determinou-se 
a máxima deformação em $0.01 \%$ a uma frequência de $6.28 \mathrm{rad} / \mathrm{s}$ para as cinco

(5) concentrações de Carbopol.

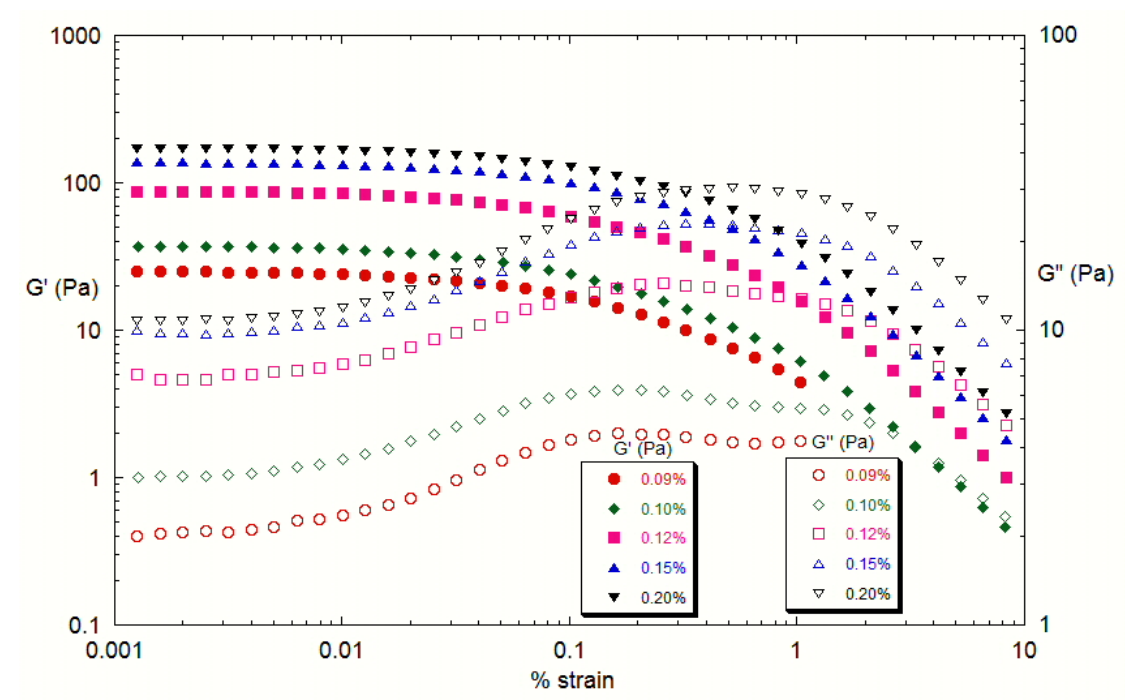

Figura 3.23: Teste strain sweep em Carbopol 980 de concentração 0.09\% ww, $0.10 \%$ ww, $0.12 \%$ ww, $0.15 \%$ ww e $0.20 \%$ ww. Frequência angular $6.28 \mathrm{rad} / \mathrm{s}$.

Com base nos resultados da Fig. 3.23 foi feito um teste frequency sweep que é mostrado na Fig. 3.24. O teste foi feito a uma deformação de $0.01 \%$ para determinar o valor dos módulos de armazenamento G' e perda G" numa ampla faixa de frequência angular (0.1-628 rad/s). Os resultados indicam um aumento dos módulos (G' e G") junto com a concentração do Carbopol, e também se observa que em todos os casos o modulo de armazenamento G' é maior que o modulo de perda G" indicando que o material é viscoplástico em regime viscoelástico.

Na Tabela 3.1 são apresentados os valores de G' e G" para uma frequência angular $\omega$ de $1 s^{-1}$ e deformação de $0.01 \%$ nas cinco (5) concentrações de polímero.

A Tabela 3.1 compila todos os parâmetros reológicos obtidos na caracterização da suspensão de Carbopol-980 em cinco (5) concentrações diferentes de polímero (0.09\% ww, $0.10 \%$ ww, $0.12 \%$ ww, $0.15 \%$ ww e $0.20 \%$ ww) a uma temperatura meia de $23.4^{\circ} \mathrm{C}$.

O Carbopol também apresenta um leve comportamento tixotrópico que em alguns casos específicos pode ser importante considerar. Quando a suspensão é cisalhada ou fluidizada, a estrutura viscoplástica se destrói em função do tempo de cisalhamento. No caso do Carbopol isto acontece de forma bem rápida, alguns segundos de cisalhamento e o material se fluidiza. Quando o cisalhamento acaba, o material apresenta um fenômeno de gelificação ou estruturação também muito rápido, levando aproximadamente $1 \mathrm{~s}$ ou $2 \mathrm{~s}$ 


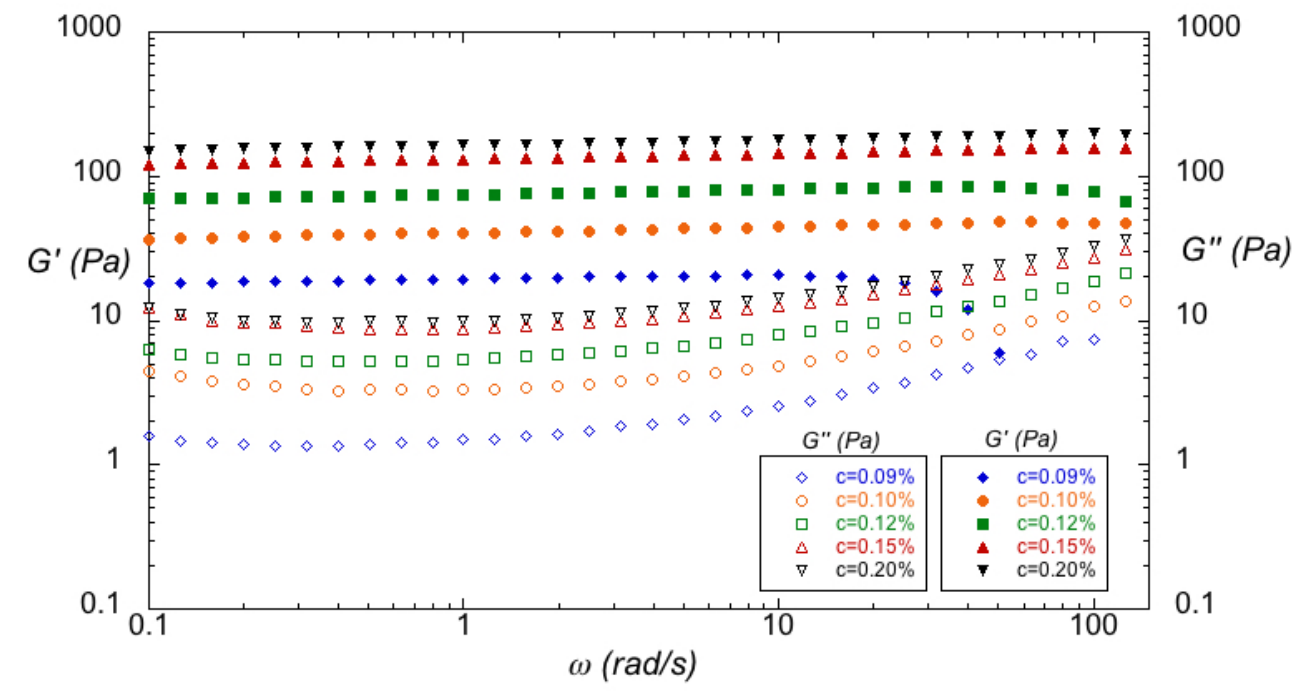

Figura 3.24: Teste frequency sweep em Carbopol 980 de concentração 0.09\% ww, $0.10 \%$ ww, $0.12 \%$ ww, $0.15 \%$ ww e $0.20 \%$ ww. $0.01 \%$ strain

Tabela 3.1: Reologia de suspensões de Carbopol 980. $\mathrm{T}=23.4^{\circ} \mathrm{C}$

\begin{tabular}{|c|c|c|c|c|c|}
\hline Concentracao & $0.09 \%$ & $0.10 \%$ & $0.12 \%$ & $0.15 \%$ & $0.20 \%$ \\
\hline$\tau_{0}[\mathrm{~Pa}]$ & 3.015 & 4.59 & 11.6 & 16.57 & 28.5 \\
\hline $\mathrm{K}[\mathrm{Pa}]$ & 1.816 & 2.022 & 3.505 & 6.044 & 7.552 \\
\hline $\mathrm{n}[-]$ & 0.4109 & 0.4197 & 0.4158 & 0.3775 & 0.4251 \\
\hline G' $[\mathrm{Pa}]\left(\omega=1 s^{-1}\right)$ & 20.55 & 40.42 & 74.61 & 131.3 & 163.4 \\
\hline G' $[\mathrm{Pa}]\left(\omega=1 s^{-1}\right)$ & 2.568 & 3.289 & 5.356 & 8.733 & 9.817 \\
\hline
\end{tabular}

para recuperar sua estrutura viscoplástica até um patamar relativamente estável, onde o fluido continua gelificando, mas muito lentamente. A reologia muda significativamente se for conferida após várias semanas em repouso. Uma semana após, a tensão limite $\tau_{0}$ aumenta de forma importante, e assim continuamente. Para a escala de tempo de nossos experimentos ou da aplicação industrial não é importante considerar esta lenta mudança na reologia, por isso durante a caracterização do Carbopol foram usados 10s de tempo de amostragem para atingir um patamar estável na reologia da suspensão.

\subsection{4}

\section{Reologia da Laponita}

A Laponita é um fluido que muda de propriedades em função do histórico de cisalhamento. A Fig. 3.25 mostra o esquema do comportamento de materiais dependentes do tempo (Time dependent behaviour fluids) que não podem ser caracterizados unicamente pela tensão de cisalhamento $\tau$ ou taxa de cisalhamento $\dot{\gamma}$. Estes materiais também são dependentes do histórico de cisalhamento ou seu histórico cinemático. Por exemplo a técnica usada para 
colocar a amostra no reômetro ou na bancada afeta a reologia, o tempo de repouso ou algum processo de pre-acondicionamento irá afetar as propriedades reológicas. Isto acontece porque os materiais sofrem um processo gradual de quebra de microestrutura interna e também um processo de reconstrução das ligações até atingir um nível de equilíbrio dinâmico onde a taxa de quebra da estrutura é igual à taxa de reconstrução. Em função de como ocorre este fenômeno interno, o material se define Tixotrópico ou Reopetico (tixotropia negativa).

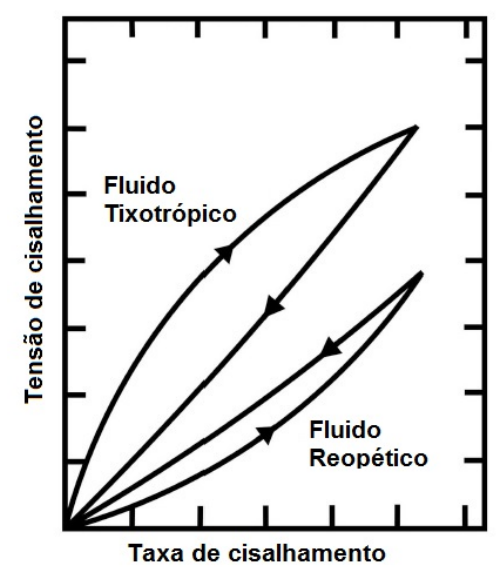

Figura 3.25: Histerese apresentada na Flowcurve de fluidos tixotrópicos e reopéticos (48).

Neste trabalho caracterizamos a Laponita com duas concentrações de partículas diferentes, $2 \%$ ww e $3 \% \mathrm{ww}$, a temperatura meia de $23.4^{\circ} \mathrm{C}$, usando um reômetro rotacional com uma geometria Couette. A caracterização da Laponita é bem mais complicada e demorada por conta das propriedades altamente tixotrópicas desta suspensão, que traz consigo vários desafios.

O primeiro é atingir um regime permanente em cada medição de tensão de cisalhamento e assim construir a curva de escoamento do material (Fig. 3.29). Esta suspensão pode levar mais de 2 hrs para atingir o regime permanente para as taxas de cisalhamento $\dot{\gamma}$ mais baixas $\left(0.01 s^{-1}\right)$. Por esta ração foi necessário fazer um teste Time sweep a taxa de cisalhamento constante $\dot{\gamma}$ para cada ponto da flowcurve da Fig. 3.29, observar a evolução da tensão de cisalhamento até atingir um patamar estável e usar esse valor na flowcurve. As Figs. 3.26 e 3.27 mostram os testes Time sweep para Laponita $2 \%$ ww e $3 \%$ ww respectivamente.

As primeiras observações indicam que com o aumento da concentração de polímero a tensão de cisalhamento $\tau$ também aumenta. Além disso, observa-se que a suspensão mais concentrada de $3 \%$ ww (Fig. 3.26) tem claramente uma tensão de cisalhamento maior que a suspensão $2 \%$ ww (Fig. 3.27). 


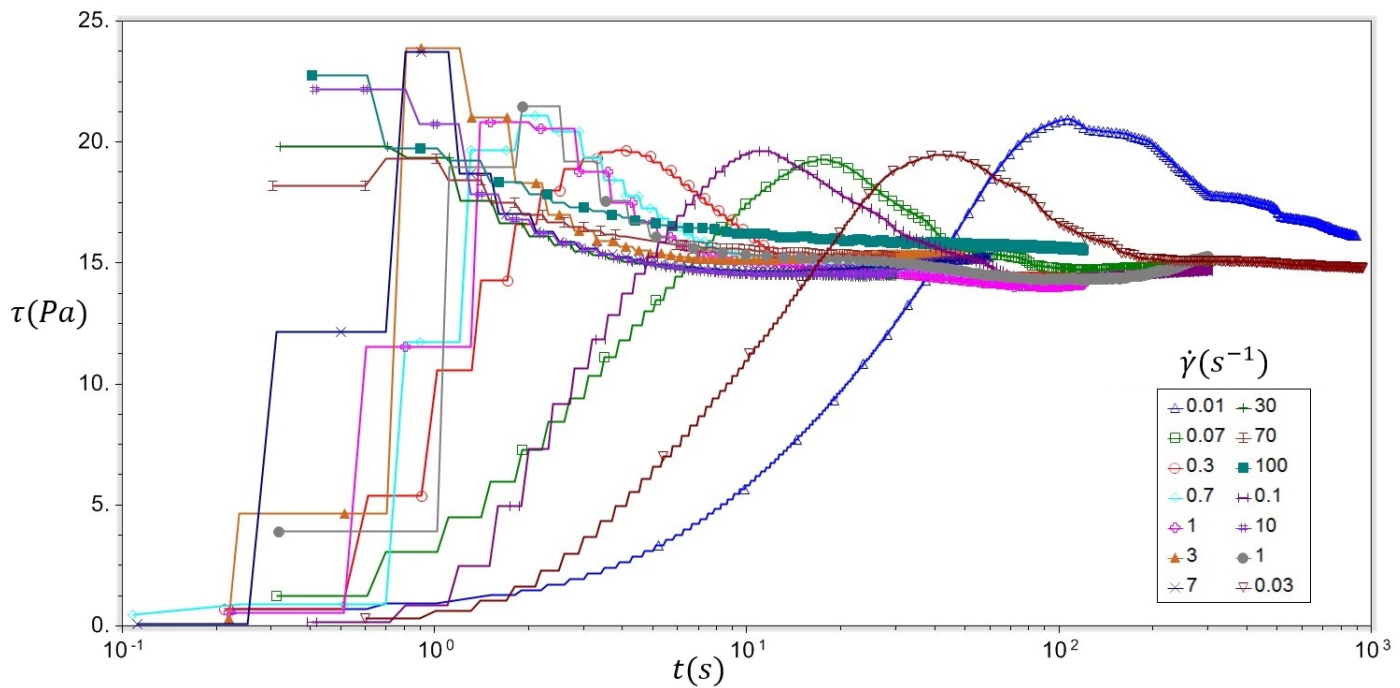

Figura 3.26: Teste Time Sweep para diferentes taxas de cisalhamento em Laponita $2 \%$ ww. Tempo de repouso da amostra 30s. Faixa de Taxa de cisalhamento 0.01-100 $s^{-1}$.

Uू

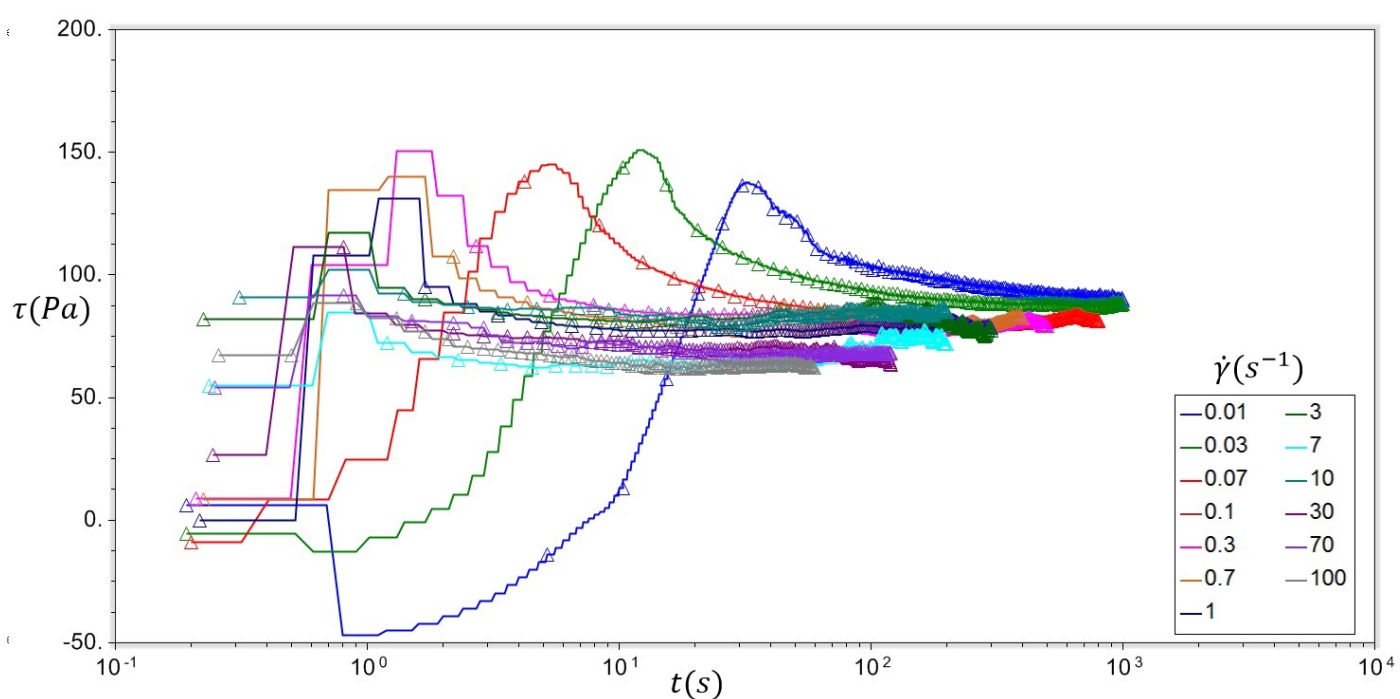

Figura 3.27: Teste Time Sweep para diferentes taxas de cisalhamento em Laponita $3 \% \mathrm{ww}$. Tempo de repouso da amostra 15min. Faixa de Taxa de cisalhamento $0.01-100(1 / \mathrm{s})$. 
Para caracterizar a Laponita foi usada uma geometria Couette no reômetro para levar o material até uma taxa de cisalhamento $\dot{\gamma}$ de $3600 \mathrm{~s}^{-1}$ e evitar vazamento de material por conta das forças centrifugas presentes a altas velocidade de rotação do reômetro. O objetivo foi estudar um fenômeno observado na Flowcurve da Laponita (Fig. 3.29). Após fazer os testes time sweep (Fig. 3.26 e Fig. 3.27) e compilar os resultados para construir a flowcurve da Fig. 3.29 observamos um valor de tensão $\tau$ quase constante nas taxas de cisalhamento $\dot{\gamma}$ aproximadamente menores a $100 \mathrm{~s}^{-1}\left(\dot{\gamma} \leq \dot{\gamma}_{0}\right)$. Aparentemente em taxas de cisalhamento relativamente baixas o material se encontra perto da tensão limite $\tau_{0}$ criando regiões próximas ao comportamento de solido viscoso. Estas regiões instáveis permitem a gelificação do material e com aporte da tixotropia do fluido pode se apresentar o fenômeno chamado shear banding (34). Consiste em regiões macroscópicas de fluido que possuem estrutura microscópica diferente por conta de um diferente nível de cisalhamento $\tau \dot{\gamma}$ e em consequência propriedades reológicas heterogêneas. A Fig. 3.28 mostra o esquema do fenômeno shear banding.

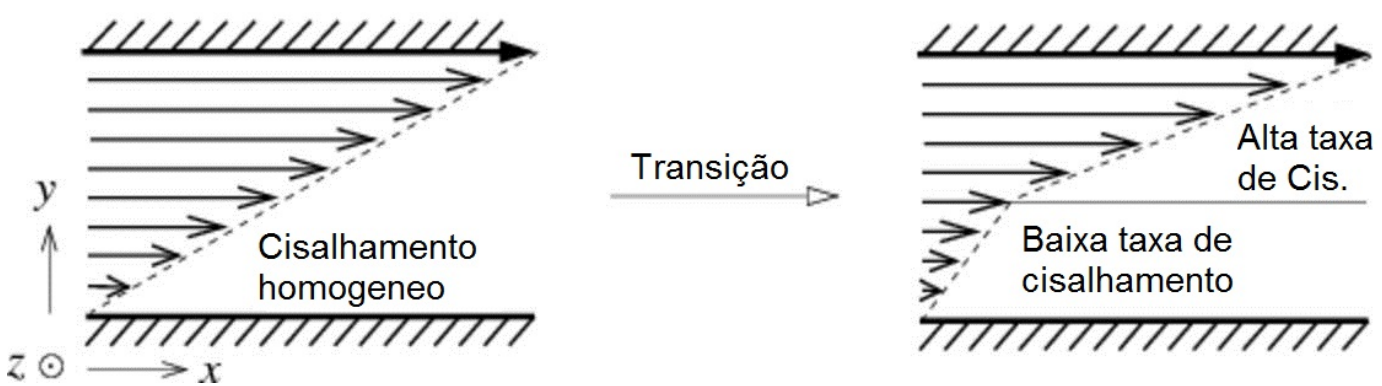

Figura 3.28: Perfil de cisalhamento em materiais com reologia homogênea e perfil em materiais que sofrem Shear banding com reologia heterogênea.

Acredita-se que em baixas taxas de cisalhamento o material se comporta como um sólido viscoso entre as placas do reômetro, e só o material na região de transição ou próxima da placa ranhurada é realmente cisalhado. Taxas de cisalhamento maiores do que $\dot{\gamma}_{0}$ poderiam evitar a existência de regiões próximas à tensão limite $\tau_{0}$, e em consequência a presença de shear banding que afete os resultados, como mostra a Fig. 3.29. A hipótese anterior poderia explicar a razão pela qual a tensão $\tau$ da Fig. 3.29 não muda ate determinada taxa de cisalhamento $\dot{\gamma_{0}}$, alguns outros autores (34) descrevem o mesmo fenômeno e apresentam hipóteses similares.

Formulamos um modelo reológico modificado na esperança de conseguir usar no analise da dinâmica de bolhas em Laponita (Sec. 5). O modelo da Eq. 3-8 é basicamente o modelo Herschel-Bulkley (Eq. 3-6) mas com um patamar constante de tensão $\tau$ para taxas de cisalhamento menores do que $\dot{\gamma}_{0}$. 


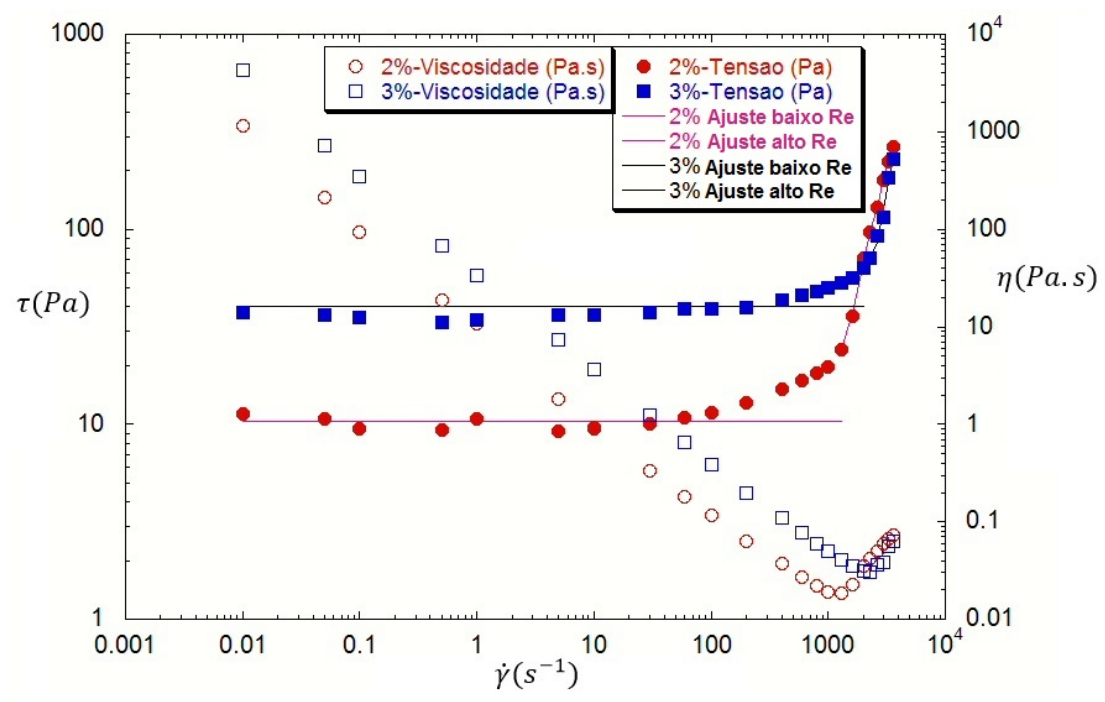

Figura 3.29: Teste Flowcurve da Laponita com concentrações de 2\% ww e $3 \%$ ww

$$
\begin{cases}\eta=\frac{\tau_{0}}{\dot{\gamma}}+K\left(\dot{\gamma}-\dot{\gamma}_{0}\right)^{n-1} & \text { if } \dot{\gamma} \geq \dot{\gamma}_{0} \\ \eta=\frac{\tau_{0}}{\dot{\gamma}} & \text { caso contrario }\end{cases}
$$

Onde $\dot{\gamma}_{0}$ é a taxa de cisalhamento maxima onde se considera constante a tensao de cisalhamento $\tau$ do modelo de ajuste (Eq. 3-8).

Seguindo o mesmo procedimento usado na seção anterior (Seção 3.2.3), para caracterizar as propriedades elásticas da Laponita foi feito um teste oscilatório tipo Strain sweep a uma frequência de $6.283 \mathrm{rad} / \mathrm{s}$, temperatura meia de $23.4^{\circ} \mathrm{C}$ em geometria Couette. A deformação máxima onde o material continua na região viscoelástica linear foi de $1 \%$ para concentrações de $2 \%$ ww e $3 \%$ ww, confirmando nossas observações, que indicam a Laponita como uma suspensão muito mais elástica que o Carbopol.

Para caracterizar a elasticidade para a Laponita foi feito um teste frequency sweep com uma deformação de 1\% (\%strain) numa faixa de frequência angular $\omega$ entre 0.1-1000 rad/s. Os resultados são similares ao Carbopol, com o aumento da concentração de Laponita o fluido se torna mais elástico, e os valores de modulo de armazenamento G' são maiores do que os de módulo de perda.

Os resultados da caracterização reológica da Laponita são apresentados na Tabela 5.1, onde os módulos de armazenamento G' e perda G" são tomados a uma frequência de $10 \mathrm{rad} / \mathrm{s}$, e se calcula a taxa de cisalhamento máxima $\dot{\gamma}_{0}$ onde a tensão da flowcurve é constante. 


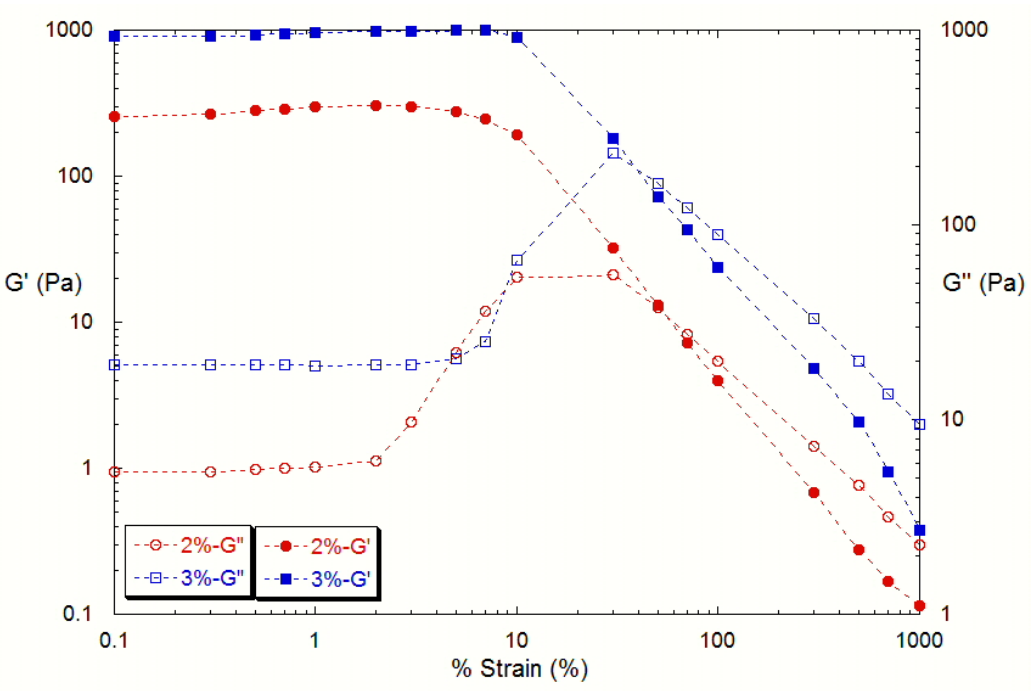

Figura 3.30: Teste Strain Sweep em Laponita 2\% ww e 3\% ww. Frequência $6.283(\mathrm{rad} / \mathrm{s})$

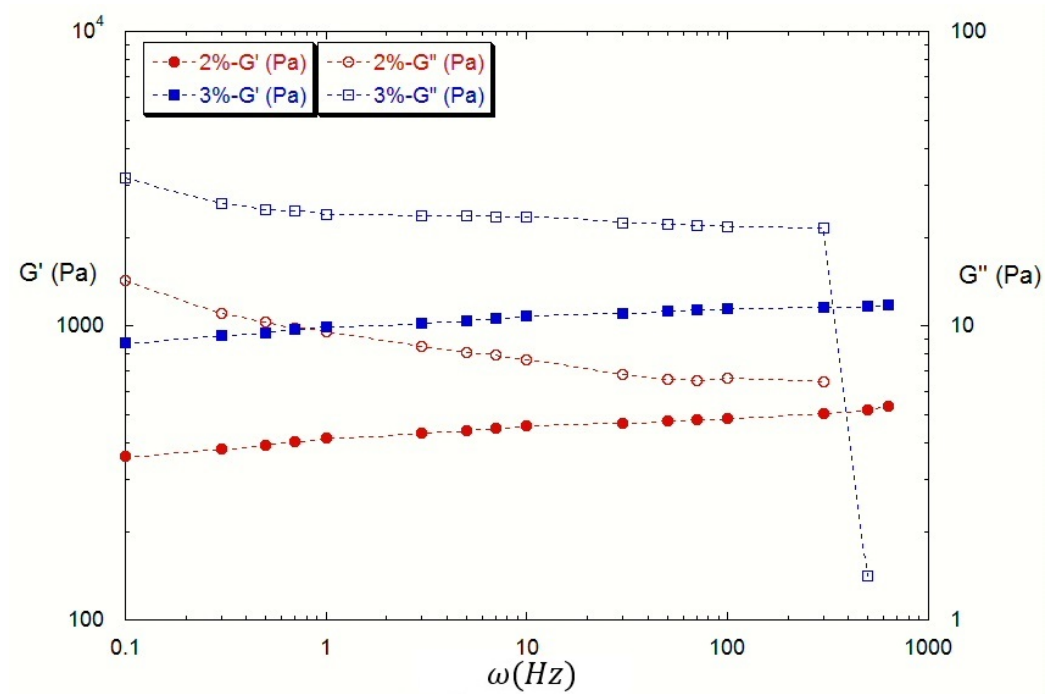

Figura 3.31: Teste Frequency Sweep em Laponita 2\% ww e 3\% ww. \% Strain $1 \%$ 
Tabela 3.2: Reologia de suspensões de Laponita com concentração $2 \%$ ww e $3 \%$ ww.

\begin{tabular}{|c|c|c|}
\hline Concentracao & $2 \%$ & $3 \%$ \\
\hline$\dot{\gamma}_{0}[1 / \mathrm{s}]$ & 1300 & 2300 \\
\hline$\tau_{0}[\mathrm{~Pa}]$ & 24.18 & 70,72 \\
\hline $\mathrm{K}[\mathrm{Pa}]$ & 0.0037 & 0.001 \\
\hline $\mathrm{n}[-]$ & 1.4303 & 1.6626 \\
\hline G' $[\mathrm{Pa}]\left(\omega=1 s^{-1}\right)$ & 458 & 1080 \\
\hline G" $[\mathrm{Pa}]\left(\omega=1 s^{-1}\right)$ & 7.68 & 23.43 \\
\hline
\end{tabular}

\subsection{5}

\section{Metodologia de Solução do Modelo Matemático}

Como parte deste trabalho foi desenvolvido um modelo matemático na Seção 5 para o cálculo da dinâmica de bolhas de gás escoando em fluidos Não-Newtonianos. O modelo pode ser aplicado nas condições experimentais desta pesquisa: bolhas de gás não esféricas escoando em fluidos viscoplásticos, elásticos e tixotrópicos em regime Stokes ou Regime Laminar. A equação proposta neste trabalho (Eq. 5-7) não é difícil de solucionar numericamente usando o Symbolic Math Toolbox de Matlab, o rotina utilizada foi anexa no Apêndice B.2 onde foram usados 32 dígitos de precisão com o pacote VPA (Variable-precision arithmetic) do software. 


\section{4 \\ Resultados Experimentais}

Neste capitulo serão apresentados os resultados da pesquisa de injeção de bolhas de gás em fluidos viscoplásticos, tixotrópicos e elásticos como as suspensões de Carbopol 980 e Laponita. Estuda-se a dinâmica de bolhas de ar em regime de Stokes e regime laminar com a medição experimental de vários parâmetros da bolha como velocidade $\mathrm{V}$, diâmetro efetivo $\mathrm{D}$ e razão de aspecto altura/largura, H/W. Continuamos com o estudo de escoamento de bolhas em suspensões altamente gelificadas e os efeitos na dinâmica e geometria da bolha. Finalmente foi estudada a formação de caminhos preferenciais e canais de escoamento de gás em alta vazão. Todo este trabalho tem como objetivo entender os fenômenos que afetam a invasão e migração de gás em pastas de cimento durante o processo de cimentação de poços de petróleo.

\section{1}

\section{Resultados Experimentais da Bancada}

Nesta seção serão apresentados os resultados experimentais de injeção de bolhas de gás em suspensões de Carbopol e Laponita na bancada experimental, mas primeiro são definidos alguns parâmetros adimensionais importantes para o estudo da dinâmica dos experimentos.

A taxa de cisalhamento característica $\dot{\gamma}_{c}$ é dada pela Eq. 4-1.

$$
\dot{\gamma}_{c}=\frac{V}{D}
$$

Onde $\mathrm{V}$ é a velocidade da partícula e $\mathrm{D}$ é o diâmetro efetivo da partícula.

O número de Reynolds Re da Eq. 4-2 expressa a relação entre forças inerciais e viscosas, e é dado por:

$$
R e=\frac{\rho V(D / 2)}{\eta_{c}}
$$

Onde $\rho$ é a densidade da fase continua e $\eta_{c}$ é a viscosidade característica, calculada pela Eq. 3-6 na taxa de cisalhamento característica $\dot{\gamma}_{c}$ (Eq. 4-1).

O número de Bingham Bi apresentado na Eq. 4-3 representa a relação entre a tensão limite de escoamento do fluido $\tau_{0}$ (yield stress) e força de empuxo. 


$$
B i=\frac{\tau_{0}}{\rho g(D / 2)}
$$

O número de Deborah da Eq. 4-4 indica a relação entre o tempo de relaxação do material $\lambda$ e o tempo característico de observação ou deformação do material $t_{c}$. $\lambda$ é definido na Eq. 4-5 e $t_{c}$ é definido na Eq. 4-6.

$$
\begin{aligned}
& D e=\frac{\lambda}{t_{c}} \\
& \lambda=\frac{G^{\prime \prime}}{w G^{\prime}}
\end{aligned}
$$

Onde G' é o modulo elástico ou de armazenamento e G" é o modulo viscoso ou de perda.

$$
t_{c}=\frac{D / 2}{V}
$$

O número de Bond Bo da Eq. 4-7 representa a relação entre forças de empuxo e forças capilares.

$$
B o=\frac{\rho g(D / 2)^{2}}{\sigma}
$$

Onde e $\sigma$ é a tensão superficial. O número de Arquimedes Ar da Eq. 4-8 é dado pela relação entre forças de empuxo e forças viscosas:

$$
A r=\frac{\rho g(D / 2)^{2}}{\eta_{c} V}
$$

O coeficiente de arrasto $C_{d}$ é obtido a partir de um balanço de forças na bolha, considerando que a mesma se encontra em sua velocidade terminal constante. Assim,

$$
F_{d}=F_{b}=g \forall \rho=g \pi D^{3} \frac{\rho}{6}
$$

Onde $F_{d}$ é a força de arrasto e $F_{b}$ é a força de empuxo. O coeficiente de arrasto é definido como

$$
C_{d}=\frac{F_{d}}{1 / 2 \rho V^{2} A_{f}}
$$

Das Eq. 4-9 e 4-10 obtém-se

$$
C_{d}=\frac{4}{3} \frac{g D}{V^{2}}
$$

\subsection{1}

\section{Pre-acondicionamento dos materiais e da bancada experimental}

Para começar a fazer os testes experimentais de injeção de bolhas é necessário tomar algumas ações previas para evitar a formação de canais preferenciais e também para evitar que o histórico de cisalhamento dos fluidos afete a dinâmica das bolhas injetadas. 
O experimento da Fig. 4.1 foi feito foi para provar que o histórico de cisalhamento causa a formação de caminhos preferenciais por onde escoam as bolhas de gás. Para este experimento foi homogeneizada inicialmente a suspensão de Carbopol usando o método da Seção 3.1.1, dessa forma temos um fluido com propriedades reológicas homogêneas e concentração de polímero uniforme. Após finalizar o processo de homogeneização se introduz uma barra de metal em direção diagonal partindo da parte superior do tanque até o bico do injetor. A barra metálica é introduzida seguindo um único caminho retilíneo até o bico injetor, e é retirada pelo mesmo caminho para não cisalhar o fluido ao redor, somente é cisalhado o fluido na trajetória da barra.

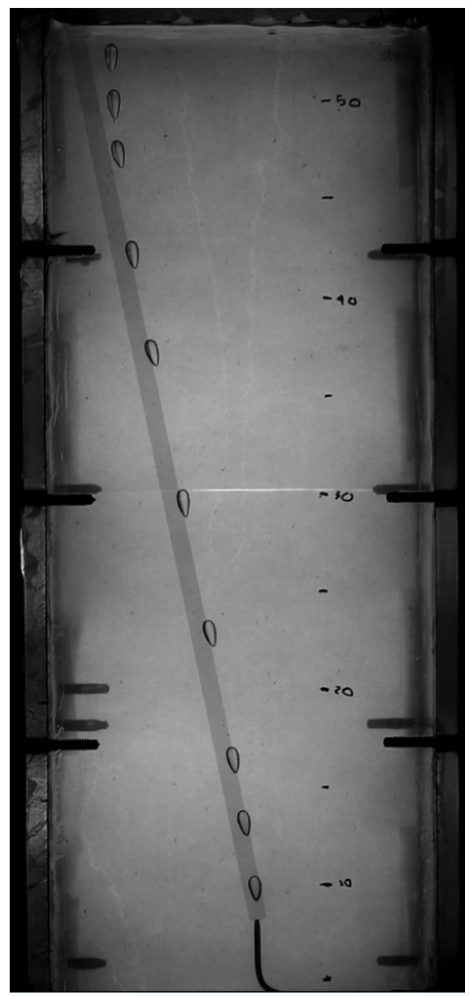

Figura 4.1: Bolha de ar escoando por caminho preferencial formado por précisalhamento do fluido localizado numa trajetória diagonal-retilínea. Foi usada uma barra sólida de $1 \mathrm{~cm}$ de diâmetro para formar o caminho preferencial.

A segunda parte do experimento da Fig. 4.1 é introduzir uma única bolha de ar e observar a trajetória. Como mostra a Fig. 4.1 a bolha segue o caminho preferencial indicado pela barra de metal. Este fenômeno ocorre porque ao introduzir a barra metálica fluidizamos a suspensão viscoplástica de Carbopol e causamos um deslocamento das partículas de polímero para regiões na vizinhança, isto reduz a concentração de polímero na trajetória da barra e quando o fluido rapidamente se gelifica, a reologia obtida é menos viscoplástica, a tensão limite $\tau_{0}$ é menor e em consequência a região na trajetória da barra 
se torna um caminho mais fácil para as bolhas escoarem.

Um segundo experimento consistiu em injetar sete (7) bolhas de ar na suspensão de Carbopol, mas sem homogeneizar o material para observar se era formado um caminho preferencial e a influencia na dinâmica e geometria das bolhas, o tempo de separação entre cada bolha injetada foi de 5 min. O fluido do tanque foi homogeneizado antes de injetar a primeira bolha e posteriormente se injetaram as outras seis (6) partículas. Os resultados se apresentam na Fig. 4.2 e Fig. 4.3.

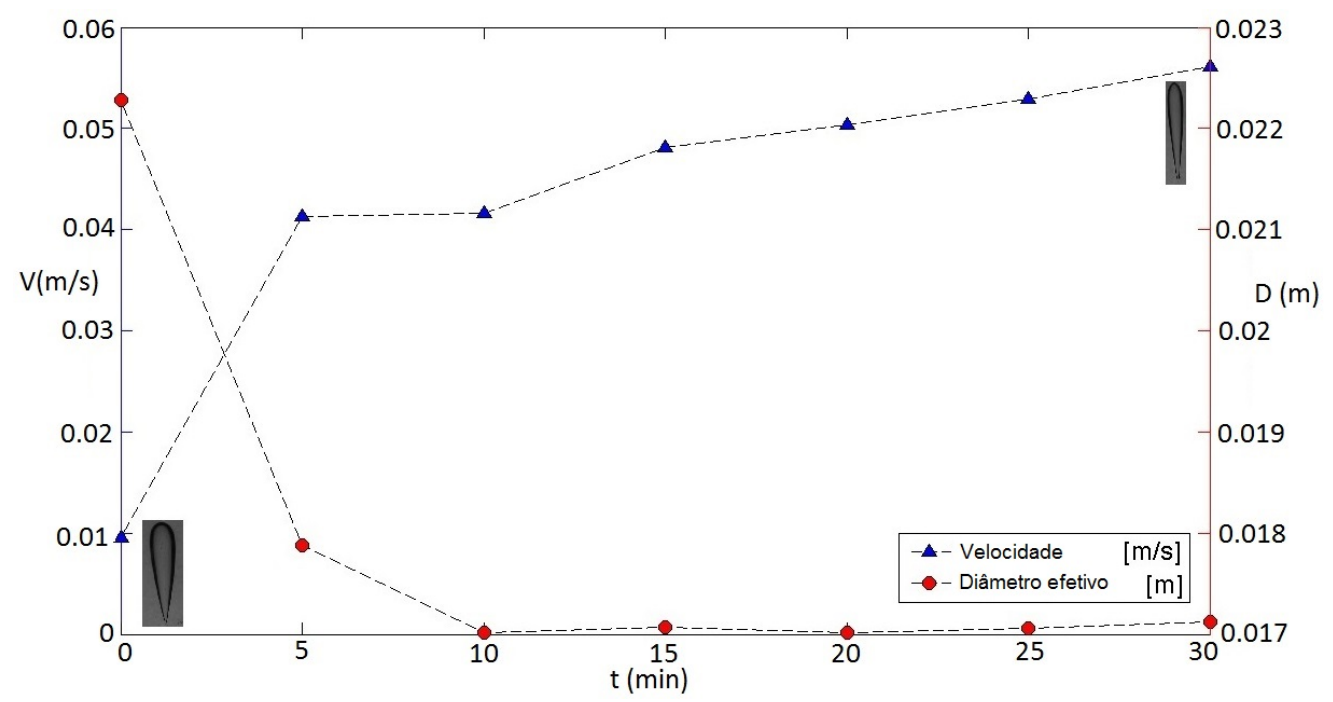

Figura 4.2: Velocidade V e Diâmetro efetivo D em função do Tempo t de injeção de bolhas de ar em Carbopol 980 de concentração $0.10 \%$ ww. O processo de homogeneização só foi usado prévio à injeção da primeira bolha.

A Fig. 4.2 mostra a velocidade da bolha $\mathrm{V}$ em função do tempo de injeção de cada bolha, os resultados indicam aumento da velocidade $\mathrm{V}$ após cada bolha injetada e a curva tem uma tendência a se assintotizar conforme se injetam mais partículas, observando a existência de uma velocidade máxima independente do número de bolhas injetadas. A Fig. 4.2 também informa o diâmetro efetivo D da bolha, onde se observa uma queda brusca no tamanho da bolha injetada tendendo a um valor assintótico. Estes fenômenos ocorrem porque cada bolha injetada fluidiza a suspensão e provavelmente desloca os cristais de polímero à vizinhança, redizindo a tensão limite do fluido e o arrasto viscoso sobre as bolhas. Como resultado, as bolhas atingem maior velocidade e além disso são menores porque a tensão limite $\tau_{0}$ é menor, fazendo com que a bolha se desprenda mais facilmente do injetor. Este experimento é como se a suspensão viscoplástica estivesse se tornando Newtoniana porque a tensão limite $\tau_{0}$ diminui ao diminuir a concentração de polímero no caminho preferencial formado pela primeira bolha injetada. 


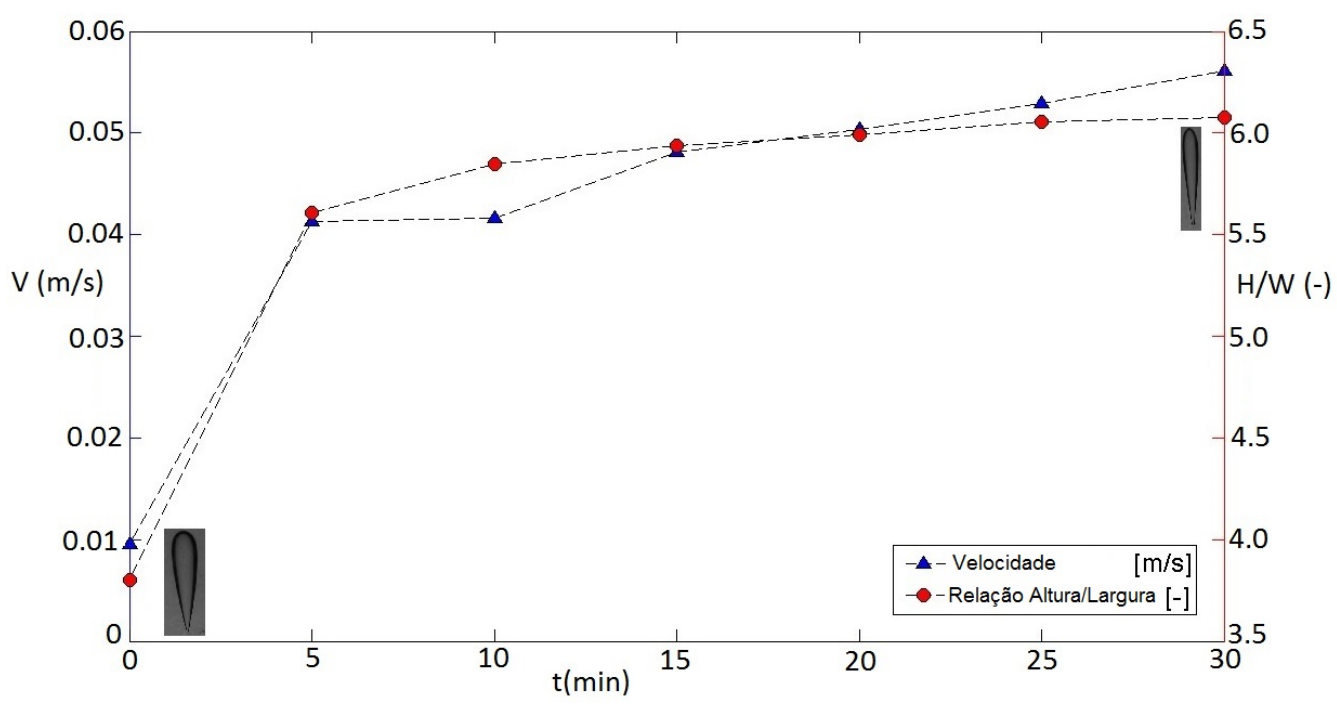

Figura 4.3: Velocidade V e Relação de aspecto Altura/Largura H/W em função do Tempo t de injeção de bolhas de ar em Carbopol 980 de concentração 0.10 \%ww. O processo de homogeneização só foi usado prévio à injeção da primeira bolha.

A Fig. 4.3 mostra a razão de aspecto Altura/Largura H/W da bolha. Observa-se bolhas mais altas e menos largas com cada bolha injetada, isto ocorre porque a medida que as bolhas vão escoando, o fluido fica menos viscoso devido ao cisalhamento.

Os resultados anteriores provam a necessidade de homogeneizar o Carbopol antes da injeção de cada bolha de gás. Este comportamento também foi observado na Laponita e por esta razão antes de cada ponto obtido nas curvas de resultados desta pesquisa foi feito um processo de homogeneização nas duas (2) suspensões usadas.

\subsection{2}

\section{Dinâmica de bolhas de gás escoando em Carbopol}

O efeito da reologia na dinâmica e geometria da bolha é analisado nesta seção. Para esta análise serão considerados os parâmetros adimensionais que governam o problema, definidos na Seção 4.1.

As Figs. 4.4 e 4.5 mostram o tamanho e a geometria da bolha de ar em função do número de Reynolds para Carbopol $0.10 \%$ ww e $0.20 \%$ ww respectivamente. Existem diferenças importantes nos dois casos. . Com o aumento da concentração da suspensão são necessárias bolhas um pouco maiores para atingir determinado patamar de velocidade V. No Carbopol 0.10\% ww a faixa de tamanho da bolha é de 8.12-32.46 mm de diâmetro efetivo D, enquanto que para a suspensão $0.20 \%$ ww a faixa é 19.6-43.6 mm. 
Adicionalmente, o tamanho crítico da bolha $D_{c}$, quando a bolha começa a escoa, também é maior com a concentração de polímero, isto por conta do aumento da tensão limite $\tau_{0}$ do material viscoplástico.

Bolhas de ar em Carbopol 0.10\% ww para Re baixos mostram uma geometria quase esférica por várias razões. No regime de Stokes a inércia do fluido deslocado é desprezível, e a baixa concentração de polímero resulta num material muito pouco elástico. A elasticidade causa vorticidade ao redor da bolha afetando a geometria, algo não observado na Fig. 4.4 com Carbopol $0.10 \%$ ww. Conforme o Re aumenta a razão de aspecto $\mathrm{H} / \mathrm{W}$ decresce pois a inércia do fluido deslocado e causa um aumento da pressão na parte superior da bolha (48) (18), e como consequência a bolha se torna mais achatada.

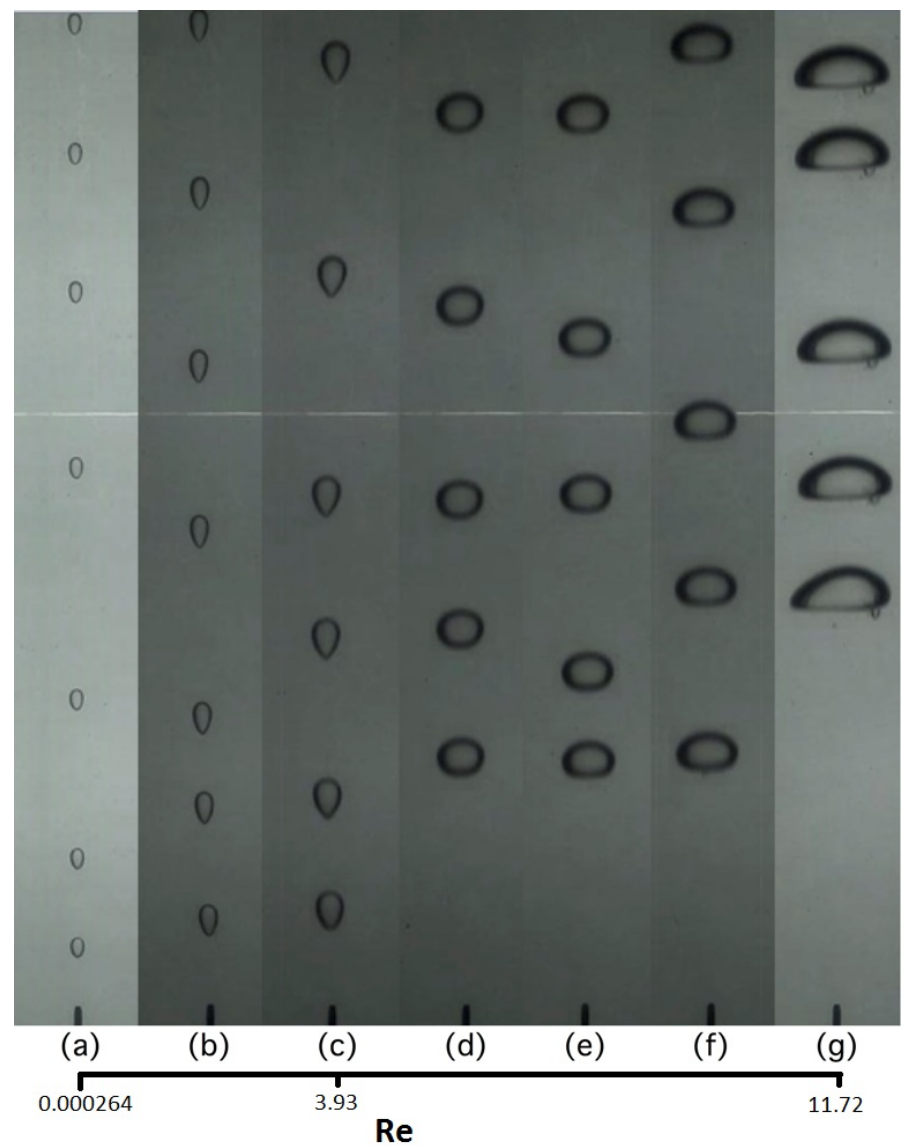

Figura 4.4: Geometria de bolhas de ar em Carbopol 0.10\% ww em função do Número de Reynolds Re.

Na Fig. 4.5 para Carbopol 0.20\% ww ocorrem fenômenos similares. Inicialmente ocorre um alongamento da bolha ou aumento da relação de aspecto $\mathrm{H} / \mathrm{W}$ em baixos Re por conta do arrasto viscoso, mas conforme o Re cresce, a bolha começa a ficar mais larga devido às forças inerciais do fluido. A maior diferença está na elasticidade do material. No Carbopol 0.20\% ww a elasticidade é muito maior,e em consequência a geometria das bolhas da 
Fig. 4.5 tem uma longa cauda na parte inferior (48) (9). Isto é motivado pelos vórtices ao redor da bolha causados pela elasticidade do fluido, gerando uma esteira negativa de fluxo na parte inferior da bolha que causa a formação da cauda.

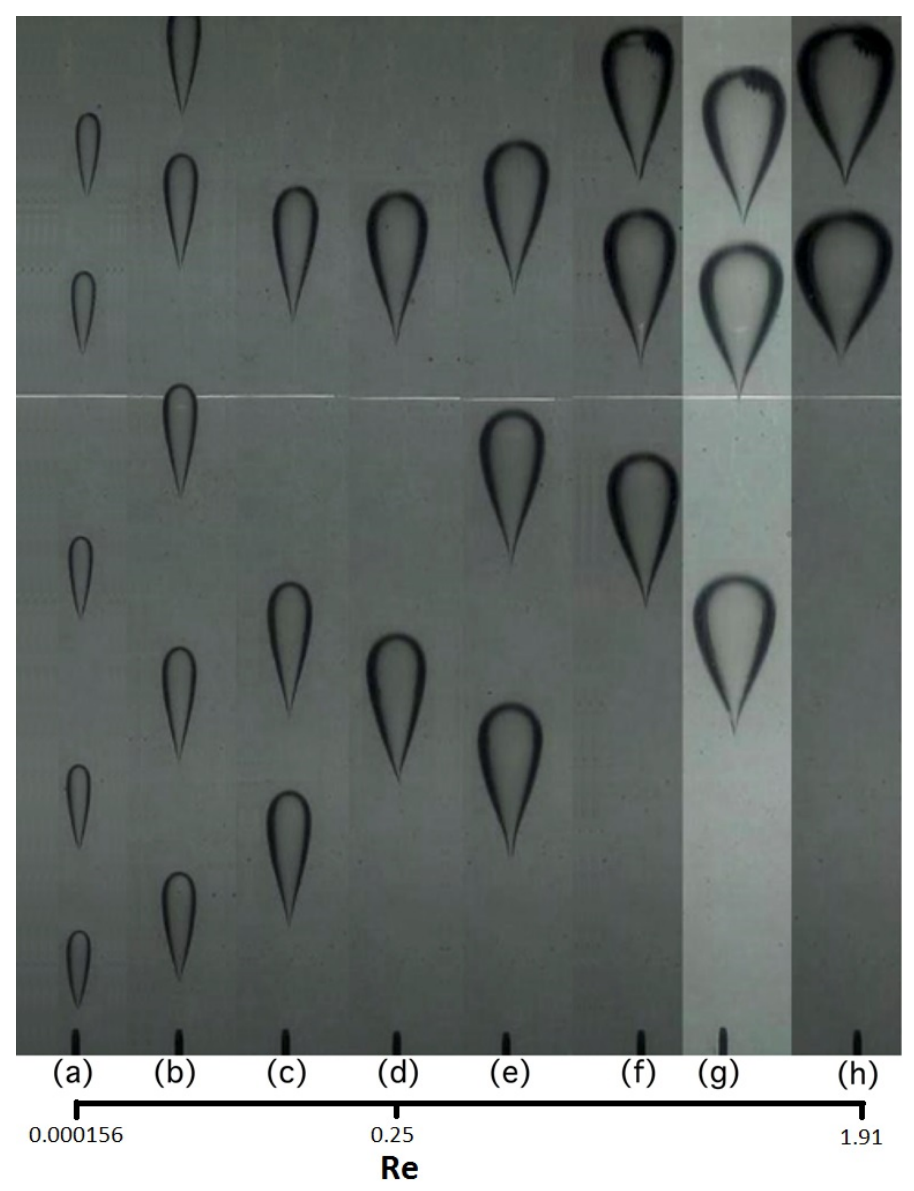

Figura 4.5: Geometria de bolhas de ar em Carbopol 0.20\% ww em função do Número de Reynolds Re

Vale a pena notar nas Figs. 4.6 e 4.7 que os parâmetros adimensionais (Re, $\mathrm{Bi}, \mathrm{De}, \mathrm{H} / \mathrm{W}, \mathrm{Re} / \mathrm{De}$ ) não podem ser controlados porque mudam em função do tamanho da bolha de ar. O Re aumenta em função do D, mas o Bi decresce com o D. Isto mostra a tendência das forças inerciais e de empuxo que se tornam dominantes, ao contrário das forças viscosas, que perdem importância ao aumentar o tamanho D.

Com relação à elasticidade, a Fig. 4.7 mostra um aumento do De em função do D até certo valor máximo e nesse ponto começa uma leve diminuição para baixas concentrações. Também se observa que para os diâmetros $\mathrm{D}$ menores o De é maior para as concentrações mais baixas de polímero, apesar do fato de que estes têm menor tempo de relaxamento. Como estas soluções são menos viscosas, as velocidades das bolhas são maiores, resultando em valores 


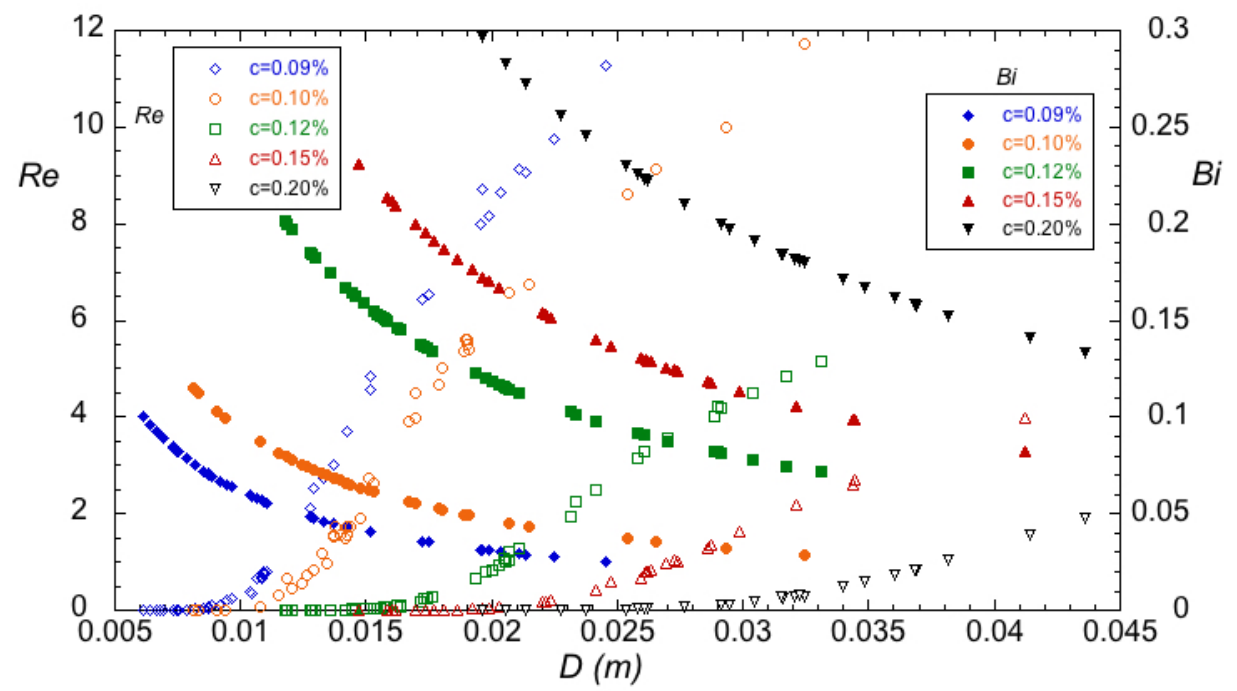

Figura 4.6: Número de Reynolds Re e Número de Bingham Bi em função do Diâmetro efetivo D da bolha de ar em Carbopol 980 de concentração 0.09\% ww, $0.10 \%$ ww, $0.12 \%$ ww, $0.15 \%$ ww e $0.20 \%$ ww.

mais altos de De e Re em suspensões de menor concentração. Para suspensões de alta concentração a tendência da curva permite pensar que o De irá atingir um valor máximo e depois cair levemente, mas os resultados experimentais não permitem confirmar esta hipótese.

A Fig. 4.8 mostra a curva de velocidade $\mathrm{V}$ em função do diâmetro efetivo D para injeção de bolhas de ar em cinco (5) concentrações diferentes de Carbopol (0.09\% ww, $0.10 \%$ ww, $0.12 \%$ ww, $0.15 \%$ ww e $0.20 \%$ ww). Para pequenos tamanhos das bolhas em cada concentração de polímero, as forças viscosas são dominantes, e observa-se que a velocidade $\mathrm{V}$ da bolha se incrementa fortemente com o aumento do tamanho da bolha D. Porém, a medida que o diâmetro cresce, a elasticidade, inércia e empuxo aumentam, fazendo com que o aumento de velocidade seja mais suave. Ao comparar a curva de V em função de D (Fig. 4.8) com as Figs. 4.4 e 4.5 se observa uma importante alteração na geometria das bolhas em Carbopol 0.10\% ww na região onde ocorre a alteração na inclinação da curva de V Vs D. No caso do Carbopol $0.20 \%$ ww o gradiente da curva muda pouco e ao observar a geometria das bolhas, a mudança também é pouca. Existe uma relação entre a geometria e o balanço de forcas na bolha e a velocidade resultante.

É importante notar que a Fig. 4.8 não mostra nenhum salto de velocidade ou instabilidade, ao contrário de resultados de diversos autores. As possíveis causas destes saltos podem estar na viscoelasticidade do material que forma uma esteira negativa gerando o fenômeno (55) (60) (59). Nas faixas de parâmetros analisadas neste trabalho provavelmente o nível de elasticidade 


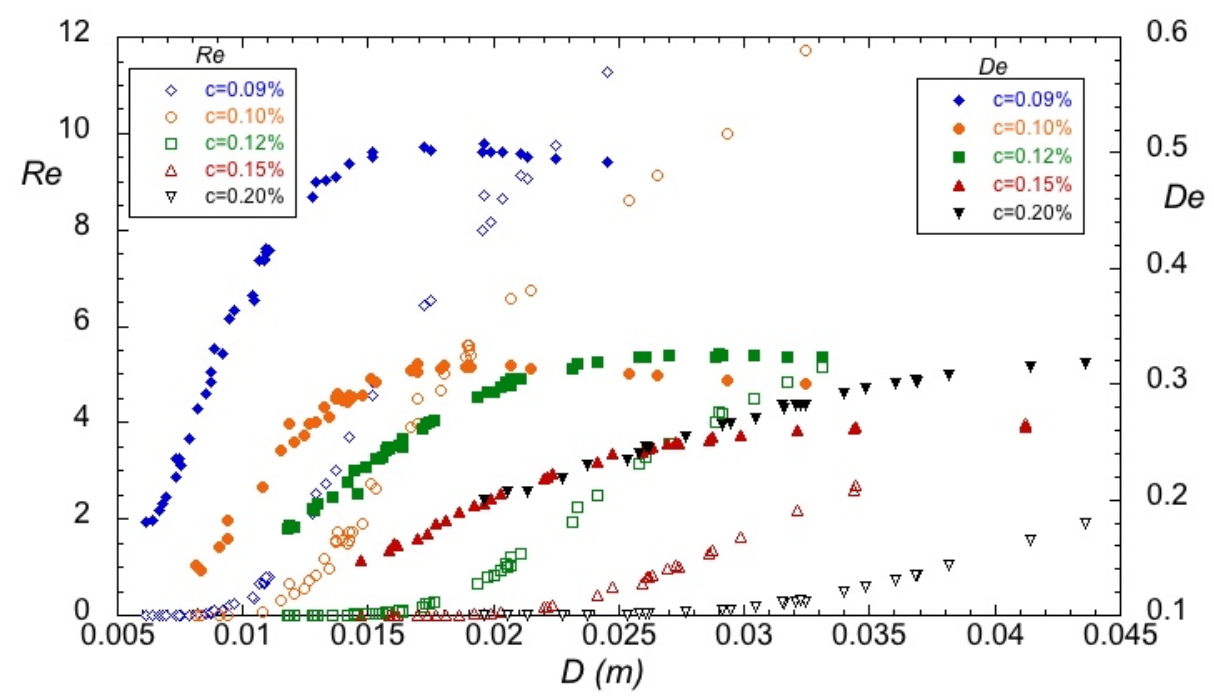

Figura 4.7: Número de Reynolds Re e Número de Deborah De em função do Diâmetro efetivo D da bolha de ar em Carbopol 980 de concentração 0.09\% ww, $0.10 \%$ ww, $0.12 \%$ ww, $0.15 \%$ ww e $0.20 \%$ ww.

não foi suficientemente alto para gerar a esteira ou as instabilidades podem ter sido amortecidas por conta da alta tensão limite $\tau_{0}$ do material.

Na Fig. 4.8 é possível observar a tendência da bolha atingir velocidade nula quando seu tamanho decresce, isto devido à tensão limite $\tau_{0}$ que tem que ser superada pela forca de empuxo $F_{b}$ na bolha. $\mathrm{O}$ mesmo resultado pode ser observado na análise de Re e Bi, mostrados na Fig. 4.9. Observa-se que Re tende a zero quando Bi atinge valores mais elevados. Existe um diâmetro crítico abaixo do qual, ou um Bi crítico acima do qual a bolha permanece estagnada. É difícil calcular o diâmetro critico $D_{c}$ ou o Bi máximo onde a bolha começa a permanecer estagnada por conta da assíntota na curva de resultados. A partir dos nossos resultados, podemos estimar esse Bi crítico entre $0,1(0,09 \%)$ e 0,3 $(0,20 \%)$. Esses valores correspondem a uma velocidade terminal de $3 \times 10^{-4}$ e $2 \times 10^{-3} \mathrm{~m} / \mathrm{s}$, respectivamente. É importante notar que os valores críticos são provavelmente menores, já que em nossas experiências bolhas abaixo de um certo tamanho crítico não se soltavam do bocal devido à força de tensão superficial em adição ao efeito da tensão limite de escoamento. Os números de Deborah também são mostrados nesta figura e podemos observar que a elasticidade não é insignificante perto do Bi crítico.

A análise dimensional mostra que o número de Arquimedes Ar também é um parâmetro do problema. No entanto, Ar pode ser escrito como $\operatorname{Reg}(D / 2) / V^{2}$, e notamos que (quando o empuxo supera a tensão de escoamento) a velocidade aumenta monotonicamente com D (veja a Fig. 4.8) de forma que o grupo $g(D / 2) / V^{2}$ não varia muito. Isto é, Re e Ar variam jun- 


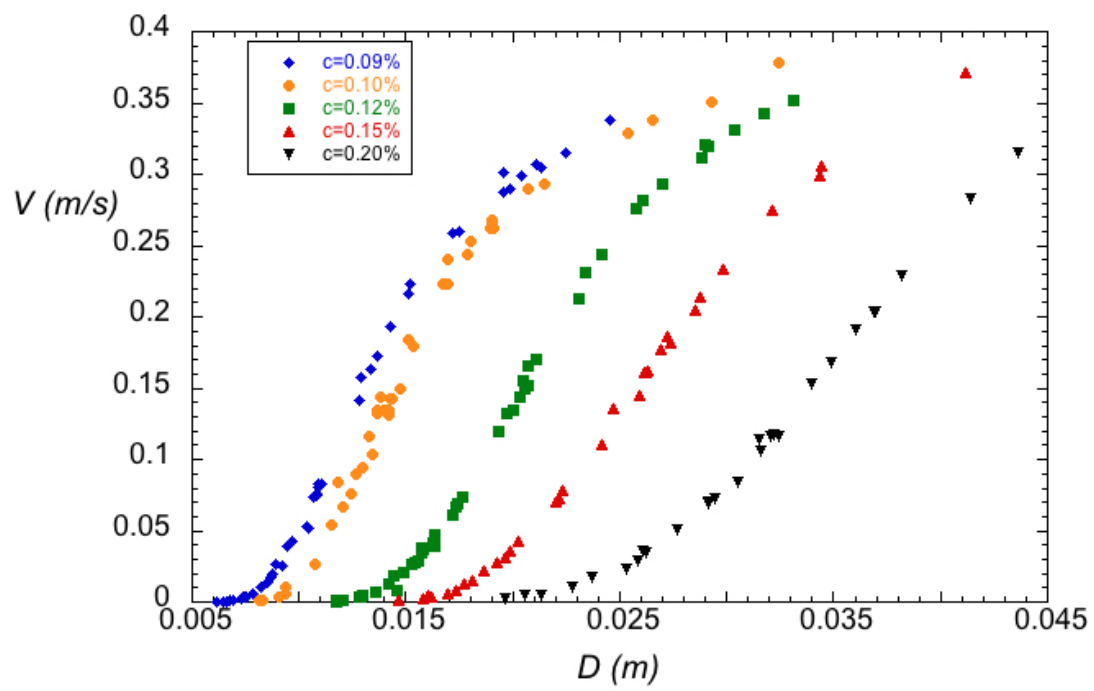

Figura 4.8: Velocidade V em função do Diâmetro efetivo D da bolha de ar em Carbopol 980 de concentração $0.09 \%$ ww, $0.10 \%$ ww, $0.12 \%$ ww, $0.15 \%$ ww e $0.20 \%$ ww.

tos, e assim as tendências observadas para Re e Ar são aproximadamente as mesmas.

Sikorsky et al. (17) usa um parâmetro diferente de Bi para estudar a viscoplasticidade, chamado yield parameter. Este yield parameter é definido como $Y=2 \pi \tau_{0} W^{2} / \rho g \forall=2 / 2 B i\left(R_{\max } / R_{e f f}\right)^{2}$. Os autores obtêm um valor crítico $\mathrm{Y}=0.5$. Nossos resultados mostram $Y \approx 0.13$. Os valores teóricos reportados por Dubash (6) em bolhas esféricas indicam $Y=0.87$, sendo que no trabalho numéricos de (53), Y=0.21. Em resumo, é difícil decidir um valor crítico representativo para o yield parameter pois enquanto os experimentos têm certas limitações, os estudos numéricos e teóricos têm outras como desprezar a elasticidade do fluido e não esfericidade da bolha.

A Fig. 4.10 mostra a razão de aspecto $\mathrm{H} / \mathrm{W}$ em função do diâmetro adimensional $\mathrm{D} / \mathrm{W}$. A razão de aspecto $\mathrm{H} / \mathrm{W}$ se incrementa com o diâmetro adimensional $\mathrm{D} / \mathrm{W}$ até determinado ponto para Carbopol de baixa concentração $(0.09 \%$ ww, $0.10 \%$ ww e $0.12 \%$ ww). Neste ponto a inércia do fluido induz uma região de alta pressão na parte alta da bolha e causa o alargamento da bolha e consequentemente uma queda do $\mathrm{H} / \mathrm{W}$, fazendo com que a curva mude de direção. Este comportamento também pode ocorrer em Carbopol de maiores concentrações $(0.15 \%$ ww e $0.20 \%$ ww), mas é necessário confirmar com experimentos de injeção de bolhas de maior tamanho. Outra observação é o aumento da razão de aspecto $\mathrm{H} / \mathrm{W}$ em função da concentração, isto provavelmente causado pelos efeitos elásticos mais intensos em suspensões mais concentradas. 


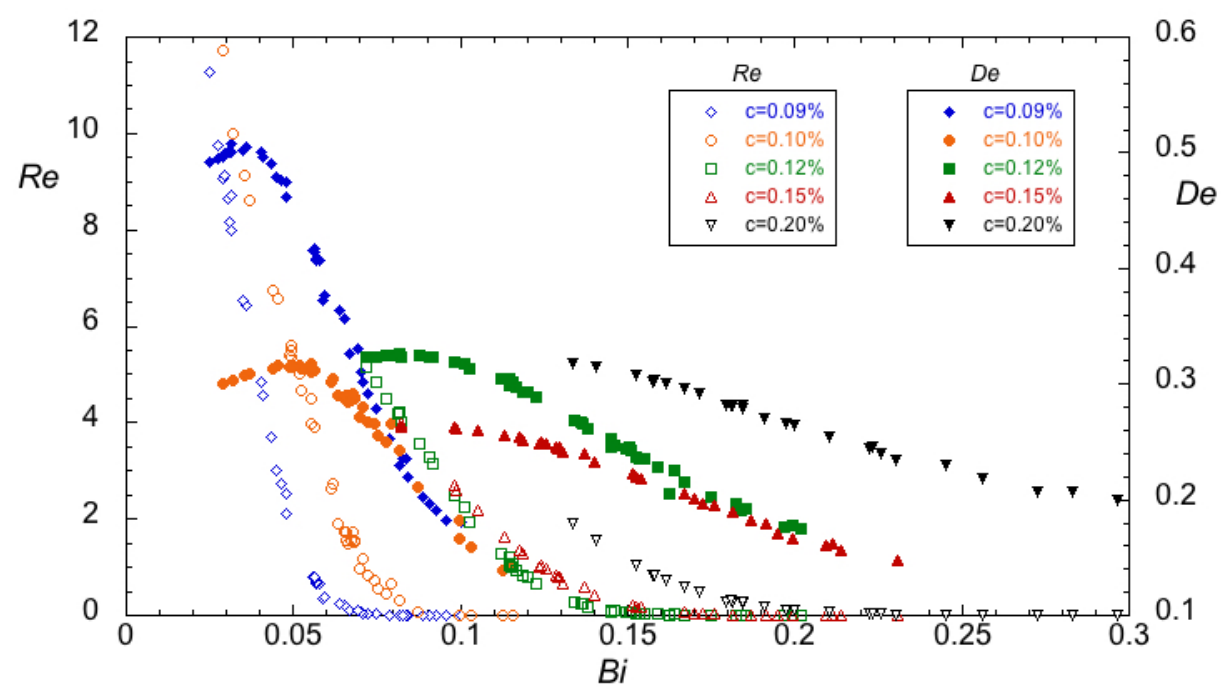

Figura 4.9: Numero de Reynolds Re e Numero de Deborah De em função do Número de Bingham Bi da bolha de ar em Carbopol 980 de concentração $0.09 \%$ ww, $0.10 \%$ ww, $0.12 \%$ ww, $0.15 \%$ ww e $0.20 \%$ ww.

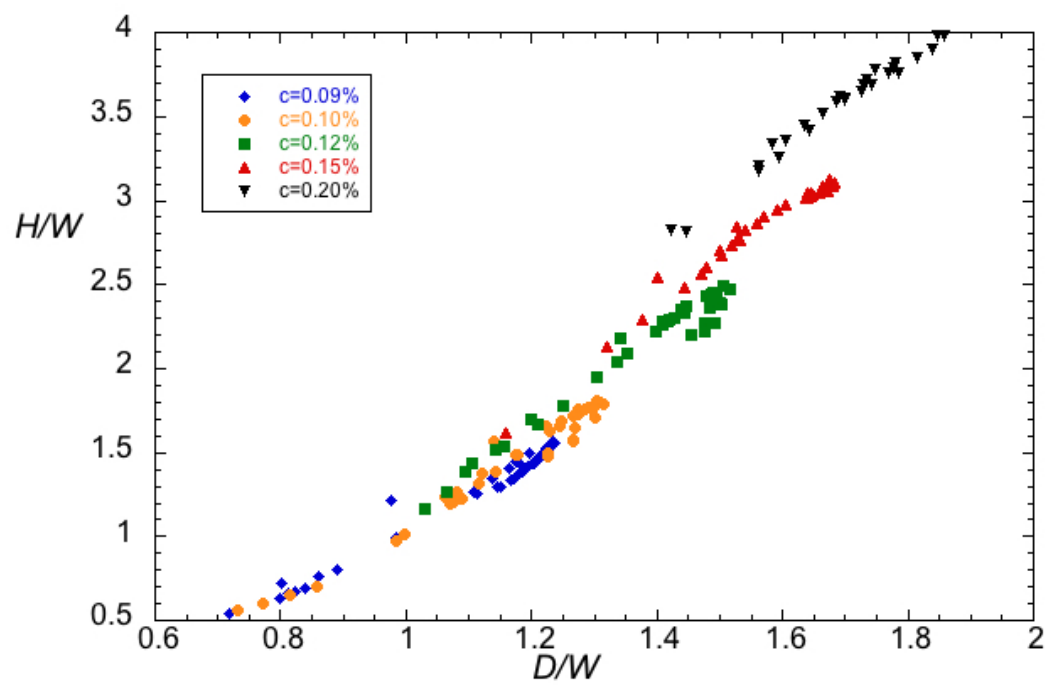

Figura 4.10: Razão de aspecto Altura/Largura H/W em função da razão d Diâmetro efetivo/Largura D/W da bolha de ar em Carbopol 980 de concentração $0.09 \%$ ww, $0.10 \%$ ww, $0.12 \%$ ww, $0.15 \%$ ww e $0.20 \%$ ww. 
A relação entre Re, De e Bi com a razão da aspecto $\mathrm{H} / \mathrm{W}$ da bolha são ilustradas nas Figs. 4.11 e 4.12. No regime de Stokes se observa um rápido aumento de H/W em função de Re/De para as concentrações mais baixas $(0.09 \%$ ww, $0.10 \%$ ww e $0.12 \%$ ww), o que sugere um rápido aumento dos efeitos elásticos que tornam a bolha mais alongada. Para as concentrações maiores ( $0.15 \%$ ww e $0.20 \%$ ww) se observa que H/W decresce com Re/De, sugerindo que os efeitos elásticos aumentam mais lentamente que os efeitos inerciais, que tornam a bolha mais larga. Observa-se um aumento de $\mathrm{H} / \mathrm{W}$ em função da concentração de polímero por conta dos efeitos elásticos. Com o aumento de Re/De a razão de aspecto decresce monoatomicamente até atingir zero, onde a bolha se separa em duas ou mais bolhas como resultado da inercia do fluido. A Fig. 4.11 mostra o valor de Re/De para $\mathrm{H} / \mathrm{W}=1$, este ponto indica a mudança de geometria alongada para geometria achatada. Nota-se que este ponto aumenta com a concentração da suspensão, em Carbopol 0.09\% ww este ponto ocorre para Re/De igual a 12 , e para Carbopol $0.10 \%$ ww para $\mathrm{Re} / \mathrm{De}$ igual a 20. Os resultados sugerem convergência no ponto em que os resultados da Fig. 4.11 se assintotizam, mas são necessários mais resultados para observação.

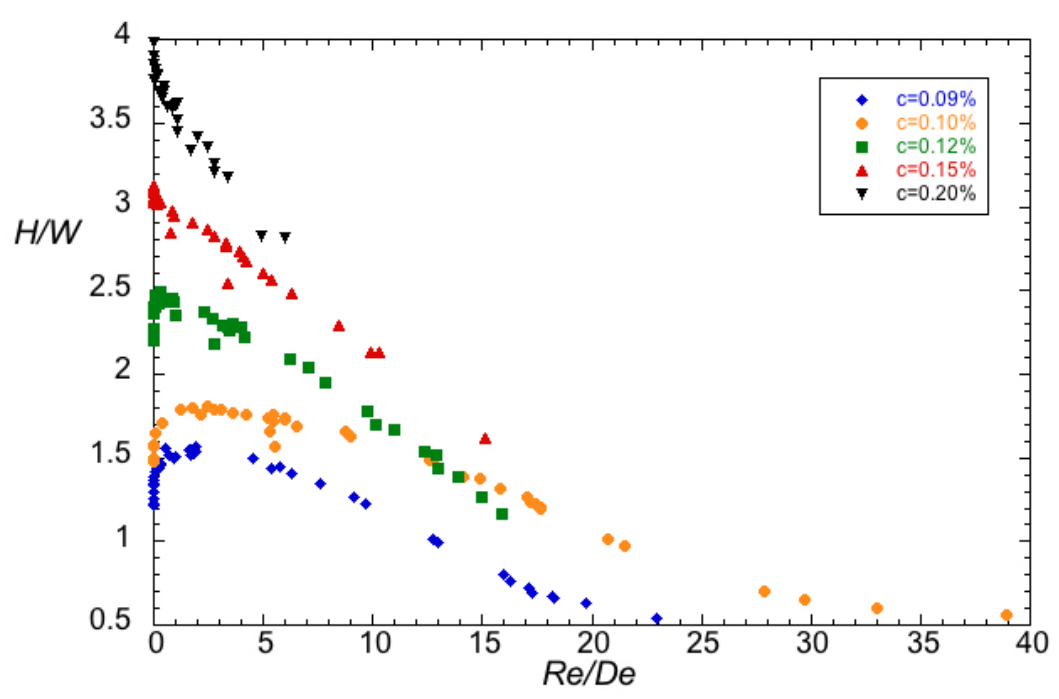

Figura 4.11: Razão de aspecto Altura/Largura H/W em função da relação Numero de Reynolds/Numero de Deborah Re/De da bolha de ar em Carbopol 980 de concentração $0.09 \%$ ww, $0.10 \%$ ww, $0.12 \%$ ww, $0.15 \%$ ww e $0.20 \%$ ww.

A Fig. 4.12 mostra que em suspensões de baixa concentração (0.09\% ww, $0.10 \%$ ww e $0.12 \%$ ww) conforme o Bi aumenta a relação de aspecto $\mathrm{H} / \mathrm{W}$ cresce acentuadamente até atingir um valor máximo e posteriormente sofre uma leve queda. Em suspensões de alta concentração ( $0.15 \%$ ww e $0.20 \%$ ww) a queda não acontece, e H/W continua crescendo, porém de forma mais suave. 
Este fenômeno acontece por conta do balanço de forças inerciais e elásticas que já foi discutido anteriormente.

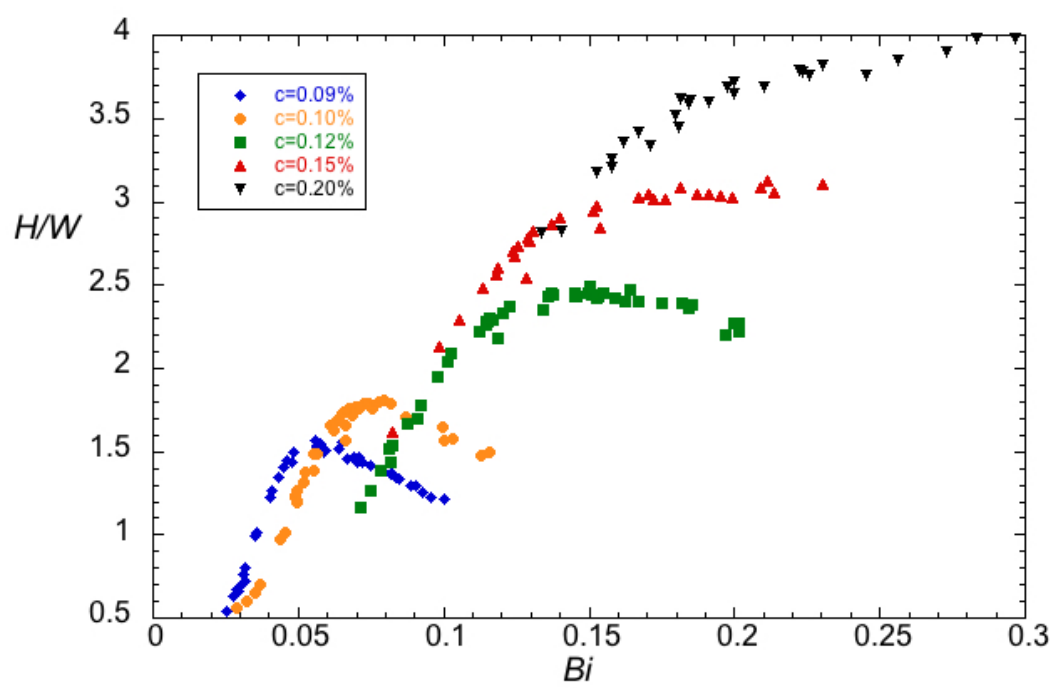

Figura 4.12: Relação de aspecto Altura/Largura H/W em função do Número de Bingham Bi da bolha de ar em Carbopol 980 de concentração 0.09\% ww, $0.10 \%$ ww, $0.12 \%$ ww, $0.15 \%$ ww e $0.20 \%$ ww.

A Fig. 4.13 mostra o coeficiente de arrasto $C_{d}$ ( Eq. 4-11 ) em função do Re. Os resultados para regime Stokes mostram uma tendência que se ajusta à lei da potencia até um valor máximo de $R e=1$. Quando o Re aumenta e o regime se torna laminar a curva tende a uma assintota horizontal como mostra a Fig. 4.13. Estes resultados são confirmados por diversos autores (79) (36) (16). Isto acontece pelo aumento acentuado da inércia em função do Re, como foi discutido anteriormente. Outra observação é uma leve diminuição na curva de $C_{d}$ conforme aumenta a concentração da suspensão, isto está relacionado com a relação entre velocidade $\mathrm{V}$ e diâmetro $\mathrm{D}$ das bolhas, pois conforme aumenta a concentração da suspensão são necessárias bolhas muito maiores para atingir os mesmos patamares de velocidade, causando queda do $C_{d}$.

A Fig. 4.14 mostra o coeficiente de arrasto $C_{d}$ ( Eq. 4-11 ) em função do Re/De, este resultado mostra a influencia das forcas inerciais e elásticas no arrasto da partícula. Ao comparar os resultados da Fig. 4.14 com a Fig. 4.13 no se observa nenhuma diferença significativa na tendencia da curva, isto pode indicar que embora o aumento da elasticidade do material altera a geometria da partícula, isto não afeta a dinâmica da bolha. As principais forcas continuam sendo a forca de empuxo $F_{b}$, as forcas viscosas e as forcas inerciais. As forcas elásticas alteram a geometria da bolha mas a dinâmica da bolha continua sendo função principalmente do tamanho da partícula D. 


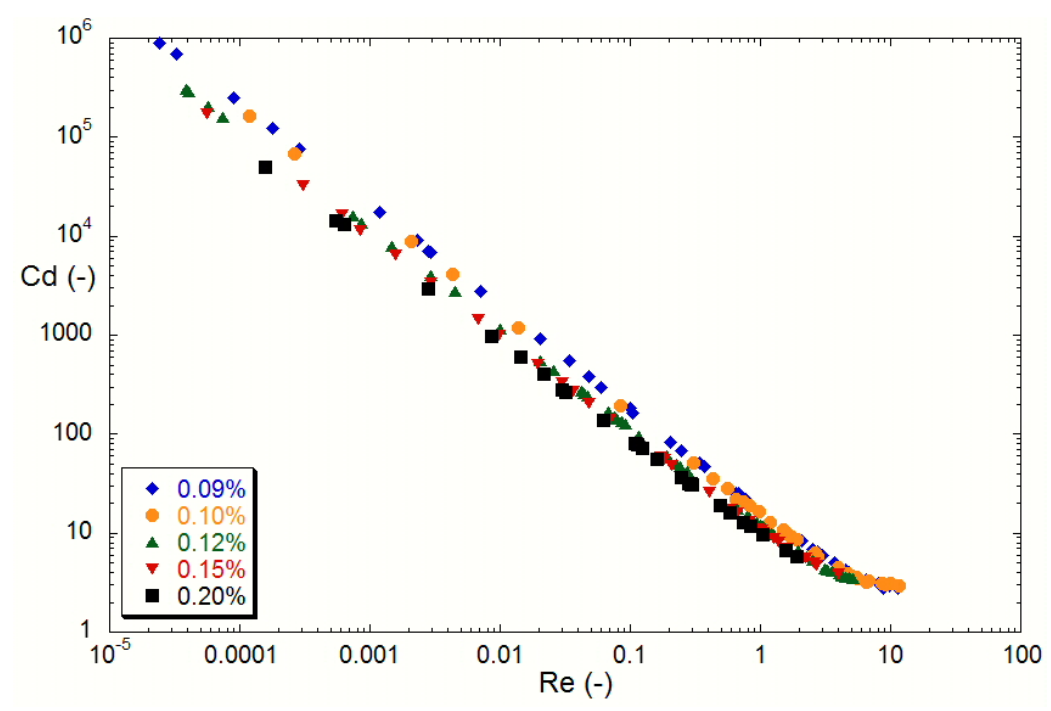

Figura 4.13: Coeficiente de arrasto Cd em função da relação Número de Reynolds Re da bolha de ar em Carbopol 980 de concentração 0.09\% ww, $0.10 \%$ ww, $0.12 \%$ ww, $0.15 \%$ ww e $0.20 \%$ ww.

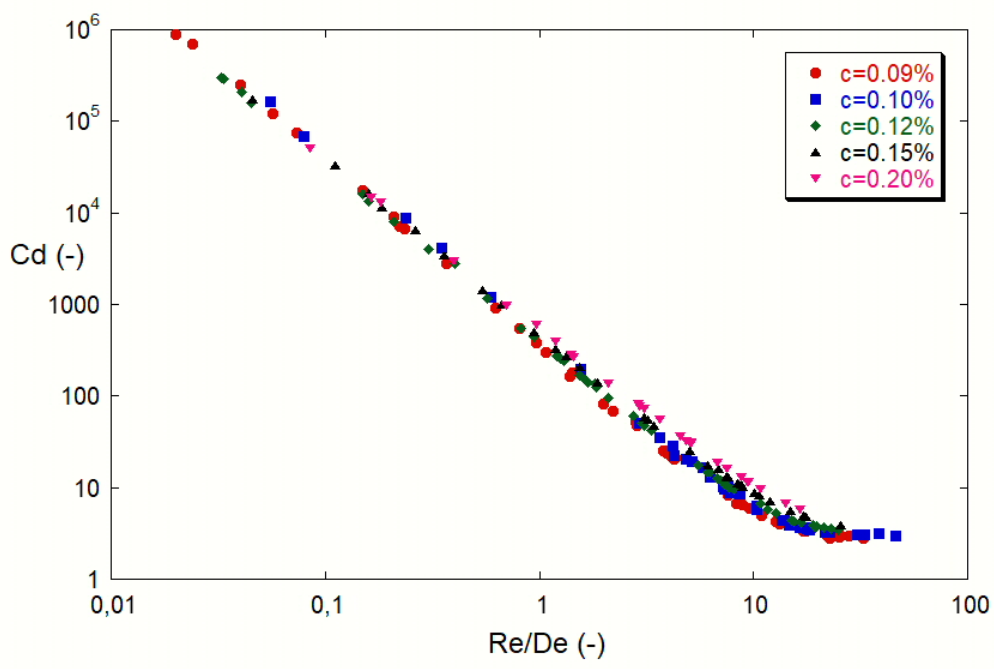

Figura 4.14: Coeficiente de arrasto $\mathrm{Cd}$ em função da relação Número de Reynolds / Numero de Deborah Re/De da bolha de ar em Carbopol 980 de concentração $0.09 \%$ ww, $0.10 \%$ ww, $0.12 \%$ ww, $0.15 \%$ ww e $0.20 \%$ ww. 
$\mathrm{O} C_{d}$ em função do Bi é mostrado na Fig. 4.15. Observa-se uma crescimento moderado para a faixa baixa de Bi em todas as concentrações. Este crescimento é bem maior para faixas de $\mathrm{Bi}$ altas até atingir o Bi critico, estes resultados concordam com (5). É importante ressaltar que baixos Bi correspondem aos maiores valores de Re/De e vice-versa.

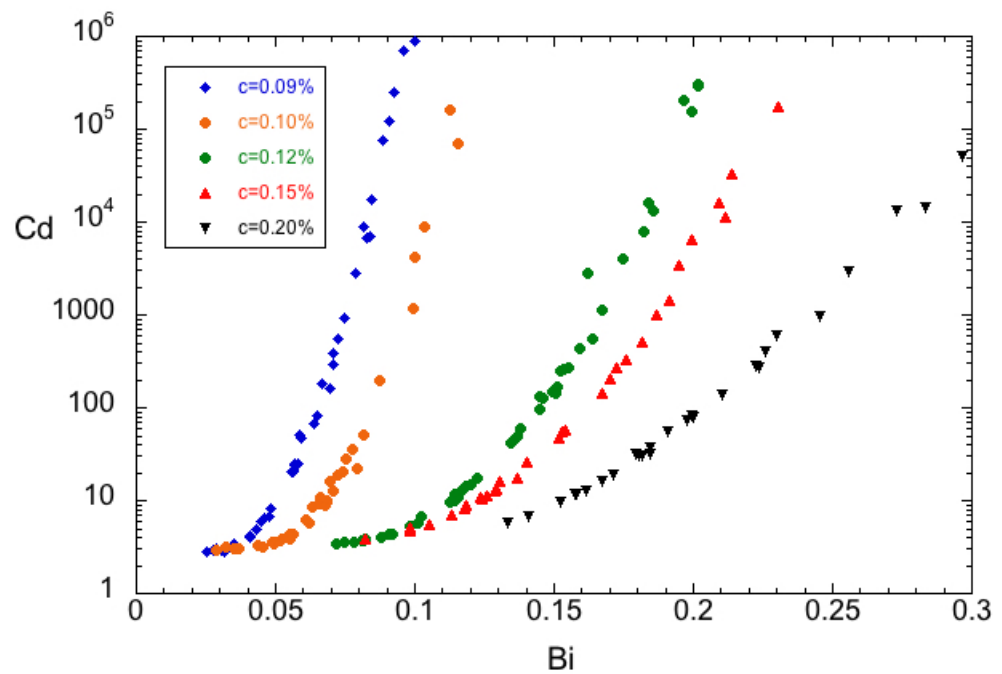

Figura 4.15: Coeficiente de arrasto Cd em função do Número de Bingham Bi da bolha de ar em Carbopol 980 de concentração 0.09\% ww, $0.10 \%$ ww, 0.12\% ww, $0.15 \%$ ww e $0.20 \%$ ww.

\subsection{3}

\section{Dinamica de bolhas de gás escoando em Laponita}

Nesta seção são apresentados os resultados experimentais de injeção de bolhas de ar em uma suspensão viscoplástica e tixotrópica de Laponita. Bolhas de gás escoando em suspensões de Laponita de baixa concentração e com um curto tempo de repouso ou gelificação se comportam de forma similar às bolhas escoando em Carbopol, apresentadas na seção 4.1.2. Isto porque o comportamento mecânico destas suspensões se assemelha ao comportamento viscoplástico não-tixotrópico do Carbopol. A Fig. 4.16 mostra a geometria e tamanho de bolhas de ar em Laponita $2 \%$ ww, para partículas em regime Stokes $($ Re « 1$)$. A geometria é quase esférica e conforme o Re aumenta $(\mathrm{Re} \sim 1)$ a razão de aspecto $\mathrm{H} / \mathrm{W}$ fica maior por conta do arrasto viscoso. Ao atingir o regime laminar $(\operatorname{Re}>1)$ as forças inerciais pressionam a bolha, que fica mais larga e com a cúspide mais achatada. A baixa elasticidade da suspensão permite a formação de bolhas sem calda, resultado similar ao da Fig. 4.4 para o Carbopol de baixa concentração e pouco elástico. 


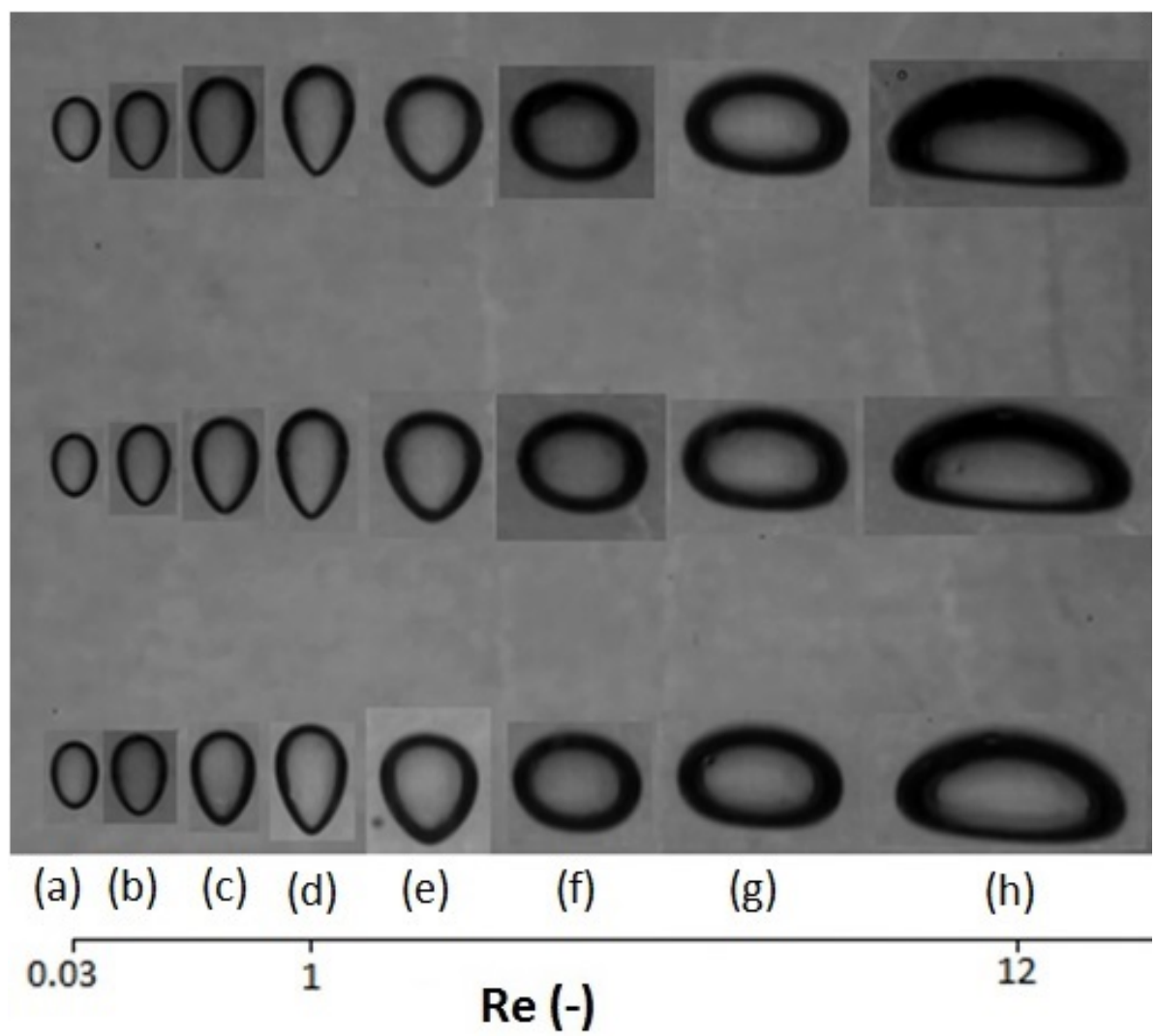

Figura 4.16: Geometria de bolhas de ar em Laponita 2\% ww em função do número de Reynolds Re. Tempo de repouso da suspensão igual a $30 \mathrm{~s}$.

A Fig. 4.17 mostra a geometria de bolhas em Laponita $3 \%$ ww, suspensão de maior concentração onde os efeitos da tixotropia e elasticidade são evidentes. A alta concentração de Laponita forma um material com alta elasticidade, que forma bolhas com uma extensa calda por conta da esteira negativa na parte inferior da bolha. Este material altamente tixotrópico possui um rápido processo de gelificação, ou um rápido crescimento da tensão limite de escoamento $\tau_{0}$, que resulta no aumento da razão de aspecto $\mathrm{H} / \mathrm{W}$. A bolha é muito alongada devido à dificuldade de se deslocar o fluido da vizinhança pelas fortes características viscoplásticas. A geometria longa também reduz o volume deslocado e em consequência a inércia da bolha ao migrar. Em curtos tempos de repouso ou gelificação da Laponita, a bolha se conserva simétrica na direção axial.

Os resultados de escoamento de bolhas em suspensões de Laponita são similares aos resultados de bolhas em suspensões poliméricas de Carbopol. Existem algumas dificuldades no cálculo da dinâmica de bolhas escoando neste material como resultado das dificuldades na caracterização do material, apresentados na Seção 3.2.4, onde a curva de escoamento (Fig. 3.29) feita em Laponita $2 \%$ ww e $3 \%$ ww apresenta um valor constante de tensão de 


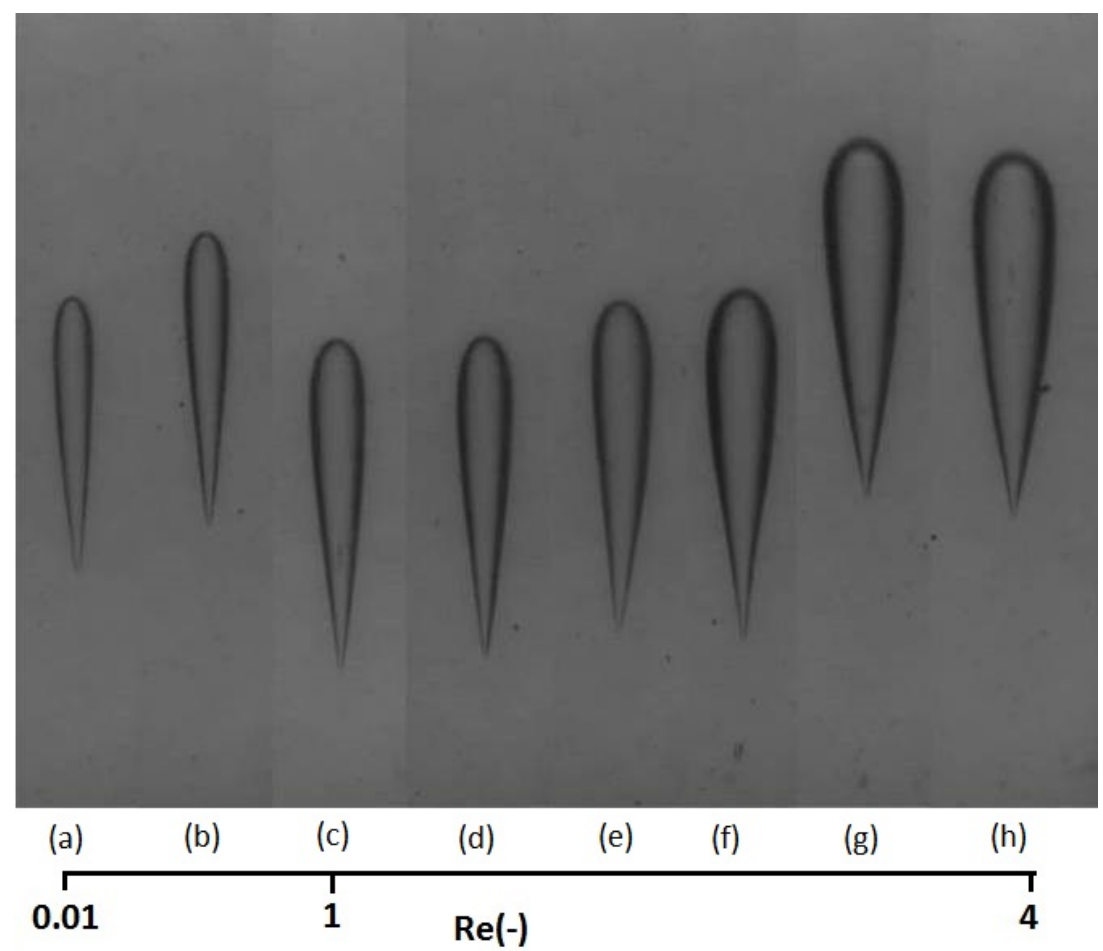

Figura 4.17: Geometria de bolhas de ar em Laponita 3\% ww em função do número de Reynolds Re. Tempo de repouso da suspensão igual a 3 min.

cisalhamento $\tau$ para a faixa de taxa de cisalhamento $\dot{\gamma}$ que corresponde aos experimentos de injeção de bolhas. Esta reologia resulta num Bi constante como mostra a Fig. 4.18 e afeta de forma geral os resultados para Laponita, este fenômeno reológico também é observado por outros autores (34).

A Fig. 4.19 mostra o número de Reynolds Re e o número de Deborah De em função do diâmetro efetivo D no escoamento de uma bolha de ar em Laponita $2 \%$ ww e $3 \%$ ww, para tempos de repouso $30 \mathrm{~s}, 3$ min e 15 min. Observa-se o aumento do Re em função do diâmetro da bolha similar aos resultados da Fig. 4.7. Com o aumento de Re as forças inerciais se tornam dominantes e as viscosas desprezíveis. Para a análise do efeito da elasticidade, observa-se através da Fig. 4.19 que o número de Deborah também cresce até um valor máximo em Laponita de baixa concentração 2\% ww. Em Laponita $3 \%$ ww não se observa este valor máximo, mas acredita-se que em bolhas de maior tamanho pode aparecer. Este comportamento mostra como as forças inerciais dominam as forças viscosas e elásticas em bolhas de maior tamanho (e maior Re). Pode-se observar também como o comportamento tixotrópico do fluido desloca as curvas da Laponita $3 \% \mathrm{ww}$ para a direita, por conta do aumento da tensão limite $\tau_{0}$ com o aumento do tempo de repouso, que leva a uma reestruturação do fluido. Em Laponita $2 \%$ ww este efeito não é observado nos tempos de repouso analisados. 


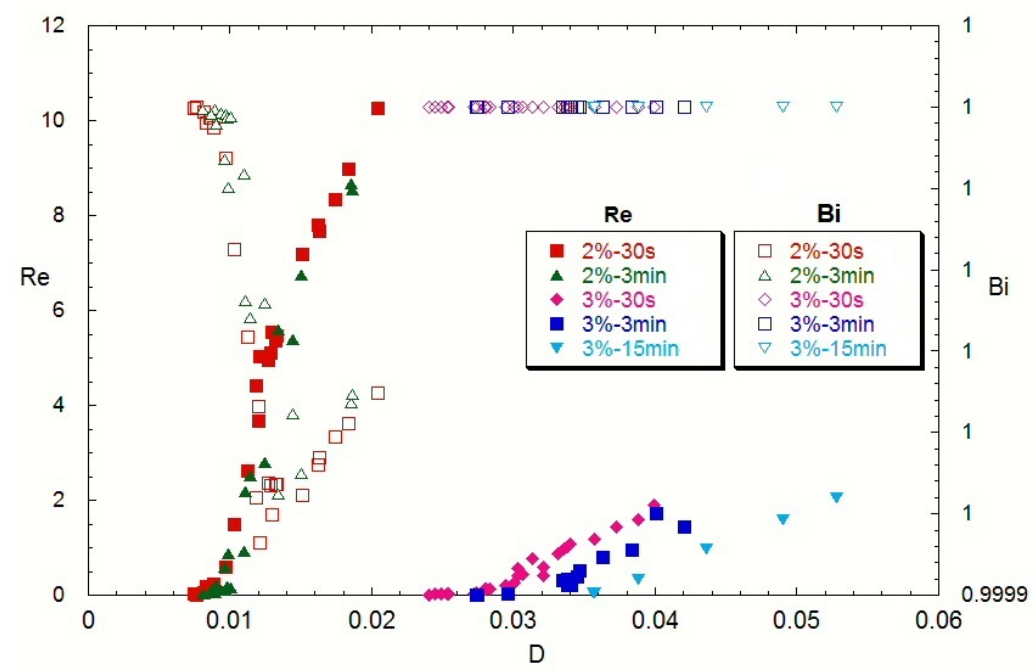

Figura 4.18: Número de Reynolds Re e número de Bingham Bi em função do diâmetro efetivo D em Laponita $2 \%$ ww e $3 \%$ ww. Tempos de repouso iguais a $30 \mathrm{~s}, 3 \mathrm{~min}$ e $15 \mathrm{~min}$.

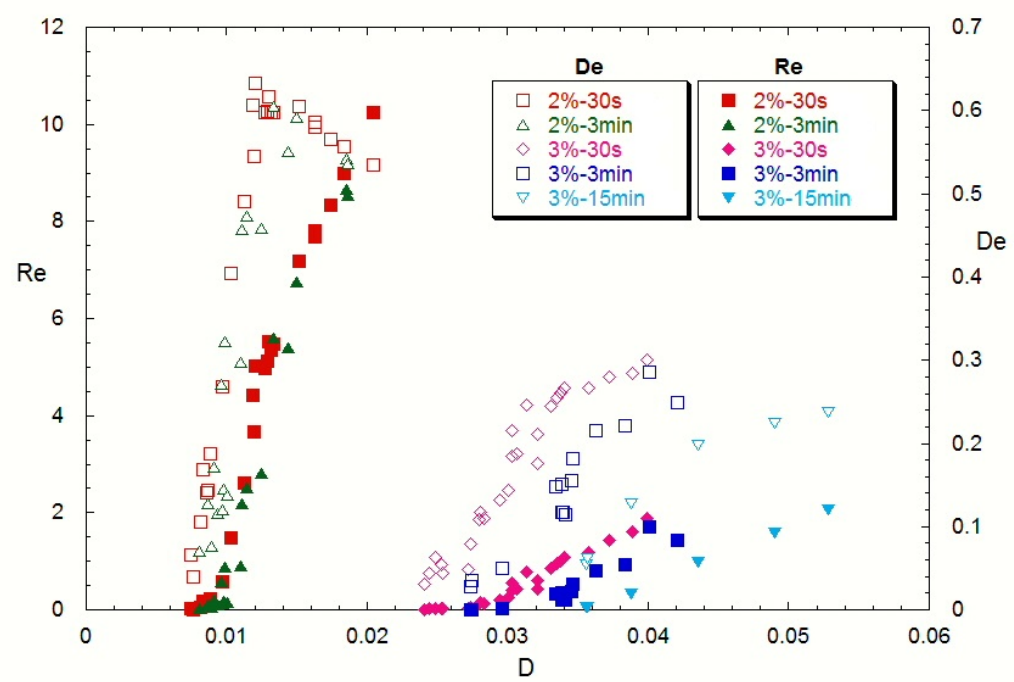

Figura 4.19: Número de Reynolds Re e número de Deborah De em função do diâmetro efetivo D em Laponita $2 \%$ ww e $3 \%$ ww. Tempos de repouso iguais a $30 \mathrm{~s}, 3 \mathrm{~min}$ e $15 \mathrm{~min}$. 
A Fig. 4.20 mostra a velocidade $\mathrm{V}$ em função do diâmetro efetivo $\mathrm{D}$ da bolha para Laponita 2\% ww e 3\% ww. Foram usados diferentes tempos de repouso para atingir diferentes patamares de gelificação da suspensão. Quanto maior o tempo de repouso, maior é a reestruturação do material e portanto maior a tensão limite de escoamento $\tau_{0}$ do fluido. Para a Laponita $2 \% \mathrm{ww}$ foram usados tempos de repouso de $30 \mathrm{~s}$ e $3 \mathrm{~min}$, mas os resultados não mostram diferença significativa. Nos testes com Laponita 3\% ww é possível observar os efeitos da tixotropia. Foram usados tempos de repouso de 30 s, 3 min e 15 min. As curvas de resultados são similares às obtidas para Carbopol na Fig. 4.8 onde para baixas faixas de diâmetros D existe uma subida mais acentuada da velocidade, mas nas faixas maiores de diâmetro o aumento da velocidade é mais suave, devido ao aumento da inércia do fluido que altera a geometria da bolha, tornando-a mais achatada. Observa-se que a variação de concentração da suspensão leva ao deslocamento das curvas por conta da alteração das propriedades viscoplásticas e elásticas do material. Nota-se também o deslocamento da curva para a direito com o aumento do tempo de repouso para uma mesma concentração, pois o fluido se reestrutura, levando a maiores valores de tensão limite e viscosidade. Assim, as bolhas se deslocam com menores velocidades. São necessárias bolhas maiores para atingir os mesmos patamares de velocidade conforme a Laponita se gelifica.

Nos experimentos com Laponita foi difícil medir o diâmetro critico $d_{c}$ da bolha, isto porque a bolha se desloca muito lentamente quando o tamanho é próximo do $d_{c}$. Esta baixa velocidade permite o fluido se gelificar e a bolha pára antes de atingir o ponto de medição com as câmeras de vídeo. Por esta razão não se observa a assíntota na Fig. 4.20 na faixa de baixos diâmetros. A faixa de diâmetro efetivo medidos para bolhas em Laponita $2 \%$ ww é 7.4-20.4 mm e para a Laponita $3 \%$ ww é 20.4-52.8 mm.

A Fig. 4.21 mostra a razão de aspecto H/W em função da razão D/W. Os resultados sao similares aos encontrados no caso do Carbopol na Fig. 4.10, com o aumento da concentração de Laponita a razão H/W cresce significativamente, esta tendência também ocorre ao aumentar o tempo de repouso da suspensão. A diferença com os resultados para Carbopol (Fig. 4.10) está na razão de aspecto $\mathrm{D} / \mathrm{W}$, que neste caso cai com o aumento na concentração da Laponita e com o aumento no tamanho da bolha. Para suspensões de Carbopol a razão D/W aumenta com a concentração de polímero e o tamanho da bolha. Na Fig. 4.21 em Laponita a proporção de crescimento da largura $\mathrm{W}$ da bolha é maior que o crescimento do diâmetro $\mathrm{D}$, isto causa uma queda na relação D/W. Para as duas concentrações de Laponita, o diâmetro D da bolha cresce em média 3 vezes, mas a Largura cresce em média sete (7) vezes. 


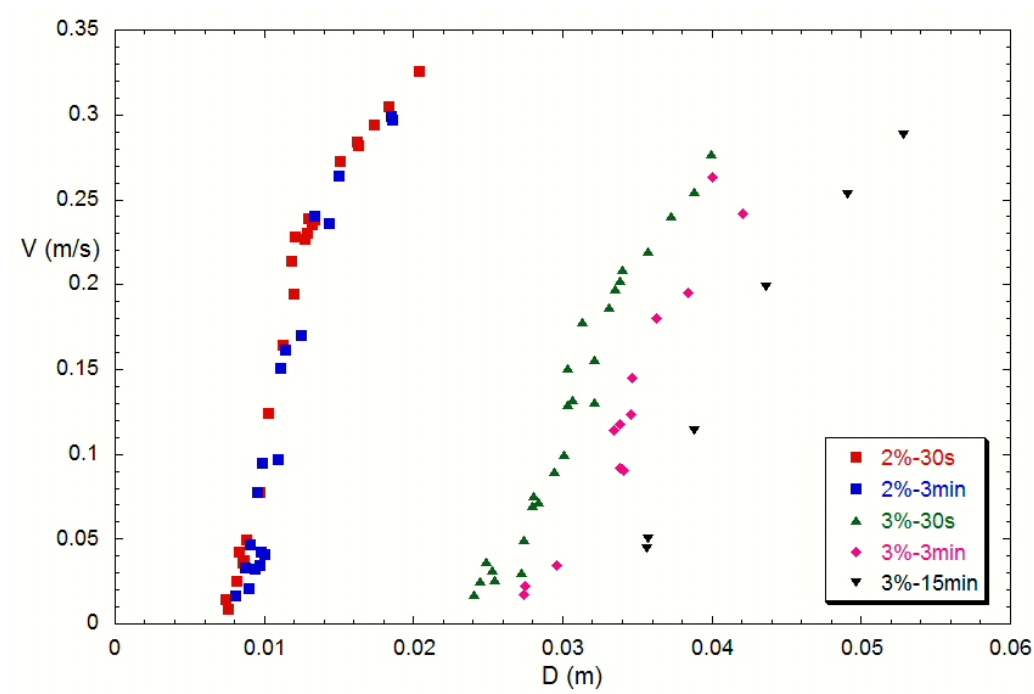

Figura 4.20: Velocidade V em função do diâmetro efetivo D em Laponita $2 \%$ ww e $3 \%$ ww. Tempos de repouso iguais a $30 \mathrm{~s}, 3$ min e $15 \mathrm{~min}$.

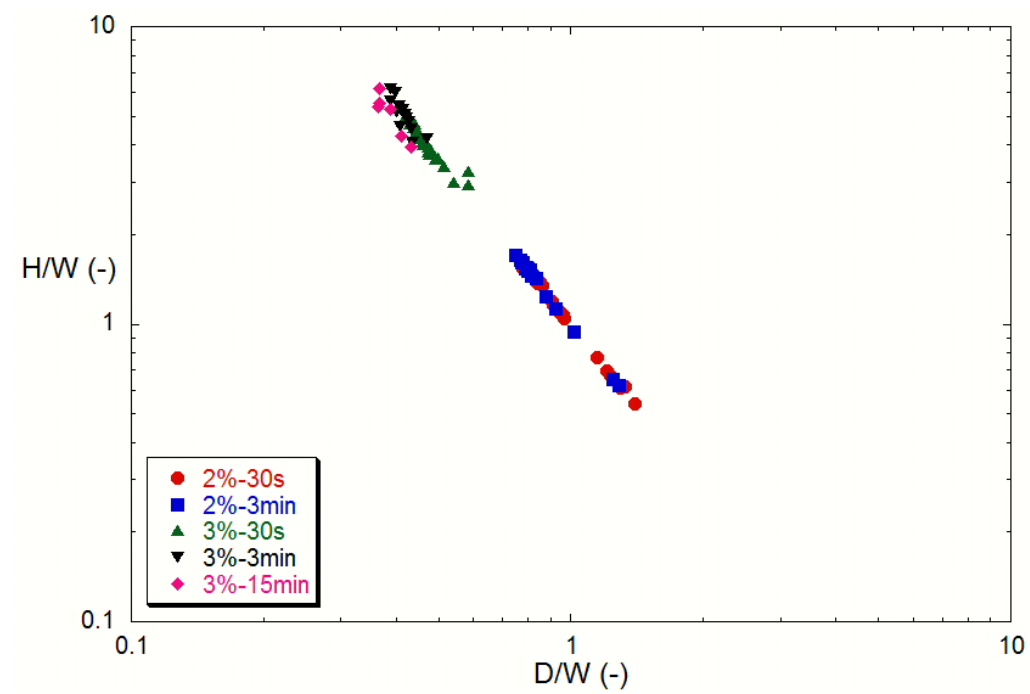

Figura 4.21: Razão de aspecto altura/largura H/W em função do diâmetro efetivo/largura D/W em Laponita $2 \%$ ww e $3 \%$ ww. Tempos de repouso iguais a $30 \mathrm{~s}, 3$ min e 15 min. 
A Fig. 4.22 mostra a razão de Altura/Largura H/W em função da relação Re/De. Nota-se que a razão de aspecto é praticamente independente de Re/De e maior do que 1 (bolhas mais alongadas) até um determinado valor, quando então começa a cair devido aos efeitos inerciais. Em Laponita $3 \%$ ww a queda é mais leve, e acredita-se que são necessárias bolhas de maior tamanho para observar uma queda mais abrupta como a ocorrida com a Laponita $2 \%$. Outra observação é que o processo de gelificação da Laponita 3\% ww eleva a curva de $\mathrm{H} / \mathrm{W}$ em função do tempo de repouso, o que está relacionado ao aumento da tensão limite $\tau_{0}$ que força uma bolha mais alongada por conta do esforço necessário para deslocar o fluido na vizinhança.

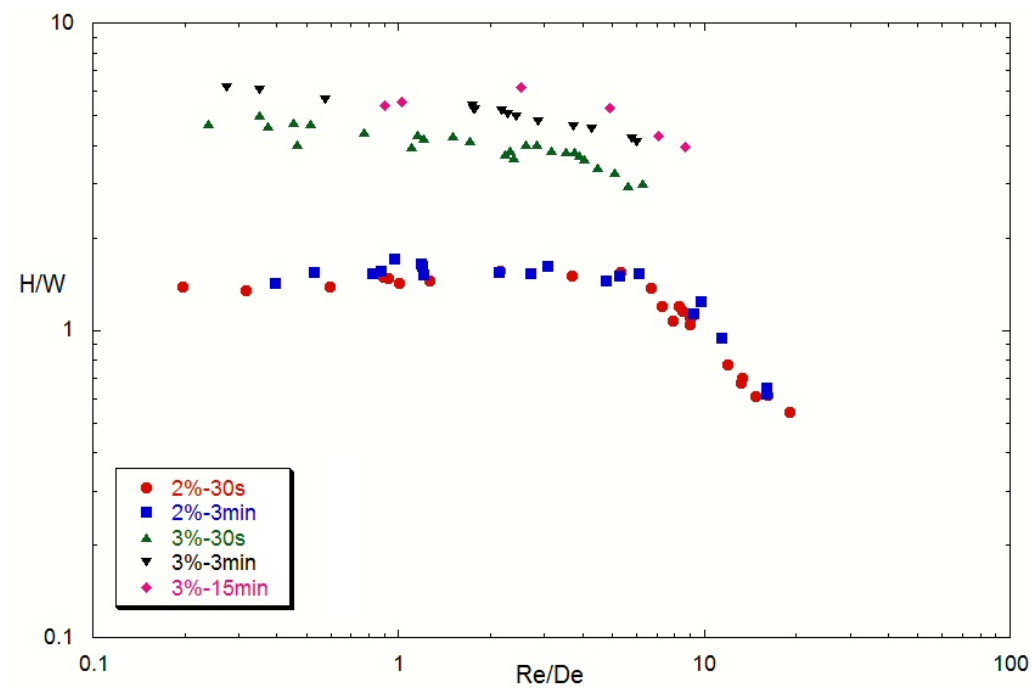

Figura 4.22: Razão de aspecto altura/largura H/W em função do número de Reynolds/número de Deborah Re/De em Laponita $2 \%$ ww e $3 \%$ ww. Tempos de repouso iguais a $30 \mathrm{~s}, 3 \mathrm{~min}$ e $15 \mathrm{~min}$.

A Fig. 4.23 mostra o coeficiente de arrasto $C_{d}$ em função do Re. Os resultados se ajustam à lei da potencia para baixos valores de $\operatorname{Re}(\operatorname{Re} \leq 5) \mathrm{e}$ para valores maiores de $\operatorname{Re}(\operatorname{Re}>5)$ a curva sofre um desvio por conta das forças inerciais que assintotizam horizontalmente a curva. Independente da concentração da Laponita ou do nível de gelificação os resultados continuam colineares.

A Fig. 4.24 mostra o coeficiente de arrasto $C_{d}$ em função da relação Re/De. Os resultados com Laponita (4.24) sao similares ao observados com Carbopol (4.14), a elasticidade do material não causa alguma alteração importante no calculo do arrasto $C_{D}$ do material. A elasticidade altera a geometria da bolha mas isto não significa que o balanco de forca muda significativamente por este fato. 


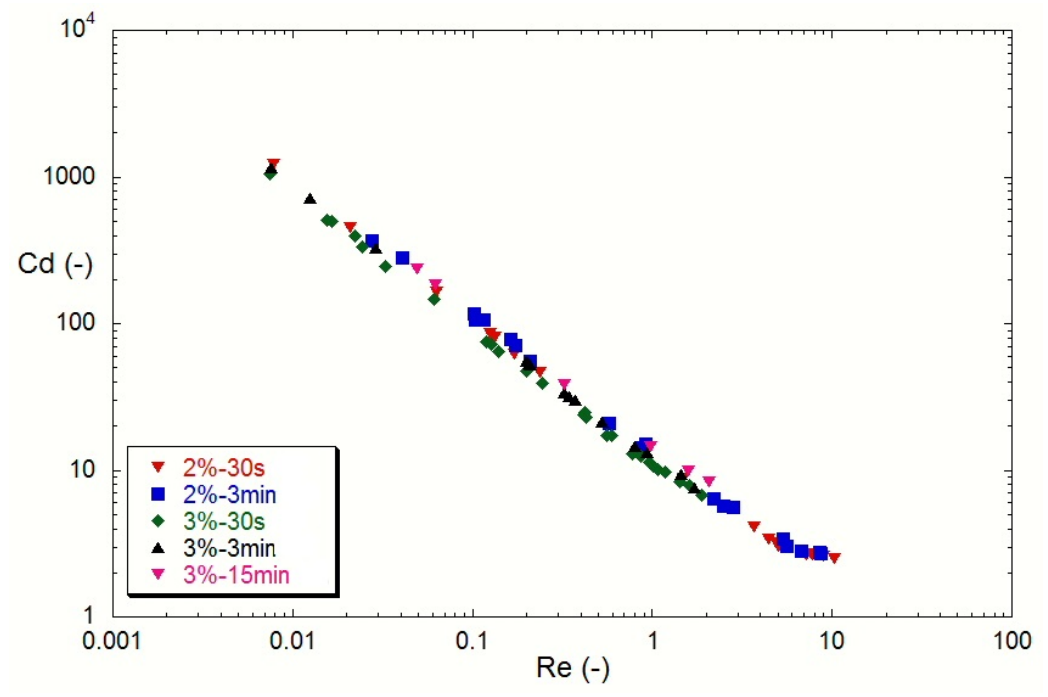

Figura 4.23: Coeficiente de arrasto $C_{d}$ em função do número de Reynolds Re em Laponita $2 \% \mathrm{ww}$ e $3 \% \mathrm{ww}$. Tempos de repouso iguais a $30 \mathrm{~s}, 3 \mathrm{~min}$ e 15 min.

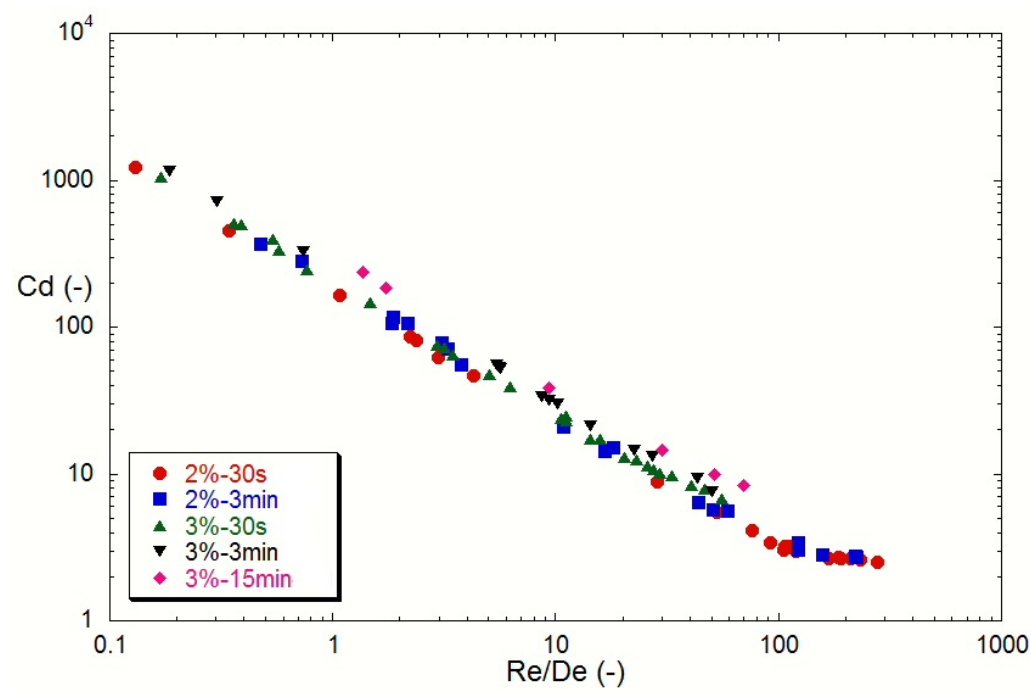

Figura 4.24: Coeficiente de arrasto $C_{d}$ em função do número de Reynolds/Numero de Deborah Re/De em Laponita $2 \%$ ww e $3 \%$ ww. Tempos de repouso iguais a $30 \mathrm{~s}, 3 \mathrm{~min}$ e $15 \mathrm{~min}$. 


\subsection{4 \\ Migração de bolhas de gás em suspensões de Laponita altamente gelifi- cada}

Esta seção irá tratar um caso de especial interesse, a injeção de bolhas de gás em materiais altamente gelificados. Quando se fala de fluido altamente gelificado está-se referindo a um material com uma tensão limite $\tau_{0}$ alta, que exige um grande esforço para ser fluidizado ou desestruturado possibilitando o deslocamento da bolha. O objetivo desta seção é entender melhor a dinâmica da bolha de gás em pastas de cimento num processo de cura avançado.

A Fig. 4.25 mostra o primeiro experimento de injeção de bolhas de gás em Carbopol 0.2\% ww com um tempo de repouso de duas (2) semanas para atingir um alto nível de gelificação. Neste trabalho estamos considerando o Carbopol não tixotrópico, mas na realidade existe sim um processo de gelificação muito lento que só é possível apreciar com no mínimo uma semana de repouso (87). Nos experimentos da Seção 4.1.2 o tempo de repouso era de no máximo 15 min, e por isto não foi observada nenhuma alteração de propriedades por conta da tixotropia. Antes do repouso, o fluido foi homogeneizado conforme o processo da Seção 3.1.1. Na Fig. 4.25 é possível observar que a bolha e a calda começam a perder simetria axial e a ficar com um formato mais plano, diferente do observado na Seção 4.1.2. Este primeiro resultado mostrou que em fluidos altamente gelificados a geometria da bolha pode mudar de forma significativa, o que pode ter consequências importantes na dinâmica da bolha.

Após estes resultados iniciais, foram feitos experimentos de injeção de bolhas de gás em Laponita $2.5 \%$ ww num alto nível de gelificação como mostra a Fig. 4.26. Este material é muito mais tixotrópico que o Carbopol e em menos tempo é possível conseguir uma suspensão bem mais gelificada ou com uma tensão limite $\tau_{0}$ muito maior. Na Fig. 4.26 é possível observar a geometria de cada bolha em função do tempo de repouso, que determina o nível de gelificação da suspensão. O tempo de repouso vai de 30 s até 192 hr (8 dias). Antes de colocar a Laponita em repouso, o fluido foi homogeneizado conforme o processo da Seção 3.1.1.

Os resultados da Fig. 4.26 para a Laponita são coerentes com os resultados da Fig. 4.25 para o Carbopol. Com o aumento do nível de gelificação, a geometria da bolha começa a perder simetria axial. A Fig. 4.26 mostra também que a geometria da bolha é cada vez mais plana com o aumento do nível de gelificação ou da tensão limite $\tau_{0}$ da suspensão. O fenômeno é mais claro após $14 \mathrm{hr}$ de repouso. Conforme a bolha se torna mais plana e fina é mais difícil observar na câmera. No último exemplo na Fig. 4.26.h a bolha é tão fina e viaja tão rápido, que a câmera tem dificuldades para capturar a bolha. Se 


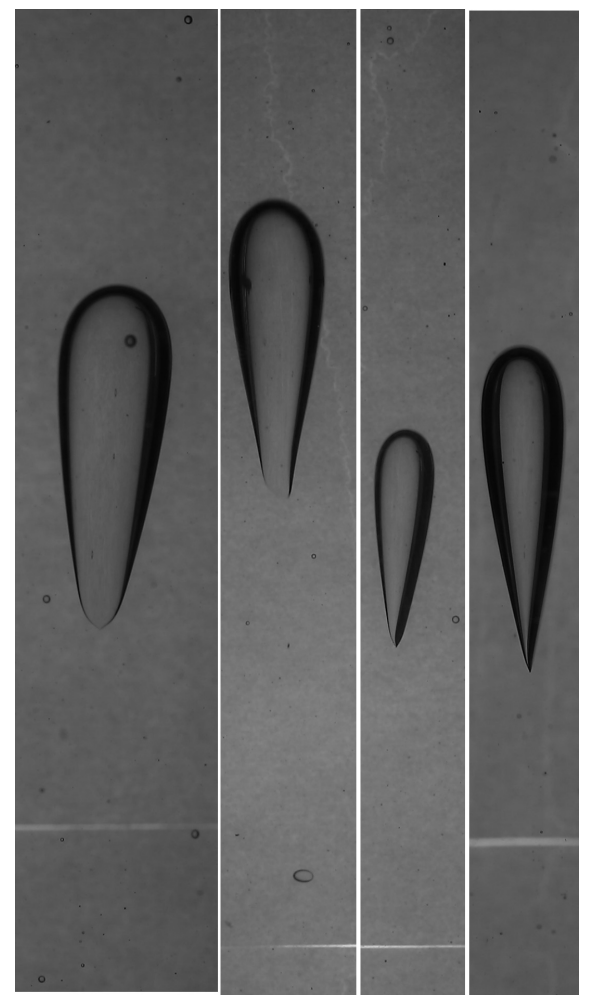

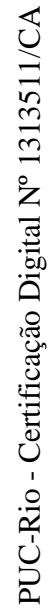

Figura 4.25: Aparência de bolhas de gás escoando em Carbopol 0.2\% ww com tempo de repouso de duas (2) semanas para aumentar a gelificação.

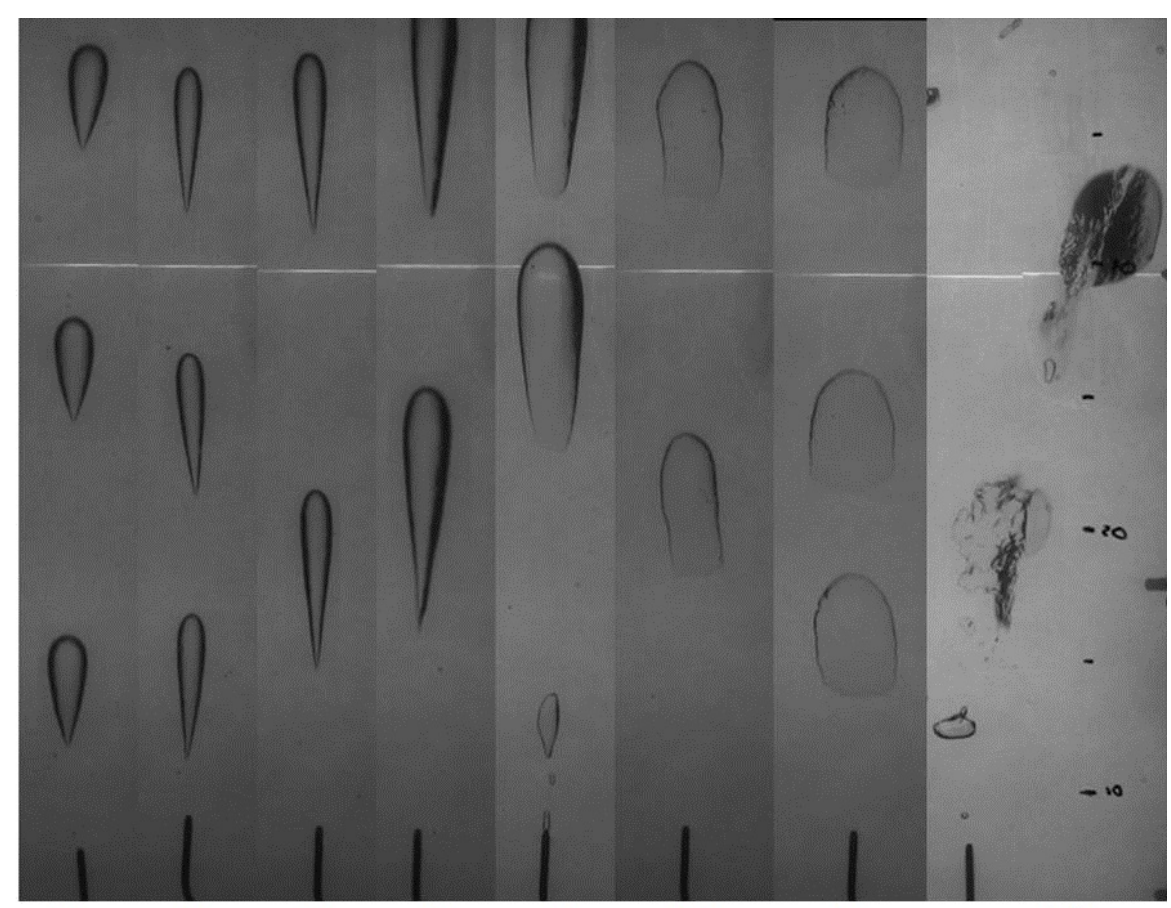

(a)

(b)

(c)

(d)

(e)

(f)

(g)

(h)

Figura 4.26: Aparência de bolhas de gás escoando em Laponita 2.5\% ww com diferentes tempos de repouso após homogeneização da suspensão. (a) $t=30$ s; (b) $\mathrm{t}=1 \mathrm{hr} ;$ (c) $\mathrm{t}=3 \mathrm{hr} ;$ (d) $\mathrm{t}=14 \mathrm{hr} ;$ (e) $\mathrm{t}=17 \mathrm{hr}$; (f) $20 \mathrm{hr}$; (g) $\mathrm{t}=94 \mathrm{hr}$; e (h) $\mathrm{t}=192 \mathrm{hr}$. 
observa qualitativamente que a bolha se torna mais rápida, mais fina e mais larga com o aumento do tempo de repouso da Laponita.

Nos experimentos mostrados na Fig. 4.27 foram injetadas bolhas de ar em Laponita 3\% ww para diferentes tempos de repouso. Além de se ter aumentado a concentração da suspensão foram usadas duas câmeras ao mesmo tempo para capturar melhor a geometria da bolha. Uma câmera frontal e outra lateral na mesma altura permitem observar em detalhe a perda da simetria axial da partícula, e a forma mais plana da bolha. Conforme o fenômeno de gelificação se torna mais visível a bolha começa a perder simetria axial e fica mais plana. Nesta figura o tempo de repouso vai desde 1 min até $17 \mathrm{hr}$. O fluido $3 \%$ ww é bem mais tixotrópico, e os efeitos são visíveis num tempo muito menor ao comparar com os resultados da Fig. 4.26. A velocidade que as bolhas atingem aumenta com o tempo de repouso ou nível de gelificação do material, devido ao maior tamanho das mesmas.

Um outro fenômeno de interesse na migração de gás em pastas de cimento na indústria de petróleo, é a formação de canais preferenciais, por onde escoa gás a uma alta vazão. Para estudar este fenômeno foi feito um estudo qualitativo de injeção de uma vazão de gás constante durante um longo período de tempo para observar a formação e evolução do canal em Laponita $3 \% \mathrm{ww}$, como mostra a Fig. 4.28. A Laponita foi homogeneizada inicialmente e colocada em repouso por um dia para atingir um alto nível de gelificação. Neste instante começou a injeção de gás. Para este experimento foi instalada uma linha de gás pressurizado que injetou gás de forma ininterrupta. A pressão de injeção foi alterada em função da evolução dos resultados na bancada. A pressão mínima usada foi de 45 mbar e aumentou a quase 200 mbar nas vazões maiores.

Na Fig. 4.28.a foi injetado gás a baixa pressão (45 mBar) para conseguir uma primeira bolha e observar a formação do caminho preferencial, esta bolha tem geometria plana e irá definir o trajeto do gás durante todo o experimento. Na Fig. 4.28.b se injeta a segunda bolha, que começa menos larga e aparentemente com tamanho menor. Considera-se que a redução no tamanho é causada pela fluidização da Laponita que favorece a separação da bolha em menor tempo e portanto com menor tamanho. Na Fig. 4.28.c a bolha fica ainda mais longa, e se deslocar pelo caminho preferencial com menor esforço, esta tendência continua até formar um canal continuo como na Fig. 4.28.d, onde se forma completamente um caminho preferencial sem nenhuma mudança de trajetória ou tamanho no tempo. Na Fig. 4.28.e aumentou-se a pressão de injeção causando um aumento na vazão, e a formação de bolhas de gás mais alongadas que conservam a geometria plana. $\mathrm{O}$ caminho preferencial continuou 


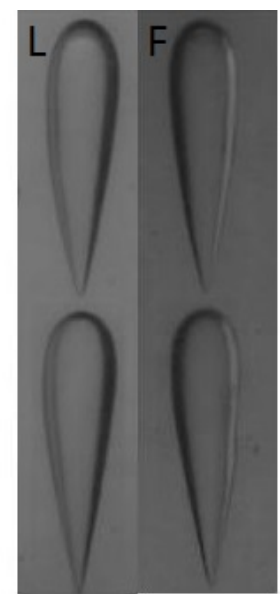

(a)

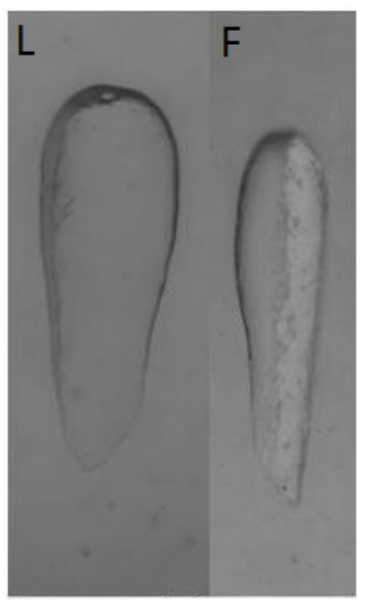

(d)

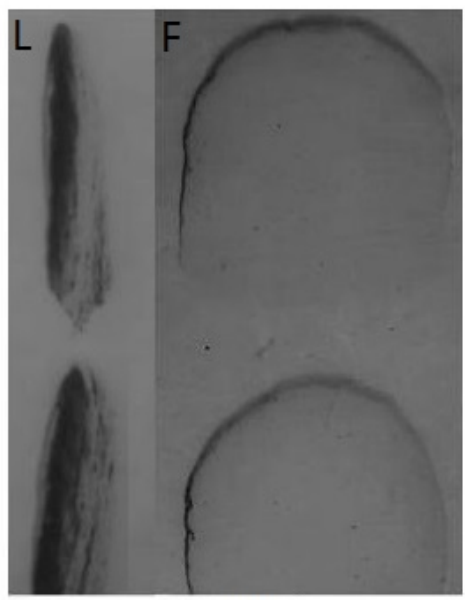

(f)

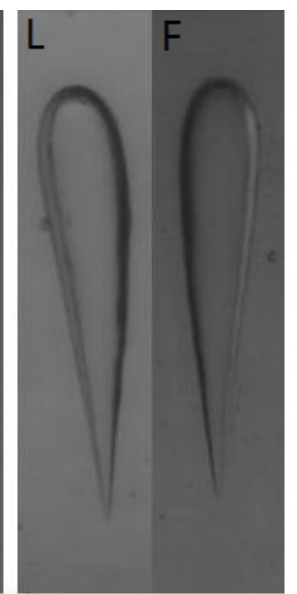

(b)

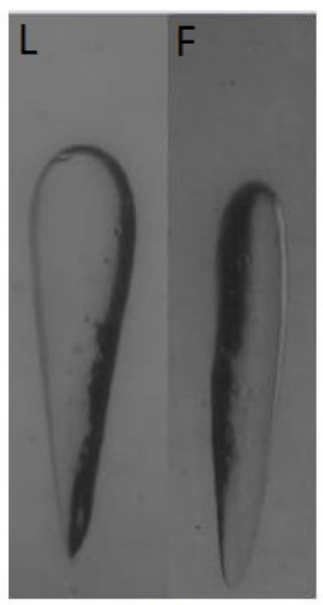

(c)

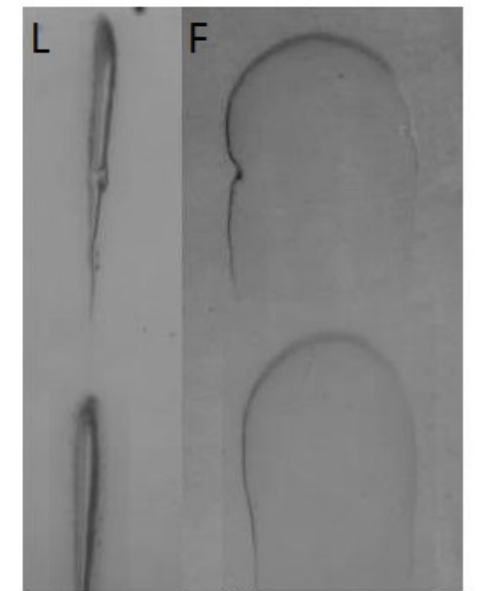

(e)

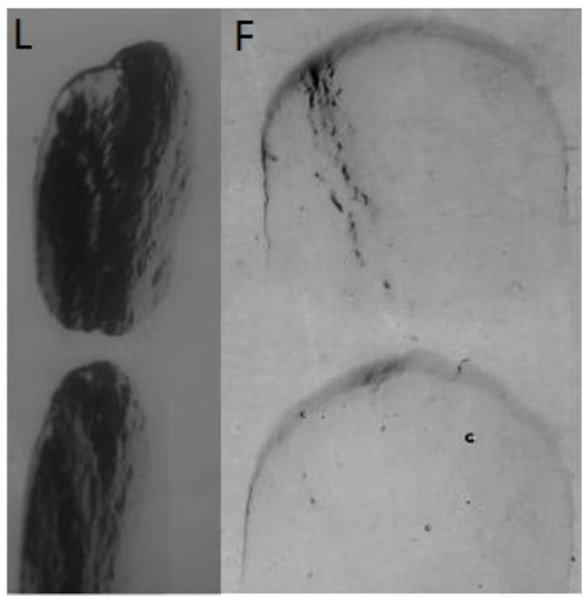

(g)

Figura 4.27: Aparência de bolhas de gás escoando em Laponita 3\% ww com diferentes tempos de gelificação após homogeneização da suspensão. (a) $\mathrm{t}=1 \mathrm{~min} ;$ (b) $\mathrm{t}=1 \mathrm{hr} ;$ (c) $\mathrm{t}=2 \mathrm{hr}$; (d) $\mathrm{t}=3 \mathrm{hr}$; (e) $\mathrm{t}=6 \mathrm{hr}$; (f) $\mathrm{t}=13 \mathrm{hr} ; \mathrm{e}$ (g) $\mathrm{t}=17 \mathrm{hr}$. $\mathrm{L}=$ Vista lateral; $\mathrm{F}=$ Vista frontal. 


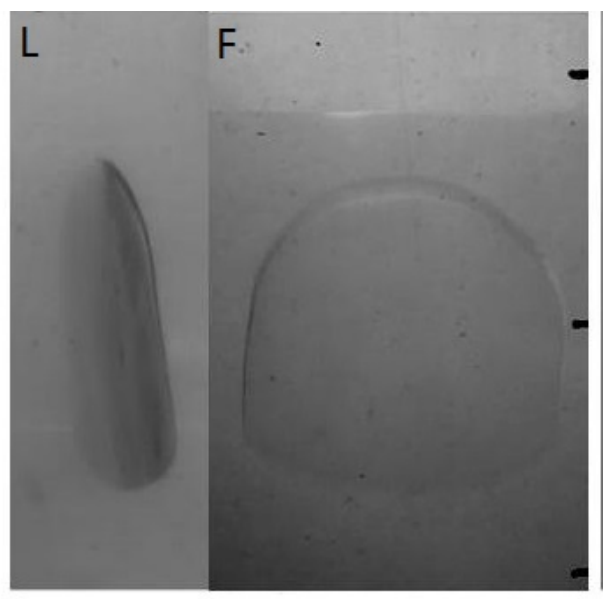

(a)

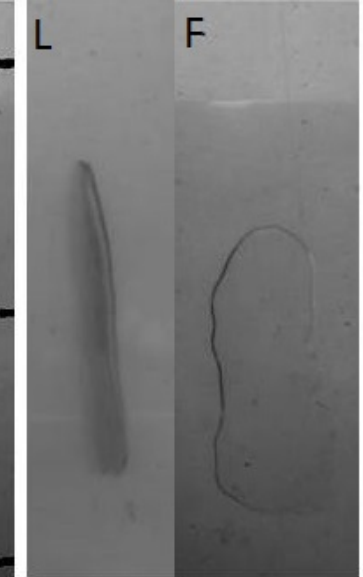

(b)

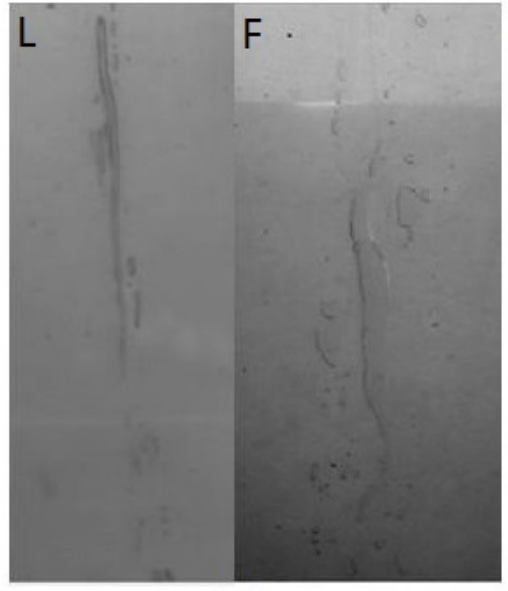

(c)

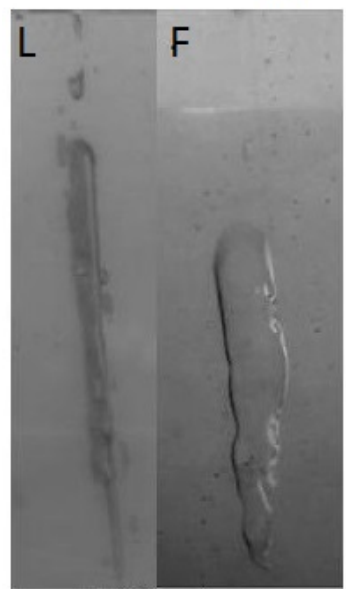

(e)

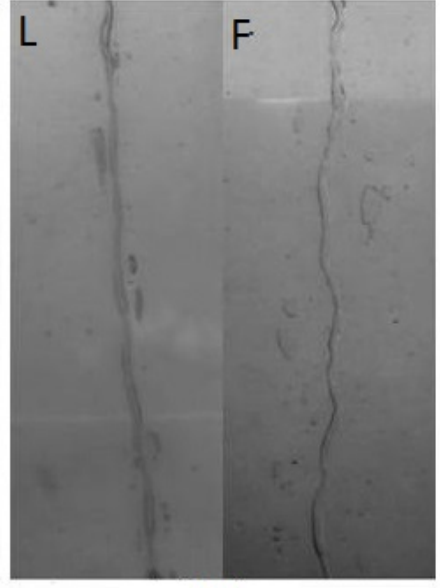

(d)

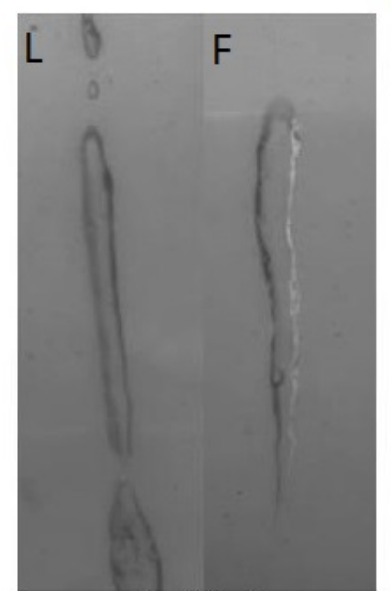

(f)

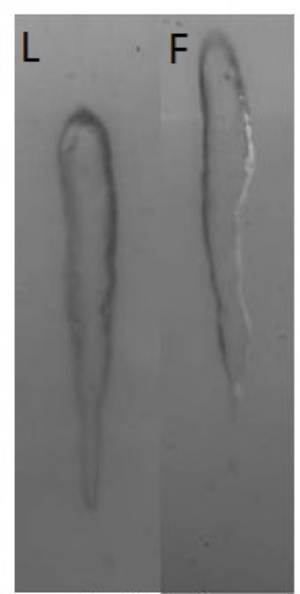

(g)

Figura 4.28: Mecanismo de formação de canais de escoamento de gás para fontes pressurizadas em Laponita $3 \% \mathrm{ww}$. (a) $\mathrm{t}=0 \mathrm{~s}$; (b) $\mathrm{t}=15 \mathrm{~s}$; (c) $\mathrm{t}=3 \mathrm{~min}$; (d) $\mathrm{t}=6 \mathrm{~min} ;(\mathrm{e}) \mathrm{t}=10 \mathrm{~min} ;(\mathrm{f}) \mathrm{t}=13 \mathrm{~min} ; \mathrm{e}(\mathrm{g}) \mathrm{t}=15 \mathrm{~min}$. $\mathrm{L}=$ Vista lateral; $\mathrm{F}=$ Vista frontal 
sendo o mesmo, mas com escoamento de bolhas separadas ao contrário do canal continuo estático da Fig. 4.28.d. Nas Figs. 4.28.f e 4.28.g as bolhas começam a ficar mais longas e axi-simétricas devido à fluidização na vizinhança do caminho preferencial. Estes experimentos mostram como uma primeira bolha plana forma o caminho preferencial para as bolhas seguintes. Assim, com a entrada contínua de gás, as bolhas começam a ficar mais longas até formar um canal preferencial com simetria axial por onde irá escoar gás com baixa resistência e alta vazão.

A Fig. 4.29 mostra um outro experimento de injeção de gás em Laponita $3 \%$ ww, usando uma fonte contínua de gás pressurizado. O tempo de repouso foi de um (1) dia após homogeneização. Na Fig. 4.29.a observa-se a primeira bolha plana que forma um caminho preferencial não-retilíneo. Na Fig. 4.29.b nota-se um escoamento mais contínuo e plano, devido à maior fluidização na vizinhança. Na Fig. 4.29.c observa-se as "bolhas"extremamente alongadas escoando pelo caminho preferencial.

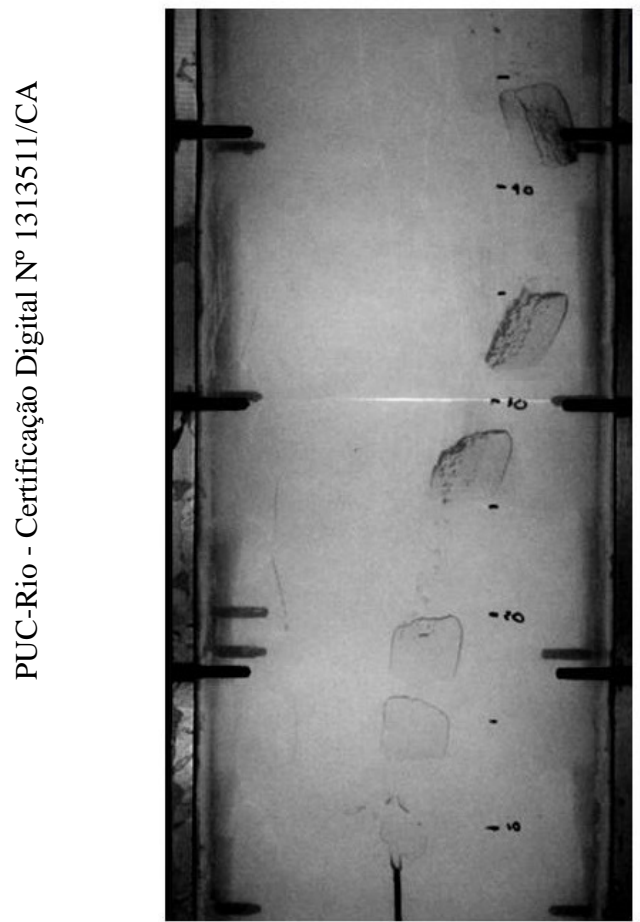

(a)

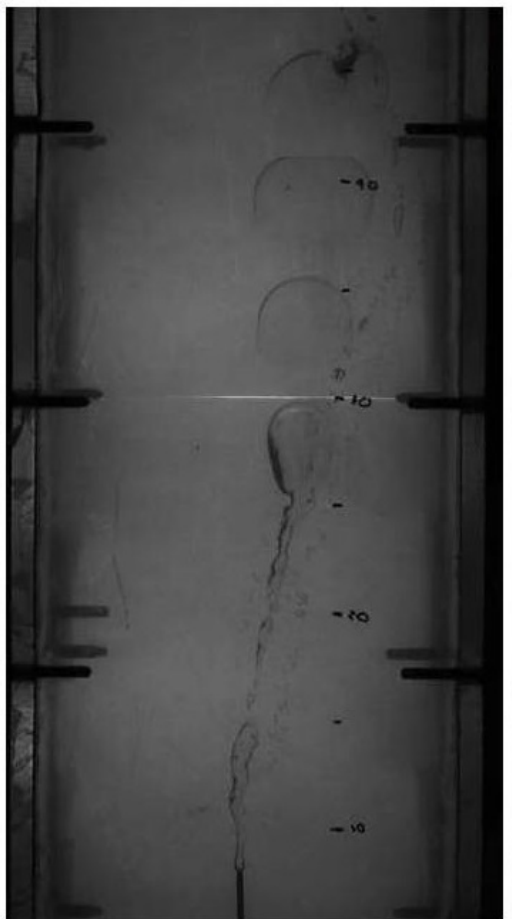

(b)

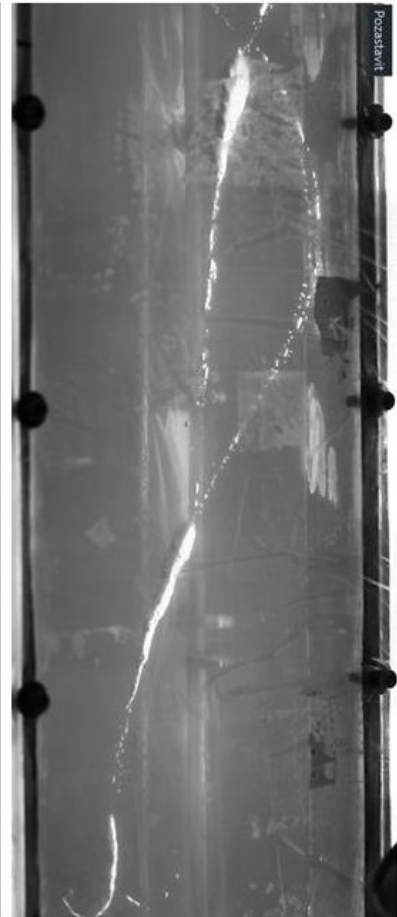

(c)

Figura 4.29: Mecanismo de formação de canais de escoamento de gás para fontes pressurizadas em Laponita 3\% ww. (a) Primeiro caminho preferencial formado; (b) Segundo caminho preferencial formado; e (c) Canais formado após vazão continua de fonte pressurizada.

A injeção de gás em fluidos altamente gelificados começa com uma bolha plana muito fina que reduz de forma importante a resistência do fluido. Desta 
forma é possível criar o caminho preferencial por onde o gás irá escoar, mesmo em suspensões com tensão limite $\tau_{0}$ muito alta. Pode-se explicar o fenômeno da seguinte forma. Uma bolha plana tem uma área transversal $A_{f}$ bem menor, e em consequência o fluido deslocado diminui fortemente, o que faz com que a inercia do fluido deslocado seja desprezível mesmo com Re altos ou regime laminar. Fluidos como a Laponita tem elasticidade desprezível. Observa-se também que apenas uma fina camada ao redor da bolha é desestruturada. Assim, só a tensão viscosa de uma fina camada de fluido ao redor da bolha causa resistência ao avanço da partícula. Estas hipóteses explicam porque as bolhas se tornam mais planas e mais rápidas em função do nível de gelificação da Laponita. Nos casos em que continua sendo injetado gás, que escoa no mesmo caminho preferencial, o fluido ao redor vai ser fluidizado lentamente e em consequência formam-se bolhas cada vez mais alongadas, até formar canais de escoamento de gás com alta vazão. 


\section{5}

\section{Modelamento Matemático}

Neste capitulo apresenta-se um modelamento matemático para prever o escoamento de bolhas de gás em fluidos com baixo nível de gelificação, onde existe simetria axial da partícula. Este modelo pode ser aplicado em regime de escoamento Stokes e laminar. Uma versão inicial do modelo matemático começou a ser desenvolvido por Lopez (75) para regime Stokes. No presente trabalho o modelo foi aprimorado para regime laminar e em novas condições reológicas.

A análise é feita considerando uma bolha sob o efeito de forças de empuxo e viscosas, conforme a Fig. 5.1. A taxa de cisalhamento característica é definida como mostra a Eq. 5-1.

$$
\dot{\gamma}=\frac{V}{D}
$$

Onde $\mathrm{V}$ é a velocidade da partícula e D é o diâmetro efetivo da partícula.

A Eq. 5-2 define a área frontal ou área transversal a montante da bolha de gás.

$$
A_{f}=\pi R^{2}
$$

Onde $R=D / 2$ é o raio efetivo da partícula.

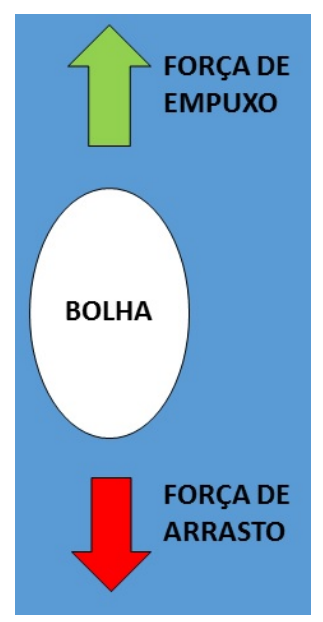

Figura 5.1: Balanço de forças de uma bolha de gás escoando num fluido. Considera-se a Força de empuxo $F_{b}$ e Força de arrasto $F_{D}$ 
O balanço de forças feito na partícula inclui a Força de empuxo $F_{b}$ e Força de arrasto $F_{d}$. A Força de empuxo $F_{b}$ é causada pela diferencia de densidade entre a partícula e o fluido ao redor e a Força de arrasto $F_{d}$ agrupa as forças que causam resistência ao escoamento da partícula. A Fig. 5.2 mostra a região fluidizada ou cisalhada (yielded region) ao redor da partícula gasosa, esta região é a responsável pelo atrito viscoso na bolha. A região mais externa é a região elástica (unyielded region), esta região é só deformada sem ser fluidizada ou quebrar a microestrutura do material, esta força elástica também deve ser considerada. A última força incluída é a inercial do fluido deslocado pela bolha que causa um aumento de pressão na parte superior da bolha. Estas forças não podem ser isoladas e por esta razão são incluídas num único termo da Eq. 5-5.

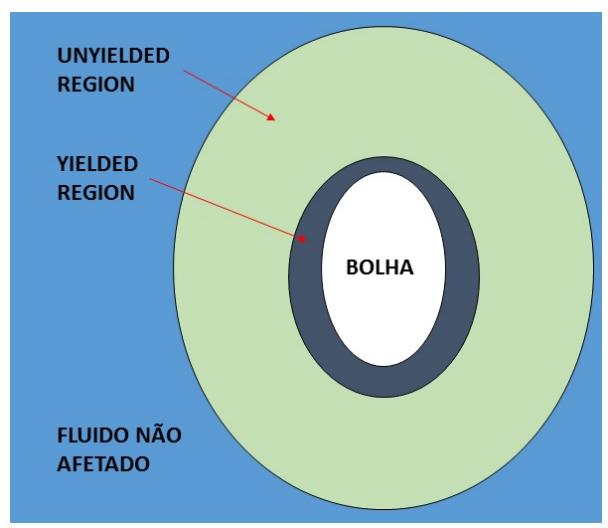

Figura 5.2: Regiões de fluido afetado ao redor da bolha escoando.

Para a condição terminal de velocidade constante,

$$
F_{b}-F_{d}=0
$$

A forca de empuxo é definida pela equação 5-4

$$
F_{b}=g \forall \rho=g \pi D^{3} \frac{\rho}{6}
$$

Onde $\mathrm{D}$ é o diâmetro efetivo da partícula, g a gravidade, $\forall$ é o volume da partícula e $\rho$ é a densidade do fluido ao redor da partícula. Esta equação foi desenvolvida para bolhas de gás e por isso a densidade do gás $\rho_{c}$ foi desprezada.

A força de arrasto $F_{d}$ é escrita em função do coeficiente de arrasto na Eq. 5-5. O arrasto é a resultante das forças viscosas, elásticas e inerciais que dificultam o escoamento da bolha.

$$
F_{d}=\frac{1}{2} \rho V^{2} A_{f} C_{D}
$$

Onde $\mathrm{V}$ é a velocidade da bolha, $A_{f}$ é a área transversal ou a montante da bolha e $C_{d}$ é o coeficiente de arrasto da bolha, determinado a partir dos resultados experimentais. 
O coeficiente de arrasto $C_{d}$ foi obtido experimentalmente em função do Re, e a Eq. 5-6 vem de um ajuste de curvas aos dados experimentais. A equação possui três (3) parâmetros de ajuste $C_{1}, C_{2}$ e $C_{3}$ para a utilização em diferentes condições reológicas e numa ampla faixa de Re. O primeiro termo da equação está relacionado com as forças em regime de Stokes,onde o arrasto viscoso é dominante e as forças inerciais e elásticas são desprezíveis. O segundo termo da equação está relacionado com o regime laminar, onde as forças inerciais e elásticas são dominantes e o arrasto viscoso é desprezível. A expressão para $C_{d}$ é dada por

$$
C_{d} \equiv \frac{24 C_{1}}{R e}\left(1+C_{2} R e^{C_{3}}\right)
$$

Onde $C_{1}$ é um parâmetro que ajusta a condição de deslizamento na superfície da bolha, este parâmetro ajusta a relação entre a superfície e o arrasto viscoso causado pela camada em contato com a bolha (yielded region), para o caso de uma bolha de gás esférica o valor de $C_{1}$ é próximo a 2/3. Os parâmetros $C_{2}$ e $C_{3}$ permitem ajustar a influência das forças de inércia e elásticas na bolha. $C_{2}$ e $C_{3}$ controlam o crescimento do segundo termo em regime laminar.

Da Eqs. 5-3, 5-4, 5-5 e 5-6 obtém-se uma equação que descreve a dinâmica da bolha de gás em regime Stokes e laminar para reologia Newtoniana ou viscoplástica:

$$
g \pi D^{3} \frac{\rho}{6}-\frac{1}{2} A_{f} \rho V^{2}\left[\frac{24 C_{1}}{R e}\left(1+C_{2} R e^{C_{3}}\right)\right]=0
$$

Existe um tamanho mínimo de bolha para que a força de empuxo $F_{b}$ supere a tensão limite $\tau_{0}$ do material levando ao escoamento da bolha no fluido. Para calcular esse tamanho foi usada a condição de velocidade zero da bolha $(\mathrm{V}=0)$, quando a bolha está no limite para começar a escoar. Assim,

$$
D_{c}=\frac{18 C_{1} \tau_{0}}{g \rho}
$$

A Fig. 5.3 mostra os resultados do ajuste dos parâmetros $C_{1}, C_{2}$ e $C_{3}$ da Eq. 5-7. Os parâmetros foram ajustados usando a rotina em Matlab da Seção B.2, e os resultados experimentais de Velocidade e Diâmetro efetivo da bolha de ar em Carbopol, apresentados na Fig. 4.8, além dos valores obtidos na caracterização reológica do Carbopol da Tabela 3.1. O ajuste matemático foi feito para as cinco (5) concentrações diferentes de polímero.

A Fig. 5.3 mostra a velocidade terminal da bolha obtida pelo modelo teórico apresentado na Eq. 5-7, em função do diâmetro efetivo. Os cálculos concordam com os resultados experimentais na faixa de diâmetros dos experimentos, e esta faixa é estendida para maiores valores de diâmetros. O modelo 


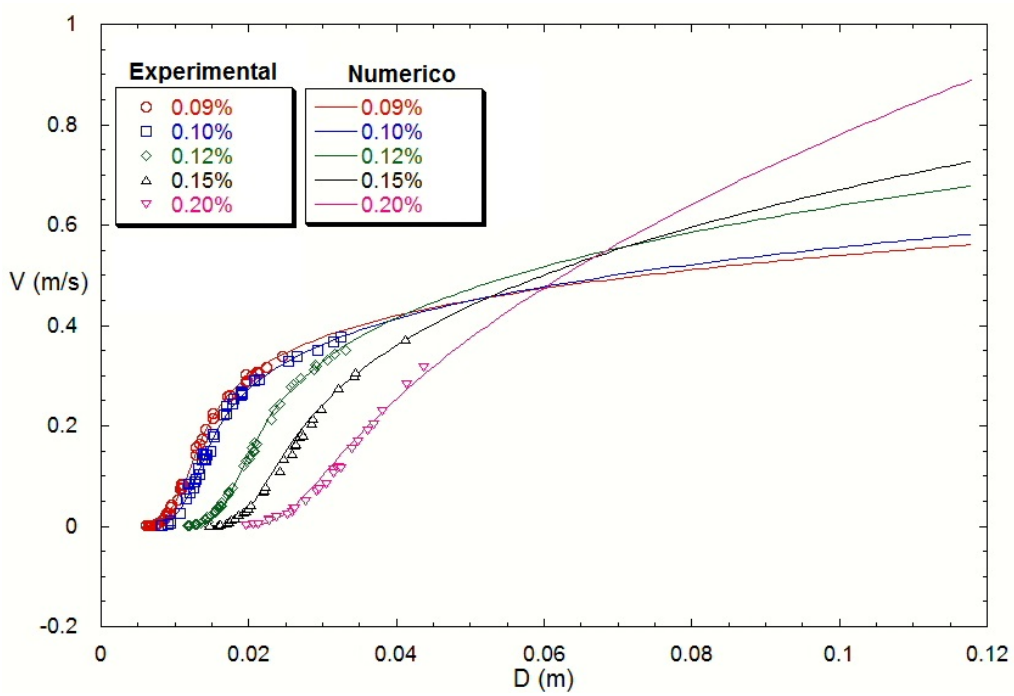

Figura 5.3: Modelo matemático ajustado (Eq. 5-7) em Carbopol 0.09\% ww, $0.10 \%$ ww $0.12 \%$ ww, $0.15 \%$ ww e $0.20 \%$ ww.

prevê velocidades maiores em suspensões mais concentradas na faixa de maiores diâmetros, inverso ao que ocorre na faixa de diâmetros menores.

Os valores dos parâmetros de ajuste $C_{1}, C_{2}, C_{3}$ e do diâmetro crítico $D_{c}$ se apresentam na Tabela 5.3.

Tabela 5.1: Parâmetros de ajuste do modelo matemático em Carbopol 980.

\begin{tabular}{|c|c|c|c|c|c|}
\hline Parametro & $0.09 \%$ & $0.10 \%$ & $0.12 \%$ & $0.15 \%$ & $0.20 \%$ \\
\hline$C_{1}[-]$ & 0.85 & 0.75 & 0.54 & 0.45 & 0.375 \\
\hline$C_{2}[-]$ & 0.0045 & 0.01 & 0.032 & 0.09 & 0.21 \\
\hline$C_{3}[-]$ & 2 & 1.85 & 1.6 & 1.3 & 0.9 \\
\hline$D_{c}[\mathrm{~m}]$ & 0.0047 & 0.0063 & 0.0114 & 0.0136 & 0.0196 \\
\hline
\end{tabular}

Ao analisar a Tabela 5.1 se observa uma clara tendência nos parâmetros $C_{1}, C_{2}, C_{3}$ e $D_{c}$ em função da concentração do Carbopol. A Fig. 5.4 mostra a tendência do parâmetro $C_{1}$, que cai com o aumento da concentração de polímero. A curva de tendência escolhida é polinomial, mas podem ser usadas outras curvas para fazer o ajuste.

A Fig. 5.5 mostra a tendência ascendente do parâmetro $C_{2}$ em função da concentração de Carbopol, usamos uma curva de tendência polinomial mas também poderia ser linear.

A Fig. 5.6 mostra a tendência descendente do parâmetro $C_{3}$ em função da concentração de Carbopol, usamos uma curva de tendência linear.

O modelo de dinâmica de bolhas de gás escoando em materiais viscoplásticos da Eq. 5-7 foi usado em suspensões de Carbopol, mas existem algumas dificuldades para usar em Laponita. O modelo de dinâmica da bolha (Eq. 5-7) 


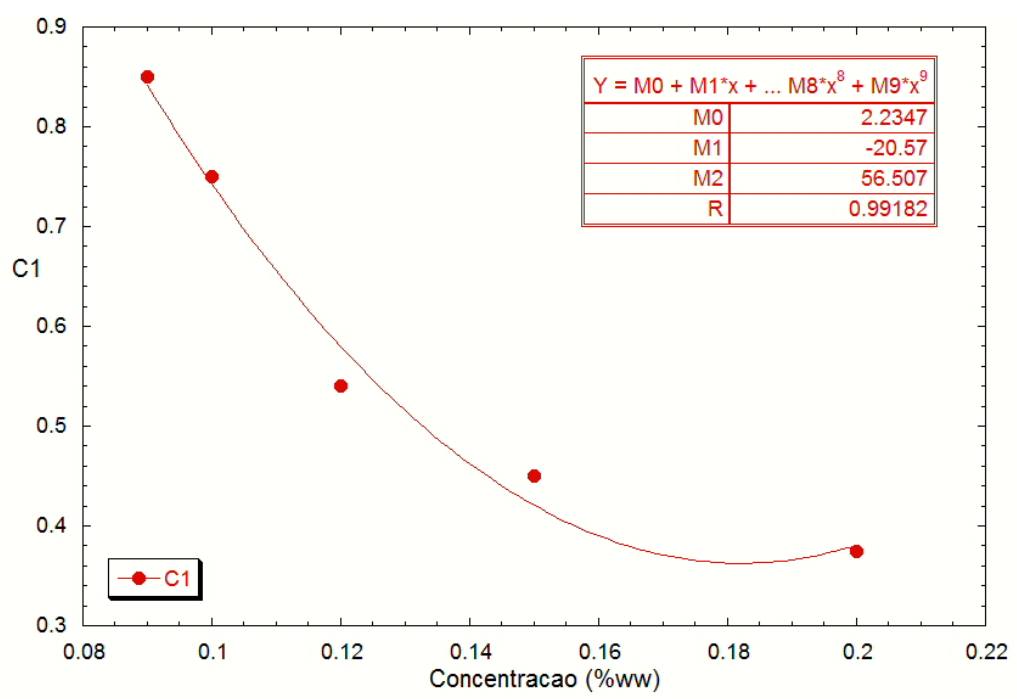

Figura 5.4: Ajuste do parâmetro $C_{1}$ do modelo matemático proposto (Eq. 5-7) em Carbopol 0.09\% ww, $0.10 \%$ ww, $0.12 \%$ ww, $0.15 \%$ ww e $0.20 \%$ ww.

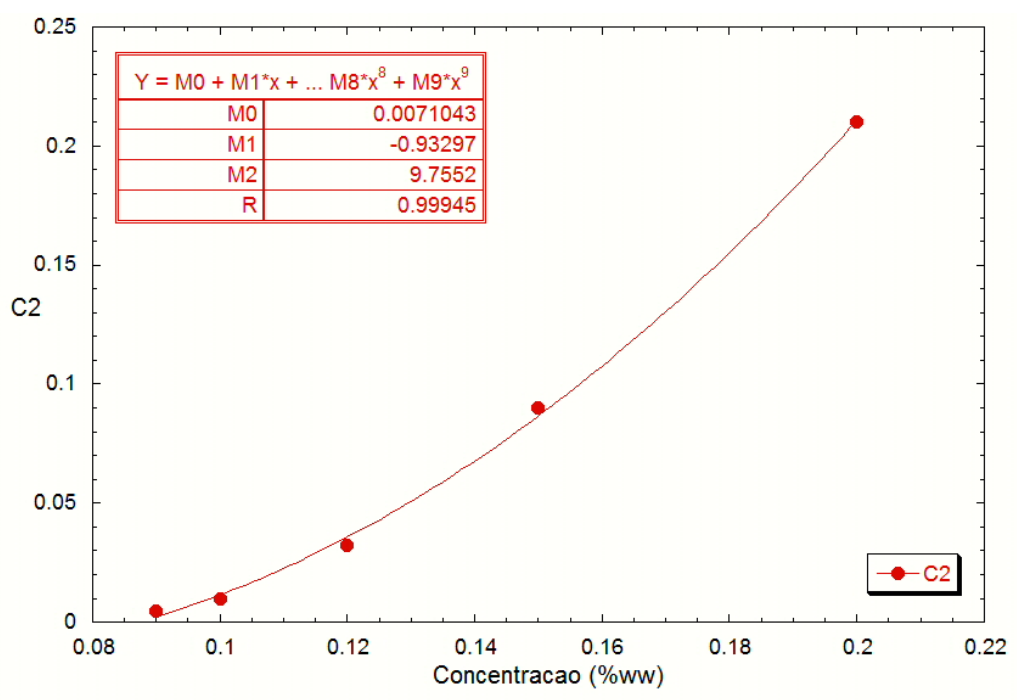

Figura 5.5: Ajuste do parâmetro $C_{2}$ do modelo matemático proposto (Eq. 5-7) em Carbopol 0.09\% ww, 0.10\% ww, $0.12 \%$ ww, $0.15 \%$ ww e $0.20 \%$ ww 


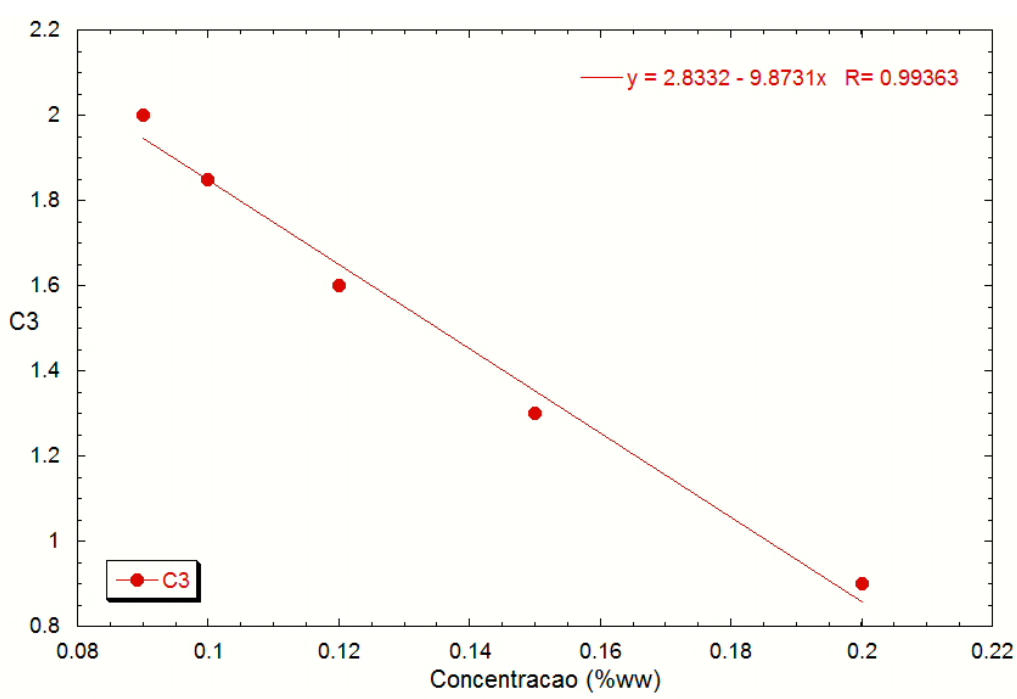

Figura 5.6: Ajuste do parâmetro $C_{3}$ do modelo matemático proposto (Eq. 5-7) em Carbopol 0.09\% ww, 0.10\% ww, 0.12\% ww, 0.15\% ww e 0.20\% ww

é função do Re e em consequência da reologia do material. No caso da Laponita o processo de caracterização reológica da Seção 3.2.4 sofre com alguns fenômenos que devem ser analisados. A Flowcurve da Fig. 3.29 aparentemente tem problemas de Shear banding, como consequência a tensão de cisalhamento $\tau$ é constante para a faixa de taxa de cisalhamento $\dot{\gamma}$ das bolhas injetadas em Laponita. Este fenômeno não permite que o modelo se ajuste adequadamente aos resultados experimentais em Laponita de velocidade em função do diâmetro da Fig. 4.20. É necessário modificar o método de caracterização do fluido para conseguir um ajuste adequado, ou a obtenção de resultados em faixas de taxas de cisalhamento maiores. Ao comparar os resultados experimentais de injeção de bolhas em Carbopol da Fig. 4.8 com os resultados em Laponita da Fig. 4.20 se observa uma tendência análoga, por isso pensamos que o processo de caracterização da Laponita deve ser melhorado para conseguir um melhor ajuste.

As Fig. 5.4, Fig. 5.5 e Fig. 5.6 podem ser expressadas em função dos parâmetros do modelo reológico Herschel-Bulkley (Eq. 3-6) usado para caracterizar os materiais. Os parâmetros reologicos do Carbopol (K, n, $\tau_{0}$, G' e G") estão consignados na Tabela 3.1 e mostram uma boa correlação com todos os parâmetros de Ajuste do modelo matemático $\left(C_{1}, C_{2}\right.$ e $\left.C_{3}\right)$ exceto o índice Power-Law n que aparentemente é constante. 


\section{6 \\ Conclusões}

Neste trabalho estudamos experimentalmente o escoamento vertical de bolhas de ar através de soluções de Carbopol e de Laponita. O Carbopol possui um comportamento mecânico elasto-viscoplástico, enquanto a Laponita tem comportamento tixotrópico. Investigou-se a influência da tensão limite de escoamento, inércia, empuxo, elasticidade e tixotropia no formato de bolha e na sua dinâmica de escoamento. É difícil isolar os efeitos de contribuições diferentes, já que todos os parâmetros dependem do diâmetro da bolha, mas foi possível identificar algumas tendências. Os resultados mostram que a tensão limite de escoamento define o diâmetro crítico para o início do movimento da bolha. Quando a bolha se movimenta, a velocidade atinge um valor terminal constante. Analisando o escoamento de diferentes bolhas, notase que a velocidade da bolha aumenta mais rapidamente até um certo diâmetro, quando a inércia começa a dominar, fazendo com que o formato das bolhas seja mais achatado, e tornando o aumento de velocidade mais suave. Os efeitos elásticos no Carbopol mudam claramente o formato da bolha para uma bolha com cauda e forma cúspida. Quando a inércia é predominante, a cabeça da bolha é mais arredondada, e a bolha tem formato mais achatado, com menores razões de aspecto. A razão entre os números de Reynolds e Deborah parece descrever bem a competição entre inércia e elasticidade.

O efeito tixotrópico da Laponita na dinâmica e geometria das bolhas de gás foi também analisado. O tempo de repouso do fluido aumenta o seu nível de estruturação e altera as suas propriedades reológicas. Para baixos tempos de repouso, a gelificação é baixa e a bolha conserva a geometria axi-simétrica, com a tendência das curvas de comportamento similares aos resultados obtidos com o Carbopol. Quando a suspensão tixotrópica de Laponita atinge um alto nível de gelificação (maior tempo de repouso), a tensão limite $\tau_{0}$ é alta o suficiente para impedir a fluidização da suspensão por parte da bolha de gás, este fenômeno força a bolha de gás a se deslocar com uma geometria plana ou de "pá" reduzindo bruscamente o arrasto da bolha e permitindo seu deslocamento mesmo em altos níveis de gelificação.

Os experimentos também mostraram a formação de caminhos preferenciais para o escoamento das bolhas, causados pelo histórico de cisalhamento no 
material. Regiões previamente cisalhadas são menos estruturadas e favorecem o escoamento das bolhas.

Foi também desenvolvido um modelo matemático simplificado para a previsão da velocidade terminal de bolhas de gás com simetria axial em fluidos viscoplásticos, usando os valores experimentais de coeficiente de arrasto. Obteve-se um bom ajuste aos dados experimentais e os resultados foram estendidos para maiores faixas de diâmetros de bolha. Porém, não se conseguiu um bom ajuste para as suspensões de Laponita pois as faixas de cisalhamento estavam em regiões de difícil caracterização reológica, onde verificou-se a possível presença do fenômeno de shear banding.

O trabalho com suspensões poliméricas de Carbopol e de argila de Laponita com propriedades viscoplásticas, elásticas e tixotrópicas mostraram aportes significativos no estudo de migração de gás em fluidos estruturados. Estes resultados podem ser utilizados no estudo da migração de gás em pastas de cimento heterogêneas num estado avançado de cura. Novos resultados podem ser conduzidos a fim de aumentar a compreensão do fenômeno e melhorar o controle dos efeitos negativos da invasão e migração de gás durante a cimentação de poços de petróleo.

\section{1}

\section{Trabalhos futuros}

As propriedades tixotrópicas e viscoplásticas das suspensões de Laponita representam um desafio na caracterização reológica. Propõe-se continuar trabalhando na caracterização para conseguir resultados que possam ser utilizados na modelagem matemática de escoamento de bolhas de gás em Laponita. Recomenda-se reduzir o GAP na geometria de placas paralelas e usar uma superfície com ranhuras menores ou até uma superfície áspera, acredita-se que as ranhuras profundas da geometria podem favorecer a presença de shear banding durante a caracterização.

Neste trabalho foi apresentado um primeiro estudo qualitativo ao escoamento de bolhas de gás em materiais altamente gelificados. Este fenômeno pode oferecer respostas importantes no fenômeno de migração de gás em pastas de cimento num avançado estado de cura, por isto se recomenda continuar o trabalho com um estudo mais quantitativo. Um trabalho de modelamento matemático de bolhas de gás planas escoando em materiais altamente gelificados e um trabalho experimental para validar o modelo poderia aportar muito na compreensão do fenômeno. Experimentos com concentrações maiores de Carbopol podem permitir resultados rápidos em suspensões altamente gelificadas sem precisar longos tempos de repouso como no caso da Laponita. 


\section{Referências bibliográficas}

[1] Kendoush, A. A.; SUlaymon, A. H. ; MOHAMmed, S. A.. Experimental evaluation of the virtual mass of two solid spheres accelerating in fluids. Experimental Thermal and Fluid Science, 31(7):813-823, jul 2007.

[2] KULKARNI, A. A.; JOSHI, J. B.. Bubble formation and bubble rise velocity in gas-liquid systems: a review. Industrial \& Engineering Chemistry Research, 44(16):5873-5931, aug 2005.

[3] SMOLIANSKI, A.; HAARIO, H. ; LUUKKA, P.. Numerical study of dynamics of single bubbles and bubble swarms. Applied Mathematical Modelling, 32(5):641-659, may 2008.

[4] BOZZANO, G.; DENTE, M.. Shape and terminal velocity of single bubble motion: a novel approach. Computers \& Chemical Engineering, 25(4-6):571-576, may 2001.

[5] DIMAKOPOULOS, Y.; PAVLIDIS, M. ; TSAMOPOULOS, J.. Steady bubble rise in herschel-bulkley fluids and comparison of predictions via the augmented lagrangian method with those via the papanastasiou model. Journal of Non-Newtonian Fluid Mechanics, 200:34-51, oct 2013.

[6] DUBASH, N.; FRIGAARD, I.. Conditions for static bubbles in viscoplastic fluids. Physics of Fluids, 16(12):4319-4330, dec 2004.

[7] DUBASH, N.; FRIGAARD, I.. Propagation and stopping of air bubbles in carbopol solutions. Journal of Non-Newtonian Fluid Mechanics, 142(1-3):123-134, mar 2007.

[8] GADDIS, E.; VOGELPOHL, A.. Bubble formation in quiescent liquids under constant flow conditions. Chemical Engineering Science, 41(1):97-105, 1986.

[9] FRAGGeDAKIS, D.; DIMAKOPOULOS, Y.; TSAMOPOULOS, J.. Yielding the yield-stress analysis: a study focused on the effects of 
elasticity on the settling of a single spherical particle in simple yield-stress fluids. Soft Matter, 12(24):5378-5401, 2016.

[10] FUNFSCHILLING, D.; LI, H.. Effects of the injection period on the rise velocity and shape of a bubble in a non-newtonian fluid. Chemical Engineering Research and Design, 84(10):875-883, oct 2006.

[11] FUNFSCHILLING, D.; LI, H. Z.. Flow of non-newtonian fluids around bubbles: PIV measurements and birefringence visualisation. Chemical Engineering Science, 56(3):1137-1141, feb 2001.

[12] ASTARITA, G.; APUZZO, G.. Motion of gas bubbles in nonnewtonian liquids. AIChE Journal, 11(5):815-820, sep 1965.

[13] KELBALIYEV, G. I.. Drag coefficients of variously shaped solid particles, drops, and bubbles. Theoretical Foundations of Chemical Engineering, 45(3):248-266, jun 2011.

[14] MOUGIN, N.; MAGNIN, A. ; PIAU, J.-M.. The significant influence of internal stresses on the dynamics of bubbles in a yield stress fluid. Journal of Non-Newtonian Fluid Mechanics, 171-172:42-55, mar 2012.

[15] PUTZ, A.; FRIGAARD, I.. Creeping flow around particles in a bingham fluid. Journal of Non-Newtonian Fluid Mechanics, 165(5-6):263280, mar 2010.

[16] RAYMOND, F.; ROSANT, J.-M.. A numerical and experimental study of the terminal velocity and shape of bubbles in viscous liquids. Chemical Engineering Science, 55(5):943-955, mar 2000.

[17] SIKORSKI, D.; TABUTEAU, H. ; DE BRUYN, J. R.. Motion and shape of bubbles rising through a yield-stress fluid. Journal of Non-Newtonian Fluid Mechanics, 159(1-3):10-16, jun 2009.

[18] ISLAM, M. T.; GANESAN, P. ; CHENG, J.. A pair of bubbles' rising dynamics in a xanthan gum solution: a CFD study. RSC Adv., 5(11):7819-7831, 2015.

[19] TRIPATHI, M. K.; SAHU, K. C.; KARAPETSAS, G. ; MATAR, O. K.. Bubble rise dynamics in a viscoplastic material. Journal of NonNewtonian Fluid Mechanics, 222:217-226, aug 2015.

[20] VÉLEZ-CORDERO, J. R.; SÁMANO, D.; YUE, P.; FENG, J. J. ; ZENIT, R.. Hydrodynamic interaction between a pair of bubbles ascending 
in shear-thinning inelastic fluids. Journal of Non-Newtonian Fluid Mechanics, 166(1-2):118-132, jan 2011.

[21] ZHANG, L.; YANG, C. ; MAO, Z.-S.. Unsteady motion of a single bubble in highly viscous liquid and empirical correlation of drag coefficient. Chemical Engineering Science, 63(8):2099-2106, apr 2008.

[22] TERASAKA, K.; TSUGE, H.. Bubble formation at a nozzle submerged in viscous liquids having yield stress. Chemical Engineering Science, 56(10):3237-3245, may 2001.

[23] RAMAKRISHNAN, S.; KUMAR, R. ; KULOOR, N.. Studies in bubble formation - $\mathrm{i}$ bubble formation under constant flow conditions. Chemical Engineering Science, 24(4):731-747, apr 1969.

[24] BEAULNE, M.; MITSOULIS, E.. Creeping motion of a sphere in tubes filled with herschel-bulkley fluids. Journal of Non-Newtonian Fluid Mechanics, 72(1):55-71, sep 1997.

[25] ATAPATTU, D.; CHHABRA, R. ; UHLHERR, P.. Creeping sphere motion in herschel-bulkley fluids: flow field and drag. Journal of Non-Newtonian Fluid Mechanics, 59(2-3):245-265, sep 1995.

[26] BLACKERY, J.; MITSOULIS, E.. Creeping motion of a sphere in tubes filled with a bingham plastic material. Journal of NonNewtonian Fluid Mechanics, 70(1-2):59-77, may 1997.

[27] TABUTEAU, H.; COUSSOT, P. ; DE BRUYN, J. R.. Drag force on a sphere in steady motion through a yield-stress fluid. Journal of Rheology, 51(1):125-137, jan 2007.

[28] HUA, J.; LOU, J.. Numerical simulation of bubble rising in viscous liquid. Journal of Computational Physics, 222(2):769-795, mar 2007.

[29] MITSOULIS, E.; GALAZOULAS, S.. Simulation of viscoplastic flow past cylinders in tubes. Journal of Non-Newtonian Fluid Mechanics, 158(1-3):132-141, may 2009.

[30] OHL, C. D.; TIJINK, A. ; PROSPERETTI, A.. The added mass of an expanding bubble. Journal of Fluid Mechanics, 482:271-290, may 2003.

[31] SAHA, G.; PUROHIT, N. ; MITRA, A.. Spherical particle terminal settling velocity and drag in bingham liquids. International Journal of Mineral Processing, 36(3-4):273-281, oct 1992. 
[32] SATYANARAYAN, A.; KUMAR, R. ; KULOOR, N.. Studies in bubble formation-II bubble formation under constant pressure conditions. Chemical Engineering Science, 24(4):749-761, apr 1969.

[33] DOLEJŠ, V.; DOLEČEK, P. ; ŠIŠKA, B.. Drag and fall velocity of a spherical particle in generalized newtonian and viscoplastic fluids. Chemical Engineering and Processing: Process Intensification, 37(2):189-195, mar 1998.

[34] TABUTEAU, H.; OPPONG, F. K.; DE BRUYN, J. R. ; COUSSOT, P.. Drag on a sphere moving through an aging system. Europhysics Letters (EPL), 78(6):68007, jun 2007.

[35] HARIHARAPUTHIRAN, M.; SUBRAMANIAN, R.; CAMPBELL, G. A. ; CHHABRA, R.. The settling of spheres in a viscoplastic fluid. Journal of Non-Newtonian Fluid Mechanics, 79(1):87-97, sep 1998.

[36] ANSLEY, R. W.; SMITH, T. N.. Motion of spherical particles in a bingham plastic. AIChE Journal, 13(6):1193-1196, nov 1967.

[37] DEDEGIL, M. Y.. Drag coefficient and settling velocity of particles in non-newtonian suspensions. Journal of Fluids Engineering, 109(3):319, 1987.

[38] PRASHANT; DERKSEN, J.. Direct simulations of spherical particle motion in bingham liquids. Computers \& Chemical Engineering, 35(7):1200-1214, jul 2011.

[39] JOSEPH, D. D.. Rise velocity of a spherical cap bubble. Journal of Fluid Mechanics, 488:213-223, jul 2003.

[40] PREMLATA, A.; TRIPATHI, M. K.; KARRI, B. ; SAHU, K. C.. Dynamics of an air bubble rising in a non-newtonian liquid in the axisymmetric regime. Journal of Non-Newtonian Fluid Mechanics, 239:53-61, jan 2017.

[41] REYNOLDS, P.; JONES, T.. An experimental study of the settling velocities of single particles in non-newtonian fluids. International Journal of Mineral Processing, 25(1-2):47-77, jan 1989.

[42] ACHARYA, A.; MASHELKAR, R. A. ; ULBRECHT, J.. Flow of inelastic and viscoelastic fluids past a sphere. Rheologica Acta, 15(9):454-470, sep 1976. 
[43] GUTOWSKI, I. A.; LEE, D.; DE BRUYN, J. R. ; FRISKEN, B. J.. Scaling and mesostructure of carbopol dispersions. Rheologica Acta, 51(5):441-450, jan 2012.

[44] KOWALCZYK, A.; OELSCHLAEGER, C. ; WILLENBACHER, N.. Visualization of micro-scale inhomogeneities in acrylic thickener solutions: A multiple particle tracking study. Polymer, 58:170-179, feb 2015.

[45] FEYS, D.; VERHOEVEN, R. ; SCHUTTER, G. D.. Fresh self compacting concrete, a shear thickening material. Cement and Concrete Research, 38(7):920-929, jul 2008.

[46] GUCUYENER, I.. A rheological model for drilling fluids and cement slurries. In: MIDDLE EAST OIL TECHNICAL CONFERENCE AND EXHIBITION. Society of Petroleum Engineers, 1983.

[47] NEHDI, M.; RAHMAN, M.-A.. Estimating rheological properties of cement pastes using various rheological models for different test geometry, gap and surface friction. Cement and Concrete Research, 34(11):1993-2007, nov 2004.

[48] CHHABRA, R.. Bubbles, Drops, and Particles in Non-Newtonian Fluids, Second Edition (Chemical Industries). CRC Press, 2006.

[49] BARNES, H. A.. Handbook of Elementary Rheology. University of Wales, Institute of Non-Newtonian Fluid Mechanics, 2000.

[50] BIRD, R. B.; ARMSTRONG, R. C. ; HASSAGER, O.. Dynamics of Polymeric Liquids, Volume 1: Fluid Mechanics. Wiley-Interscience, 1987.

[51] CHHABRA, R. P.; RICHARDSON, J.. Non-Newtonian Flow: Fundamentals and Engineering Applications. Butterworth-Heinemann, 1999.

[52] KARIMIPOUR, S.; PUGSLEY, T.. A critical evaluation of literature correlations for predicting bubble size and velocity in gas-solid fluidized beds. Powder Technology, 205(1-3):1-14, jan 2011.

[53] TSAMOPOULOS, J.; DIMAKOPOULOS, Y.; CHATZIDAI, N.; KARAPETSAS, G. ; PAVLIDIS, M.. Steady bubble rise and deformation in newtonian and viscoplastic fluids and conditions for bubble entrapment. Journal of Fluid Mechanics, 601, apr 2008. 
[54] VALENTIK, L.; WHITMORE, R. L.. The terminal velocity of spheres in bingham plastics. British Journal of Applied Physics, 16(8):1197-1203, aug 1965.

[55] HERRERA-VELARDE, J.; ZENIT, R.; CHEHATA, D. ; MENA, B.. The flow of non-newtonian fluids around bubbles and its connection to the jump discontinuity. Journal of Non-Newtonian Fluid Mechanics, 111(2-3):199-209, apr 2003.

[56] D.D. ATAPATTU, R. P. CHHABRA, C. T.; UHLHERR, P. T.. The effect of cylindrical boundaries for spheres falling in fluids having a yield stress. 9th Australasian fluid mechanics conference, 1986.

[57] BANFILL, P. F. G.. The rheology of fresh cement and concrete-a review. 11th International Cement Chemistry Congress, 2003.

[58] BONETT, A.; PAFITIS, D.. Getting to the root of gas migration. Oilfield Review Journal, 1996.

[59] LIND, S.; PHILLIPS, T.. The effect of viscoelasticity on a rising gas bubble. Journal of Non-Newtonian Fluid Mechanics, 165(15-16):852-865, aug 2010 .

[60] ORTIZ, S. L.; LEE, J. S.; FIGUEROA-ESPINOZA, B. ; MENA, B.. An experimental note on the deformation and breakup of viscoelastic droplets rising in non-newtonian fluids. Rheologica Acta, 55(11-12):879-887, oct 2016.

[61] HABERMAN, W.; MORTON, R.. An experimental investigation of the drag and shape of air bubbles rising in various liquids. Technical Report 19377, David Taylor Model Basin Washington Dc, 1953.

[62] HASSAN, N.; KHAN, M. M. ; RASUL, M.. A study of bubble trajectory and drag co-efficient in water and non-newtonian fluids. 3, 01 2008.

[63] CHEN, P.. Modeling the Fluid Dynamics of Bubble Column Flows. PhD thesis, Washington University, 2004.

[64] PROHASKA, M.; FRUHWIRTH, R. ; ECONOMIDES, M.. Modeling early-time gas migration through cement slurries (includes associated papers 36370 and 36766 and 37387 and 37684). SPE Drilling \& Completion, 10(03):178-185, sep 1995. 
[65] SADEGHY, K.; VAHABI, M.. The effect of thixotropy on a rising gas bubble: A numerical study. Korea-Australia Rheology Journal, 28(3):207-216, aug 2016.

[66] SOTO, E.; GOUJON, C.; ZENIT, R. ; MANERO, O.. A study of velocity discontinuity for single air bubbles rising in an associative polymer. Physics of Fluids, 18(12):121510, dec 2006.

[67] FRANK, X.; CHARPENTIER, J.-C.; CANNEVIÈRE, F.; MIDOUX, N. ; LI, H.. Bubbles in non-newtonian fluids: A multiscale modeling. Oil \& Gas Science and Technology - Revue d'IFP Energies nouvelles, 68(6):10591072, jun 2013.

[68] MIKAELIAN, D.; LARCY, A.; DEHAECK, S. ; HAUT, B.. A new experimental method to analyze the dynamics and the morphology of bubbles in liquids: Application to single ellipsoidal bubbles. Chemical Engineering Science, 100:529-538, aug 2013.

[69] MALDONADO, M.; QUINN, J.; GOMEZ, C. ; FINCH, J.. An experimental study examining the relationship between bubble shape and rise velocity. Chemical Engineering Science, 98:7-11, jul 2013.

[70] LIU, L.; YAN, H. ; ZHAO, G.. Experimental studies on the shape and motion of air bubbles in viscous liquids. Experimental Thermal and Fluid Science, 62:109-121, apr 2015.

[71] MAGNAUDET, J.; RIVERO, M. ; FABRE, J.. Accelerated flows past a rigid sphere or a spherical bubble. part 1. steady straining flow. Journal of Fluid Mechanics, 284(-1):97, feb 1995.

[72] LIU, L.; YAN, H.; ZHAO, G. ; ZHUANG, J.. Experimental studies on the terminal velocity of air bubbles in water and glycerol aqueous solution. Experimental Thermal and Fluid Science, 78:254-265, nov 2016.

[73] BOND, W.. LXXXII.bubbles and drops and stokes' law. The London, Edinburgh, and Dublin Philosophical Magazine and Journal of Science, 4(24):889-898, nov 1927.

[74] BOND, W.; NEWTON, D. A.. LXXXII.bubbles, drops, and stokes' law. (paper 2). The London, Edinburgh, and Dublin Philosophical Magazine and Journal of Science, 5(30):794-800, apr 1928.

[75] LOPEZ, W. F.; NACCACHE, M. F. ; DE SOUZA MENDES, P. R.. Rising bubbles in yield stress materials. Journal of Rheology, 2017. 
[76] MOISÉS, G. V. L.. Yield stress and thixotropy effects of nonnewtonian fluids in horizontal pipe flows. Master's thesis, Pontificia Universidad Católica de Río de Janeiro, 2016.

[77] TRIPATHI, M. K.; SAHU, K. C. ; GOVINDARAJAN, R.. Why a falling drop does not in general behave like a rising bubble. Scientific Reports, 2014.

[78] PARCEVAUX, P.; RAE, P. ; DRECQ, P.. 8 prevention of annular gas migration. p. 8-1-8-22, 1990.

[79] MOORE, D. W.. The velocity of rise of distorted gas bubbles in a liquid of small viscosity. Journal of Fluid Mechanics, 23(04):749, dec 1965.

[80] CLIFT, R.. Bubbles, Drops, and Particles. Academic Pr, 1978.

[81] ROSA, A. J.. Engenharia de Reservatório de Petróleo (Em Portuguese do Brasil). Interciência, 2006.

[82] DOS SANTOS ROCHA, L. A.. Projetos de Poços de Petróleo. Interciência, 2009.

[83] THOMAS, J. E.. Fundamentos de Engenharia de Petróleo (Em Portuguese do Brasil). Interciência, 2004.

[84] SCHRAMM, G.. Reologia e Reometria: Fundamentos Teoricos e Praticos. Artliber, 2006.

[85] BRENNEN, C.. A review of added mass and fluid inertial forces. 011982.

[86] KENDOUSH, A. A.. The virtual mass of an oblate-ellipsoidal bubble. Physics Letters A, 366(3):253-255, jun 2007.

[87] DINKGREVE, M.; FAZILATI, M.; DENN, M. M. ; BONN, D.. Carbopol: From a simple to a thixotropic yield stress fluid. Journal of Rheology, 62(3):773-780, may 2018.

[88] BHATIA, R.. Effect of molecular mass, concentration and temperature on the rheological properties of non-newtonian aqueous polymeric solutions. PhD thesis, University of Cincinnati, 2011. 
A

\section{Preparação suspensões aquosas}

O processo de preparação das suspensões aquosas é delicado e demorado como mostra a Fig. A.1, precisa treinamento e diversos materiais para conseguir um substituto adequado para o cimento, além é necessário muito cuidado com o contato com alguns reagentes ácidos e especialmente atenção com a segurança ao trabalhar com as altas velocidades nos misturadores (Fig. 3.13).

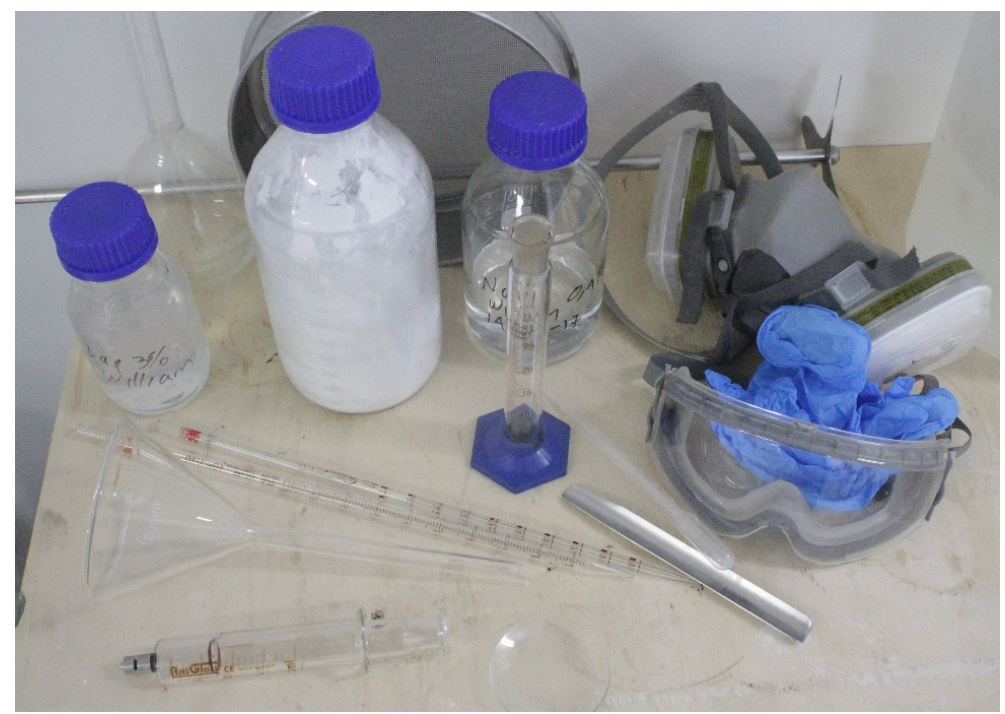

Figura A.1: Materiais, reagentes e equipamento de segurança necessários na preparação das suspensões aquosas usadas nesta pesquisa.

Os principais requisitos do fluido são ser transparente para permitir visualização com videocâmaras, não pode ser turvo ou leitoso como acontece com a Laponita em concentrações muito altas. O fluido deve se comportar como uma suspensão onde o polímero adicionado não entra em solução com a base aquosa, esta característica ira nos permitir analisar a influência do histórico de cisalhamento na reologia e a formação de canais preferenciais. $\mathrm{O}$ fluido deve ser viscoplástico, tixotrópico e elástico para analisar a influência destas propriedades na dinâmica e geometria da bolha, além de nos permitir simular o processo de cura do cimento em função do tempo. 


\section{A.1}

\section{Preparação Carbopol 980 - Carbomero}

A seguir se apresentam algumas recomendações iniciais para a preparação da suspensão:

- Neste processo é usado Carbopol 980 e NaOH 18\%ww.

- Durante o processo é recomendado mudar com frequência a posição e profundidade da hélice do misturador para evitar volumes sem cisalhar.

- No processo de preparação será usado o termo velocidade limite, esta é a máxima velocidade de rotação do misturador que não causa entrada de bolhas de ar ou fluido pingando fora do tanque. Recomenda-se uma velocidade não superior a 1100 RPM para evitar destruir o fluido.

- O misturador usado no laboratório inclui uma base planetária e um raspador. Recomenda-se o uso destes acessórios para evitar uma suspensão com uma reologia diferente nas paredes do tanque.

Materiais Para preparar um litro de $\mathrm{NaOH} 18 \%$ ww a seguir se indicam os materiais:

- Volume final da solução: 1L

- Densidade do $\mathrm{NaOH} 18 \% \mathrm{ww}=1.195 \mathrm{~g} / \mathrm{ml}$

- Concentração do NaOH na solução: $18 \%$ ww

- Massa de $\mathrm{NaOH}$ puro: 215.1g

- Massa de água: 979.9g

- Massa de NaOH 18\%ww:1195g

Para preparar um litro de Carbopol 0,1\%ww a seguir se indicam os materiais:

- Volume da suspensão finalizada: 1L

- Concentração do Carbopol na suspensão: 0.1\%ww

- Concentração de $\mathrm{NaOH} 18 \%$ ww na suspensão=0.23\%ww

- Massa de Carbopol: $1 \mathrm{~g}$

- Massa de $\mathrm{NaOH} 18 \%$ ww na suspensão=2,3g

- Água: 996.7g 


\section{Processo de preparação}

1. Usar água filtrada e deionizada no tanque do misturador.

2. Peneirar o Carbopol para eliminar as partículas grandes. Recomenda-se uma peneira de $0.6 \mathrm{~mm}$ de tamanho de poro.

3. Adicionar o Carbopol muito lentamente, o tempo aproximado de adição são 30 min., isto reduz a probabilidade de formação de grumos. Para misturar o fluido se recomenda o uso de uma hélice naval, esta favorece a circulação do fluido em todo o tanque, também se recomenda o uso da hélice perto da superfície durante a adição do Carbopol para evitar a formação de grumos.

4. Misturar por 2 horas a velocidade limite mudando periodicamente a posição e profundidade da hélice.

5. Deixar o Carbopol em repouso durante 10 min. para eliminar o gás da suspensão.

6. Adicionar muito lentamente o $\mathrm{NaOH} 18 \%$ ww com um conta-gotas, este processo tarda aproximadamente $30 \mathrm{~min}$. Recomenda-se a hélice perto da superfície durante a adição do $\mathrm{NaOH}$ para facilitar a mistura. A concentração de NAOH usada neste processo é 2.3 vezes a concentração de Carbopol.

7. Misturar por 1 hora na velocidade limite mudando periodicamente a posição e profundidade da hélice.

8. Para finalizar se recomenda usar uma hélice centrifuga. Esta hélice dentada permite desfazer os grumos que ainda podem existir na suspensão. Usar esta hélice por meia hora a uma velocidade máxima de 1100 RPM mudando periodicamente a posição e profundidade.

Para preparar volumes maiores se recomenda misturar o conteúdo de todos os tanques preparados e colocar de volta no misturador para homogeneizar a reologia entre eles. 


\section{A. 2}

\section{Preparação da Laponita}

\section{Materiais}

- Laponita $80 \mathrm{~g}$

- Água Deionizada 4000g

- Cloreto de Sódio 0,4M 10,00mL

- Hidróxido de Sódio 0,04M 10,00mL

Processo de preparação $\mathrm{O}$ processo de preparação de $4 \mathrm{~L}$ de Laponita com concentração $2 \% \mathrm{ww}$ é descrito a seguir. Para concentrações diferentes o processo é o mesmo mas deve considerar as tabelas A.1 e A.2 do autor Lourenço (76).

1. Pesar os reagentes de acordo com a concentração (ver tabela) a ser usada;

2. Acrescentar ao balde com água deionizada $10,23 \mathrm{~mL}$ de $\mathrm{NaOH}$ e homogeneizar. Para isso, use duas pipetas: uma volumétrica de 10,00mL e uma graduada de 1,0mL;

3. Depois de homogeneizado com bastão de vidro, retirar, com auxílio de uma proveta, 100mL dessa solução e descartar;

4. Colocar o balde com a solução preparada no agitador mecânico, com a pá helicoidal, utilizando a rotação de aproximadamente 500 rpm, para acrescentar a Laponita. Observação importante: é preciso que o aparato para a pá esteja levantado;

5. Acrescentar cuidadosamente a Laponita pesada, para que não disperse muito (dica: jogue entre a pá e a parede do balde), e aumentar a rotação para $1600 \mathrm{rpm}$;

6. Agitar nessa rotação por 30 minutos;

7. Acrescentar $10,0 \mathrm{~mL}$ de $\mathrm{NaCl}$ e agitar por mais 30 minutos;

8. Deixar repousar por 8 dias antes dos testes. 
Tabela A.1: Quantidade de polímero de Laponita necessária para um tanque de 4L de suspensão em função da concentração em peso (\%ww) (76)

\begin{tabular}{|c|c|}
\hline Laponita \%ww & Laponita massa $[\mathrm{g}]$ \\
\hline 1.5 & 60 \\
\hline 2.0 & 80 \\
\hline 2.5 & 100 \\
\hline 3.0 & 120 \\
\hline
\end{tabular}

Tabela A.2: Quantidade de $\mathrm{NaCl}$ e $\mathrm{NaOH}$ para um tanque de $4 \mathrm{~L}$ de Laponita em função das concentrações desejadas (76)

\begin{tabular}{|c|c|c|c|c|}
\hline $\begin{array}{c}\text { Laponita } \\
\% \text { ww }\end{array}$ & $\begin{array}{c}\mathrm{NaCl} \\
{[\mathrm{mol} / \mathrm{L}]}\end{array}$ & $\begin{array}{c}\text { Vol NaCl } \\
{[\mathrm{ml}]}\end{array}$ & $\begin{array}{c}\text { Vol NaOH } \\
\text { Low }[\mathrm{ml}]\end{array}$ & $\begin{array}{c}\text { Vol NaOH } \\
\text { High }[\mathrm{ml}]\end{array}$ \\
\hline 1.5 & $10^{-4}$ & 1 & 3939 & 10.15 \\
\hline 1.5 & $10^{-3}$ & 10 & 3930 & 10.18 \\
\hline 1.5 & $10^{-2}$ & 100 & 3840 & 10.42 \\
\hline 1.5 & $10^{-1}$ & 1000 & 2940 & 13.61 \\
\hline 2.0 & $10^{-4}$ & 1 & 3919 & 10.21 \\
\hline 2.0 & $10^{-3}$ & 10 & 3910 & 10.23 \\
\hline 2.0 & $10^{-2}$ & 100 & 3820 & 10.47 \\
\hline 2.0 & $10^{-1}$ & 1000 & 2920 & 13.70 \\
\hline 2.5 & $10^{-4}$ & 1 & 3899 & 10.26 \\
\hline 2.5 & $10^{-3}$ & 10 & 3890 & 10.28 \\
\hline 2.5 & $10^{-2}$ & 100 & 3800 & 10.53 \\
\hline 2.5 & $10^{-1}$ & 1000 & 2900 & 13.79 \\
\hline 3.0 & $10^{-4}$ & 1 & 3879 & 10.31 \\
\hline 3.0 & $10^{-3}$ & 10 & 3870 & 10.34 \\
\hline 3.0 & $10^{-2}$ & 100 & 3780 & 10.58 \\
\hline 3.0 & $10^{-1}$ & 1000 & 2880 & 13.89 \\
\hline
\end{tabular}


B

\section{Rotinas em Matlab}

\section{B.1}

\section{Rotina de Post-Processamento de Imagens}

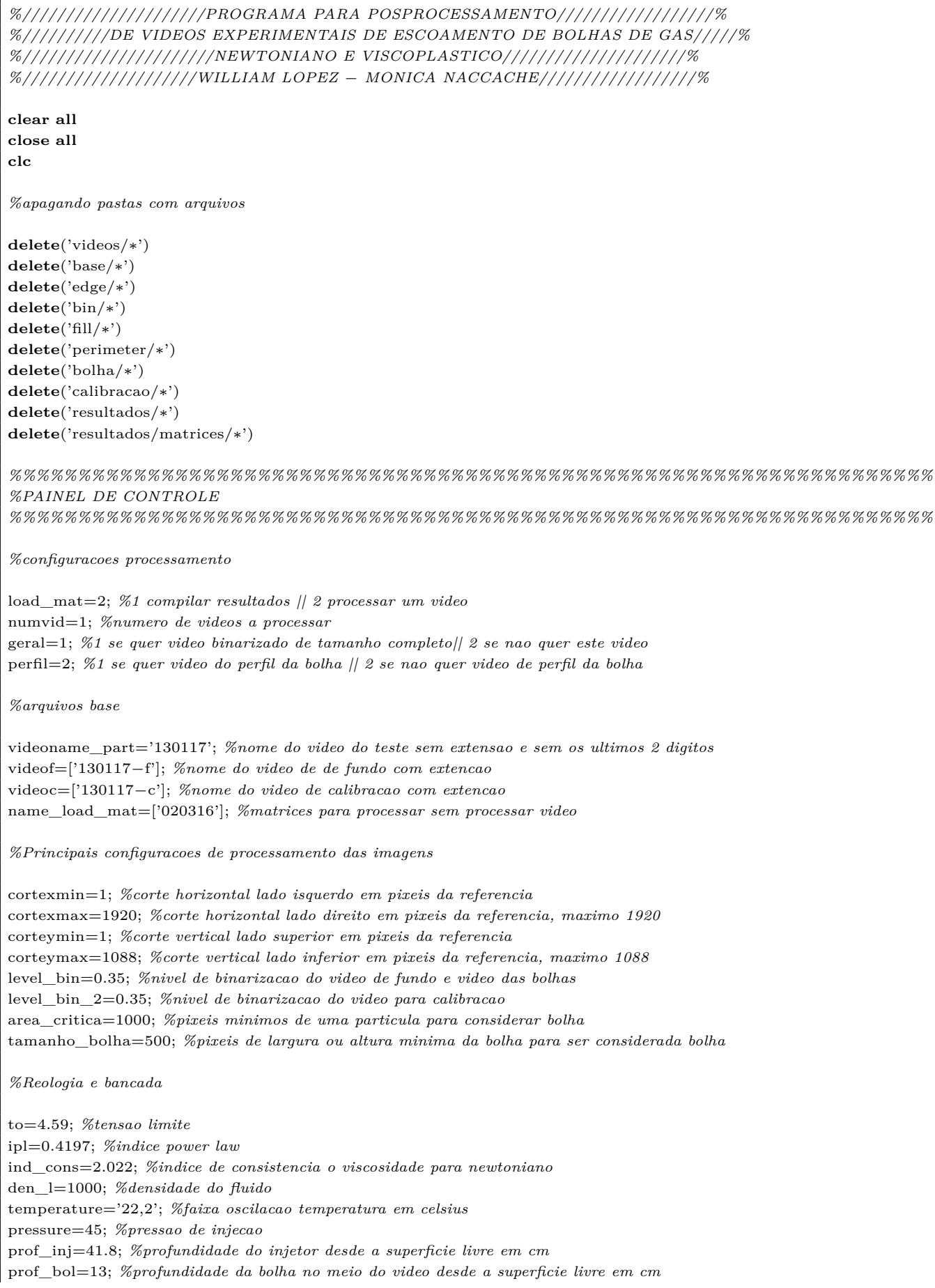




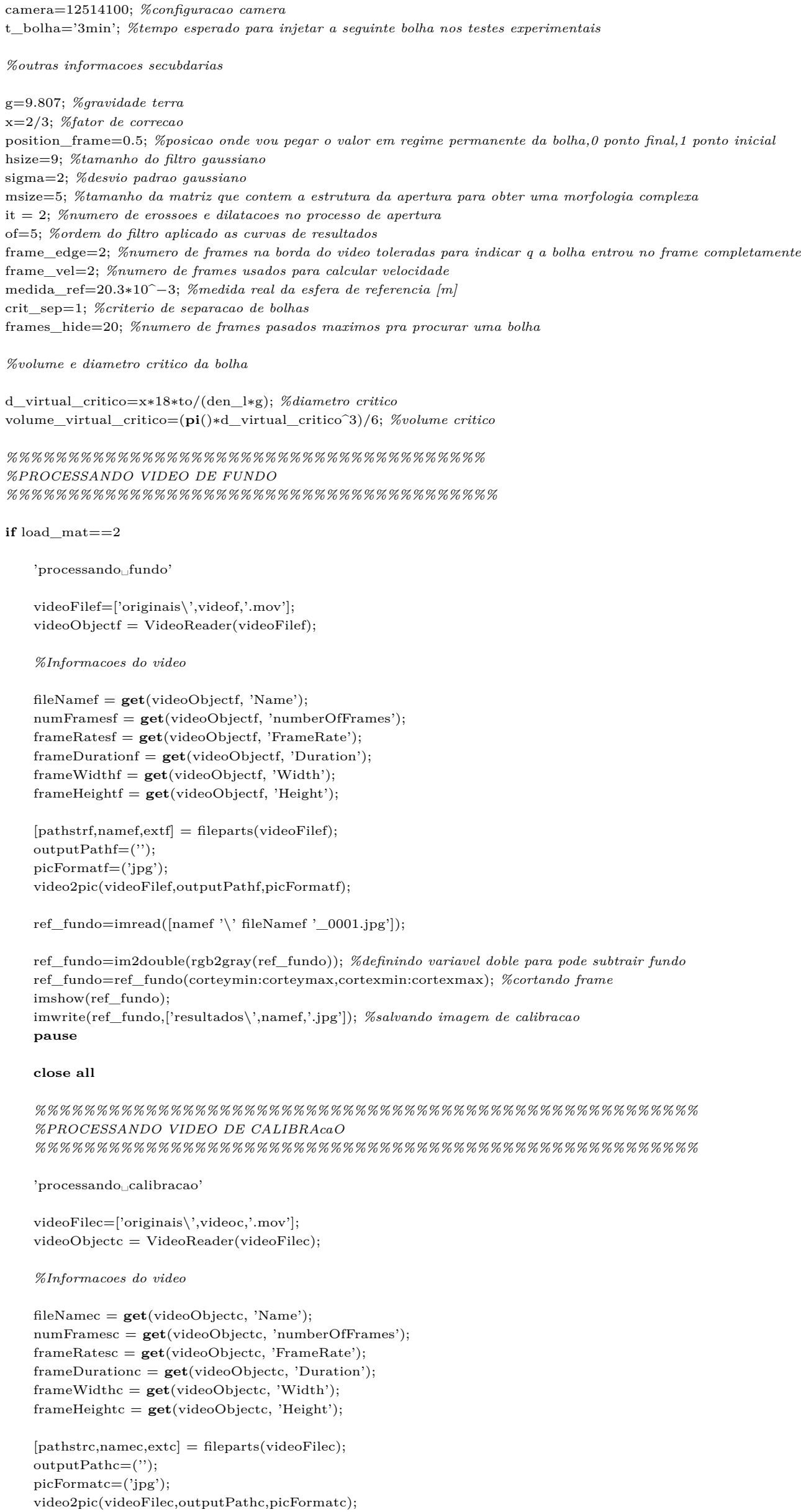


ref=imread ([namec ' ' fileNamec '_0001.jpg'] );

ref=im2double(rgb2gray(ref)); \%definindo arranjo doble para podem substrair o fundo

\%eliminando o fundo

ref=ref(corteymin:corteymax,cortexmin:cortexmax); \%cortando frame

Isub $=$ ref - ref_fundo;

$\operatorname{Isub}=(\operatorname{Isub}-\overline{\min }(\operatorname{Isub}(:))) /(\max (\operatorname{Isub}(:))-\min (\operatorname{Isub}(:))) ; \%$ normalize

\%Filtro gaussiano

$\mathrm{h}=$ fspecial('gaussian',hsize,sigma); \%fspecial('gaussian',hsize,sigma)

Ifilt $=$ imfilter(Isub,h,'replicate'); \%Gaussian smooth

\%binarizando

Ibin $=$ Ifilt $<$ level_bin_2; \%binarize

\%preenchendo os vazios da esfera

Ibin $=$ imfill(Ibin,'holes'); \%fill bubble

$\%$ processo de apertura para obter uma morfologia complexa

se $=$ strel('disk',msize); \%or 'diamond'

for $\mathrm{i}=1: \mathrm{it} \%$ erossionando a particula

Ibin $=$ imerode $($ Ibin,se);

end

for $\mathrm{i}=1: \mathrm{it} \%$ dilatando a particula

Ibin = imdilate $($ Ibin,se $)$

end

\%prenchendo vazios na referencia

imwrite(Ibin, ['resultados \',namec,'-calibracao.jpg']); \%salvando imagem de calibracao imshow(Ibin);

\%calculando area do esfera e calibrando

stats_ref= regionprops(Ibin,'Area','MajorAxisLength'); \%calculando centroide e area [statl_ref, ]=size(stats_ref); \%numero de particulas detetadas

for $\mathrm{i}=1$ :statl_ref

areai_ref=stats_ref(i).Area;

if $i==1$

max_area_ref=areai_ref;

stati_ref $=1$

else

if areai $r e f>\max$ area ref

max_area_ref=areai_ref

stati_ref $=$ i;

end

end

end

pause

close all \%calculo da maxima area da referencia e a maior bolha

\%calculo da escala do video

maior_diam $1=2 * \mathbf{s q r t}(\max$ area_ref $/(\mathbf{p i}()))$; \%maior diametro da esfera baseado na area

escala_video1=medida_ref/maior_diam $1 ; \%$ escala do video baseada na area $/ \mathrm{m} / \mathrm{px}]$

diametro_recalculado=escala_video $1 *\left(4 * \max \_ \text {area_ref } / \mathbf{p i}()\right)^{\wedge}(1 / 2) ; \%$ diametro da esfera

clearvars fileNamec outputPathc picFormatc ref bin_ref_cut bin_ref videoFilec videoObjectc stats_ref areai_ref $\hookrightarrow$ max_area_ref stati_ref Ibin Ifilt Isub

\%\%\%\%\%\%\%\%\%\%\%\%\%\%\%\%\%\%\%\%\%\%\%\%\%\%\%\%\%\%\%\%\%\%\%\%\%\%\%\%

\%PROCESSANDO VIDEO

\%\%\%\%\%\%\%\%\%\%\%\%\%\%\%\%\%\%\%\%\%\%\%\%\%\%\%\%\%\%\%\%\%\%\%\%\%\%\%\%

$\mathrm{kk}=0$; \%switch para ver imagem da bolha inicial

zero_b $=0$;

sw_img $=0$;

position_frame $=1-$ position_frame;

for $\mathrm{q}=1$ :numvid \%numero do video a processar

'processando $\_$video' 


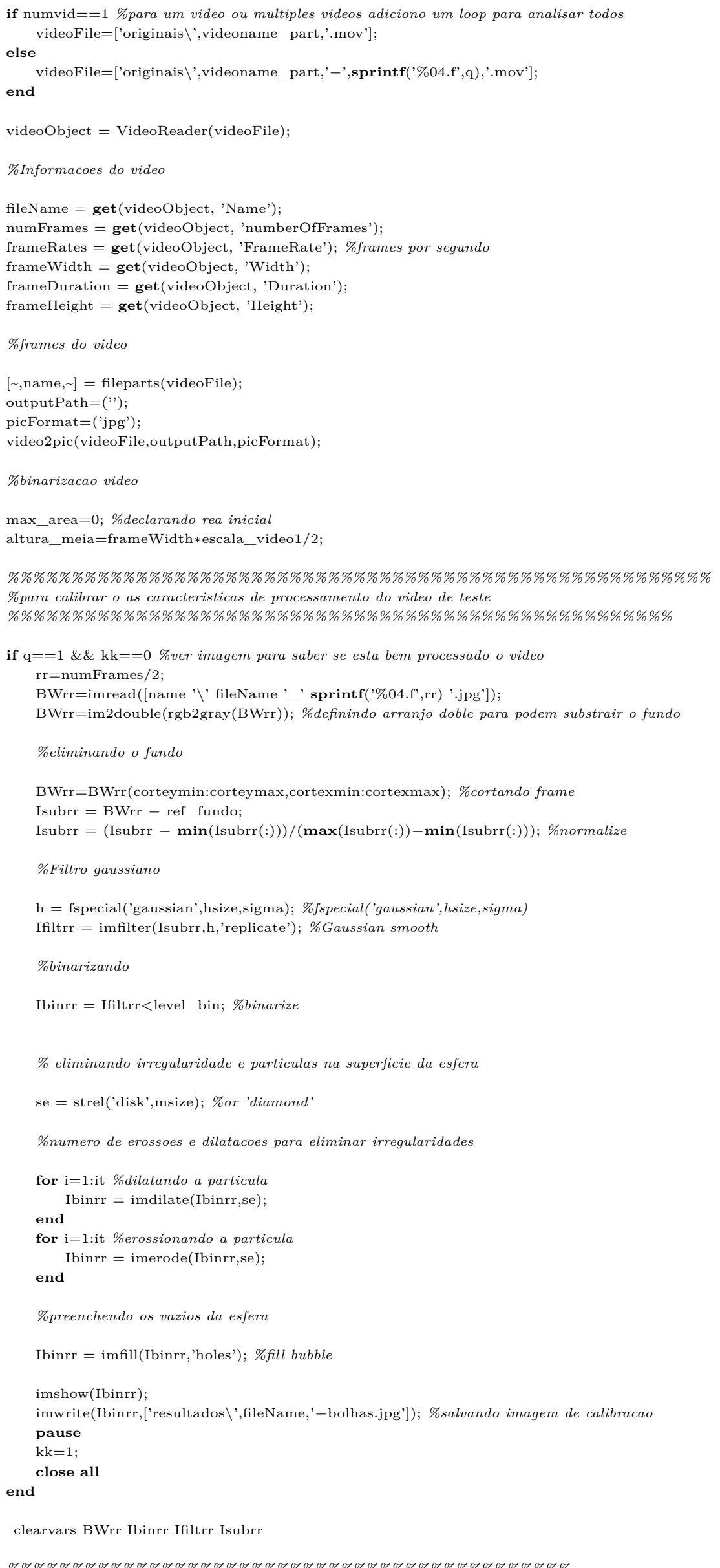


\%PROCESSANDO AS BOLHAS DO TESTE

\%\%\%\%\%\%\%\%\%\%\%\%\%\%\%\%\%\%\%\%\%\%\%\%\%\%\%\%\%\%\%\%\%\%\%\%\%\%\%\%\%\%\%\%

sw_first_frame $=0$

sw_non_bubble $=0$;

for $\mathrm{k}=1$ :numFrames \%cada frame do video

[num2str(q),'/',num2str(numvid),'l|',num2str(k), '/,', num2str(numFrames)]

BW=imread([name '’' fileName '_,' sprintf('\%04.f',k) '.jpg']);

$\mathrm{BW}=\mathrm{im} 2 \mathrm{double}(\mathrm{rgb} 2 \mathrm{gray}(\mathrm{BW}))$; \%alterando tipo variavel da matriz para dupla

\%eliminando o fundo

$\mathrm{BW}=\mathrm{BW}$ (corteymin:corteymax,cortexmin:cortexmax); \%cortando frame

IsubBW $=$ BW - ref_fundo;

IsubBW $=(\operatorname{IsubBW}-\boldsymbol{m i n}(\operatorname{IsubBW}(:))) /(\boldsymbol{m a x}(\operatorname{IsubBW}(:))-\boldsymbol{m i n}(\operatorname{IsubBW}(:))) ; \%$ normalize

\%Filtro gaussiano

$\mathrm{h}=$ fspecial('gaussian',hsize,sigma); \%fspecial('gaussian',hsize,sigma)

IfiltBW = imfilter(IsubBW,h,'replicate'); \%Gaussian smooth

\%binarizando

IbinBW $=$ IfiltBW $<$ level_bin; \%binarize

$\%$ eliminando irregularidade e particulas na superficie da esfera

se $=\operatorname{strel}($ 'disk',msize); \%or 'diamond'

\%numero de erossoes e dilatacoes para eliminar irregularidades

for $\mathrm{i}=1: \mathrm{it} \%$ dilatando a particula

IbinBW = imdilate(IbinBW,se);

end

for $\mathrm{i}=1: \mathrm{it} \%$ erossionando a particula

IbinBW = imerode(IbinBW,se);

end

\%preenchendo os vazios da esfera

IbinBW = imfill(IbinBW,'holes'); \%fill bubble

if geral $==1 \|$ perfil==1 \%imagem para video geral

imwrite(IbinBW,['base $\backslash$ base' sprintf('\%04.f',k) '.jpg']); \%salvando frames originais end

\%calculando caracteristicas das particulas

stats= regionprops(IbinBW,'centroid','Area','BoundingBox'); \%identificando particulas e calculado centroides e $\hookrightarrow$ areas

$[$ statl, $]=\mathbf{s i z e}($ stats); \%numero de particulas detetadas

if statl $\sim=0 \%$ condicao para nao entrar se nao encontrar particula, esta identificando todas as particulas por $\hookrightarrow$ embaixo da area critica

\%codigo para cada particula no mesmo frame

$\mathrm{n}=0 ; \%$ reinicio do numero de particulas por cada frame

for $\mathrm{i}=1$ :statl \%para cada particula no mesmo frame

areai $=$ stats $(i)$. Area

if areai>area_critica \%processando particulas maiores que a area critica

limite temp=stats(i).BoundingBox; \%largura e altura da maior particula do frame em pixeis if limite_temp $(1)+$ limite_temp $(3)<\operatorname{cortexmax} \& \&$ limite_temp $(1)>$ cortexmin \%no limite direito $\hookrightarrow$ e isquerdo se tem pixeis brancos q nao sejam da bolha, tem um maximo de pixeis para $\hookrightarrow$ considerar $q$ eh nova bolha

$\mathrm{n}=\mathrm{n}+1 ; \%$ numero de particulas em cada frame

area_pix $(\mathrm{k}, 1, \mathrm{n}, 1)=\mathrm{stats}(\mathrm{i})$.Area; \%almacenando area em pixeis

area centroide $(\mathrm{k}, 1, \mathrm{n}, 1)=$ area $\operatorname{pix}(\mathrm{k}, 1, \mathrm{n}, 1) *$ escala video1^2;\%almacenando area de particula $\hookrightarrow$ de maior tamanho para cada frame $\mathrm{m}^{\widehat{2}}$

centroide_pix $(\mathrm{k},:, \mathrm{n}, 1)=\mathrm{stats}(\mathrm{i})$.Centroid; \%coordenadas em pixeis da posicao da bolha centroide $(\mathrm{k},:, \mathrm{n}, 1)=$ centroide__pix $(\mathrm{k},:, \mathrm{n}, 1) *$ escala_video1; \% almacenando centroide de maior $\hookrightarrow$ particula para cada frame em $\mathrm{m}^{\wedge} 2$

limites_pix $(\mathrm{k},:, \mathrm{n}, 1)=\mathrm{stats}(\mathrm{i})$.BoundingBox; \%largura e altura da maior particula do frame em $\hookrightarrow$ pixeis

$\operatorname{limites}(\mathrm{k},:, \mathrm{n}, 1)=$ escala_video $1 * \operatorname{stats}(\mathrm{i})$.BoundingBox; \%largura e altura da maior particula do $\hookrightarrow$ frame em pixeis

diametro_virt $(\mathrm{k}, 1, \mathrm{n}, 1)=2 * \mathbf{s q r t}($ area_centroide $(\mathrm{k}, 1, \mathrm{n}, 1) /(\mathbf{p i}()))$; \%raio virtual da bolha esferica volume $(\mathrm{k}, 1, \mathrm{n}, 1)=(4 / 3) * \mathbf{p i}() *(\text { diametro } \operatorname{virt}(\mathrm{k}, 1, \mathrm{n}, 1) / 2)^{\wedge} 3 ; \%$ volume da bolha 
ratio_al $(\mathrm{k}, 1, \mathrm{n}, 1)=$ limites_pix $(\mathrm{k}, 3, \mathrm{n}, 1) /$ limites_pix $(\mathrm{k}, 4, \mathrm{n}, 1)$; \%relacao altura/largura da bolha tempo $(\mathrm{k}, 1, \mathrm{n}, 1)=\mathrm{k} /$ frameRates; \%tempo de avanco do video original

$\mathrm{n} \_$frame $(\mathrm{k}, 1)=\mathrm{n} ; \%$ numero de particulas nesse frame $q$ video

if geral $==1 \quad \mid$ perfil $==1$

bubble_temp $(:,:, 1,1)=\mathrm{IbinBW}$; \% preparando matriz para adicionar a uma matriz de $\hookrightarrow$ multiples dimensoes

bubblefill(:,:, $, \mathrm{n}, \mathrm{n}, 1)=$ bubble_temp; \%almacenando matriz multidimensional

$\operatorname{rectangle}(\mathrm{n},:)=\operatorname{int} 16\left(\left[\right.\right.$ floor $($ limites_pix $(\mathrm{k}, 1, \mathrm{n}, 1))-1$,floor $\left(\operatorname{limites} \_\right.$pix $\left.(\mathrm{k}, 2, \mathrm{n}, 1)\right)-1$, ceil( $\hookrightarrow$ limites_pix $(\mathrm{k}, 3, \mathrm{n}, 1))+4$, ceil(limites_pix $(\mathrm{k}, 4, \mathrm{n}, 1))+4])$; \%informacoes do $\hookrightarrow$ rectangulo ao redor da bolha

$\operatorname{circle}(\mathrm{n},:)=\operatorname{int} 16([$ centroide_pix $(\mathrm{k}, 1, \mathrm{n}, 1)$, centroide_pix $(\mathrm{k}, 2, \mathrm{n}, 1), 4])$; \%informacoes do $\hookrightarrow$ circulo ao redor da particula

end

end

end

if $\mathrm{n}==0 \%$ se a unica bolha atingiu o limite do frame, ele cria o valor zero

$\mathrm{n} \_$frame $(\mathrm{k}, 1)=0$

end

\%\%\%\%\%\%\%\%\%\%\%\%\%\%\%\%\%\%\%\%\%\%\%\%\%\%\%\%\%\%\%\%\%\%\%\%\%\%\%\%\%\%\%

\%identificando bolhas

\%\%\%\%\%\%\%\%\%\%\%\%\%\%\%\%\%\%\%\%\%\%\%\%\%\%\%\%\%\%\%\%\%\%\%\%\%\%\%\%\%\%\%\%

if $\mathrm{n}$ frame $(\mathrm{k}, 1)>0 \%$ se o frame nao tem bolhas ou a unica bolha esta no limite do frame

if $\mathrm{sw}$ _first_frame $==0 \%$ se encontrou a primeira particula

for $\mathrm{j}=1: \mathrm{n} \_$frame $(\mathrm{k}, 1) \%$ particulas no primeiro frame

centroide_unit $(\mathrm{j},:, \mathrm{k}, 1)=\operatorname{centroide}(\mathrm{k},:, \mathrm{j}, 1)$

limites_unit $(\mathrm{j},:, \mathrm{k}, 1)=\operatorname{limites}(\mathrm{k},:, \mathrm{j}, 1)$;

volume_unit $(\mathrm{j}, \mathrm{k}, 1)=\operatorname{volume}(\mathrm{k}, 1, \mathrm{j}, 1)$;

ratio al unit $(\mathrm{j}, \mathrm{k}, 1)=$ ratio $\operatorname{al}(\mathrm{k}, 1, \mathrm{j}, 1)$;

diametro_virt_unit $(\mathrm{j}, \mathrm{k}, 1)=$ diametro_virt $(\mathrm{k}, 1, \mathrm{j}, 1)$;

bolha_unit $(\mathrm{j}, \mathrm{k}, 1)=\mathrm{j}$;

tempo_unit $(\mathrm{j}, \mathrm{k}, 1)=\operatorname{tempo}(\mathrm{k}, 1, \mathrm{j}, 1)$

sw first frame $=1$

zero_b $=0$;

sw_non_bubble $=1$;

end

else \% frame $>1$

[vertical_unit, ] =size(bolha_unit);

for $\mathrm{j}=1: \mathrm{n}$ _frame $(\mathrm{k}, 1) \%$ particula do frame atual

$\mathrm{sw} \_\mathrm{b}=0 ; \% 1$ indica se ja identificou de que bolha pertence a nova bolha // 0 indica q nao pertence $\hookrightarrow \quad$ a nenhuma bolha anterior

zero $b=1$;

while $\mathrm{sw} \_\mathrm{b}==0 \%$ bolha identificada pertence a mesma bolha ja identificada if $\mathrm{k}$-zero_b $>1$

while $\mathrm{n}$ frame $(\mathrm{k}-$ zero $\mathrm{b}, 1)==0$ \&\& zero $\mathrm{b}<$ frames hide \%caso algum frame

$\hookrightarrow$ intermediario nao tenha bolhas, nem entra e retrocede outro frame

end

end

if zero_b $>=$ frames_hide $\& \& \mathrm{n} \_$frame $\left(\mathrm{k}-\mathrm{zero} \_\mathrm{b}, 1\right)==0$

frame_i $=\mathrm{k}-$ zero_b;

bolha_nova $=\max (\max ($ bolha_unit $))+1$;

bolha_unit(bolha_nova,, 1$)=$ bolha_nova;

centroide unit(bolha nova,:, $\mathrm{k}, 1)=\operatorname{centroide}(\mathrm{k},:, \mathrm{j}, 1)$;

limites_unit(bolha_nova, $, \mathrm{k}, 1)=\operatorname{limites}(\mathrm{k},:, \mathrm{j}, 1)$;

volume_unit(bolha_nova, $\mathrm{k}, 1)=\operatorname{volume}(\mathrm{k}, 1, \mathrm{j}, 1)$;

ratio_al_unit(bolha_nova, $\mathrm{k}, 1)=$ ratio_al $(\mathrm{k}, 1, \mathrm{j}, 1)$

diametro_virt_unit(bolha_nova, $\mathrm{k}, 1)=$ diametro_virt $(\mathrm{k}, 1, \mathrm{j}, 1)$;

tempo_unit(bolha_nova, $\mathrm{k}, 1)=\operatorname{tempo}(\mathrm{k}, 1, \mathrm{j}, 1)$;

zero_b $=1$;

sw_b $=1$

else

for $\mathrm{i}=1: \mathrm{n} \_$frame(k-zero_b,1) \%particula dos frames anteriores...ESTA CORRETO,

$\rightarrow$ preciso outro for para buscar na tabela unit, se identificar ele entra e faz o for bolha_frame_anterior $=\mathrm{i}$

$\mathrm{a}=\operatorname{abs}\left((\operatorname{centroide}(\mathrm{k}, 1, \mathrm{j}, 1)-\operatorname{centroide}(\mathrm{k}-\right.$ zero_b $\left., 1, \mathrm{i}, 1)) /\left(\operatorname{crit} \_\operatorname{sep} * \operatorname{limites}(\mathrm{k}, 3, \mathrm{j}, 1)\right)\right)$;

if $\mathrm{sw} \quad \mathrm{b}==0$

if a $<1 \%$ para reconhecer bolhas de frames pasados

[vertical_unit, ] =size(bolha_unit);

for unit=1:vertical_unit

$\mathrm{b}=\mathbf{a b s}(($ centroide $(\mathrm{k}, 1, \mathrm{j}, 1)$ - centroide_unit (unit, $1, \mathrm{k}$-zero_b, 1$)) /($ $\hookrightarrow$ crit_sep*limites $(\mathrm{k}, 3, \mathrm{j}, 1)))$;

if $\mathrm{b}<1$ \&\& $\mathrm{sw} \quad \mathrm{b}==0 \% \& \&$ bolha unit(unit, $k$-zero $b$ ) $\sim=0$

frame $i=k$-zero $b$

bolha_ja_reconhecida=bolha_unit(unit, $\mathrm{k}-$ zero_b, 1 )

if bolha_unit(unit, $\mathrm{k}$-zero_b,1) $>0$ 


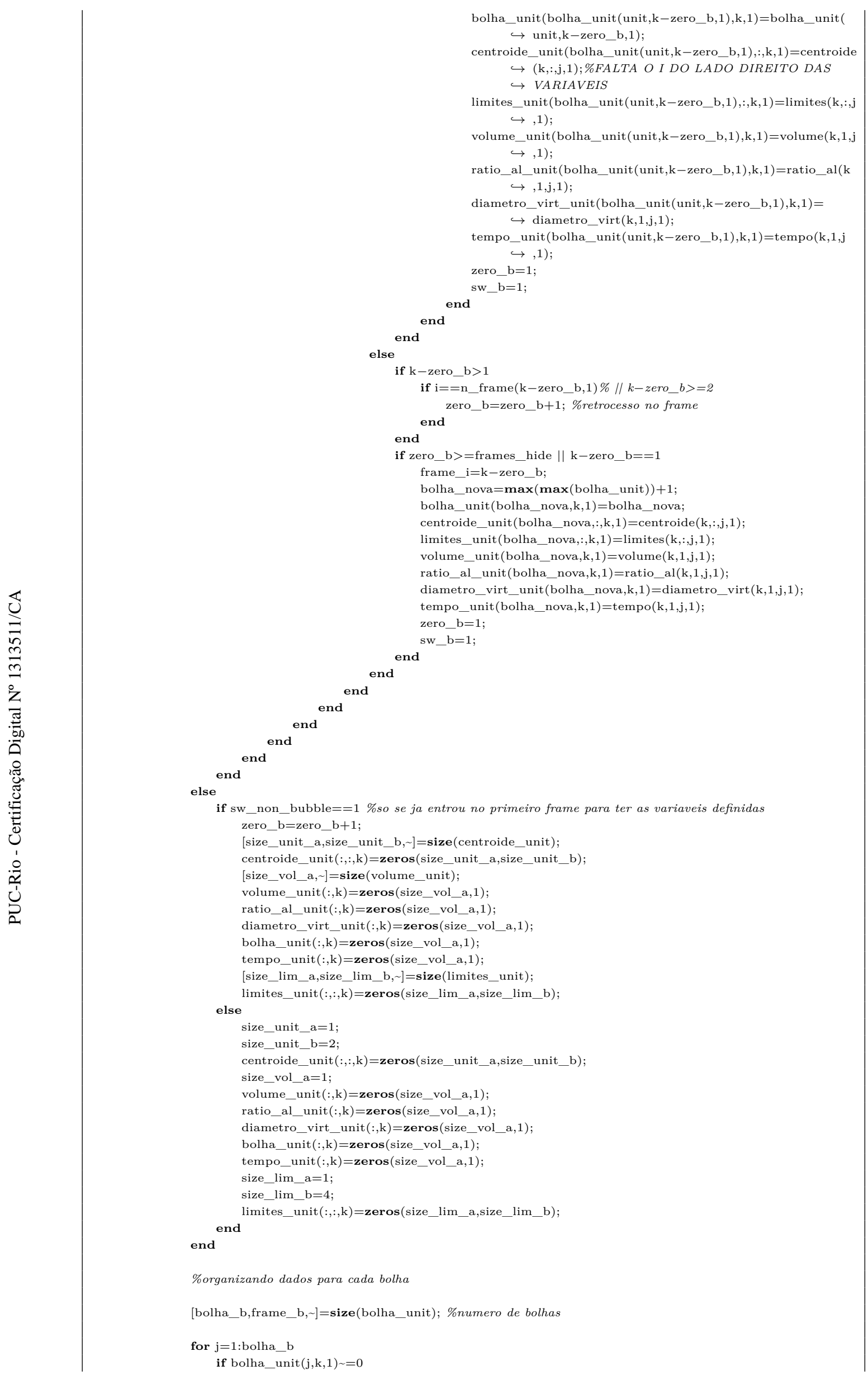


centroide bolha $(\mathrm{k},:$, bolha unit $(\mathrm{j}, \mathrm{k}, 1), 1)=$ centroide unit $(\mathrm{j},:, \mathrm{k}, 1)$;

limites_bolha $(\mathrm{k},:$, bolha_unit $(\mathrm{j}, \mathrm{k}, 1), 1)=$ limites_unit $(\mathrm{j},:, \mathrm{k}, 1)$;

volume_bolha $\left(\mathrm{k}, \mathrm{bolha} \_u n i t(\mathrm{j}, \mathrm{k}, 1), 1\right)=\operatorname{volume\_ unit}(\mathrm{j}, \mathrm{k}, 1)$;

ratio_bolha $(\mathrm{k}$,bolha_unit $(\mathrm{j}, \mathrm{k}, 1), 1)=$ ratio_al_unit $(\mathrm{j}, \mathrm{k}, 1)$;

diametro_virt_bolha $\left(\mathrm{k}, \mathrm{bolha} \_u n i t(\mathrm{j}, \mathrm{k}, 1), 1\right)=$ diametro_virt_unit $(\mathrm{j}, \mathrm{k}, 1)$;

tempo_bolha $\left(\bar{k}, b o l h a \_u n i t(j, \bar{k}, 1), 1\right)=$ tempo_unit $(\mathrm{j}, \mathrm{k}, 1)$;

end

\%adicionando um rectangulo e circulo ao redor da bolha no video

if geral $==1$

if $\mathrm{n} \sim=0$

IbinBW $=$ im2uint8(IbinBW $)$;

red=uint $8\left(\left[\begin{array}{lll}255 & 0 & 0\end{array}\right]\right)$;

image_shape $=\operatorname{repmat}(\operatorname{IbinBW},[1,1,3]) ; \%$ imagem na qual foi colocada a figura

shapeInserter = vision.ShapeInserter('Shape','Rectangles','BorderColor','Custom', '

$\hookrightarrow$ CustomBorderColor', red );

shapeInserter_circle = vision.ShapeInserter('Shape','Circles','BorderColor','Custom', ',

$\hookrightarrow$ CustomBorderColor', red );

for $\mathrm{i}=1: \mathrm{n}$

image_shape $=\operatorname{step}($ shapeInserter, image_shape, rectangle $(i,:))$;

image_shape $=\operatorname{step}($ shapeInserter_circle, image_shape, $\operatorname{circle}(i,:))$;

end

if geral==1 \%imagem para video geral

imwrite(image_shape,['bin \bin' sprintf('\%04.f',k) '.jpg']); \%salvando imagem prenchida e com $\hookrightarrow$ cores invertidos

end

en

end

else

if $\mathrm{sw} \_$non_bubble $==1 \%$ so se $j$ a entrou no primeiro frame para ter as variaveis definidas

zero_b=zero_b +1

[size_unit_a,size_unit_b, ] $=$ size(centroide_unit);

centroide_unit $(:,,:, \mathrm{k})=\mathbf{z e r o s}($ size_unit_a,size_unit_b);

[size_vol_a, ] $=$ size(volume_unit);

volume_unit $(:, \mathrm{k})=$ zeros $($ size_vol_a, 1$)$

ratio_al_unit $(:, \mathrm{k})=\mathbf{z e r o s}($ size_vol_a, 1$)$;

diametro_virt_unit $(:, \mathrm{k})=\mathbf{z e r o s}\left(\mathrm{size} \_\right.$vol_a, 1$)$;

bolha_unit $(:, \mathrm{k})=$ zeros(size_vol_a, 1$)$;

tempo_unit $(:, \mathrm{k})=$ zeros(size_vol_a, 1$)$;

[size_lim_a,size_lim_b, ] $=\mathbf{s i z e}($ limites_unit);

limites_unit $(:,:, \mathrm{k})=$ zeros $($ size_lim_a,size_lim_b)

end

end

clearvars BW bubble_temp IbinBW IfiltBW image_shape IsubBW tempo \%limpando variaveis end \%end $k$ para cada frame

exist centroide_bolha

if ans $==0$

'Nao $\sqcup$ achou $\sqcup$ bolha $\sqcup$ O $\sqcup$ programa'

else

[frame_vol,part_vol,bolha_vol,video_vol] =size(centroide_bolha); end

for bol=1:bolha_vol \%cada bolha do video

sw_n $=0$;

sw_v $=0$

position_frame_orig=abs(frameWidth $*$ escala_video $1 *$ position_frame); \%posicao de referencia para calcular o $\hookrightarrow$ ponto mais proximo

diferenca_frame $=\mathbf{a b s}($ frameWidth $*$ escala_video1-position_frame_orig); \%posicao original de diferenca entre a $\hookrightarrow$ bolha e o ponto de referencia

for $\mathrm{k}=1$ :frame_vol

if volume_bolha $(\mathrm{k}, \mathrm{bol}, 1) \sim=0 \%$ para um deslocamento com mais de um frame, sao necesarios multiples frames $\hookrightarrow$ com uma bolha para calcular velocidade

sw_n $=$ sw_n +1 ;

dif_point $=\mathbf{a b s}($ centroide_bolha $(\mathrm{k}, 1, \mathrm{bol}, 1)$ - position_frame_orig); \%diferencia entre bolha e ponto de $\hookrightarrow$ referencia para cada frame

if $\mathrm{sw} \mathrm{n}>$ frame vel

$\mathrm{sw}-\mathrm{v}=\mathrm{sw}-\mathrm{v}+1$

deslocamento_temp $=\mathbf{s q r t}(($ centroide_bolha $(\mathrm{k}, 1, \mathrm{bol}, 1)-$ centroide_bolha $(\mathrm{k}-$ frame_vel, $1, \mathrm{bol}, 1))$

$\hookrightarrow{ }^{\wedge} 2+\left(\right.$ centroide bolha $\left(\mathrm{k}, 2\right.$,bol,1) - centroide bolha $\left.(\mathrm{k} \text {-frame vel,2,bol,1) })^{\wedge} 2\right)$

deslocamento(sw $\mathrm{v}, 1, \mathrm{bol}, 1)=$ deslocamento temp;

velocidade $\left(\mathrm{sw} \_\mathrm{v}, 1, \mathrm{bol}, 1\right)=\operatorname{deslocamento}\left(\mathrm{sw} \_\mathrm{v}, 1, \mathrm{bol}, 1\right) /(((1 /$ frameRates $) *$ frame_vel $))$; reynolds $\left(\mathrm{sw} \_\mathrm{v}, 1, \mathrm{bol}, 1\right)=\operatorname{velocidade}\left(\mathrm{sw} \_\mathrm{v}, 1, \mathrm{bol}, 1\right) \wedge(2-\mathrm{ipl}) * \operatorname{limites} \_\mathrm{bolha}(\mathrm{k}, 3, \mathrm{bol}, 1) \wedge \mathrm{ipl} * \mathrm{den} \_\mathrm{l} /$

$\hookrightarrow$ ind_cons; 
reynolds_2(sw_v, $1, \mathrm{bol}, 1)=$ velocidade $\left(\mathrm{sw} \_\mathrm{v}, 1, \mathrm{bol}, 1\right) *$ limites_bolha $(\mathrm{k}, 3, \mathrm{bol}, 1) *$ den_l $/(\mathrm{to} /($

$\hookrightarrow$ velocidade(sw_v, 1,bol,1)/limites_bolha $(\mathrm{k}, 3, \mathrm{bol}, 1))+\mathrm{ind} \_$cons $*\left(\operatorname{velocidade}\left(\mathrm{sw} \_\mathrm{v}, 1, \mathrm{bol}, 1\right)\right.$ $\hookrightarrow /$ limites_bolha $\left.(\mathrm{k}, 3, \mathrm{bol}, 1))^{\wedge}(\mathrm{ipl}-1)\right)$;

bingham $\left(\mathrm{sw} \_\mathrm{v}, 1, \mathrm{bol}, 1\right)=($ to/ind_cons $) *\left(\left(\right.\right.$ limites_bolha $\left.(\mathrm{k}, 3, \mathrm{bol}, 1) / \operatorname{velocidade}\left(\mathrm{sw} \_\mathrm{v}, 1, \mathrm{bol}, 1\right)\right)($ ipl $)$ $\hookrightarrow)$;

centroide_vel $\left(\mathrm{sw} \_\mathrm{v},:, \mathrm{bol}, 1\right)=$ centroide_bolha $(\mathrm{k},:, \mathrm{bol}, 1)$;

diam_2(sw_v, $1, \mathrm{bol}, 1)=$ diametro_virt_bolha $(\mathrm{k}, \mathrm{bol}, 1)$;

ratio_bolha_2(sw_v, $1, \mathrm{bol}, 1)=$ ratio_bolha $(\mathrm{k}, \mathrm{bol}, 1)$;

deslocamento_1 $\left(\mathrm{sw} \_\mathrm{v}, 1, \mathrm{bol}, 1\right)=$ cortexmax $*$ escala_video $1-$ centroide_bolha $(\mathrm{k}, 1, \mathrm{bol}, 1)$

\%calculo da cinematica da bolha num ponto especifico

if dif_point $<=$ diferenca_frame

centroide_frame $(\mathrm{bol},:, \mathrm{q})=$ centroide_bolha $(\mathrm{k},:, \mathrm{bol}, 1)$;

volume_frame $(\mathrm{bol}, \mathrm{q})=$ volume_bolha $(\mathrm{k}, \mathrm{bol}, 1)$;

diam_frame $(\mathrm{bol}, \mathrm{q})=$ diametro_virt_bolha $(\mathrm{k}, \mathrm{bol}, 1)$;

velocidade_frame $(\mathrm{bol}, \mathrm{q})=$ velocidade $\left(\mathrm{sw} \_\mathrm{v}, 1, \mathrm{bol}, 1\right)$

ratio_al_frame $(\mathrm{bol}, \mathrm{q})=$ ratio_bolha $(\mathrm{k}, \mathrm{bol}, 1)$;

tempo_frame $($ bol,q) $=$ tempo_bolha $(\mathrm{k}, \mathrm{bol}, 1)$;

reynolds_frame $(\mathrm{bol}, \mathrm{q})=\operatorname{reynolds}\left(\mathrm{sw} \_\mathrm{v}, 1, \mathrm{bol}, 1\right)$;

reynolds_frame_2 $(\mathrm{bol}, \mathrm{q})=$ reynolds_ $2\left(\mathrm{sw} \_\mathrm{v}, 1, \mathrm{bol}, 1\right)$;

bingham_frame $(\mathrm{bol}, \mathrm{q})=$ bingham $\left(\mathrm{sw} \_\mathrm{v}, 1, \mathrm{bol}, 1\right)$;

centroide_vel_frame $(\mathrm{bol}, \mathrm{q})=$ centroide_vel $\left(\mathrm{sw} \_\mathrm{v}, 1, \mathrm{bol}, 1\right)$;

diferenca_frame $=\mathbf{a b s}($ centroide bolha $(\mathrm{k}, 1, \mathrm{bol}, 1)$ - position frame orig);

dif_frame_temp $(b o l, q)=$ diferenca_frame;

limites_frame $(\mathrm{bol},:, \mathrm{q})=$ limites_bolha $(\mathrm{k},:, \mathrm{bol}, 1)$;

end

end

else

sw_n $=0$;

end

end

end

\%CALCULANDO SEPARACaO DAS BOLHAS

for $\mathrm{k}=1$ :frame $\mathrm{vol}$

for bol=1:bolha_vol-1

if centroide bolha $(\mathrm{k}, 1, \mathrm{bol}, 1) \sim=0$ \&\& centroide bolha $(\mathrm{k}, 1, \mathrm{bol}+1,1) \sim=0$

separacao $(\mathrm{k}, 1, \mathrm{bol}, 1)=\mathbf{a b s}\left(\mathrm{centroide \_ bolha}(\mathrm{k}, 1, \mathrm{bol}, 1)-\right.$ centroide_bolha $\left.(\mathrm{k}, 1, \mathrm{bol}+1,1)\right)$; frame_sep $(\mathrm{k}, 1, \mathrm{bol}, 1)=\mathrm{k}$;

end

end

delete('base/*')

delete('bolha/*')

delete('calibracao/*')

[frame_fil,bolha_fil,q_fil] $=$ size(diametro_virt_bolha);

clearvars frame base plotframe framebubble perimeter alturamax BWcut binFill binImage coordenada

$\hookrightarrow$ deslocamento image_circle image_rectangle rgb fileName shapeInserter videoFile videoObject

$\hookrightarrow$ shapeInserter_circle stats

$\% \% \% \% \% \% \% \% \% \% \% \% \% \% \% \% \% \% \% \% \% \% \% \% \% \% \% \% \% \% \% \% \% \% \% \% \% \% \% \% \% \% \% \% \% \% \%$

\%CURVAS DA CINEMATICA DA BOLHA REGIME TRASIENTE

\%\%\%\%\%\%\%\%\%\%\%\%\%\%\%\%\%\%\%\%\%\%\%\%\%\%\%\%\%\%\%\%\%\%\%\%\%\%\%\%\%\%\%\%\%\%\%

'curvas $\sqcup$ resultados'

$\mathrm{sw} \_\mathrm{img}=\mathrm{sw} \_\mathrm{img}+1$

if $\mathrm{sw} \_$img $==1$

detail=figure

end

if numvid $>1$

mapcolor=numvid; \%criando informacoes para as legendas das imagens

$\mathrm{cc}=\mathbf{h s v}$ (mapcolor);

legenda $=\operatorname{cell}($ numvid, 1$)$

for iter $=1$ :numvid

legenda $\{$ iter, 1$\}=$ strcat ('v',num2str(iter)); end

else

mapcolor=bolha vol; \%criando informacoes para as legendas das imagens

$\mathrm{cc}=\mathbf{h s v}$ (mapcolor);

legenda $=$ cell(bolha_vol,1);

for iter=1:bolha vol

legenda $\{$ iter, 1$\}=\operatorname{strcat}($ 'b', num2str(iter));

$$
\text { end }
$$

end 
larguramax $=\operatorname{ceil}(\max (\max (\max (\max ($ limites_pix $(:, 3,:,:,:))))))+5 ;$ \%gerando as medidas do maior frame para criar $\hookrightarrow$ um frame para todos os perfis da bolha

$\operatorname{alturamax}=\operatorname{ceil}(\max (\max (\max (\max ($ limites_pix $(:, 4,:,:,::))))))+5$;

$[$ sizem,, ,sizej, $\sim, \sim, \sim]=\operatorname{size}($ area__pix);

frame_base=zeros(alturamax,larguramax,sizem,sizej);

for $\mathrm{j}=1$ :bolha_fil \%para cada bolha do ultimo video

$\mathrm{f}=1$; \%trajeto continuo da bolha

centroide_temp $=\left[\begin{array}{ll}0 & 0\end{array}\right]$;

for $\mathrm{k}=1$ :frame_fil \%para cada frame

if centroide_bolha $(\mathrm{k}, 1, \mathrm{j}, 1) \sim=0 \%$ calculando o vetor para uma bolha ou um trajeto continua da bolha para $\hookrightarrow$ graficar

centroide_temp $(\mathrm{f},:)=$ centroide_bolha $(\mathrm{k},:, \mathrm{j}, 1)$;

centroide_temp_inv $(\mathrm{f}, 1)=$ cortexmax $*$ escala_video 1 -centroide_temp $(\mathrm{f}, 1)$;

limites_temp $(\mathrm{f},:)=$ limites_bolha $(\mathrm{k},:, \mathrm{j}, 1)$;

diametro_virt_temp $(\mathrm{f}, 1)=$ diametro_virt_bolha $(\mathrm{k}, \mathrm{j}, 1)$;

volume_temp $(\mathrm{f}, 1)=$ volume_bolha $(\mathrm{k}, \mathrm{j}, 1)$;

ratio_temp $(\mathrm{f}, 1)=$ ratio_bolha $(\mathrm{k}, \mathrm{j}, 1)$;

deslocamento_temp $1(\mathrm{f}, 1)=$ centroide_bolha $(\mathrm{k}, 1, \mathrm{j}, 1)$;

$\mathrm{f}=\mathrm{f}+1$;

end

end

if $\operatorname{sum}($ centroide_temp_inv $(:, 1)) \sim=0$

volume temp fil=medfilt1(volume temp,of); \%aplicando filtro medio nos vetores de resultados ratio_temp_fil $=$ medfilt 1 (ratio_temp,of); \%\%aplicando filtro medio nos vetores de resultados diam_temp_fil=medfilt1(diametro_virt_temp,of); \%aplicando filtro medio nos vetores de resultados deslocamento temp1 fil=medfilt1(deslocamento_temp1,of); \%aplicando filtro medio nos vetores de $\hookrightarrow$ resultados

\%calculando o valor meio para a trajetoria no video

[size_temp_1, ] $=\mathbf{s i z e}($ volume_temp_fil);

volume_temp_fil_meia $(\mathrm{j}, \mathrm{q})=\mathbf{s u m}($ volume_temp_fil $) / \mathrm{size} \_t e m p \_1$;

ratio_temp_fil_meia $(\mathrm{j}, \mathrm{q})=\mathbf{s u m}($ ratio_temp_fil $) /$ size_temp_1;

diam_temp_fil_meia $(\mathrm{j}, \mathrm{q})=\mathbf{s u m}\left(\mathrm{diam} \_\right.$temp_fil $) / \operatorname{size} \_t e m p \_1$;

deslocamento_temp_fil_meia $(\mathrm{j}, \mathrm{q})=\mathbf{s u m}($ deslocamento_temp1_fil $) / \mathrm{size} \_t e m p \_1$;

\%calculando maximo valor de todas as bolhas do ultimo video

if $\mathrm{j}==1 \quad \& \& \quad \mathrm{q}==1$

vol_max $=\max ($ volume_temp_fil $)$

ratio_max $=\max ($ ratio_temp_fil $)$;

diam_max $=\max ($ diam_temp_fil $)$;

deslocamento_max $=\max \left(\operatorname{deslocamento\_ temp1\_ fil)}\right.$;

else

if $\max ($ volume_temp_fil) $>$ vol_max

end

vol_max $=\max ($ volume_temp_fil $)$;

if $\max ($ ratio_temp_fil) $>$ ratio_max ratio_max $=\max ($ ratio_temp_fil $)$;

end

if $\max ($ diam_temp_fil $)>$ diam_max

diam_max $=\max ($ diam_temp_fil $)$;

end

if $\max$ (deslocamento_temp1_fil) $>$ deslocamento_max deslocamento_max $=\max ($ deslocamento_temp1_fil $)$;

end

end

\%curvas de velocidade e numero de reynolds

$\left[\mathrm{k} \_\right.$vel,, bolha_vel, $]=\operatorname{size}($ velocidade $)$;

if $\mathbf{j}<=$ bolha_vel

velocidade_temp $=[0]$;

$\mathrm{f}=1$;

for $\mathrm{j} j=1: \mathrm{k} \_$vel

if velocidade $(\mathrm{jj}, 1, \mathrm{j}, 1) \sim=0$

velocidade_temp $(f,:)=\operatorname{velocidade}(\mathrm{jj}, 1, \mathrm{j}, 1)$;

reynolds_temp $(f,:)=\operatorname{reynolds}(\mathrm{jj}, 1, \mathrm{j}, 1)$

reynolds_temp_2(f,:) =reynolds_2(jj, $1, \mathrm{j}, 1)$;

bingham_temp $(\mathrm{f},:)=\operatorname{bingham}(\mathrm{jj}, 1, \mathrm{j}, 1)$;

centroide_vel_temp $(\mathrm{f},:)=$ centroide_vel $(\mathrm{jj},:, \mathrm{j}, 1)$;

centroide_vel_temp_inv $(f, 1)=$ cortexmax $*$ escala_video1 - centroide_vel $(f, 1)$;

diam_2_temp $(\mathrm{f}, 1)=$ diam_2 $(\mathrm{jj}, 1, \mathrm{j}, 1)$;

ratio_bolha_2_temp $(\mathrm{f}, 1)=$ ratio_bolha_2 $(\mathrm{jj}, 1, \mathrm{j}, 1)$;

deslocamento1_temp $(\mathrm{f}, 1)=$ deslocamento_ $1(\mathrm{jj}, 1, \mathrm{j}, 1)$;

$\mathrm{f}=\mathrm{f}+1$; 
end

if $\operatorname{sum}($ velocidade_temp $(:, 1)) \sim=0$

velocidade_temp_fil=medfilt 1 (velocidade_temp,of); \%aplicando filtro medio nos vetores de $\hookrightarrow$ resultados

reynolds_temp_fil $=$ medfilt 1 (reynolds_temp,of);

reynolds_temp_fil_2=medfilt1(reynolds_temp_2,of)

bingham_temp_fil=medfilt 1 (bingham_temp,of);

diam_2_temp_fil =medfilt 1 (diam_2_temp,of);

ratio_bolha_2_temp_fil =medfilt1 (ratio_bolha_2_temp,of);

deslocamento1_temp_fil =medfilt1(deslocamento1_temp,of);

\%calculando o valor meio para a trajetoria no video

[size_temp_2, ] $=\operatorname{size}($ velocidade_temp_fil);

velocidade_temp_fil_meia $(\mathrm{j}, \mathrm{q})=\mathbf{s u m}($ velocidade_temp_fil)/size_temp_2;

reynolds_temp_fil_meia $(\mathrm{j}, \mathrm{q})=\mathbf{s u m}($ reynolds_temp_fil $) / \mathrm{size} \_t e m p \_2$;

reynolds_temp_fil_2_meia $(\mathrm{j}, \mathrm{q})=\mathbf{s u m}\left(\mathrm{reynolds} \_t e m p \_f i l \_2\right) / \operatorname{size} \_t e m p \_2$;

bingham_temp_fil_meia $(\mathrm{j}, \mathrm{q})=\mathbf{s u m}\left(\mathrm{bingham \_ temp \_ fil)/ \operatorname {size } \_ t e m p \_ 2}\right.$

diam_2_temp_fil_meia $(\mathrm{j}, \mathrm{q})=\mathbf{s u m}\left(\mathrm{diam} \_2 \_t e m p \_f i l\right) / \mathrm{size} \_t e m p \_2$;

ratio_bolha_2_temp_fil_meia $(\mathrm{j}, \mathrm{q})=\mathbf{s u m}\left(\mathrm{ratio} \_b o l h a \_2 \_t e m p \_f i l\right) / \operatorname{size} \_t e m p \_2$;

deslocamento1_temp_fil_meia $(\mathrm{j}, \mathrm{q})=\mathbf{s u m}\left(\operatorname{deslocamento1} \_t e m p \_f i l\right) / s i z e \_t e m p \_2$;

\%calculando maximo valor no eixo vertical

if $\mathrm{j}==1 \quad \& \& \mathrm{q}==1$

vel_max $=\max ($ velocidade_temp_fil $)$;

reynolds_max $=\max ($ reynolds_temp_fil $)$

reynolds_max_2 $=\max ($ reynolds_temp_2)

bingham_max $=\max ($ bingham_temp);

vel_max_temp $(\mathrm{q})=$ vel_max;

diam 2 max $=\max (\operatorname{diam} 2$ temp fil);

ratio_bolha_2_max $=\max ($ ratio_bolha_2_temp $)$;

deslocamento1_max $=\max ($ deslocamento1_temp $)$;

vel_min $=\min (\min ($ velocidade_temp_fil $($ velocidade_temp_fil $>0)))$;

reynolds_min $=\min (\min ($ reynolds_temp_fil $($ reynolds_temp_fil $>0)))$;

reynolds_min_2 $=\min (\min ($ reynolds_temp_2(reynolds_temp_2>0) $)$ );

bingham_min $=\min (\boldsymbol{m i n}($ bingham_temp $($ bingham_temp $>0)))$;

diam_2_min $=\min \left(\min \left(\operatorname{diam} \_2 \_t e m p \_f i l\left(d i a m \_2 \_t e m p \_f i l>0\right)\right)\right)$;

ratio_bolha_2_min $=\min \left(\min \left(r a t i o \_b o l h a \_2 \_t e m p\left(r a t i o \_b o l h a \_2\right.\right.\right.$ temp $\left.\left.>0\right)\right)$ ) else

deslocamento1_min $=\min (\boldsymbol{m i n}($ deslocamento1_temp $($ deslocamento1_temp $>0)))$;

if $\max ($ velocidade_temp_fil) $>$ vel_max

vel_max $=\max ($ velocidade_temp_fil $)$;

vel_max_temp $(q)=v e l \_$max;

end

if $\max ($ reynolds_temp_fil $)>$ reynolds_max

reynolds_max $=\max ($ reynolds_temp_fil $)$;

end

if $\max$ (reynolds_temp_fil_2) $>$ reynolds_max 2

reynolds_max_2 $=\max ($ reynolds_temp_fil_2 $)$;

end

if $\max$ (bingham_temp_fil) > bingham_max

bingham_max $=\max ($ bingham_temp_fil $)$;

end

if $\max ($ diam_2_temp_fil $)>$ diam_2_max

diam_2_max $=\max ($ diam_2_temp_fil $)$;

end

if $\max ($ ratio_bolha_2_temp_fil) $>$ ratio_bolha_2_max

ratio_bolha_2_max $=\max ($ ratio_bolha_2_temp_fil);

end

if $\max ($ deslocamento1_temp_fil $)>$ deslocamento1_max

deslocamento1_max $=\max ($ deslocamento1_temp_fil $)$

end

if $\min (\min ($ velocidade_temp_fil (velocidade_temp_fil $>0)))<$ vel_min end vel_min $=\min (\min ($ velocidade_temp_fil $($ velocidade_temp_fil $>0)))$;

$\min (\min ($ reynolds_temp_fil (reynolds_temp_fil $>0)))<$ reynolds_min reynolds_min $=\min (\min ($ reynolds_temp_fil $($ reynolds_temp_fil $>0)))$;

end

if $\min (\min ($ reynolds_temp_fil_2(reynolds_temp_fil__2>0) $))<$ reynolds_min_2 reynolds_min_2 $=\min (\boldsymbol{m i n}($ reynolds_temp_fil_2(reynolds_temp_fil_2 $>0))$ );

end

if $\min (\min ($ bingham_temp_fil $($ bingham_temp_fil $>0)))<$ bingham_min bingham_min $=\mathbf{m i n}(\min ($ bingham_temp_fil $($ bingham_temp_fil $>0)))$;

end

if $\min (\min ($ diam_2_temp_fil $($ diam_2_temp_fil $>0)))<$ diam_2_min 


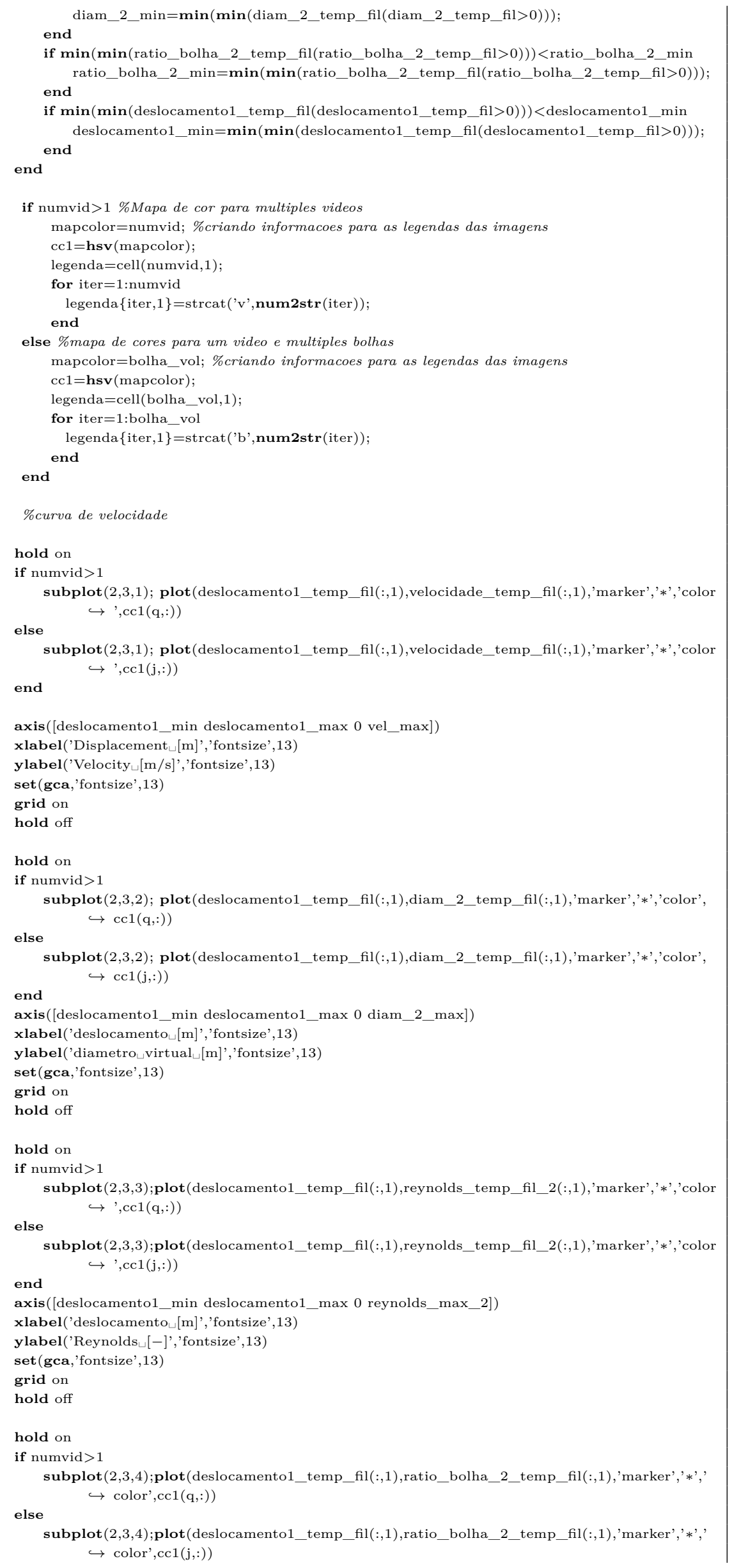


end

axis([deslocamento1_min deslocamento1_max 0 ratio_bolha_2_max])

xlabel('deslocamento॰[m]','fontsize',13)

ylabel('relacao $\_$altura/largura $\sqcup[-]$ ','fontsize',13)

set (gca,'fontsize',13)

grid on

hold off

hold on

if numvid $>1$

subplot $(2,3,5) ; \operatorname{plot}($ deslocamento1_temp_fil(:,1),bingham_temp_fil(:,1),'marker','*','color', $\hookrightarrow \operatorname{cc} 1(\mathrm{q},:))$

else

subplot $(2,3,5) ; \boldsymbol{p l o t}($ deslocamento1_temp_fil(:,1),bingham_temp_fil(:,1),'marker','*','color', $\hookrightarrow \operatorname{cc} 1(\mathrm{j},:))$

end

axis([deslocamento1_min deslocamento1_max 0 bingham_max])

xlabel('deslocamento $[\mathrm{m}]$ ',' fontsize',13)

ylabel('Bingham $\sqcup[-]$ ','fontsize',13)

set (gca,'fontsize',13)

grid on

hold off

end

end

if $\mathrm{q}==$ numvid \&\& $\mathrm{j}==$ bolha_fil

$\mathrm{h}=$ legend(legenda,'Location','southwest','position',[0.95,0,0.0005,1]); set $\left(\mathrm{h},{ }^{\prime}\right.$ FontSize',4);

end

end

clearvars deslocamento1 temp fil deslocamento1 temp ratio bolha 2 temp diam 2 temp

$\hookrightarrow$ ratio_bolha_2_temp_fil diam_2_temp_fil ratio_bolha_2_temp centroide_vel_temp_inv

$\hookrightarrow$ velocidade_temp_inv centroide_temp_inv porc_var_sep_temp_fil separacao_temp

$\hookrightarrow$ porcentagem_sep_temp frame_sep_temp separacao_temp separacao_temp_fil centroide_vel_temp

$\hookrightarrow$ reynolds_temp reynolds_temp_2 bingham_temp velocidade_temp ratio_temp_fil limites_temp

$\hookrightarrow$ diam_temp_fil diametro_virt_temp limites_temp centroide_temp diam_temp

$\hookrightarrow$ ratio_al_vel_temp_fil ratio_al_vel_temp ratio_temp_fil volume_temp_fil velocidade_temp_fil

$\hookrightarrow$ reynolds_temp_fil reynolds_temp_fil_2 volume_temp area_temp maxeixo_temp velocidade_temp

end

$\hookrightarrow$ reynolds_temp centroide_vel_temp diam_temp_fil ratio_temp tempo_temp \%limpando variaveis

\%compilando resultados

vol media $=\operatorname{sum}($ volume frame $(:, q)) / \mathbf{n n z}(\operatorname{volume}$ frame $(:, q))$;

velocidade_media $=\mathbf{s u m}\left(\operatorname{velocidade\_ frame}(:, \mathrm{q})\right) / \mathbf{n n z}\left(\operatorname{volume\_ frame}(:, \mathrm{q})\right)$;

ratio_al_frame_media $=\mathbf{s u m}($ ratio_al_frame $(:, q)) / \mathbf{n n z}\left(\operatorname{volume\_ frame}(:, q)\right)$;

reynolds_frame_media $=\mathbf{s u m}($ reynolds_frame $(:, q)) / \mathbf{n n z}($ volume_frame $(:, q))$;

reynolds_frame_media_2 $=\mathbf{s u m}($ reynolds_frame_2(:,q))/nnz(volume_frame $(:, \mathrm{q}))$;

bingham_frame_media $=\mathbf{s u m}($ bingham_frame $(:, \mathrm{q})) / \mathbf{n n z}\left(\operatorname{volume} \_\right.$frame $\left.(:, \mathrm{q})\right)$;

diam_media $(\mathrm{q})=\mathbf{s u m}\left(\operatorname{diam} \_\right.$frame $\left.(:, \mathrm{q})\right) / \mathbf{n n z}\left(\operatorname{volume\_ frame}(:, \mathrm{q})\right)$;

\%\%\%\%\%\%\%\%\%\%\%\%\%\%\%\%\%\%\%\%\%\%\%\%\%\%\%\%\%\%\%\%\%\%\%\%\%\%\%\%\%\%\%\%\%\%\%\%\%

\%CALCULANDO PERFIL DAS BOLHAS

\%\%\%\%\%\%\%\%\%\%\%\%\%\%\%\%\%\%\%\%\%\%\%\%\%\%\%\%\%\%\%\%\%\%\%\%\%\%\%\%\%\%\%\%\%\%\%\%\%

$\mathrm{h}=0$;

if perfil $==1$

'perfil $\sqcup$ da $\sqcup$ bolha'

for $\mathrm{i}=1$ :sizej \%para cada bolha

plotframe $=$ zeros $($ alturamax, larguramax $, 1,1)$;

$\mathrm{w}=0$;

for $\mathrm{p}=1$ :sizem \% cada frame

if limites_pix $(\mathrm{p}, 1, \mathrm{i})>$ cortexmin

else

$\mathrm{x} 1=\mathbf{f l o o r}($ limites_pix $(\mathrm{p}, 1, \mathrm{i})) ; \%$ coordenada horizontal

$\mathrm{x} 1=\mathbf{c e i l}($ limites_pix $(\mathrm{p}, 1, \mathrm{i})) ; \%$ coordenada horizontal

end

if limites_pix $(\mathrm{p}, 2, \mathrm{i})>$ corteymin

$\mathrm{y} 1=$ floor(limites_pix $(\mathrm{p}, 2, \mathrm{i}))$; \%aproximando por defeito a medida de coordenada vertical

else

$\mathrm{y} 1=\mathbf{c e i l}($ limites_pix $(\mathrm{p}, 2, \mathrm{i})) ; \%$ aproximando por defeito a medida de coordenada vertical

end

if limites_pix $(\mathrm{p}, 1, \mathrm{i})+$ limites_pix $(\mathrm{p}, 3, \mathrm{i})>$ cortexmax - cortexmin +1 


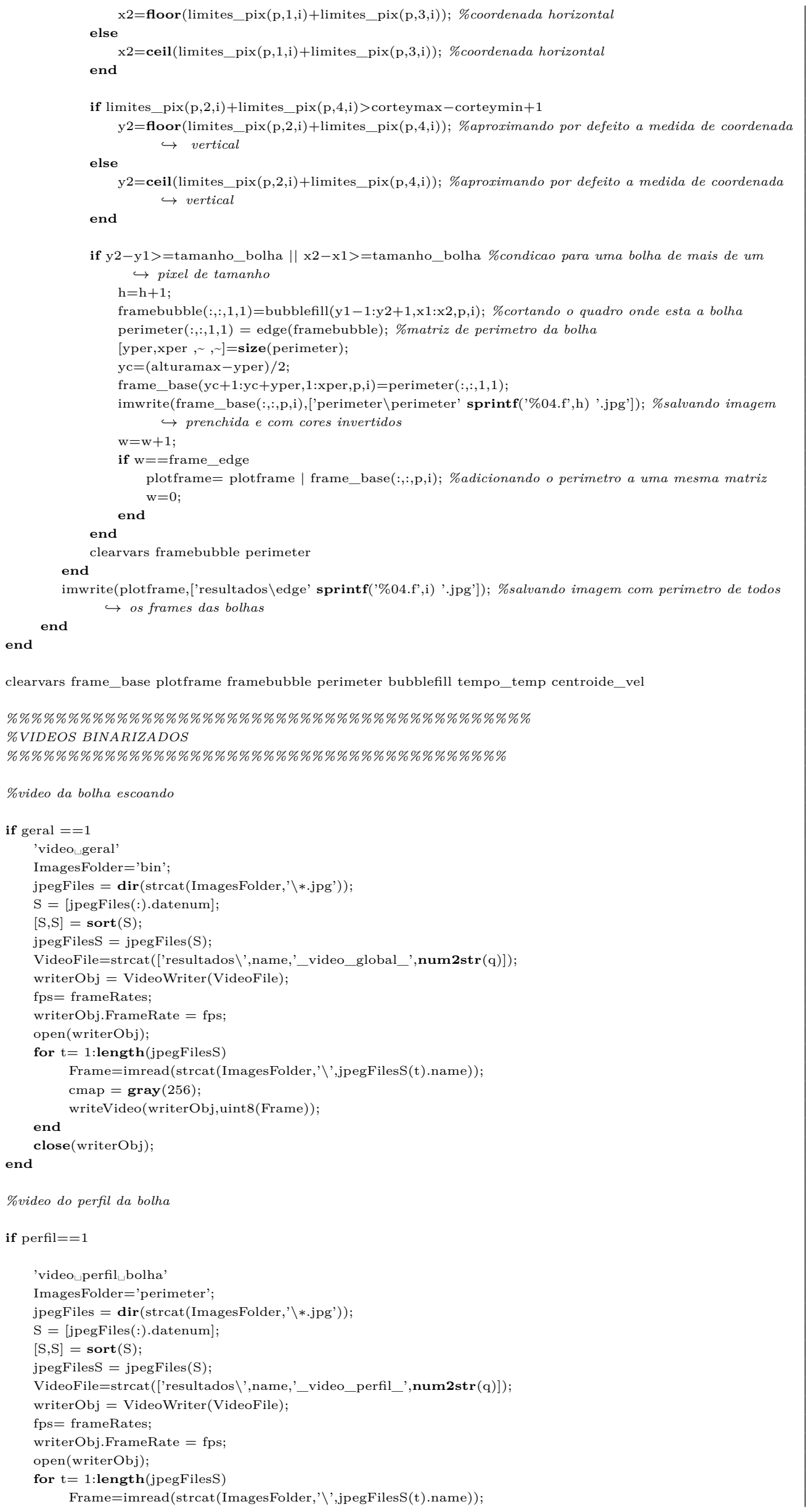




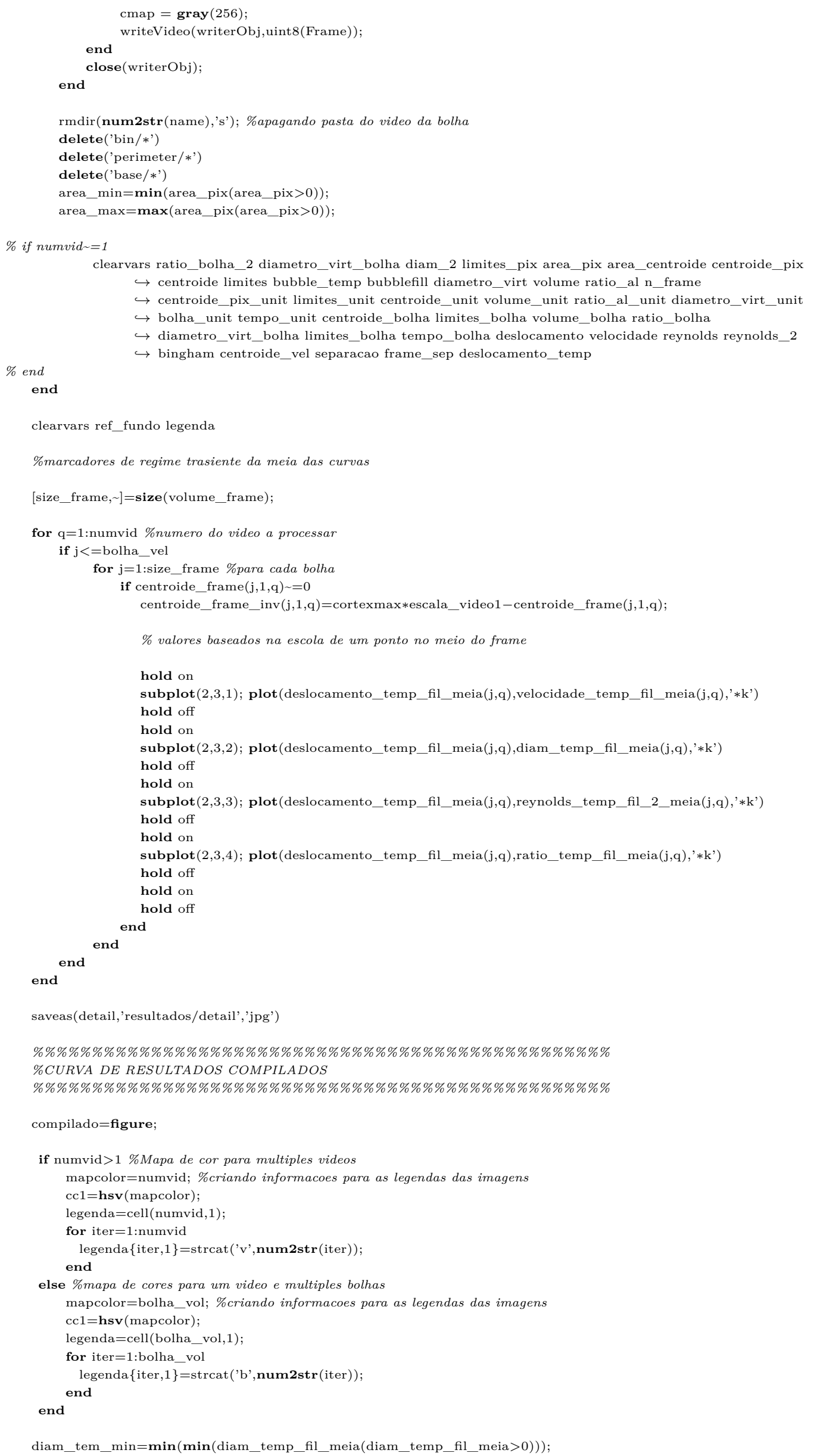


vol_tem_min $=\min (\min ($ volume_temp_fil_meia $($ volume_temp_fil_meia $>0)))$

ratio_tem_min $=\min \left(\min \left(r a t i o \_t e m p \_f i l \_m e i a\left(r a t i o \_t e m p \_f i l \_m e i a>0\right)\right)\right)$;

vel_tem_min $=\min (\min ($ velocidade_temp_fil_meia $($ velocidade_temp_fil_meia $>0)))$;

rey_tem_min $=\min (\min ($ reynolds temp_fil_2_meia $($ reynolds temp_fil_meia $>0))$ )

rey_tem_min_2 $=\min (\min ($ reynolds_temp_fil_2_meia $($ reynolds_temp_fil_2_meia $>0)))$;

bing_tem_min $=\min \left(\min \left(\operatorname{bingham} \_t e m p \_f i l \_m e i a\left(b i n g h a m \_t e m p \_f i l \_m e i a>0\right)\right)\right)$;

$[$ bolha_fil1, $]=\operatorname{size}($ diam_frame $)$;

for $\mathrm{q}=1$ :numvid \%numero de video

for $\mathrm{j}=1$ :bolha fill \%numero de frame

if diam_frame $(\mathrm{j}, \mathrm{q}) \sim=0$

if numvid $>1$

hold on

$\operatorname{subplot}(2,2,1)$; plot(diam_temp_fil_meia(j,q),velocidade_temp_fil_meia(j,q),'marker','*','color',cc1 $\longrightarrow(\mathrm{q},:))$

else

hold on

$\operatorname{subplot}(2,2,1)$; plot(diam_temp_fil_meia(j,q),velocidade_temp_fil_meia(j,q),'marker','*','color',cc1 $\hookrightarrow(\mathrm{j},:))$

end

hold off

if numvid $>1$

$\operatorname{axis}\left(\left[\right.\right.$ diam_tem_min $\max (\max ($ diam_temp_fil_meia $\left.\left.)) 0 \max \left(\max \left(\operatorname{velocidade} \_t e m p \_f i l \_m e i a\right)\right)\right]\right)$ end

ylabel('velocity $[\mathrm{m} / \mathrm{s}]$ ','fontsize',13)

xlabel('Virtual $\_$diameter $\sqcup[\mathrm{m}]$ ', 'fontsize',13)

set (gca,'fontsize',13)

grid on

if numvid $>1$

hold on

$\operatorname{subplot}(2,2,2)$; $\boldsymbol{p l o t}\left(\operatorname{bingham} \_t e m p \_f i l \_m e i a(j, q)\right.$, reynolds_temp_fil__2_meia(j,q),'marker','*','color' hold off $\hookrightarrow, \mathrm{cc} 1(\mathrm{q},:))$

else

hold on

subplot $(2,2,2)$; $\boldsymbol{p l o t}\left(\operatorname{bingham} \_t e m p \_f i l \_m e i a(j, \mathrm{q})\right.$,reynolds_temp_fil_2_meia(j,q),'marker','*','color' hold off $\rightarrow, \operatorname{cc} 1(\mathrm{j},:))$

if numvid $>1$

$\operatorname{axis}([$ bing_tem_min $\max (\max ($ bingham_temp_fil_meia) $) 0 \max (\max ($ reynolds_temp_fil_2_meia $)$ $\hookrightarrow)]$

end

ylabel('Reynolds $\sqcup$ number $\sqcup[-]$ ','fontsize',13)

xlabel('Bingham $\sqcup$ number $_{\sqcup}[-]$ ','fontsize',13)

set(gca,'fontsize',13)

grid on

if numvid $>1$

hold on

subplot $(2,2,3)$; plot(diam_temp_fil_meia(j,q),ratio_temp_fil_meia(j,q), 'marker','*','color',cc1(q,:)) hold off

else

hold on

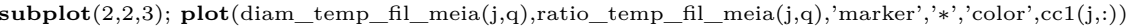
hold off

end

if numvid $>1$

$\operatorname{axis}([$ diam_tem_min $\max (\max ($ diam_temp_fil_meia $)) 0 \max (\max ($ ratio_temp_fil_meia $))])$

end

xlabel('Virtual $\_$diameter $\sqcup[\mathrm{m}]$ ','fontsize',13)

ylabel('ratio $\_$height/width $\sqcup[-]$ ','fontsize',13

set(gca,'fontsize',13)

grid on

if numvid $>1$

hold on

subplot $(2,2,4)$; plot(bingham_temp_fil_meia(j,q),ratio_temp_fil_meia(j,q),'marker','*','color',cc1(q $\hookrightarrow,:$ ))

hold off

hold on

subplot $(2,2,4)$; plot(bingham_temp_fil_meia(j,q),ratio_temp_fil_meia(j,q),'marker', '*','color',cc1(j $\hookrightarrow,:))$

end

hold off

if numvid $>1$

$\operatorname{axis}([$ bing_tem_min $\max (\max ($ bingham_temp_fil_meia $)) 0 \max (\max ($ ratio_temp_fil_meia $))])$ 
end

ylabel('ratio $\llcorner$ height/width $\sqcup[-]$ ','fontsize',13)

xlabel('Bingham $\sqcup$ number $_{\sqcup}[-]$ ','fontsize',13)

set (gca,'fontsize',13)

grid on

if $\mathrm{q}==$ numvid \&\& $\mathrm{j}==$ bolha_fil

h2=legend(legenda,'Location','southwest','position', [0.95, 0,0.0005,1]); set(h2,'FontSize',4);

end

clearvars diam_tem vol_tem ratio_tem vel_tem ref_fundo

end

saveas(compilado,'resultados/compilado','jpg')

clearvars legenda

save (['resultados $\backslash$ matrices $\backslash$ ',num2str(videoname part),'-centroide frame.mat'],'centroide frame');

save (['resultados $\backslash$ matrices $\backslash$ ',num2str(videoname_part), '-limites_frame.mat'], 'limites_frame');

save (['resultados \matrices $\backslash$ ',num2str(videoname_part), '-volume_frame.mat'], 'volume_temp_fil_meia');

save (['resultados $\backslash$ matrices $\backslash$ ',num2str(videoname_part),'_diam_frame.mat'],'diam_temp_fil_meia');

save (['resultados $\backslash$ matrices $\backslash$ ', num2str(videoname_part), '-velocidade_frame.mat'],'velocidade_temp_fil_meia');

save (['resultados $\backslash$ matrices $\backslash$ ',num2str(videoname_part), '-ratio_al_frame.mat'],'ratio_temp_fil_meia');

save (['resultados $\backslash$ matrices $\backslash$ ',num2str(videoname_part),'-tempo_frame.mat'],'tempo_frame');

save (['resultados $\backslash$ matrices $\backslash$ ', num2str(videoname_part), '-reynolds_frame.mat'],'reynolds_temp_fil_meia');

save (['resultados $\backslash$ matrices $\backslash$, num2str(videoname_part), '-reynolds_frame_2.mat'],'reynolds_temp_fil_2_meia');

save (['resultados $\backslash$ matrices $\backslash$ ', num2str(videoname_part),'-bingham_frame.mat'],'bingham_temp_fil_meia');

save (['resultados $\backslash$ matrices $\backslash$ ', num2str(videoname_part), '-centroide_vel_frame.mat'],'centroide_vel_frame');

save (['resultados $\backslash$ matrices $\backslash$ ',num2str(videoname_part), '-diferenca_frame.mat'],'diferenca_frame');

save (['resultados $\backslash$ matrices $\backslash$ ',num2str(videoname_part), '-dif_frame_temp.mat'],'dif_frame_temp')

end

\%\%\%\%\%\%\%\%\%\%\%\%\%\%\%\%\%\%\%\%\%\%\%\%\%\%\%

\% COMPILACAO DE MULTIPLES RESULTADOS DIFERENTES

$\% \% \% \% \% \% \% \% \% \% \% \% \% \% \% \% \% \% \% \% \% \% \% \% \% \% \% \%$

sw_comp $=0$;

if load mat $==1$

$[i i i, \sim]=\mathbf{s i z e}($ name_load_mat);

\%legenda da imagem

mapcolor=iii; \%criando informacoes para as legendas das imagens

cc2 $=\mathbf{h s v}$ (mapcolor);

legenda $1=\operatorname{cell}(\mathrm{iii}, 1)$;

for iter=1:iii

legenda1 $\{$ iter, 1$\}=$ strcat('b',num2str(iter));

end

compilado=figure;

for $\mathrm{qq}=1:$ iii \%bateria de videos

load(['originais $\backslash$ matrices $\backslash$ ',num2str(name_load_mat(qq,: )),'-centroide_frame.mat']);

load (['originais $\backslash$ matrices $\backslash$ ',num2str(name_load_mat(qq,:)),'-volume_frame.mat']);

load (['originais $\backslash$ matrices $\backslash$, ,num2str(name_load_mat(qq,:)),'-diam_frame.mat']);

load (['originais $\backslash$ matrices $\backslash$ ', num2str(name_load_mat(qq,:)), '-velocidade_frame.mat']);

load (['originais $\backslash$ matrices $\backslash$ ', $\operatorname{num2str}($ name_load_mat $(\mathrm{qq},:)),{ }^{\prime}$-ratio_al_frame.mat']);

load (['originais $\backslash$ matrices $\backslash$ ', num2str(name_load_mat(qq,: )), '-tempo_frame.mat']);

load (['originais $\backslash$ matrices $\backslash$ ', num2str(name_load_mat $(\mathrm{qq},:)),{ }^{\prime}$-reynolds_frame.mat']);

load (['originais $\backslash$ matrices $\backslash$ ', num2str(name_load_mat (qq,:)), '-reynolds_frame_2.mat']);

load (['originais $\backslash$ matrices $\backslash$ ', num2str(name_load_mat $(\mathrm{qq},:)),{ }^{\prime}$ - bingham_frame.mat']);

load (['originais $\backslash$ matrices $\backslash$ ', num2str(name_load_mat(qq,:)),' - centroide_vel_frame.mat']);

load (['originais $\backslash$ matrices $\backslash$ ', $\operatorname{num2str}($ name_load_mat(qq, :)), '-diferenca_frame.mat']);

load (['originais $\backslash$ matrices $\backslash$, ,num2str(name_load_mat(qq,:)), '-dif_frame_temp.mat']);

diam_frame=diam_temp_fil_meia;

velocidade_frame=velocidade_temp_fil_meia;

ratio_al_frame=ratio_temp_fil_meia;

reynolds_frame_2=reynolds_temp_fil_2_meia;

bingham_frame=bingham_temp_fil_meia;

[bolha_fil1,num_vid_ser]=size(diam_frame); \%numero de bolhas por bateria de videos

if num_vid_ser $\sim 1$

if $\mathrm{qq}==1$ 
diam_frame_min $=\min (\min ($ diam_frame $($ diam_frame $>0)))$;

diam_frame_max $=\max (\max (($ diam_frame $)))$;

velocidade_frame_min $=\min (\min ($ velocidade_frame $($ velocidade_frame $>0)))$;

velocidade_frame_max $=\max (\max ($ velocidade_frame $))$;

ratio_min $=\min (\min ($ ratio_al_frame $($ ratio_al_frame $>0)))$;

ratio_max $=\max (\max ($ ratio_al_frame $))$;

reynolds_min $=\min (\min ($ reynolds_frame_2(reynolds_frame_2 $>0)))$;

reynolds_max $=\max (\max ($ reynolds_frame_2 $))$

bingham_min $=\min (\min ($ bingham_frame $($ bingham_frame $>0)))$;

bingham_max $=\max (\max ($ bingham_frame $))$;

else

sw_comp $=$ sw_comp +1

if $\mathrm{sw} \_\mathrm{comp}==1$

diam frame $\max =\max (\max ($ diam frame $))$

velocidade_frame_max $=\max (\max ($ velocidade_frame $))$;

ratio_max $=\max (\max ($ ratio_al_frame $))$;

reynolds_max $=\max (\max ($ reynolds_frame_2 $))$;

bingham_max $=\max (\max ($ bingham_frame $))$

diam_frame_min $=\min \left(\min \left(\operatorname{diam} \_\right.\right.$frame $\left(\operatorname{diam} \_\right.$frame $\left.\left.\left.>0\right)\right)\right)$;

velocidade_frame_min $=\min (\boldsymbol{m i n}($ velocidade_frame $($ velocidade_frame $>0)))$;

ratio_min $=\min (\min ($ ratio_al_frame $($ ratio_al_frame $>0)))$;

reynolds_min $=\min (\min ($ reynolds_frame_2(reynolds_frame_2>0) $)$ );

reynolds_min $=\min (\boldsymbol{m i n}($ bingham_frame $($ bingham_frame $>0)))$;

else

if $\max (\max ($ diam_frame $))>$ diam_frame_max

end

diam_frame_max $=\max (\max ($ diam_frame $))$

if $\max (\max ($ velocidade_frame $))>$ velocidade_frame_max velocidade_frame_max $=\max (\max ($ velocidade_frame $))$;

end

if $\max (\max ($ ratio_al_frame $))>$ ratio_max

nd atio_max $=\max (\max ($ ratio_al_frame $))$

if $\max (\max ($ reynolds_frame_2 $))>$ reynolds_max reynolds_max $=\max (\max ($ reynolds_frame_2 $))$;

end

if $\max (\max ($ bingham_frame $))>$ bingham_max bingham_max $=\max (\max ($ bingham_frame $))$

if $\min (\min ($ diam_frame $($ diam_frame $>0)))<$ diam_frame_min diam_frame_min $=\min \left(\min \left(\operatorname{diam} \_\right.\right.$frame $\left(\operatorname{diam} \_\right.$frame $\left.\left.\left.>0\right)\right)\right)$

end

if $\min (\min ($ velocidade_frame $($ velocidade_frame $>0)))<$ velocidade_frame_min velocidade_frame_min $=\min (\min ($ velocidade_frame $($ velocidade_frame $>0)))$; end

if $\min (\min ($ ratio al frame $($ ratio al frame $>0)))<$ ratio min ratio_min $=\min (\min ($ ratio_al_frame $($ ratio_al_frame $>0)))$;

end

if $\min (\min ($ reynolds frame $2($ reynolds frame $2>0))$ ) $<$ reynolds min reynolds_min $=\min (\min ($ reynolds_frame_2(reynolds_frame_2 $>0))$ )

end

if $\min (\boldsymbol{m i n}($ bingham frame(bingham frame $>0)))<$ bingham min bingham_min $=\min (\min ($ bingham_frame $($ bingham_frame $>0)))$; end

end

end

end

hold on

$\operatorname{subplot}(2,2,1)$; scatter(diam_frame $(1,:)$, velocidade_frame $\left.(1,:),{ }^{\prime} * r^{\prime}\right)$

if num_vid_ser $\sim 1$

end

axis([diam_frame_min diam_frame_max 0 velocidade_frame_max $])$

ylabel('Velocity $[\mathrm{m} / \mathrm{s}]$ ', 'FontSize', 13)

xlabel('Virtual $\_$diameter $\sqcup[\mathrm{m}]$ ', 'FontSize', 13)

set(gca,'fontsize',13)

grid on

hold off

hold on

subplot $(2,2,2)$; $\log \log \left(\right.$ bingham frame $(1,:)$, reynolds frame $\left.2(1,:),{ }^{\prime} * \mathrm{r}^{\prime}\right)$;

if num_vid_ser $\sim 1$

axis $([$ bingham_min bingham_max 0 reynolds_max $])$

end

xlabel('Bingham $\_$number $\sqcup[-]$ ', 'FontSize', 13)

ylabel('Reynolds $\_$number $\sqcup[-]$ ', 'FontSize', 13)

set (gca,'fontsize',13)

grid on

hold off

hold on 
subplot $(2,2,3)$; scatter(reynolds_frame_2(1,:),ratio_al_frame( $(1,:),{ }^{\prime} *$ r');

if num_vid_ser $\sim 1$

end

axis([reynolds_min reynolds_max ratio_min ratio_max])

xlabel('Reynolds $\backsim$ number $\sqcup[-]$ ', 'FontSize', 13)

ylabel('ratio $\llcorner$ height/width $\sqcup[-]$ ', 'FontSize', 13)

set (gca,'fontsize',13)

grid on

hold off

hold on

subplot $(2,2,4)$; scatter(bingham_frame $(1,:)$, ratio_al_frame $\left.(1,:),{ }^{\prime} * \mathrm{r}^{\prime}\right)$;

if num_vid_ser $\sim=1$

axis([bingham_min bingham_max ratio_min ratio_max])

end

xlabel('Bingham $\sqcup$ number $\sqcup[-]$ ', 'FontSize', 13)

ylabel('ratio height/width $\sqcup[-]$ ', 'FontSize', 13)

set (gca,'fontsize',13)

grid on

hold off

if $\mathrm{qq}==\mathrm{iii}$

h3=legend(legenda1,'Location','southwest','position', $[0.95,0,0.0005,1])$;

set $(\mathrm{h} 3$,'FontSize',13)

end

clearvars ratio_al_frame bingham_frame reynolds_frame_2 diam_frame velocidade_frame centroide_frame

$\hookrightarrow$ volume_frame diam_frame velocidade_frame ratio_al_frame tempo_frame reynolds_frame

$\hookrightarrow$ reynolds_frame_2 centroide_vel_frame diferenca_frame dif_frame_temp

end

end

aveas(compilado,'resultados/compilado','jpg')

if load_mat $==2$

rmdir(num2str(videoc), 's')

rmdir(num2str(videof), 's');

end

\section{B.2}

Rotina de Solução do Modelo Matemático e calculo dos parâmetros de ajuste

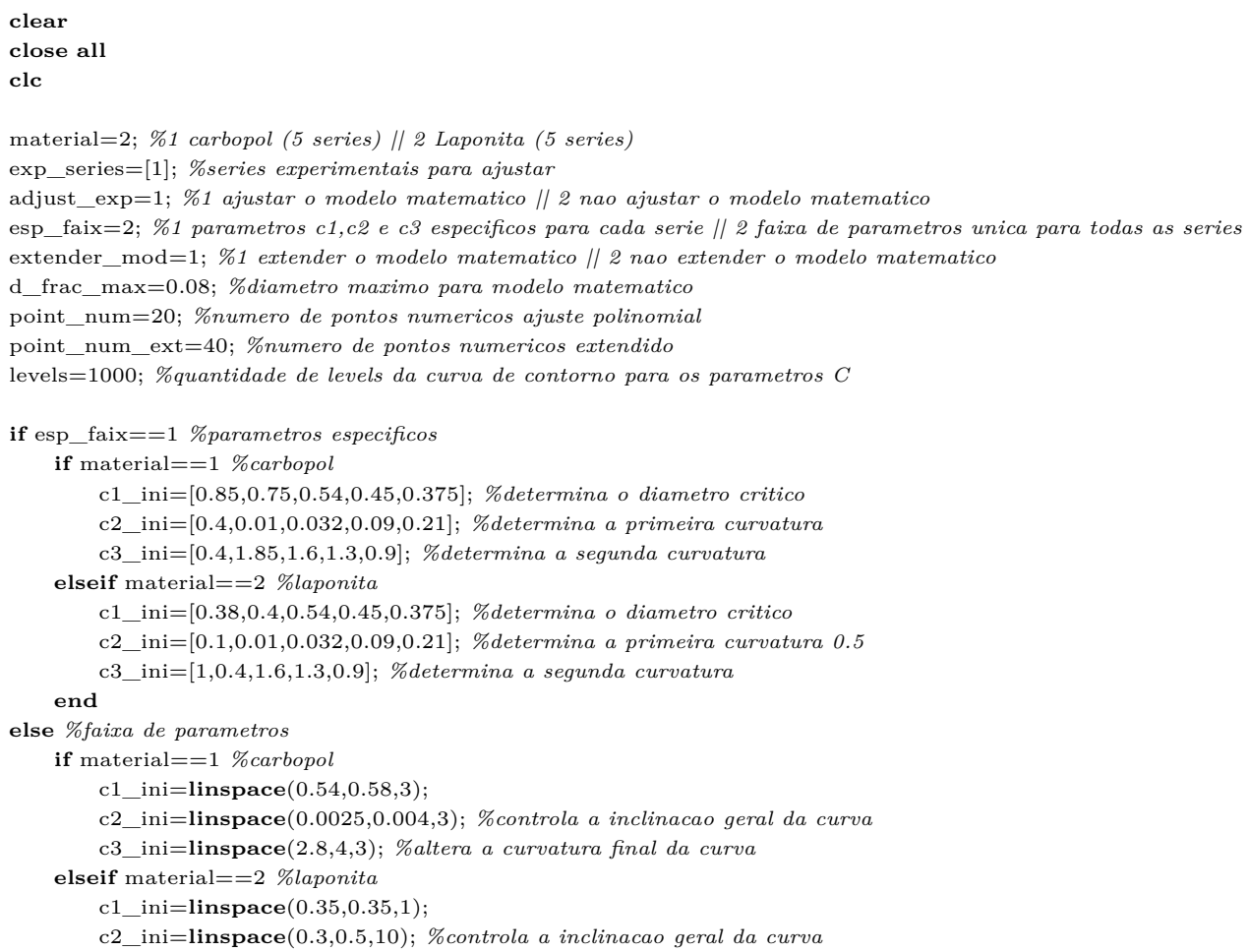


c3 ini=linspace $(0.6,0.8,20)$; \%altera a curvatura final da curva nd

\%GRAFICOS EXPERIMENTAIS E DIAMETRO MAXIMO

$\mathrm{g}=9.81$

rho $=1000$;

if material $==1$

$\mathrm{tau}=[3.015,4.59,11.6,16.57,28.5]$;

$\mathrm{n}=[0.4109,0.4197,0.4158,0.3775,0.4251]$;

$\mathrm{mi}=[1.816,2.022,3.505,6.044,7.552]$;

elseif material $==2$

tau $=[10.34,10.34,40.47,40.47,40.47]$;

$\mathrm{n}=[2.487,2.487,3.9867,3.9867,3.9867]$;

end

$\mathrm{mi}=\left[3.710 * 10^{\curlyvee}(-7), 3.710 * 10^{\curlyvee}(-7), 1.254 * 10^{\curlyvee}(-12), 1.254 * 10^{\curlyvee}(-12), 1.254 * 10^{\curlyvee}(-12)\right]$;

if material $==1$

load('exp_v_d_carb.mat');

elseif material $==2$

end

load('exp_v_d_lap.mat');

$\left[\max \_\mathrm{k} 1, \sim\right]=\operatorname{size}\left(\exp \_\mathrm{v} \_\mathrm{d}\right)$;

$\left[\sim, \max \_\right.$exp_series $]=\operatorname{size}\left(\exp \_s e r i e s\right)$;

for $\mathrm{r}=1$ :max_exp_series

$\mathrm{q}=\exp \_$series $(1, \mathrm{r})$;

exp_temp $=[$ exp_v_d $(:, 2 * q-1)$, exp_v_d $(:, 2 * q)]$;

swift_non_zero $(1, \mathrm{r})=0$;

for $\mathrm{k}=1$ :max $\_\mathrm{k} 1$

if exp_temp $(\mathrm{k}, 2) \sim=0$

swift_non_zero $(1, \mathrm{r})=$ swift_non_zero $(1, \mathrm{r})+1$;

exp_final2 (swift_non_zero $(1, \mathrm{r}),:)=\left[\exp \_\operatorname{temp}(\mathrm{k}, 1), \exp \_t \operatorname{temp}(\mathrm{k}, 2)\right]$

if swift_non_zero $(1, \mathrm{r})==1$

diam_range_max $(\mathrm{r})=\mathrm{exp} \_$temp $(\mathrm{k}, 1)$;

else

if $\exp \_$temp $(\mathrm{k}, 1)>$ diam_range_max $(\mathrm{r})$

diam_range_max $(\mathrm{r})=\exp \_$temp $(\mathrm{k}, 1)$;

end

en

end

\%valores experimentais

hold on

subplot $(2,3,1)$; $p$ plot(exp_final2(:,1),exp_final2(:,2),'bo'); \%dados experimentais

hold on

subplot $(2,3,2)$; plot(exp_final2(:,1),exp_final2(:,2),'bo'); \%dados experimentais

clearvars exp_temp exp_final3 step

$\mathrm{q}=\exp \_\operatorname{series}(1, \mathrm{r})$;

if esp_faix $==1$

$\mathrm{c} 1=\mathrm{c} 1 \_$ini $(1, \mathrm{q})$;

$\mathrm{c} 2=\mathrm{c} 2 \_$ini $(1, \mathrm{q})$;

else

c3 $=$ c3_ini $(1, q)$;

$\mathrm{c} 1=\mathrm{c} 1$ _ini;

c2 $=$ c2_ini;

$\mathrm{c} 3=\mathrm{c} 3 \_$ini;

end

$\left[\sim, \mathrm{c} 1 \_\operatorname{size}\right]=\operatorname{size}(\mathrm{c} 1)$;

$\left[\sim, \mathrm{c} 2 \_\operatorname{size}\right]=\operatorname{size}(\mathrm{c} 2)$

$\left[\sim, \mathrm{c} 3 \_\right.$size $]=\operatorname{size}(\mathrm{c} 3)$;

if $\mathrm{c} 1 \_\mathrm{size}==1$

exp_final2_min_num $=18 * \mathrm{c} 1 * \operatorname{tau}(\mathrm{q}) /(\mathrm{g} * \mathrm{rho})+0.000001 ; \%$ diametro minimo numerico

exp_final2_min_num $=$ exp_final2_min_num;

exp_final2_max_num $=\max \left(\operatorname{exp\_ final2}(:, 1)\right) ; \%$ diametro maximo numerico

$\mathrm{step}=\left(\exp \_\right.$final2_max_num $-\mathrm{exp} \_$final2_min_num $) /($point_num +1$)$;

exp_final3=(exp_final2 min num:step:exp final2 max num $)^{\prime}$ '

p3 = polyfit (exp_final2(:,1),exp_final2 $(:, 2), 3)$;

$\mathrm{p} 4=$ polyfit $\left(\operatorname{exp\_ final2}(:, 1)\right.$, exp_final $\left.2(:, 2), 4\right)$;

$\mathrm{f} 3=\operatorname{polyval}\left(\mathrm{p} 3, \exp \_\right.$final $\left.3(:, 1)\right)$

$\mathrm{f} 4=\operatorname{polyval}\left(\mathrm{p} 4, \exp \_\right.$final $\left.3(:, 1)\right)$;

hold on

$\operatorname{subplot}(2,3,1)$; $\boldsymbol{p l o t}\left(\exp \_\right.$final3,f3,' $\mathrm{k}-$-')

hold on

end

$\operatorname{subplot}(2,3,1)$; plot (exp_final3,f4,'c--')

$[$ size_exp $3, \sim]=\operatorname{size}\left(\exp \_\right.$final3); 


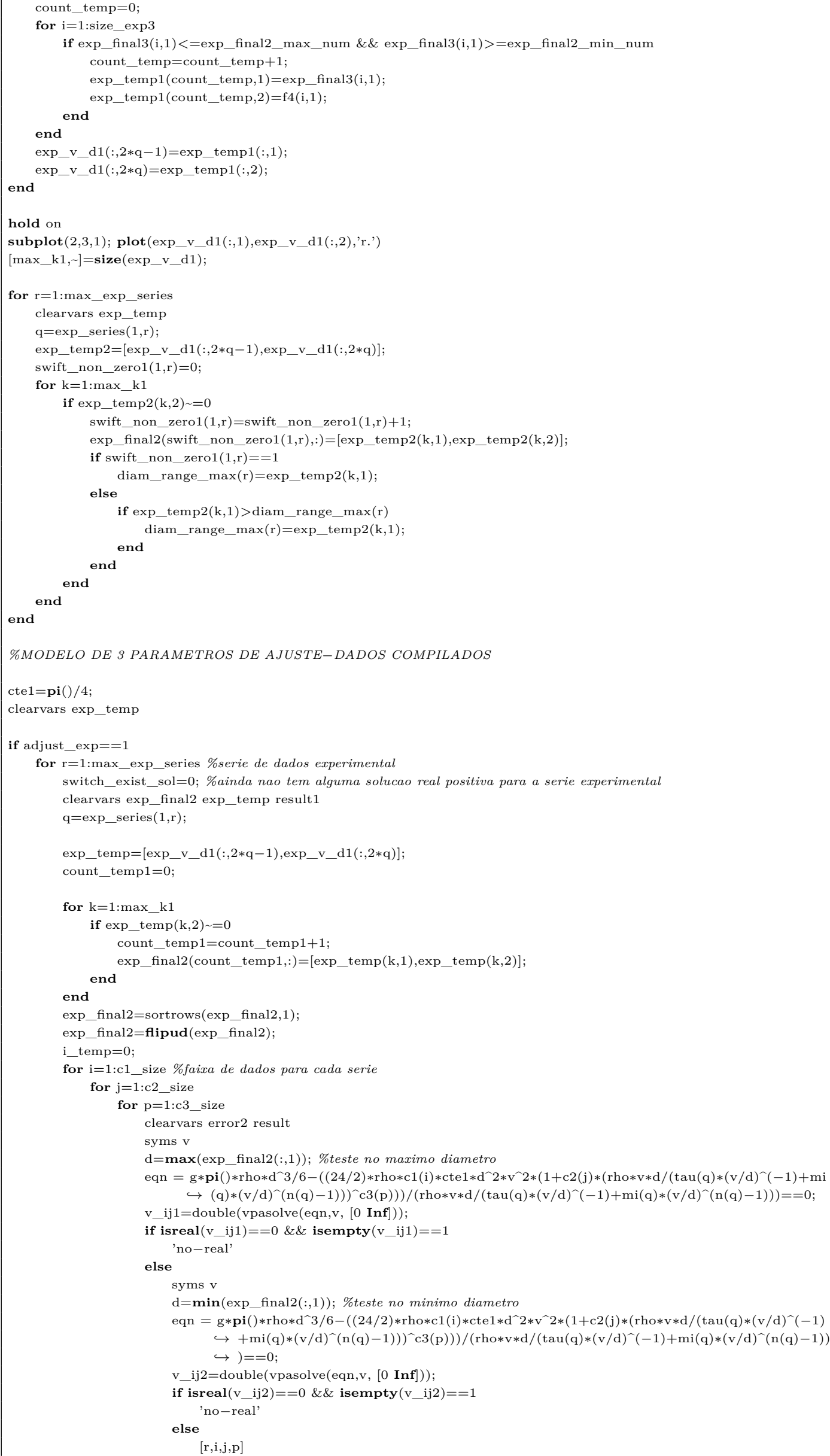




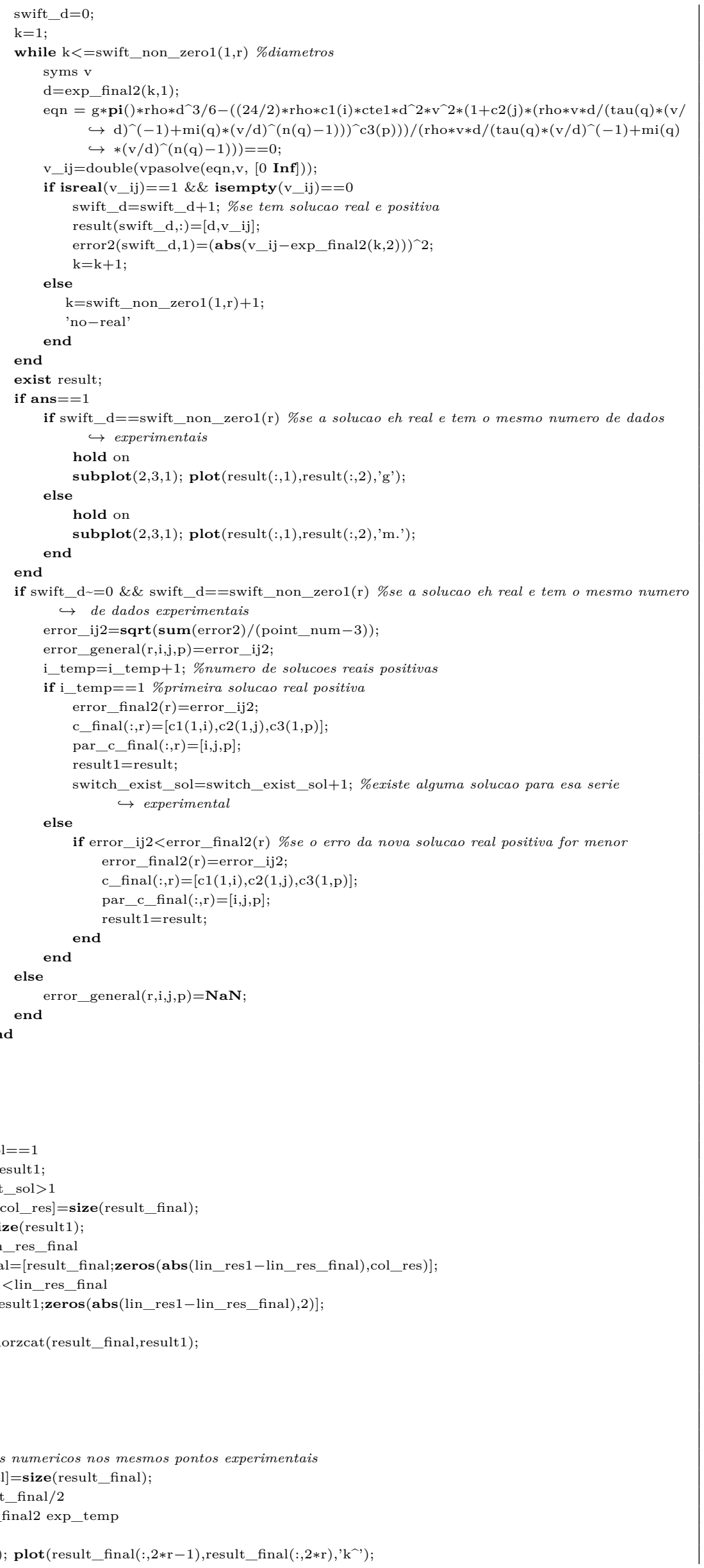


ylabel(' $v \sqcup[\mathrm{m} / \mathrm{s}]$ ')

xlabel('d $\mathrm{d}[\mathrm{m}]$ ')

hold on

subplot $(2,3,2)$; plot(result_final(:,2*r-1),result_final(:,2*r), ''k');

ylabel ('v $v_{\lrcorner}[\mathrm{m} / \mathrm{s}]$ ')

end

xlabel('d $\mathrm{d}_{\sqcup}[\mathrm{m}]$ ')

c final

else

'no-real'

end

$\left[\sim, \mathrm{c} 1 \_\right.$size $]=\operatorname{size}\left(\mathrm{c} 1 \_\right.$ini $)$;

$\left[\sim, \mathrm{c} 2 \_\right.$size $]=\operatorname{size}\left(\mathrm{c} 2 \_\right.$ini $)$;

$\left[\sim, \mathrm{c} 3 \_\right.$size $]=\operatorname{size}\left(\mathrm{c} 3 \_\right.$ini $)$;

if $\mathrm{c} 1 \_$size $==1 \& \&$ esp_faix $==2 \& \& \max \_$exp_series $==1$

error_contourn $(:,:)=$ error_general $(1,1,:,:)$;

hold on

subplot $(2,3,6)$; contour(c3 ini,c2 ini,error contourn,levels)

hold off

ylabel('C2 [-]')

xlabel('C3 $[-]$ ')

hold on

subplot $(2,3,6) ; \operatorname{plot}\left(\mathrm{c} \_f i n a l(3,1)\right.$, c_final $(2,1)$,'or')

hold off

for $\mathrm{i}=1: \mathrm{c} 2$ _size

for $j=1: c 3 \_s i z e$

if isnan (error_contourn $(i, j))==1$

hold on

subplot $(2,3,6)$; plot $(\mathrm{c} 3$ _ini $(1, \mathrm{j}), \mathrm{c} 2$ _ini $(1, \mathrm{i})$, 'sk')

hold off

end

end

end

end

\%SOLUCAO NUMERICA EXTENDIDA-D

if extender_mod $==1$

'modelo $\sqcup$ extendido'

for $\mathrm{r}=1: \mathrm{max} \_$exp_series \%serie de dados experimental

switch_exist_sol=0; \%ainda nao tem alguma solucao real positiva para a serie experimental

clearvars exp final2 exp temp result1 result num c ext final

$\mathrm{q}=\exp \_$series $(1, \mathrm{r})$;

$\mathrm{c} 1=\mathrm{c} \_$final $(1, \mathrm{r})$;

$\mathrm{c} 2=\mathrm{c} \_$final $(2, \mathrm{r})$;

c3 $=$ c_final $(3, \mathrm{r})$;

$\left[\sim, \mathrm{c} 1 \_\right.$size $]=\operatorname{size}(\mathrm{c} 1)$;

$\left[\sim, \mathrm{c} 2 \_\operatorname{size}\right]=\operatorname{size}(\mathrm{c} 2)$

$\left[\sim, \mathrm{c} 3 \_\right.$size $]=\operatorname{size}(\mathrm{c} 3)$;

exp_temp $=\left[\exp \_\mathrm{v} \_\mathrm{d} 1(:, 2 * \mathrm{q}-1), \mathrm{exp} \_\mathrm{v} \_\mathrm{d} 1(:, 2 * \mathrm{q})\right]$;

count_temp $1=0$

for $\mathrm{k}=1$ :max $\mathrm{k}$

if exp_temp $(\mathrm{k}, 2) \sim=0$

count_temp1=count_temp $1+1$;

exp_final2(count_temp $1,:)=\left[\exp \_\right.$temp $(\mathrm{k}, 1), \exp \_$temp $\left.(\mathrm{k}, 2)\right]$

end

end

exp_final3=sortrows (exp_final2,1)

exp_final3=flipud (exp_final3);

exp_final2_min_num $=18 * \mathrm{c} 1 * \operatorname{tau}(\mathrm{q}) /(\mathrm{g} * \mathrm{rho}) ; \%$ diametro minimo numerico

exp_final2_min_num $=$ exp_final2_min_num + exp_final2_min_num $* 0.000001$;

exp_final2_max_num=d_frac_max; \%diametro maximo numerico

step $=($ exp_final2_max_num - exp_final2_min_num $) /($ point_num_ext +1$)$;

exp final3 $=\left(\exp \_ \text {final2 min num:step:exp_final2_max_num }\right)^{\prime}$

[size_point_num, $]=\operatorname{size}\left(\exp \_\right.$final 3$)$;

i_temp $=0$;

for $\mathrm{i}=1: \mathrm{c} 1$ size \%faixa de dados para cada serie

for $\mathrm{j}=1: \mathrm{c} 2 \_$size

for $\mathrm{p}=1: \mathrm{c} 3 \_$size

clearvars error2 result_num

swift_d $=0$;

for $\mathrm{k}=1: \mathrm{size} \_$point_num

syms v

$\mathrm{d}=$ exp_final $3(\mathrm{k}, 1)$

eqn $=\mathrm{g} * \mathbf{p i}() * \mathrm{rho}^{-} * \mathrm{~d}^{\wedge} 3 / 6-\left((24 / 2) * \mathrm{rho} * \mathrm{c} 1(\mathrm{i}) * \operatorname{cte} 1 * \mathrm{~d}^{\wedge} 2 * \mathrm{v}^{\wedge} 2 *(1+\mathrm{c} 2(\mathrm{j}) *(\mathrm{rho} * \mathrm{v} * \mathrm{~d} /(\operatorname{tau}(\mathrm{q}) *(\mathrm{v} / \mathrm{d})\right.$ $\left.\left.\left.\left.\left.\hookrightarrow \wedge^{-1}\right)+\operatorname{mi}(\mathrm{q}) *(\mathrm{v} / \mathrm{d})^{\wedge}(\mathrm{n}(\mathrm{q})-1)\right)\right)^{\wedge} \mathrm{c} 3(\mathrm{p})\right)\right) /\left(\operatorname{rho} * \mathrm{v} * \mathrm{~d} /\left(\operatorname{tau}(\mathrm{q}) *(\mathrm{v} / \mathrm{d})^{\wedge}(-1)+\operatorname{mi}(\mathrm{q}) *(\mathrm{v} / \mathrm{d})\right.\right.$ $\left.\left.\hookrightarrow \Upsilon^{\prime}(\mathrm{n}(\mathrm{q})-1)\right)\right)==0$; 


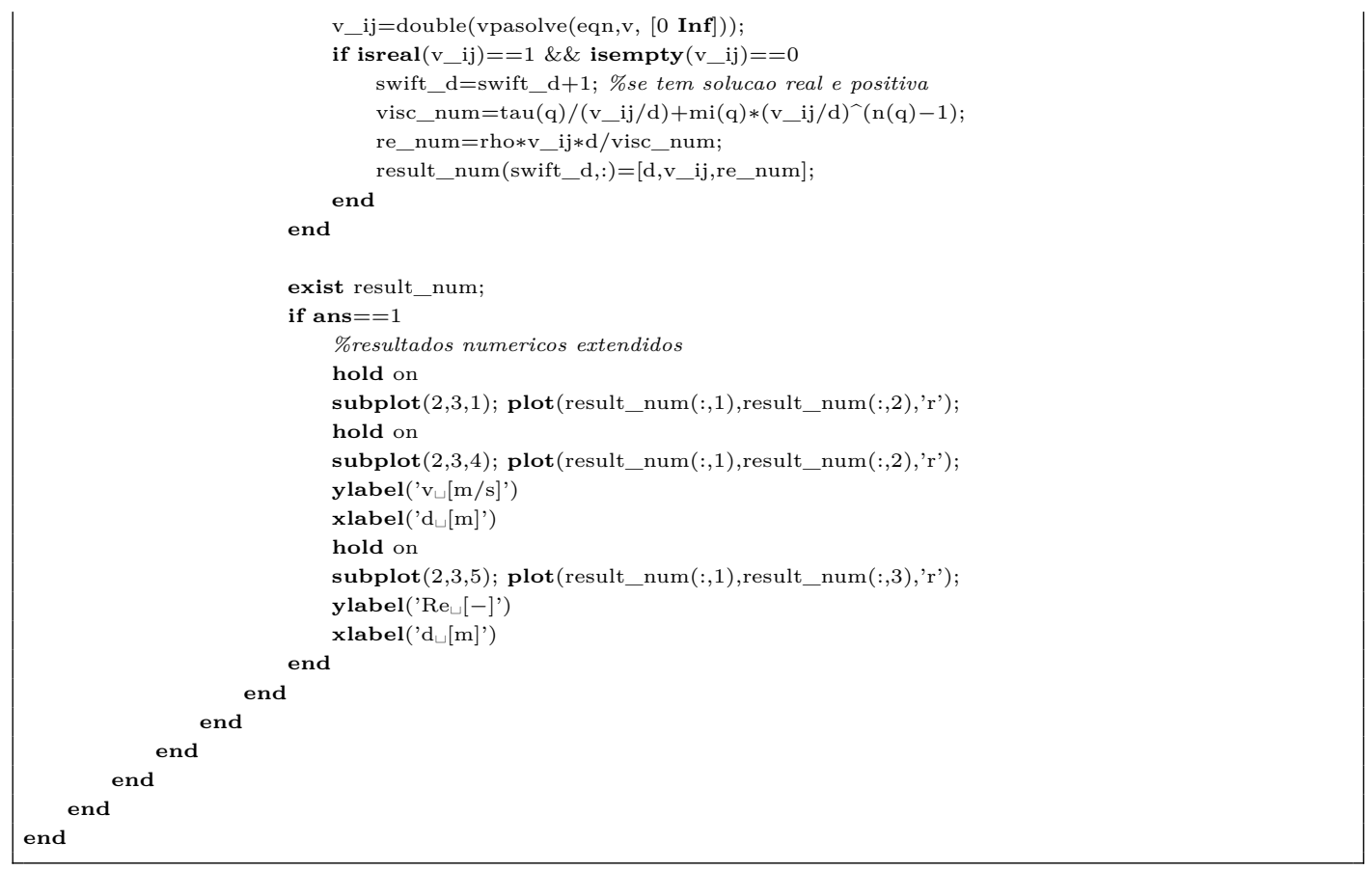

